\title{
Health status assessment in COPD
}

Citation for published version (APA):

Smid, D. E. (2018). Health status assessment in COPD. [Doctoral Thesis, Maastricht University]. Datawyse / Universitaire Pers Maastricht. https://doi.org/10.26481/dis.20180112ds

Document status and date:

Published: 01/01/2018

DOI:

10.26481/dis.20180112ds

Document Version:

Publisher's PDF, also known as Version of record

\section{Please check the document version of this publication:}

- A submitted manuscript is the version of the article upon submission and before peer-review. There can be important differences between the submitted version and the official published version of record.

People interested in the research are advised to contact the author for the final version of the publication, or visit the DOI to the publisher's website.

- The final author version and the galley proof are versions of the publication after peer review.

- The final published version features the final layout of the paper including the volume, issue and page numbers.

Link to publication

\footnotetext{
General rights rights.

- You may freely distribute the URL identifying the publication in the public portal. please follow below link for the End User Agreement:

www.umlib.nl/taverne-license

Take down policy

If you believe that this document breaches copyright please contact us at:

repository@maastrichtuniversity.nl

providing details and we will investigate your claim.
}

Copyright and moral rights for the publications made accessible in the public portal are retained by the authors and/or other copyright owners and it is a condition of accessing publications that users recognise and abide by the legal requirements associated with these

- Users may download and print one copy of any publication from the public portal for the purpose of private study or research.

- You may not further distribute the material or use it for any profit-making activity or commercial gain

If the publication is distributed under the terms of Article $25 \mathrm{fa}$ of the Dutch Copyright Act, indicated by the "Taverne" license above, 


\section{Health status}

assessment in COPD

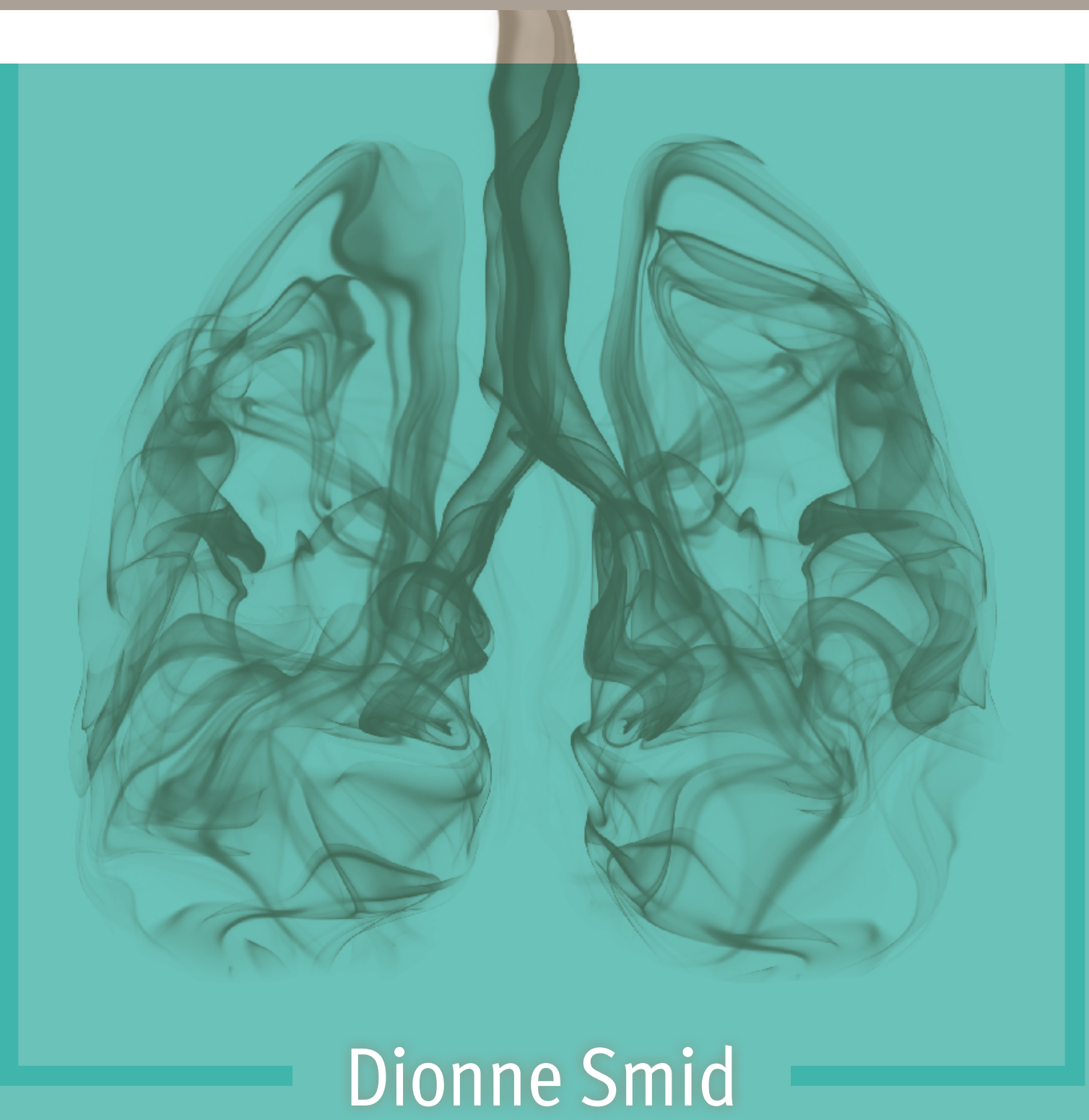


(C) copyright Dionne Ellen Smid, Maastricht 2018

Cover design | Bertjan Tromp

Invitation design | Sanne Godec

Printing: Datawyse | Universitaire Pers Maastricht

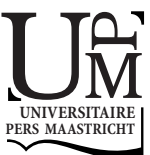

ISBN 9789461597892 


\section{Health status assessment in COPD}

\section{PROEFSCHRIFT}

ter verkrijging van de graad van doctor aan de Universiteit Maastricht, op gezag van de Rector Magnificus, Prof. Dr. Rianne M. Letschert, volgens het besluit van College van Decanen, in het openbaar te verdedigen op vrijdag 12 januari 2018 om 12.00 uur

door

Dionne E. Smid 


\section{Promotors}

Prof. Dr. E.F.M. Wouters

Prof. Dr. M.A. Spruit

Copromotor

Dr. F.M.E. Franssen

Beoordelingscommissie

Prof. Dr. J.M.G.A. Schols

Prof. Dr. F. Smeenk

Prof. Dr. G. Wesseling

Prof. Dr. H.A.M. Kerstjens

Prof. Dr. P-R. Burgel

This thesis was financially supported by CIRO Horn the Netherlands, Lung Foundation the Netherlands (3.4.10.015) and GlaxoSmithKline (GSK)

Printing and distribution of this thesis was financially supported by CIRO Horn the Netherlands, Lung Foundation Amersfoort the Netherlands, Chiesi Pharmaceuticals B.V Rijswijk the Netherlands., Boehringer Ingelheim B.V. Alkmaar the Netherlands and Stichting Astmabestrijding, Amsterdam the Netherlands. 


\section{TABLE OF CONTENTS}

Chapter 1 General introduction 7

$\begin{array}{lll}\text { Chapter } 2 \text { The impact of cardiovascular comorbidities on COPD } & 27\end{array}$

Assessment Test (CAT) and its responsiveness to

pulmonary rehabilitation in patients with moderate to very severe COPD: the protocol of the Chance study

Chapter 3 How to determine an impaired health status in COPD?

Results from a population-based study

Chapter 4 The physical, mental and social impact of COPD

in a population based sample

Chapter 5 Burden of COPD in patients treated in different care

settings in the Netherlands

Chapter 6 Responsiveness and minimum clinically important

difference estimates for CAT, CCQ and HADS

in patients with COPD: a prospective analysis

Chapter 7 The 2014 updated GOLD strategy:

a comparison of the various scenarios

Chapter 8 Redefining cut-points for high symptom burden of the Global Initiative for Chronic Obstructive Lung Disease Classification in 18,577 patients with Chronic Obstructive Pulmonary Disease

Chapter 9 General discussion

Summary

$\begin{array}{ll}\text { Samenvatting } & 207\end{array}$

Valorization addendum 213

Dankwoord 219

$\begin{array}{ll}\text { Curriculum vitae } & 225\end{array}$

$\begin{array}{ll}\text { List of publications } & 227\end{array}$ 



\section{Chapter 1}

General introduction 



\section{CHRONIC OBSTRUCTIVE PULMONARY DISEASE}

Chronic obstructive pulmonary disease (COPD) is defined by the Global initiative

for chronic Obstructive Pulmonary Disease (GOLD) strategy as "a common preventable and treatable disease, characterized by persistent airflow limitation that is usually progressive and associated with an enhanced chronic inflammatory response in the airways and the lungs to noxious particles or gases". COPD usually consists of a mixture of small airway diseases (chronic bronchitis) and parenchymal destruction (pulmonary emphysema), leading to an impaired airflow in the lungs (1). A major risk factor for developing COPD is tobacco smoke (2). The most common symptoms are cough, breathlessness and/or an abnormal amount of sputum, which are chronic and progressive and can vary from day-to-day (3, 4). Accordingly, patients with COPD often experience difficulties in performing daily activities (5). While its origins can begin very early in life, generally, COPD becomes clinically apparent around the age of 40-50 years, but is often diagnosed at a later age $(2,6)$. COPD is an incurable disease. Therefore, treatment mainly focusses on the reduction of symptoms and the prevention of further deterioration (1).

Recently, COPD is recognized as a multicomponent disease. Besides affecting the lungs, organs outside the lungs can also become affected in the clinical course of the disease. In COPD, there is an increased occurrence of psychological conditions, fatigue, muscle dysfunction, weight loss, physical inactivity level and/or comorbidities like cardiovascular disease (7). These systemic features substantially contribute to morbidity and mortality in COPD. Furthermore, patients with COPD frequently experience exacerbations. Exacerbations are defined as "an event in the natural course of the disease characterized by a change in the patient's baseline cough, dyspnea, and/or sputum that is beyond normal day-to-day variations". It is acute in onset, contributes to the overall severity of COPD and warrants a change in regular medication (1).

The diagnosis of COPD is based on a simple lung function test, more specific a spirometry. A forced expiratory volume in the first second $\left(\mathrm{FEV}_{1}\right) /$ forced vital capacity (FVC) below 0.7, after taking a bronchodilator, indicates a chronic airflow limitation (1). In 2015, Global Lung function Initiative (GLI) reference values were introduced, suggesting that a post-bronchodilator $\mathrm{FEV}_{1} / \mathrm{FVC}$ ratio below the $5^{\text {th }}$ percentile (from reference values) is a better indicator for airflow limitation (8) than the fixed cut-off point $\left(\mathrm{FEV}_{1} / \mathrm{FVC}\right.$ ratio $\left.<0.7\right)$. This, to avoid overdiagnosis of airflow limitation in individuals over 50 years and underdiagnosis in individuals under 50 years (9). To date however, the fixed cut-off is still mainly used to diagnose and classify patients with COPD (10). 


\section{PREVALENCE AND BURDEN}

COPD is a major cause of morbidity and mortality and is the most common chronic lung disease in the world (10). Approximately 6\% (i.e. 3.3 million people) of all deaths worldwide are caused by COPD (11). It is the fifth leading cause of death and is expected to become the fourth leading cause of death by 2030 (12). It is also the fifth major cause of years lived with disability (13). An estimated 328 million people have COPD worldwide (13). Prevalence rates vary from country to country (14). International prevalence rates of COPD are estimated at $10 \%$ in people aged 40 years and older, with a higher prevalence in men and older ages (15). Due to continued exposure to risk factors of COPD and demographic shift of an aging population, it is projected that the prevalence of COPD will increase even further (16). In 2007, prevalence rates were estimated for the Netherlands, showing that $18.3 \%$ of men and $15.5 \%$ of women had COPD (17). In 2012, Vanfleteren and colleagues performed a population-based study using postbronchodilator spirometry and reported an overall COPD prevalence of $24 \%$ (men, 28.5\%; women, 19.5\%) in Maastricht, the Netherlands (18).

COPD has a tremendous impact on the healthcare system by its personal, economic and social impact. (19). The total use of healthcare of patients with COPD is significantly higher than healthcare use in the general population. Previous research performed in the Netherlands shows that about $95 \%$ of people with COPD contacted their general practitioner (GP) minimally once a year, versus $76 \%$ in the general population. In addition, $94 \%$ of the patients with COPD received prescribed medication (versus 40\%, respectively) and over three-quarters went to a medical specialist (versus 40\%, respectively) (20). The economic burden of COPD is associated with direct and indirect costs (1). Annual direct costs range between $\$ 504$,- and $\$ 9.981$,- per patient. Concerning indirect costs, e.g. the ability to maintain a job, $6 \%$ to $52 \%$ of the patients with COPD is not able to work due to COPD symptoms (21). High personal and economic burden are associated with the disease severity of COPD and number and severity of symptoms (22). The highest costs are found among patients with a high disease burden and a large number of comorbidities $(21,23)$. The social burden of COPD can be expressed in Disability Adjusted Life Years (DALYs), containing the loss of quantity of life and the loss of quality of life. In the Netherlands, the DALYs for COPD are established at a mean of 5.6 years per COPD patient. COPD is number 5 of diseases with the largest DALY losses in Netherlands (24). 


\section{HEALTH STATUS}

COPD has an important impact on a patient's life. While severity of airflow limitation is often used to classify patients with COPD, the association between this parameter and disease activity or progression, comorbidities, extra-pulmonary features and prognosis in patients with COPD is moderate-to-poor $(7,25)$. In contrast, health status seems to be well associated with disease burden (26). Health status is defined as "the impact of health on a person's ability to perform and derive fulfilment from the activities of daily life" (27). While this is a subjective matter, health status measurements are able to objectify and standardize the impact of a disease on the patients' health, daily life, and wellbeing, making it less "touchyfeely" (28). An impaired health status is a common feature in patients with COPD, irrespective of the degree of airflow limitation (29). Though, the impact of an impaired health status is often underestimated $(30,31)$. According to the latest GOLD document, COPD assessment is aimed at determining disease severity, including the impact on patient's health status, in order to guide treatment (1). Validated and standardized health status questionnaires are used to assess the overall impact of COPD (28).

A distinction can be made between two different types of questionnaires. First, generic tools can be applied which measure quality of life for the general population, regardless of the presence or absence of diseases (e.g. Short Form-36, SF-36; Short Form-12, SF-12; and EuroQoL-5D, EQ-5D) (32-34). Second, disease-specific instruments measuring the impact of a specific disease, such as COPD, can be used (e.g. Saint George's Respiratory Questionnaire, SGRQ; Clinical COPD Questionnaire, CCQ; and COPD Assessment Test, CAT) (35-37). Generic health status questionnaires tend to cover aspects like functional states, perceptions and social opportunities. They are more widely applicable than diseasespecific questionnaires. For example, they can be used to compare health status between various diseases, to make a comparison with healthy subjects or to calculate quality-adjusted life years (QALYs). On the other hand, disease-specific questionnaires focus more on functional impairments and symptoms associated with the disease, resulting in a higher sensitivity in detecting an impaired health status and change in clinical status $(28,38,39)$. Though, it is shown that both generic as disease-specific questionnaires adequately reflect the burden of COPD and comorbid conditions (40). In the current thesis, we will focus on diseasespecific instruments, i.e. the SGRQ, CCQ and CAT, to measure health status, as the GOLD strategy recommends these questionnaires to classify patients with COPD. In addition, we will particularly focus on the newly developed diseasespecific CAT questionnaire as described below. 
The SGRQ has proven to be a responsive, valid and reliable instrument for quality of life evaluation in patients with $\operatorname{COPD}(35,41,42)$. This questionnaire contains three subdomains: impact, dyspnea and activity. It includes 50 items, in which each score ranges from 1 to $100(43,44)$. The SGRQ is widely used in COPD trials (4549). However, this questionnaire is sometimes difficult to understand by patients, reasonably time-consuming to complete, and has a (too) complex scoring algorithm for routine use in clinical practice (50). Moreover, the CCQ is a commonly used reliable and valid questionnaire in Dutch clinical practice. It is proven to be easier and faster to complete than the SGRQ (50). The CCQ consists of 10 items, comprising the domains symptoms, mental status and functionality, in which total scores range between 0 and 6 points (36). In 2009, the CAT, a new short and simple questionnaire to measure health status in COPD, was developed (37). The CAT is an eight-item patient-completed questionnaire, designed to measure health status in patient with COPD, focusing on cough, phlegm, chest tightness, breathlessness, going up stairs or hills, activity limitation at home, confidence leaving home, sleep, and energy level (see appendix Figure 1). Item scores range from 0 to 5 points, whereby the total score varies between 0 (best health status) and 40 points (worst health status) (37). The CAT is considered reliable, valid and responsive (51). Currently, a CAT total score of $\geq 10$ points indicates an abnormal health status (1). Studies determining cut-points for abnormal values in other measurement tools, often derived these from the $95^{\text {th }}$ percentile in a non-COPD population (52-54). Former research shows that CAT values between 14 and 28 points were found at the $95^{\text {th }}$ percentile (55-57). Understanding what is an abnormal CAT value is very important, as it consequently also influences treatment and management of COPD. Little is known about normative values in a non-COPD population in the Netherlands. In addition, it is shown that clinical characteristics, like health status, and management of COPD can differ between countries (58). For example, Gupta and colleagues showed CAT total scores of 7.3 points in Japan and 20.9 points in Turkey (51). Previous research performed in various countries also show higher CAT scores in COPD patients versus non-COPD patients, with the worse health status in female subjects $(57,59)$. In addition, former research shows that employment can have a positive influence on CAT scores (55). In the current thesis we will focus on the impact of COPD, normative values and the influence of work status on health status in a Dutch population.

A high score on health status questionnaires stands for more than only a poor health status. It assesses general disease severity (60), is associated with higher levels of dyspnea (5), predicts the occurrence of exacerbations and mortality (61, 62 ), is closely related to symptoms of anxiety and depression (63), and often 
indicates a deterioration and/or less functional capacity (64). Nonetheless, most studies investigated clinical characteristics and the burden of COPD in selected patient populations. Patients without a significant smoking history $(>15$ pack years) or various comorbidities are often excluded, while patients visiting a chest physician or referred for pulmonary rehabilitation are examined more extensively (65). This emphasizes the importance of including a broad population of COPD patients. It also questions the generalizability of previously performed studies. Thus, there is a need to study the impact of COPD on physical status, mental status, and social status in population based samples, which will be covered in the current thesis.

\section{TREATMENT}

In the Netherlands, treatment can be provided in primary care (GPs), secondary care (chest physician) and/or tertiary care (advanced medical investigation and treatment, e.g. pulmonary rehabilitation) (66). According to the Dutch guidelines, the choice of healthcare setting depends on the severity of COPD, diagnostic problems (e.g. COPD at young age) and/or progress in treatment goals (67). Whether and to what extent patients with COPD treated in various healthcare settings differ in disease burden and healthcare utilization remains unknown.

The American Thoracic Society (ATS) and the European Respiratory Society (ERS) defines pulmonary rehabilitation as "a comprehensive intervention based on a thorough patient assessment followed by patient-tailored therapies that include, but are not limited to, exercise training, education, and behaviour change, designed to improve the physical and psychological condition of people with chronic respiratory disease and to promote the long-term adherence to health-enhancing behaviours" and states that it is the best available means to improve health status in patients with COPD who are symptomatic despite otherwise optimal therapy at the start of a pulmonary rehabilitation program (68). Indeed, previous research shows psychosocial, physiological, symptom-reducing and health economic benefits after pulmonary rehabilitation in patients with COPD (69). It is also shown that pulmonary rehabilitation outcomes are differential (46) and depend on the method of outcome assessment. Thus, there is a need for studies to investigate the response of various health status questionnaires after pulmonary rehabilitation. Hence, this will be addressed in the present thesis. 
To determine if a change in health status is clinically relevant, the minimal clinically important difference (MCID) should be reached. The MCID is defined as "the smallest difference in a measurable clinical parameter that indicates a meaningful change in the condition for better or for worse, as perceived by the patient, clinician or investigator" (70). A MCID is also frequently used to perform a sample size calculation, assess the efficacy of specific therapies and to assist in interpreting statistical significant results $(71,72)$. To estimate a MCID, anchor- and distribution-based approaches can be applied (71). Multiple studies looked at MCIDs for health status questionnaires. The MCID is established at 4 points for the SGRQ (73), at 0.4 points for the CCQ (74-77), and between 1.6 points and 2.0 points for the CAT (78-80). However, MCIDs differ between studies and various methods were applied to derive these. MCIDs can vary depending on study context and/or studied population. Previous research shows the same variation in MCIDs with regard to other measurements (e.g. 6-min walk test, 6MWT; incremental shuttle walk test, ISWT; and endurance shuttle walk test, ESWT) to assess the burden of COPD (81). For that reason, we studied the previously known MCIDs concerning health status and compared these with MCIDs derived from our own data, resulting in new recommendations for the use of estimated MCIDs.

\section{GOLD CLASSIFICATION}

The GOLD strategy describes the newest practice guidelines on the diagnosis, prevention, and management of COPD (1). Formerly, patients with COPD were classified into GOLD stages 1 to 4, which was solely based on degree of airflow limitation (82). The GOLD 2014 strategic document recommends categorization of COPD patients in GOLD groups A to D by combining severity of symptoms (mMRC $\geq 2$ points, CAT $\geq 10$ points, CCQ $\geq 1-1.5$ points or SGRQ $\geq 25$ points) and risk assessment (degree of airflow limitation and two or more exacerbations/one or more hospitalization in the last 12 months), see figure 1 for 2014 ABCD GOLD diagram. In 2017, during the execution of the current thesis, the GOLD classification of airflow limitation (left $\mathrm{Y}$-axis) was removed from the GOLD diagram.

The GOLD diagram provides the opportunity to classify patients with COPD based on more than lung function alone. Though, the GOLD document also recommends multiple assessment tools to define symptoms and risk. The impact of the four different assessment tools to measure symptoms and different definitions of future risk on frequency distribution and clinical characteristics remains unknown. 


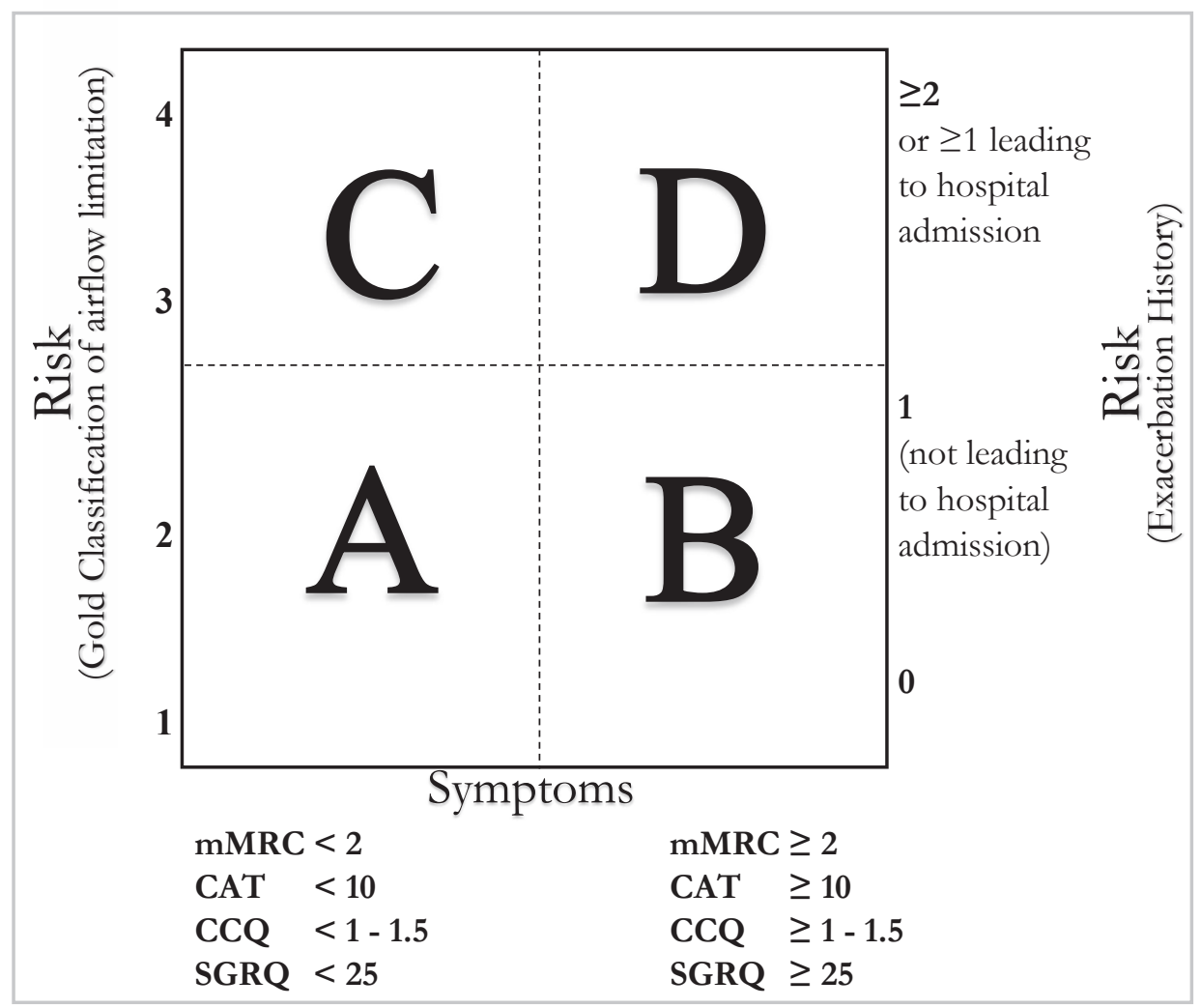

Figure 1. GOLD 2014 assessment, using spirometric classification, symptoms, breathlessness and risk of exacerbations

Significant differences are observed between characteristics of the four GOLD groups (56). Patients in group B and D report a worse disease-specific health status $(57,58)$ and worse exercise capacity $(58)$ compared to patients in group A and C. Though, regarding the currently applied GOLD cut-points for symptom measures, it is shown that the cut-points did not match with each other $(83,84)$. Assessment with the CAT, CCQ or SGRQ increases the number of patients in high-symptom groups (B and D), compared with mMRC (85-87). In response, categorization in different GOLD groups lead to different types of treatment and management (e.g. medication, pulmonary rehabilitation). Moreover, previous research implies that an impaired health status, derived from the GOLD cut-points for symptom measures, already occurs in half of the current or former smokers without having an airflow limitation and solely a minority of primary care COPD patients have a normal health status $(83,88)$. This highlights the importance of understanding what are normal values for these symptom measures. Indeed, the GOLD Scientific Committee recognizes that the current cut-points of symptom measures are an 


\section{Chapter 1}

important topic that needs to be addressed in the next revision of the GOLD document (89). Therefore, refinement of GOLD cut-points for symptom measures is necessary and will be addressed in the current thesis.

\section{AIMS OF THIS THESIS}

Given the relevance of health status as a patient-related outcome in COPD and the central of health status measurement in modern COPD management, it is essential to increase our understanding of assessment of health status in a broad population of COPD patients and of normal health status values in non-COPD.

Therefore, the aims of this thesis were:

- To investigate which cut-off value represents an abnormal CAT score for non-COPD subjects in a Dutch population; and to measure the impact of COPD on health status in a Dutch population, after stratification for work status

- To study the baseline characteristics of subjects with COPD in a Dutch population-based sample; and to compare physical status, mental status, and social status in a population-based sample of COPD subjects with nonCOPD subjects from the same population

- To compare burden of disease and healthcare utilization between patients with COPD treated in primary care, secondary care or tertiary care and explore possibilities for optimization of care

- To determine the responsiveness of SGRQ, CAT, CCQ and HADS following a comprehensive pulmonary rehabilitation program in patients with COPD; and to estimate MCIDs for CAT, CCQ and HADS using anchor-based and distribution-based methods

- To investigate the impact of the four different assessment tools for symptoms and different definitions of future risk on frequency distribution of GOLD groups A to D; and to study differences in clinical characteristics between the GOLD groups using these different scenarios

- To re-calibrate the current cut-off points for symptom measures of the GOLD criteria using existing datasets, with a mMRC grade of 2 or higher as the points of reference and to study the impact of the newly derived cutpoints of all questionnaires on the frequency distribution of the GOLD staging in a large COPD cohort 


\section{OUTLINE OF THIS THESIS}

At first, the study design, population, procedure, in- and exclusion criteria and applied measurements of our Chance study are described in chapter 2. Health status values in a non-COPD and COPD population are described in chapter 3. New normative values are suggested for the CAT in non-COPD subjects and the impact of COPD on health status in a Dutch population, after stratification for work status, is discussed. Following, chapter 4 demonstrates the general characteristics of patients with COPD in a general Dutch population. Additionally, differences in physical-, mental- and social status of a COPD population compared to non-COPD controls are described. As it remains unknown whether and to what extent patients with COPD treated in various healthcare settings differ in clinically relevant characteristics, in chapter 5, the burden of disease and healthcare utilization in COPD patients treated in primary, secondary and tertiary care setting in the Netherlands is outlined. Subsequently, shortcomings of care for COPD patients in the Netherlands are uncovered and possibilities for optimization are suggested.

Pulmonary rehabilitation is able to reduce COPD symptoms and improve health status in COPD. Tough, not all changes are clinically relevant. Estimated MCIDs for health status and mood status are determined by previous research. Changes in mood status can be assessed using the Hospital Anxiety and Depression Scale (HADS), providing a depression (HADS-D) and anxiety (HADS-A) score. As MCIDs for health status questionnaires vary between studies and various methods were applied to derive these, in chapter $\mathbf{6}$ we assessed the responsiveness of the SGRQ, CAT, CCQ and HADS to pulmonary rehabilitation and determined new MCID ranges for the CAT, CCQ and HADS. Chapter 7 describes the impact of GOLD recommended measures (exacerbation frequency, hospitalization frequency and symptom measures) to determine GOLD groups, on the frequency distribution of GOLD groups $A$ to $D$ as well as their clinical characteristics. Following, in chapter 8 new recommendations are made to change cut-points of the symptom measures the current GOLD ABCD diagram, with a mMRC dyspnea grade of two or higher as point of reference. Finally, chapter 9 generally discusses previous chapters and gives future directions for research. 


\section{REFERENCES}

1. Global Strategy For The Diagnosis, Management, and Prevention of Chronic, Obstructive Pulmonary Disease. Updated 2015. [PDF file]. www.goldcopd.com. [updated januari 2015].

2. Postma DS, Bush A, van den Berge M. Risk factors and early origins of chronic obstructive pulmonary disease. Lancet. 2015;385(9971):899-909.

3. Chronic obstructive pulmonary disease (COPD) http://www.who.int/en/2015 [updated January 2015].

4. Kart L, Akkoyunlu ME, Bayram M, Yakar F, Kutbay Ozcelik H, Karakose F, et al. COPD: an underdiagnosed disease at hospital environment. Wiener klinische Wochenschrift. 2014;126(3-4):73-8.

5. Janssen DJ, Spruit MA, Uszko-Lencer NH, Schols JM, Wouters EF. Symptoms, comorbidities, and health care in advanced chronic obstructive pulmonary disease or chronic heart failure. Journal of palliative medicine. 2011;14(6):735-43.

6. Afonso AS, Verhamme KM, Sturkenboom MC, Brusselle GG. COPD in the general population: prevalence, incidence and survival. Respiratory medicine. 2011;105(12):1872-84.

7. Agusti A. Systemic effects of chronic obstructive pulmonary disease: what we know and what we don't know (but should). Proceedings of the American Thoracic Society. 2007;4(7):522-5.

8. Quanjer PH, Brazzale DJ, Boros PW, Pretto JJ. Implications of adopting the Global Lungs Initiative 2012 all-age reference equations for spirometry. The European respiratory journal. 2013;42(4):1046-54.

9. Geijer RM, Tuut MK, in't Veen JC, Broekhuizen BD, Chavannes NH, Smeele IJ. [The NHG guidelines 'Adult asthma' and 'COPD']. Nederlands tijdschrift voor geneeskunde. 2015;159:A9076.

10. Vestbo J, Hurd SS, Agusti AG, Jones PW, Vogelmeier C, Anzueto A, et al. Global strategy for the diagnosis, management, and prevention of chronic obstructive pulmonary disease: GOLD executive summary. American journal of respiratory and critical care medicine. 2013;187(4):347-65.

11. Gibson GJ, Loddenkemper R, Lundback B, Sibille Y. Respiratory health and disease in Europe: the new European Lung White Book. The European respiratory journal. 2013;42(3):559-63.

12. Mathers CD, Loncar D. Projections of global mortality and burden of disease from 2002 to 2030. PLoS medicine. 2006;3(11):e442.

13. Vos T, Flaxman AD, Naghavi M, Lozano R, Michaud C, Ezzati M, et al. Years lived with disability (YLDs) for 1160 sequelae of 289 diseases and injuries 1990-2010: a systematic analysis for the Global Burden of Disease Study 2010. Lancet. 2012;380(9859):2163-96.

14. Atsou K, Chouaid C, Hejblum G. Variability of the chronic obstructive pulmonary disease key epidemiological data in Europe: systematic review. BMC medicine. 2011;9:7. 
15. Buist AS, McBurnie MA, Vollmer WM, Gillespie S, Burney P, Mannino DM, et al. International variation in the prevalence of COPD (the BOLD Study): a populationbased prevalence study. Lancet. 2007;370(9589):741-50.

16. Hoogendoorn M, Rutten-van Molken MP, Hoogenveen RT, van Genugten ML, Buist AS, Wouters EF, et al. A dynamic population model of disease progression in COPD. The European respiratory journal. 2005;26(2):223-33.

17. Longziekten: feiten en cijfers 2013 Amersfoort: Long Alliantie Nederland; 2013 [updated 17-6-2014.

18. Vanfleteren LE, Franssen FM, Wesseling G, Wouters EF. The prevalence of chronic obstructive pulmonary disease in Maastricht, the Netherlands. Respiratory medicine. 2012;106(6):871-4.

19. Wouters EF. Economic analysis of the Confronting COPD survey: an overview of results. Respiratory medicine. 2003;97 Suppl C:S3-14.

20. Heijmans MJWM, Spreeuwenberg P, PM. R. Monitor Zorg- en Leefsituatie van mensen met astma en mensen met COPD, Trends en ontwikkelingen over de periode 2001 - 2004. NIVEL. 2005.

21. Foo J, Landis SH, Maskell J, Oh YM, van der Molen T, Han MK, et al. Continuing to Confront COPD International Patient Survey: Economic Impact of COPD in 12 Countries. PloS one. 2016;11(4):e0152618.

22. Srivastava K, Thakur D, Sharma S, Punekar YS. Systematic review of humanistic and economic burden of symptomatic chronic obstructive pulmonary disease. Pharmacoeconomics. 2015;33(5):467-88.

23. Polatli M, Ben Kheder A, Wali S, Javed A, Khattab A, Mahboub B, et al. Chronic obstructive pulmonary disease and associated healthcare resource consumption in the Middle East and North Africa: the BREATHE study. Respiratory medicine. 2012;106 Suppl 2:S75-85.

24. Poos MJJC, Gool van CH, AM G. Ziektelast in DALY's: Wat is de ziektelast in Nederland? http://www.nationaalkompas.nl. 2014.

25. Spruit MA, Polkey MI, Celli B, Edwards LD, Watkins ML, Pinto-Plata V, et al. Predicting outcomes from 6-minute walk distance in chronic obstructive pulmonary disease. Journal of the American Medical Directors Association. 2012;13(3):291-7.

26. Voll-Aanerud M, Eagan TM, Wentzel-Larsen T, Gulsvik A, Bakke PS. Respiratory symptoms, COPD severity, and health related quality of life in a general population sample. Respiratory medicine. 2008;102(3):399-406.

27. Curtis JR, Patrick DL. The assessment of health status among patients with COPD. The European respiratory journal Supplement. 2003;41:36s-45s.

28. Jones PW. Health status measurement in chronic obstructive pulmonary disease. Thorax. 2001;56(11):880-7.

29. Jones PW, Brusselle G, Dal Negro RW, Ferrer M, Kardos P, Levy ML, et al. Healthrelated quality of life in patients by COPD severity within primary care in Europe. Respiratory medicine. 2011;105(1):57-66.

30. ZuWallack R. How are you doing? What are you doing? Differing perspectives in the assessment of individuals with COPD. Copd. 2007;4(3):293-7. 
31. Rennard S, Decramer M, Calverley PM, Pride NB, Soriano JB, Vermeire PA, et al. Impact of COPD in North America and Europe in 2000: subjects' perspective of Confronting COPD International Survey. The European respiratory journal. 2002;20(4):799-805.

32. Mahler DA, Mackowiak JI. Evaluation of the short-form 36-item questionnaire to measure health-related quality of life in patients with COPD. Chest. 1995;107(6):1585-9.

33. Miravitlles M, Alvarez-Sala JL, Lamarca R, Ferrer M, Masa F, Verea H, et al. Treatment and quality of life in patients with chronic obstructive pulmonary disease. Quality of life research : an international journal of quality of life aspects of treatment, care and rehabilitation. 2002;11(4):329-38.

34. Herdman M, Gudex C, Lloyd A, Janssen M, Kind P, Parkin D, et al. Development and preliminary testing of the new five-level version of EQ-5D (EQ-5D-5L). Quality of life research : an international journal of quality of life aspects of treatment, care and rehabilitation. 2011;20(10):1727-36.

35. Jones PW, Quirk FH, Baveystock CM, Littlejohns P. A self-complete measure of health status for chronic airflow limitation. The St. George's Respiratory Questionnaire. The American review of respiratory disease. 1992;145(6):1321-7.

36. van der Molen T, Willemse BW, Schokker S, ten Hacken NH, Postma DS, Juniper EF. Development, validity and responsiveness of the Clinical COPD Questionnaire. Health and quality of life outcomes. 2003;1:13.

37. Jones PW, Harding G, Berry P, Wiklund I, Chen WH, Kline Leidy N. Development and first validation of the COPD Assessment Test. The European respiratory journal. 2009;34(3):648-54.

38. Weldam SW, Schuurmans MJ, Liu R, Lammers JW. Evaluation of Quality of Life instruments for use in COPD care and research: a systematic review. International journal of nursing studies. 2013;50(5):688-707.

39. Maly M, Vondra V. Generic versus disease-specific instruments in quality-of-life assessment of chronic obstructive pulmonary disease. Methods Inf Med. 2006;45(2):211-5.

40. Wacker ME, Jorres RA, Karch A, Wilke S, Heinrich J, Karrasch S, et al. Assessing health-related quality of life in COPD: comparing generic and disease-specific instruments with focus on comorbidities. BMC pulmonary medicine. 2016;16(1):70.

41. Harper R, Brazier JE, Waterhouse JC, Walters SJ, Jones NM, Howard P. Comparison of outcome measures for patients with chronic obstructive pulmonary disease (COPD) in an outpatient setting. Thorax. 1997;52(10):879-87.

42. Xu W, Collet JP, Shapiro S, Lin Y, Yang T, Wang C, et al. Validation and clinical interpretation of the St George's Respiratory Questionnaire among COPD patients, China. The international journal of tuberculosis and lung disease : the official journal of the International Union against Tuberculosis and Lung Disease. 2009;13(2):181-9.

43. Ferrer M, Alonso J, Prieto L, Plaza V, Monso E, Marrades R, et al. Validity and reliability of the St George's Respiratory Questionnaire after adaptation to a different language and culture: the Spanish example. The European respiratory journal. 1996;9(6):1160-6. 
44. Meguro M, Barley EA, Spencer S, Jones PW. Development and Validation of an Improved, COPD-Specific Version of the St. George Respiratory Questionnaire. Chest. 2007;132(2):456-63.

45. Jones PW, Quirk FH, Baveystock CM. The St George's Respiratory Questionnaire. Respiratory medicine. 1991;85 Suppl B:25-31; discussion 3-7.

46. Spruit MA, Augustin IM, Vanfleteren L, Janssen DJ, Gaffron S, Pennings HJ, et al. Differential response to pulmonary rehabilitation in COPD: multidimensional profiling. The European respiratory journal. 2015.

47. Carone M, Antoniu S, Baiardi P, Digilio VS, Jones PW, Bertolotti G. Predictors of Mortality in Patients with COPD and Chronic Respiratory Failure: The Quality-of-Life Evaluation and Survival Study (QuESS): A Three-Year Study. Copd. 2015:1-9.

48. Han MK, Muellerova H, Curran-Everett D, Dransfield MT, Washko GR, Regan EA, et al. GOLD 2011 disease severity classification in COPDGene: a prospective cohort study. The Lancet Respiratory medicine. 2013;1(1):43-50.

49. Welling JB, Hartman JE, Ten Hacken NH, Klooster K, Slebos DJ. The minimal important difference for the St George's Respiratory Questionnaire in patients with severe COPD. The European respiratory journal. 2015.

50. Ringbaek T, Martinez G, Lange P. A comparison of the assessment of quality of life with CAT, CCQ, and SGRQ in COPD patients participating in pulmonary rehabilitation. Copd. 2012;9(1):12-5.

51. Gupta N, Pinto LM, Morogan A, Bourbeau J. The COPD assessment test: a systematic review. The European respiratory journal. 2014;44(4):873-84.

52. Evans BJ, Stevenson SJ. The Pattern Glare Test: a review and determination of normative values. Ophthalmic Physiol Opt. 2008;28(4):295-309.

53. Echocardiographic Normal Ranges Meta-Analysis of the Left Heart C. Ethnic-Specific Normative Reference Values for Echocardiographic LA and LV Size, LV Mass, and Systolic Function: The EchoNoRMAL Study. JACC Cardiovasc Imaging. 2015;8(6):656-65.

54. Guo X, Fu M, Lu J, Chen Q, Zeng Y, Ding X, et al. Normative distribution of visual acuity in 3- to 6-year-old Chinese preschoolers: the Shenzhen kindergarten eye study. Invest Ophthalmol Vis Sci. 2015;56(3):1985-92.

55. Nishimura K, Mitsuma S, Kobayashi A, Yanagida M, Nakayasu K, Hasegawa Y, et al. COPD and disease-specific health status in a working population. Respiratory research. 2013;14(1):61.

56. Pinto LM, Gupta N, Tan W, Li PZ, Benedetti A, Jones PW, et al. Derivation of normative data for the COPD assessment test (CAT). Respiratory research. 2014;15(1):68.

57. Jones PW, Shahrour N, Nejjari C, Lahlou A, Doble A, Rashid N, et al. Psychometric evaluation of the COPD assessment test: data from the BREATHE study in the Middle East and North Africa region. Respiratory medicine. 2012;106 Suppl 2:S86-99.

58. Miravitlles M, Murio C, Tirado-Conde G, Levy G, Muellerova H, Soriano JB, et al. Geographic differences in clinical characteristics and management of COPD: the EPOCA study. International journal of chronic obstructive pulmonary disease. 2008;3(4):803-14. 
59. Pinto LM, Gupta N, Tan W, Li PZ, Benedetti A, Jones PW, et al. Derivation of normative data for the COPD assessment test (CAT). Respiratory research. 2014;15:68.

60. Ilic M, Kopitovic I, Zvezdin B, Tomasevic N, Vitas L. Application CAT questionnaire of the treatment of patients with COPD. European Respitory Society Annual Congress Vienna, Austria 2012.

61. Rovina N, Symiakakis M, Tsioka A, Travlos A, Vlachos K, Koutsoukou A, et al. COPD assessment test (CAT) in acute exacerbation of COPD and in the long term follow up of COPD patients. European Respiratory Society Annual Congress Barcelona, Spain 2013.

62. Casanova C, Marin JM, Martinez-Gonzalez C, de Lucas-Ramos P, Mir-Viladrich I, Cosio B, et al. Differential effect of mMRC dyspnea, CAT and CCQ for symptom evaluation within the new GOLD staging and mortality in COPD. Chest. 2015.

63. Panagioti M, Scott C, Blakemore A, Coventry PA. Overview of the prevalence, impact, and management of depression and anxiety in chronic obstructive pulmonary disease. International journal of chronic obstructive pulmonary disease. 2014;9:1289-306.

64. Gomes T, Ladeira IT, Castro A, Ribeiro C, Guimaraes M, Taveira N. CAT IN COPD - Measuring The Real Impact To Improve Management Of Disease. American Thoracic Society International Congress; San Francisco, California 2012.

65. Herland K, Akselsen JP, Skjonsberg OH, Bjermer L. How representative are clinical study patients with asthma or COPD for a larger "real life" population of patients with obstructive lung disease? Respiratory medicine. 2005;99(1):11-9.

66. Management of chronic obstructive pulmonary disease in adults in primary and secondary care http://www.nice.org.uk/guidance/cg101/resources/guidance-chronicobstructive-pulmonary-disease-pdf: National Institute for Health and Clinical Excellence (NICE) 2010.

67. Smeele IJM, Van Weel C, Van Schayck CP, Van der Molen T, Thoonen B, Schermer T, et al. NHG-Standaard COPD. Huisarts en Wetenschap. 2007;50(8).

68. Spruit MA, Singh SJ, Garvey C, ZuWallack R, Nici L, Rochester C, et al. An official American Thoracic Society/European Respiratory Society statement: key concepts and advances in pulmonary rehabilitation. American journal of respiratory and critical care medicine. 2013;188(8):e13-64.

69. Rochester CL, Vogiatzis I, Holland AE, Lareau SC, Marciniuk DD, Puhan MA, et al. An Official American Thoracic Society/European Respiratory Society Policy Statement: Enhancing Implementation, Use, and Delivery of Pulmonary Rehabilitation. American journal of respiratory and critical care medicine. 2015;192(11):1373-86.

70. Kiley JP, Sri Ram J, Croxton TL, Weinmann GG. Challenges associated with estimating minimal clinically important differences in COPD-the NHLBI perspective. Copd. 2005;2(1):43-6.

71. Revicki D, Hays RD, Cella D, Sloan J. Recommended methods for determining responsiveness and minimally important differences for patient-reported outcomes. Journal of clinical epidemiology. 2008;61(2):102-9. 
72. Halme AS, Fritel X, Benedetti A, Eng K, Tannenbaum C. Implications of the minimal clinically important difference for health-related quality-of-life outcomes: a comparison of sample size requirements for an incontinence treatment trial. Value in health: the journal of the International Society for Pharmacoeconomics and Outcomes Research. 2015;18(2):292-8.

73. Jones PW. St. George's Respiratory Questionnaire: MCID. Copd. 2005;2(1):75-9.

74. Kon SS, Dilaver D, Mittal M, Nolan CM, Clark AL, Canavan JL, et al. The Clinical COPD Questionnaire: response to pulmonary rehabilitation and minimal clinically important difference. Thorax. 2014;69(9):793-8.

75. Canavan JL, Dilaver D, Clark AL, Jones SE, Nolan CM, Kon SS, et al. Clinical COPD Questionnaire in patients with chronic respiratory disease. Respirology. 2014;19(7):100612.

76. Tsiligianni IG, van der Molen T, Moraitaki D, Lopez I, Kocks JW, Karagiannis K, et al. Assessing health status in COPD. A head-to-head comparison between the COPD assessment test (CAT) and the clinical COPD questionnaire (CCQ). BMC pulmonary medicine. 2012;12:20.

77. Kocks JW, Tuinenga MG, Uil SM, van den Berg JW, Stahl E, van der Molen T. Health status measurement in COPD: the minimal clinically important difference of the clinical COPD questionnaire. Respiratory research. 2006;7:62.

78. Dodd JW, Hogg L, Nolan J, Jefford H, Grant A, Lord VM, et al. The COPD assessment test (CAT): response to pulmonary rehabilitation. A multicentre, prospective study. Thorax. 2011;66(5):425-9.

79. Jones PW, Harding G, Wiklund I, Berry P, Tabberer M, Yu R, et al. Tests of the responsiveness of the COPD assessment test following acute exacerbation and pulmonary rehabilitation. Chest. 2012;142(1):134-40.

80. Kon SS, Canavan JL, Jones SE, Nolan CM, Clark AL, Dickson MJ, et al. Minimum clinically important difference for the COPD Assessment Test: a prospective analysis. The Lancet Respiratory medicine. 2014;2(3):195-203.

81. Singh SJ, Puhan MA, Andrianopoulos V, Hernandes NA, Mitchell KE, Hill CJ, et al. An official systematic review of the European Respiratory Society/American Thoracic Society: measurement properties of field walking tests in chronic respiratory disease. The European respiratory journal. 2014;44(6):1447-78.

82. Rabe KF, Hurd S, Anzueto A, Barnes PJ, Buist SA, Calverley P, et al. Global strategy for the diagnosis, management, and prevention of chronic obstructive pulmonary disease: GOLD executive summary. American journal of respiratory and critical care medicine. 2007;176(6):532-55.

83. Jones PW, Adamek L, Nadeau G, Banik N. Comparisons of health status scores with MRC grades in COPD: implications for the GOLD 2011 classification. The European respiratory journal. 2013;42(3):647-54.

84. Miravitlles M, Huerta A, Fernandez-Villar JA, Alcazar B, Villa G, Forne C, et al. Generic utilities in chronic obstructive pulmonary disease patients stratified according to different staging systems. Health and quality of life outcomes. 2014;12:120. 


\section{Chapter 1}

85. Rubinsztajn R, Przybylowski T, Maskey-Warzechowska M, Karwat K, Chazan R. [GOLD 2011 - COPD from a new perspective]. Polski merkuriusz lekarski: organ Polskiego Towarzystwa Lekarskiego. 2013;34(202):192-5.

86. Kim S, Oh J, Kim YI, Ban HJ, Kwon YS, Oh IJ, et al. Differences in classification of COPD group using COPD assessment test (CAT) or modified Medical Research Council (mMRC) dyspnea scores: a cross-sectional analyses. BMC pulmonary medicine. 2013;13:35.

87. Small M, Broomfield S, Higgins V. Quantification and treatment patterns of real-world patients classified by the GOLD 2011 strategy. European Respitory Society Annual Congress; Vienna, Austria 2012.

88. Woodruff PG, Barr RG, Bleecker E, Christenson SA, Couper D, Curtis JL, et al. Clinical Significance of Symptoms in Smokers with Preserved Pulmonary Function. N Engl J Med. 2016;374(19):1811-21.

89. Vogelmeier CF, Vestbo J, Hurd SS, Decramer M. Changes in GOLD: today and tomorrow. The Lancet Respiratory medicine. 2015;3(6):424-6. 


\section{How is your COPD? Take the COPD Assessment Test ${ }^{T M}$ (CAT)}

This questionnaire will help you and your healthcare professional measure the impact COPD (Chronic Obstructive Pulmonary Disease) is having on your wellbeing and daily life. Your answers, and test score, can be used by you and your healthcare professional to help improve the management of your COPD and get the greatest benefit from treatment.

For each item below, place a mark $(X)$ in the box that best describes you currently. Be sure to only select one response for each question.

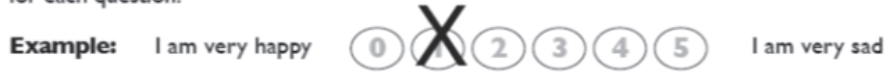

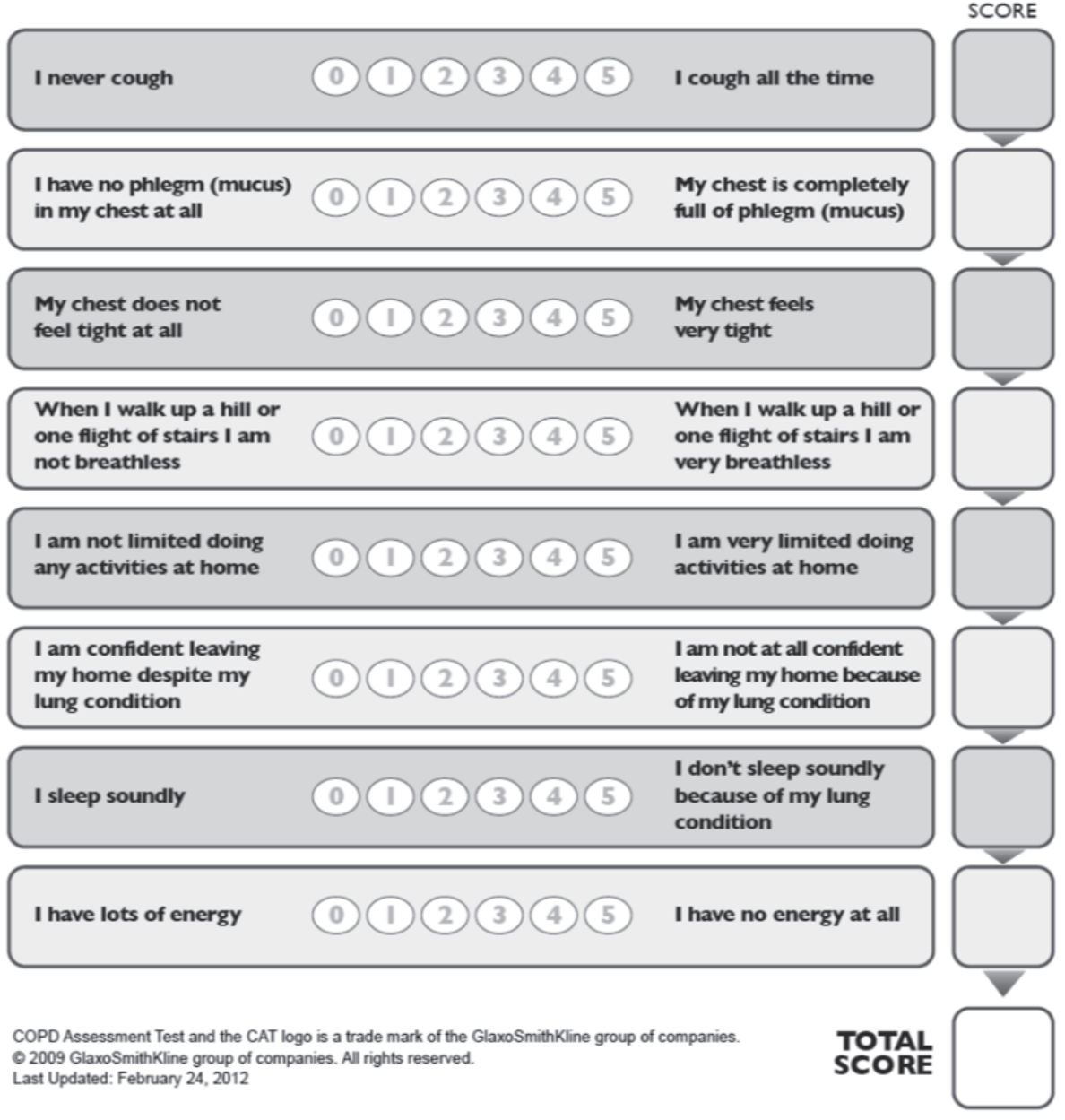

Figure 1. COPD Assessment Test (CAT) 



\section{Chapter 2}

The impact of cardiovascular comorbidities on COPD Assessment Test (CAT) and its responsiveness to pulmonary rehabilitation in patients with moderate to very severe COPD: the protocol of the Chance study

Dionne E Smid, Sarah Wilke, Paul W Jones, Jean W M Muris, Emiel F M Wouters, Frits M E Franssen, Martijn A Spruit 


\section{ABSTRACT}

Introduction Chronic obstructive pulmonary disease (COPD) is a major cause of morbidity and mortality. Patients with COPD are characterised by a reduced health status, which can be easily assessed by the COPD Assessment Test (CAT). Previous studies show that health status can be worsened by the presence of comorbidities. However, the impact of cardiovascular comorbidities on health status as assessed with CAT is not sufficiently investigated. Therefore, the current study has the following objectives: 1) to study the clinical, (patho)physiological and psychosocial determinants of the CAT, and impact of previously established and/or newly diagnosed cardiovascular comorbidities on health status in tertiary care patients with COPD; 2) to assess the effects of pulmonary rehabilitation on CAT scores in patients with COPD; 3) to develop reference values for the CAT in Dutch elderly patients without COPD; and 4) to validate the CAT in a broad sample of Dutch patients with COPD.

Methods and analysis The COPD, Health status and Comorbidities (Chance) study is a monocentre study consisting of an observational cross-sectional part and a longitudinal part. Demographic and clinical characteristics will be assessed in primary care, secondary care and tertiary care patients with COPD, and in patients without COPD. To assess health status, the CAT, Clinical COPD Questionnaire (CCQ) and St George's Respiratory Questionnaire (SGRQ) will be used. The longitudinal part consists of a comprehensive pulmonary rehabilitation programme in 500 tertiary care patients. For the cross-sectional part of the study, 150 patients without COPD, 100 primary care patients and 100 secondary care patients will be assessed during a single home visit.

Ethics and dissemination The Medical Ethical Committee of the Maastricht University Medical Centre+ (MUMC+), Maastricht, the Netherlands (METC 11-3-070), has approved this study. The study has been registered at the Dutch Trial Register (NTR 3416). 


\section{BACKGROUND}

Health status in patients with chronic obstructive pulmonary disease (COPD) is impaired irrespective of the degree of airflow limitation (1). Therefore, optimising health status is an important goal in COPD management (2). Indeed, according to the latest Global initiative for chronic Obstructive Lung Disease (GOLD) document, COPD assessment should include the assessment of health status as an objective in disease diagnosis and follow-up (3). Poor health status is multifactorially determined in patients with COPD, as it is associated with higher levels of dyspnea (4), reduced exercise capacity (5), symptoms of anxiety and depression (6), and frequent exacerbations and mortality (7). In addition, health status in patients with COPD can be worsened by the presence of comorbidities (8). Vanfleteren et al showed that $97.7 \%$ of all patients with COPD have one or more comorbidities (9). In European primary care patients with COPD, the presence of $\geq 3$ comorbidities was associated with a worse health status (10). Cardiovascular diseases are presumably the most important comorbid conditions in COPD. The risk of cardiovascular morbidity and mortality is twofold to threefold higher in patients with COPD in comparison to an age-matched and gender-matched population without COPD (11). Probably due to shared pathophysiological mechanisms, cardiovascular comorbidities often remain unrecognised in patients with COPD (11). Rutten et al reported a prevalence of $20 \%$ for previously undiagnosed heart failure in primary care patients with COPD (12). In addition, it was recently shown that echocardiographic abnormalities were highly prevalent in patients with COPD at the time of their first hospital admission due to a severe exacerbation (13). However, the frequency of echocardiographic abnormalities in patients with COPD referred for pulmonary rehabilitation is not known.

Health status in COPD is often assessed by disease-specific questionnaires, namely, the St George's Respiratory Questionnaire (SGRQ) and the Clinical COPD Questionnaire (CCQ) $(14,15)$. The SGRQ is reasonably time-consuming to complete, sometimes difficult to understand by patients and has a scoring algorithm that is too complex for routine use in clinical practice (16). In the Netherlands, the CCQ is commonly used in clinical practice. The reliability and validity of the CCQ in patients with COPD have previously been studied (16). In addition, a simple eight-item patient-completed questionnaire, the COPD Assessment Test (CAT) was developed some years ago (17). However, to a lesser extent, studies investigated the properties of the CAT and associations with clinical, physiological and psychological outcomes in COPD. Additionally, during the period that the current study protocol was designed, few studies about CAT in the Dutch population were published. Therefore, the 
COPD, Health status and Comorbidities (Chance) study was initiated and the following objectives were formulated:

1. To study the clinical, (patho)physiological and psychosocial determinants of the CAT and impact of previously established and/or new diagnosed cardiovascular comorbidities on health status in tertiary care patients with COPD.

2. To assess the effects of pulmonary rehabilitation on CAT scores in patients with COPD.

3. To develop reference values for the CAT by comparing patients with COPD using elderly Dutch patients without COPD.

4. To validate the CAT in a broad sample of Dutch patients with COPD.

\section{METHODS}

\section{Study design}

The current study is a monocentre, observational study consisting of a cross-sectional part (objectives 1, 3 and 4) and a longitudinal part (objective 2), see figure 1.

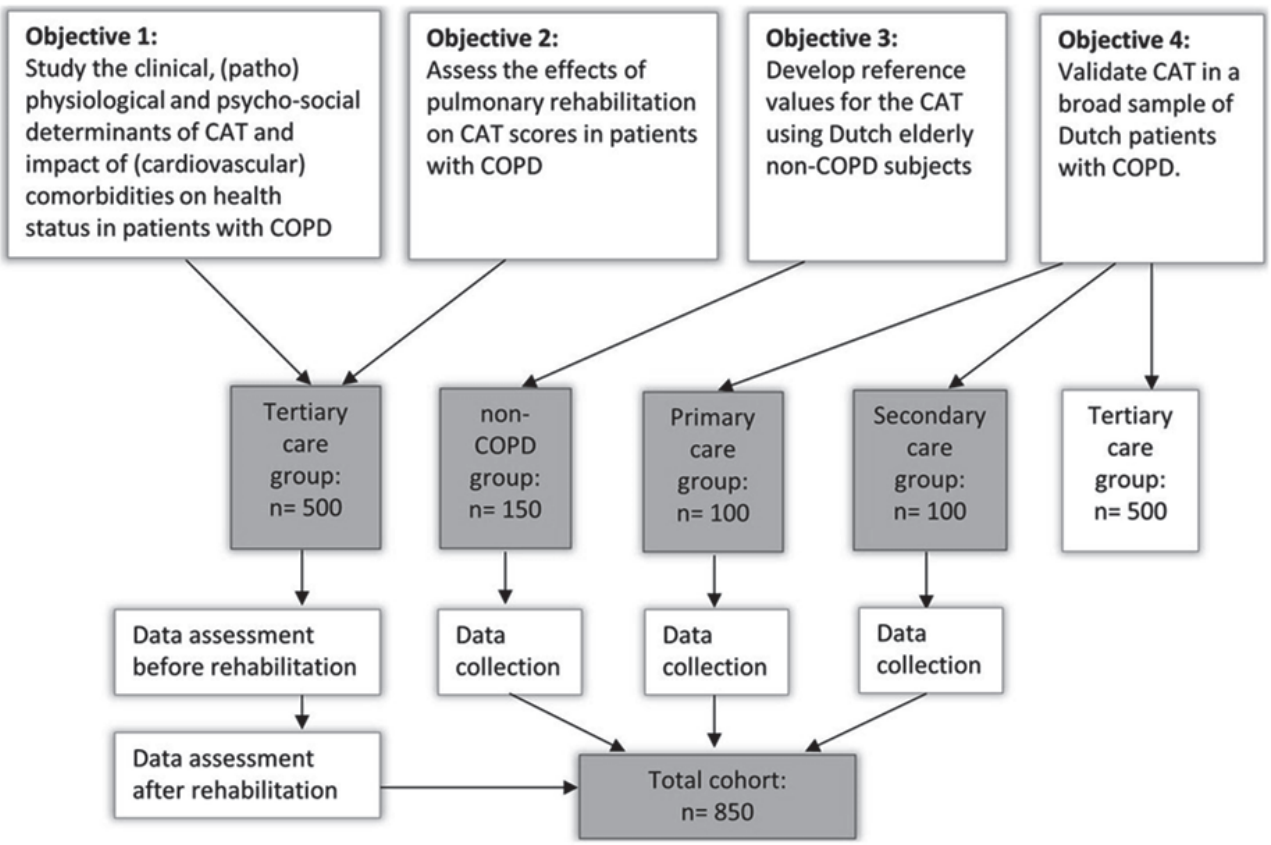

Figure 1. Flow diagram of patient participation and data assessment

(CAT, COPD Assessment Test; COPD, chronic obstructive pulmonary disease) 


\section{Study population}

Patients will be recruited from primary (general practitioners, GPs), secondary (chest physicians) and tertiary (pulmonary rehabilitation) care. The inclusion of patients started in April 2012. The inclusion of the patients from the tertiary care setting was completed in September 2014. It is expected that the inclusion of the patients without COPD, and patients from the primary and secondary care setting, will be completed in early 2015. Figure 1 shows an overview of the study objectives and study population. In order to study objectives 1 and 2, 500 patients with COPD, referred for clinical assessment and pulmonary rehabilitation to CIRO, Horn, The Netherlands, will be recruited (18). In order to examine objective 3 (see figure 1) 150 patients without COPD will be recruited from GPs via the 'Registration Network of Family Practices (RNH)' (19). Objective 4 (see figure 1) will be studied by assessing 100 patients with COPD from a primary care setting (recruited from GPs via RNH) and 100 patients with COPD from secondary care settings (partly recruited via RNH and partly at the outpatient pulmonary consultation of Maastricht University Medical Centre (MUMC) Maastricht). Primary care patients are eligible if they are exclusively treated by a GP without being treated by a chest physician or have been treated in tertiary care in the previous 5 years. Secondary care patients are eligible when they are only being treated by a chest physician and have not been treated in tertiary care for the previous 5 years. In addition, 500 patients with COPD from the tertiary care setting will be included for the fourth objective. The 500 tertiary care patients who will be tested for objectives 1 and 2 will be part of the sample for objective 4 . All study procedures will be conducted by CIRO.

\section{Study procedure}

Patients without COPD, primary care patients and part of the secondary care patients will be recruited via RNH. RNH will provide the contact details of participating GPs. Accordingly, the investigator will contact the responsible GP practices if they are willing to participate. After the GP's approval of collaboration, medical records of the practice are screened using RNH software, according to the eligibility criteria for the study. Following approval of the responsible GP, the investigators from $\mathrm{CIRO}$ will send a letter to every eligible patient on behalf of the GP, introducing the research and asking whether the patient wants to participate. In case of patient's consent, a response letter with contact details will be returned to $\mathrm{CIRO}$, enabling the investigator to contact the participant and check the eligibility criteria via phone. If the patient is still eligible and interested, an appointment for a home visit will be scheduled. The remaining secondary care patients will be recruited by chest physicians from an academic hospital (MUMC). During their outpatient 


\section{Chapter 2}

pulmonary consultations, the chest physicians will ask the patient if he/she is interested in participating in the study. If the patient is interested, the CIRO investigators will be provided with the contact details, will contact the potential candidate and will possibly schedule an appointment. Patients from primary and secondary care, and patients without COPD, will be visited at their home. A home visit will last approximately $1 \frac{1}{2}$ to 2 hour. If it is not possible to conduct the visit in their home environment, participants will be asked to come to CIRO for 2 hour All patients will be asked to give written informed consent at the beginning of the home visit or at the time of the visit to CIRO. Tertiary care patients will be recruited at CIRO during their pre-rehabilitation assessment. Eligible patients will be asked if they are willing to participate in the study. After approval and signing the informed consent, required data will be gathered. In these patients, baseline and outcome assessment data will be collected (see figure 1). CIRO is providing a state-of-the-art interdisciplinary pulmonary rehabilitation programme for patients with COPD, in line with the latest American Thoracic Society/European Respiratory Society Statement on Pulmonary Rehabilitation (20). Patients are referred for inpatient (8 weeks) or outpatient (16 weeks) pulmonary rehabilitation based on their prerehabilitation assessment (18). The pulmonary rehabilitation programme in this study is part of the usual care of these patients at CIRO.

\section{Eligibility criteria}

Patients are eligible if they fulfil the following criteria:

1. Age 40-85 years.

2. A diagnosis of COPD according to GOLD guidelines (3).

Patients with COPD from the tertiary care setting also have to fulfil the following criteria:

1. Referral for assessment and pulmonary rehabilitation at CIRO by a chest physician.

Patients without COPD are eligible if they fulfil the following criteria:

1. Age 40-85 years.

2. Post-bronchodilator forced expiratory volume in $1 \mathrm{~s} /$ forced vital capacity $\left(\mathrm{FEV}_{1} / \mathrm{FVC}\right) \geq 70 \%$.

3. Healthy, as judged by the investigator, and determined by medical history and physical examination (specified under the heading 'exclusion criteria for the patients without COPD’). 
Exclusion criteria for the patients with COPD:

1. A history of asthma, lung cancer, sarcoidosis, tuberculosis, lung fibrosis, cystic fibrosis or any other significant respiratory disease.

2. A moderate or severe exacerbation or pneumonia requiring systemic corticosteroids, antibiotics or hospitalisation during the past 4 weeks.

3. Having undergone lung surgery (e.g., lung volume reduction, lung transplantation).

4. Any clinically relevant disease that, in the opinion of the investigator, may influence the results of the study, in other words, diseases influencing health status not related to symptoms of COPD.

5. Malignancy within the past 5 years.

6. For primary care patients: treatment by respiratory physician in secondary or tertiary care.

7. For secondary care patients: treatment in a tertiary care setting in the previous 5 years.

Exclusion criteria for the patients without COPD:

1. A history of COPD, asthma, lung cancer, sarcoidosis, tuberculosis, lung fibrosis, cystic fibrosis or any other significant respiratory disease, lung surgery in the past.

2. Chronic heart failure in medical history.

3. Any clinically relevant disease that, in the opinion of the investigator, may influence the results of the study, in other words, diseases influencing health status not related to symptoms of COPD.

4. Malignancy within the past 5 years.

\section{Outcomes}

Table 1 provides an overview of the recorded variables for each group.

\section{Sample size calculation}

The protocol was developed in 2012. At that time, the minimally clinically important difference (MCID) had not yet been established for the CAT. An estimation of the MCID was made to calculate the sample size for the current study. During the study period, the MCID of the CAT was set on two points (35). Subsequently, the sample size calculation was adjusted based on the most recent findings (calculated with the program Gxpower 3.1.9). Resulting in a study population of 150 patients without COPD, 100 primary care patients, 100 secondary care patients and 500 tertiary care patients. The full sample size calculation is accessible via the online supplementary material. 
Table 1. Outcome measures per healthcare group

\begin{tabular}{|c|c|c|c|c|c|}
\hline Outcomes & $\begin{array}{l}\text { Non- } \\
\text { COPD }\end{array}$ & $\begin{array}{l}\text { Primary } \\
\text { care }\end{array}$ & $\begin{array}{l}\text { Secondary } \\
\text { care }\end{array}$ & $\begin{array}{l}\text { Tertiary } \\
\text { care } \\
\text { (pre PR) }\end{array}$ & $\begin{array}{l}\text { Tertiary } \\
\text { care } \\
\text { (post PR) }\end{array}$ \\
\hline $\begin{array}{l}\text { Demographics, including age, gender, } \\
\text { height, weight, marital status, ethnic } \\
\text { origin }\end{array}$ & & $\mathrm{Y}$ & $\mathrm{Y}$ & $\mathrm{Y}$ & $\mathrm{Y}$ \\
\hline $\begin{array}{l}\text { Smoking history: current smoking and } \\
\text { pack years }\end{array}$ & & Y & Y & Y & $\mathrm{Y}$ \\
\hline $\begin{array}{l}\text { Medical history, including current } \\
\text { medication }\end{array}$ & Y & Y & Y & Y & $\mathrm{N}$ \\
\hline $\begin{array}{l}\text { COPD history: number of } \\
\text { exacerbations and hospitalisations for } \\
\text { COPD (<12 months) }\end{array}$ & $\mathrm{Y}$ & Y & Y & Y & Y \\
\hline $\begin{array}{l}\text { Use of long-term oxygen or non- } \\
\text { invasive ventilation }\end{array}$ & $\mathrm{Y}$ & $\mathrm{Y}$ & $\mathrm{Y}$ & $\mathrm{Y}$ & $\mathrm{Y}$ \\
\hline $\begin{array}{l}\text { Lung function: post-bronchodilator } \\
\text { (salbutamol) spirometry measured by } \\
\text { a handheld SpiroPro Viasys }\end{array}$ & $\mathrm{Y}$ & Y & Y & $\mathrm{N}$ & $\mathrm{N}$ \\
\hline 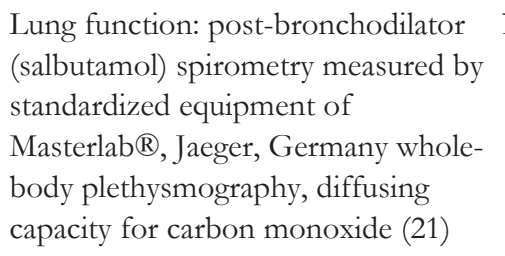 & $\mathrm{N}$ & $\mathrm{N}$ & $\mathrm{N}$ & Y & Y \\
\hline $\begin{array}{l}\text { Degree of self-perceived physical and } \\
\text { psychological symptoms* }\end{array}$ & $\mathrm{Y}$ & Y & Y & Y & $\mathrm{N}$ \\
\hline $\begin{array}{l}\text { Physical examination including vital } \\
\text { signs: pulse, blood pressure, saturation }\end{array}$ & Y & $\mathrm{Y}$ & $\mathrm{Y}$ & $\mathrm{Y}$ & $\mathrm{Y}$ \\
\hline Charlson co-morbidity index (22) & $\mathrm{Y}$ & $\mathrm{Y}$ & $\mathrm{Y}$ & $\mathrm{Y}$ & $\mathrm{Y}$ \\
\hline $\begin{array}{l}\text { mMRC dyspnea grading (23) and } \\
\text { NYHA Functional Classification (24) }\end{array}$ & $\mathrm{Y}$ & Y & Y & Y & Y \\
\hline $\begin{array}{l}\text { Health status questionnaires: SGRQ- } \\
\text { C, CAT, and CCQ (25) }\end{array}$ & $\mathrm{Y}$ & Y & Y & Y & Y \\
\hline $\begin{array}{l}\text { Hospital Anxiety and Depression } \\
\text { Scale (26) }\end{array}$ & $\mathrm{Y}$ & $\mathrm{Y}$ & $\mathrm{Y}$ & $\mathrm{Y}$ & $\mathrm{Y}$ \\
\hline $\begin{array}{l}\text { Daily physical functioning: timed 'up- } \\
\text { and-go' test (27) }\end{array}$ & $\mathrm{Y}$ & Y & Y & $\mathrm{Y}$ & $\mathrm{Y}$ \\
\hline Care Dependency Scale (28) & Y & Y & Y & Y & Y \\
\hline $\begin{array}{l}\text { Coping strategies: Utrecht Coping List } \\
\text { (37) }\end{array}$ & & $\mathrm{N}$ & $\mathrm{N}$ & Y & Y \\
\hline
\end{tabular}




\begin{tabular}{|c|c|c|c|c|c|}
\hline Outcomes & $\begin{array}{l}\text { Non- } \\
\text { COPD }\end{array}$ & $\begin{array}{l}\text { Primary } \\
\text { care }\end{array}$ & $\begin{array}{l}\text { Secondary } \\
\text { care }\end{array}$ & $\begin{array}{l}\text { Tertiary } \\
\text { care } \\
\text { (pre PR) }\end{array}$ & $\begin{array}{l}\text { Tertiary } \\
\text { care } \\
\text { (post PR) }\end{array}$ \\
\hline $\begin{array}{l}\text { Body composition: fat-free mass, fat } \\
\text { mass using bioelectrical impedance } \\
\text { assessment (29) }\end{array}$ & $\mathrm{Y}$ & $\mathrm{Y}$ & $\mathrm{Y}$ & $\mathrm{Y}$ & $\mathrm{N}$ \\
\hline $\begin{array}{l}\text { Body composition: whole-body/local I } \\
\text { dual energy x-ray absorptiometry } \\
\text { (DEXA) scan (30) }\end{array}$ & $\mathrm{N}$ & $\mathrm{N}$ & $\mathrm{N}$ & Y & $\mathrm{Y}$ \\
\hline Systemic inflammation: hsCRP & $\mathrm{N}$ & $\mathrm{N}$ & $\mathrm{N}$ & Y & $\mathrm{Y}$ \\
\hline $\begin{array}{l}\text { Six Minute Walk test ( } 2 \mathrm{x} \text { at baseline) } \\
\text { (31) }\end{array}$ & $\mathrm{N}$ & $\mathrm{N}$ & $\mathrm{N}$ & Y & $\mathrm{Y}$ \\
\hline $\begin{array}{l}\text { Constant work-rate bicycle test (32) } \\
\text { and cardio pulmonary exercise test }\end{array}$ & $\mathrm{N}$ & $\mathrm{N}$ & $\mathrm{N}$ & Y & $\mathrm{Y}$ \\
\hline $\begin{array}{l}\text { Daily physical activity level using a } \\
\text { validated accelerometer (33) }\end{array}$ & $\mathrm{N}$ & $\mathrm{N}$ & $\mathrm{N}$ & Y & $\mathrm{Y}$ \\
\hline $\begin{array}{l}\text { Problematic activities of daily life: } \\
\text { Canadian Occupational Performance } \\
\text { Measure (34) }\end{array}$ & $\mathrm{N}$ & $\mathrm{N}$ & $\mathrm{N}$ & Y & $\mathrm{Y}$ \\
\hline $\begin{array}{l}\text { Lower-limb muscle function: peak } \\
\text { isokinetic quadriceps strength using a } \\
\text { Biodex (38) }\end{array}$ & $\mathrm{N}$ & $\mathrm{N}$ & $\mathrm{N}$ & $\mathrm{Y}$ & $\mathrm{Y}$ \\
\hline Echocardiography & $\mathrm{N}$ & $\mathrm{N}$ & $\mathrm{N}$ & Y & $\mathrm{N}$ \\
\hline ECG (39) & $\mathrm{N}$ & $\mathrm{N}$ & $\mathrm{N}$ & Y & $\mathrm{Y}$ \\
\hline $\begin{array}{l}\text { NT-proBNP and other cardiovascular } 1 \\
\text { markers (to be determined) }\end{array}$ & & $\mathrm{N}$ & $\mathrm{N}$ & Y & $\mathrm{Y}$ \\
\hline $\begin{array}{l}\text { Biomarkers metabolic syndrome (40): } \\
\text { fasting glucose, cholesterol, HDL, } \\
\text { LDL, triglycerides }\end{array}$ & $\mathrm{N}$ & $\mathrm{N}$ & $\mathrm{N}$ & Y & $\mathrm{Y}$ \\
\hline
\end{tabular}

*Patient-completed checklist referring to dyspnea, fatigue, cough, muscle strength, appetite, insomnia, depression, anxiety, panic attacks, pain, mouth soreness, itching, edema, thirst, muscle cramps, restless legs, dizziness, pain on the chest and frequency of urination with visual analogue scales to score the severity of the complaint (questionnaire is approved by the Medical Ethical Committee of the Maastricht University Medical Centre, METC 07-3-054).

Abbreviations: CAT, COPD Assessment Test; CCQ, Clinical COPD Questionnaire; COPD, chronic obstructive pulmonary disease; DEXA, dual-energy X-ray absorptiometry; HDL, high-density lipoprotein; hsCRP, high-sensitivity C reactive protein; LDL, low-density lipoprotein; mMRC, modified Medical Research Council; N, measurement not conducted; NT-proBNP, N-terminal probrain natriuretic peptide; NYHA, New York Heart Association; PR, pulmonary rehabilitation; SGRQ-C, COPD-specific version of the St. George respiratory questionnaire; Y, measurement conducted. 


\section{Data management and statistics}

Data will be screened for missing values. In order to reduce the number of missing data, a researcher will be present when filling out the questionnaires. When there are missing data in the questionnaires, the missing values will be processed according to the guidelines of the different questionnaires. This will be carried out for every variable and participant. Other missing values will be excluded by listwise deletion.

All variables will be tested for normality. Descriptive statistics, including means (SD), medians (IQR) and frequencies, will be applied. Continuous variables will be presented as mean $(95 \% \mathrm{CI})$. To answer objective 1, the differences between groups will be assessed with unpaired Student t test. Multiple clinical outcomes will be tested for their association with CAT scores via multiple ordinary least squares (OLS) regression models. For objective 2, an analysis of variance (ANOVA) of repeated measurement will be performed to measure the change in CAT scores and a one-way ANOVA or two-tailed paired Student $\mathrm{t}$ test will be used to determine changes in CAT scores following a comprehensive pulmonary rehabilitation programme. To examine objective 3 , the characteristics and the CAT scores of the patients without COPD will be tested for normality with the Kolmogorov-Smirnov test. To validate and look at reference values for the CAT, the upper limit of the $95 \%$ CI of the CAT scores will be determined in the patients without COPD. All scores above this value will be defined as 'an abnormal health status'. For objective 4, differences in the CAT scores and other clinical characteristics between primary care and secondary care, and tertiary care COPD samples, will be assessed by using a one-way ANOVA. Finally, the scores of the CAT between the groups of primary, secondary and tertiary care, and patients without COPD, will be examined. All statistics will be processed using SPSS V.20.0 and GraphPad Prism. A p value of less than 0.05 is considered statistically significant.

\section{Dissemination}

Study data will be stored in the data centre at CIRO. The investigator will ensure that all data in the data centre are accurate and will be responsible for the monitoring of the data collection. Results will be presented at (inter) national conferences and will be submitted for publication in peer-reviewed journals. Participants are given the opportunity to be informed about the results of the study. 


\section{DISCUSSION}

The current study is designed to examine the validity and responsiveness of the CAT to pulmonary rehabilitation in a Dutch population. Initially, the clinical, (patho)physiological and psychosocial determinants of the CAT, and impact of cardiovascular comorbidities on health status in tertiary care patients with COPD, will be examined. In addition, reference values for the CAT will be developed by comparing patients with COPD with elderly Dutch patients without COPD. The strengths and limitations of the current study are described below.

\section{Strengths}

In the current literature, most COPD studies focus on patients from secondary or tertiary care (36). To our knowledge, this is the first study including patients with COPD treated in primary care as well as patients with COPD treated in secondary and tertiary care. In addition, the current study includes patients without COPD, enabling a comparison between primary, secondary and tertiary care patients and patients without COPD, regarding, for example, health status, mood status and functional status. Consequently, reference values for the CAT in Dutch elderly patients without COPD can be determined. Additionally, the majority of the measurements will be taken with the same devices. This provides a high reliability, despite the fact that the measurements will be carried out at different places. Furthermore, interobserver bias will be minimised, because all measurements in patients without COPD, primary care and secondary care patients will be performed by one researcher. Furthermore, as mentioned before, patients with COPD have a twofold to threefold higher chance of developing cardiovascular morbidity and higher risk of mortality than people without COPD (11), underscoring the importance of assessing these comorbid conditions carefully. The current study is the first to investigate a wide range of (extra) pulmonary parameters, providing the possibility of studying the individual effect of cardiovascular comorbidities on outcomes, for example, health status. Finally, patients are recruited from eight different GP practices (RNH affiliated), an academic hospital and a pulmonary rehabilitation centre (CIRO), increasing the internal and external validity.

\section{Limitations}

The results of the current study will be subject to several limitations. First, the study sample consists of a convenience sample: possibly in all four healthcare groups the patients with more symptoms, lack of motivation or more severe COPD are less willing to participate in the study, which can lead to selection bias. 
Consequently, outcomes can be more favourable. To limit selection bias as much as possible, every eligible patient without COPD, primary care patient and secondary care patient will be approached by their GP or chest physician, respectively, to participate in the current study. Second, health status may seem a subjective measure. Questionnaires addressing health status usually look at the emotional, psychological and physical effect of a disease. Measuring health status implies quantifying the impact of the illness on health, well-being and daily life, in a standardised and objective manner. According to Jones, the end product does not give a clinical impression, because an impaired health status may express itself differently in each patient. However, these questionnaires make it possible to compare health status in patients with COPD (41). Third, spirometry will not be performed with the same devices. The spirometry performed in tertiary patients with COPD will be carried out at CIRO as a part of patients' usual care with standardised spirometer equipment from Masterlab. However, this device is not portable, making it impossible to take on home visits. Therefore, the SpiroPro Viasys will be used to measure lung function in patients without COPD, and primary and secondary care patients. Both devices are valid and reliable instruments $(21,42)$, and are currently used in COPD studies $(43,44)$. The choice is made to perform only one measurement method per person, to decrease the risk of adverse effects (such as exhaustion). Subsequently, it is important to consider that spirometry is mainly performed to confirm or exclude diagnoses in the different populations. $\mathrm{FEV}_{1}$ or $\mathrm{FEV}_{1} / \mathrm{FVC}$ are no outcome parameters in the current study. Fourth, comorbidities are extensively assessed in tertiary care. Comprehensive comorbidity assessment is not being undertaken for patients without COPD, primary and secondary care patients with COPD. These groups only completed the Charlson comorbidity index. Finally, measurements in primary and secondary care patients as well as patients without COPD will only be conducted cross-sectionally, not providing the possibility to determine causality.

\section{Clinical consequences}

The current study is very likely to have clinical implications. Initially, it will give more insight in understanding the systemic effects of COPD, especially the impact of cardiovascular comorbidities on health status. By performing echocardiography, we will be able to examine cardiac abnormalities, for example, an impaired systolic left ventricular function, valvular abnormalities or increased right ventricular pressures, in relation to clinical outcomes in COPD. This will enable better monitoring of patients and ensure patient safety during pulmonary rehabilitation. Ultimately, patients at risk can receive more personalised, predictive, preventive and participatory (P4 medicine) care, for example, to prevent worsening and/or to 
optimise health status (45). In addition, the current study will examine whether the CAT is a valid measurement to assess health status in Dutch patients, and local reference values for clinical practice will be developed. Moreover, by comparing patients without COPD and primary, secondary and tertiary care patients with COPD, this study will increase our understanding of similarities and differences between the various healthcare categories in the Netherlands.

\section{CONCLUSION}

To conclude, health status is an important patient-related outcome in COPD. Thus, understanding the validity, responsiveness and clinical determinants of the CAT is essential for the management of patients with this disease. The Chance study will greatly extend the current knowledge on the CAT in patients with COPD and without COPD. In this article, the study protocol is described, and possible strengths and limitations are outlined. 


\section{REFERENCES}

1. Agusti A, Calverley PM, Celli B, et al. Characterisation of COPD heterogeneity in the ECLIPSE cohort. Respir Res 2010;11:122.

2. Vestbo J, Hurd SS, Agusti AG, et al. Global strategy for the diagnosis, management, and prevention of chronic obstructive pulmonary disease: GOLD executive summary. Am J Respir Crit Care Med 2013;187:347-65.

3. Global Strategy for the Diagnosis, Management, and Prevention of Chronic, Obstructive Pulmonary Disease. Updated 2015. [PDF file] http://www.goldcopd.com (updated January 2015.6-3-2015).

4. Hajiro T, Nishimura K, Tsukino M, et al. A comparison of the level of dyspnea vs disease severity in indicating the health-related quality of life of patients with COPD. Chest 1999;116:1632-7.

5. Spruit MA, Watkins ML, Edwards LD, et al. Determinants of poor 6-min walking distance in patients with COPD: the ECLIPSE cohort. Respir Med 2010;104:849-57.

6. Cully JA, Graham DP, Stanley MA, et al. Quality of life in patients with chronic obstructive pulmonary disease and comorbid anxiety or depression. Psychosomatics 2006;47:312-19.

7. Domingo-Salvany A, Lamarca R, Ferrer M, et al. Health-related quality of life and mortality in male patients with chronic obstructive pulmonary disease. Am J Respir Crit Care Med 2002;166:680-5.

8. Sin DD, Wu L, Man SF. The relationship between reduced lung function and cardiovascular mortality: a population-based study and a systematic review of the literature. Chest 2005;127:1952-9.

9. Vanfleteren LE, Spruit MA, Groenen M, et al. Clusters of comorbidities based on validated objective measurements and systemic inflammation in patients with chronic obstructive pulmonary disease. Am J Respir Crit Care Med 2013;187:728-35.

10. Jones PW, Brusselle G, Dal Negro RW, et al. Properties of the COPD assessment test in a cross-sectional European study. Eur Respir J 2011;38:29-35.

11. Huiart L, Ernst P, Suissa S. Cardiovascular morbidity and mortality in COPD. Chest 2005;128:2640-6.

12. Rutten FH, Cramer MJ, Grobbee DE, et al. Unrecognized heart failure in elderly patients with stable chronic obstructive pulmonary disease. Eur Heart J 2005;26:1887-94.

13. Freixa X, Portillo K, Pare C, et al. Echocardiographic abnormalities in patients with COPD at their first hospital admission. Eur Respir J 2013;41:784-91.

14. Jones PW, Quirk FH, Baveystock CM, et al. A self-complete measure of health status for chronic airflow limitation. The St. George's Respiratory Questionnaire. Am Rev Respir Dis 1992;145:1321-7.

15. van der Molen T, Willemse BW, Schokker S, et al. Development, validity and responsiveness of the Clinical COPD Questionnaire. Health Qual Life Outcomes 2003;1:13.

16. Ringbaek T, Martinez G, Lange P. A comparison of the assessment of quality of life with CAT, CCQ, and SGRQ in COPD patients participating in pulmonary rehabilitation. COPD 2012;9:12-15. 
17. Jones PW, Harding G, Berry P, et al. Development and first validation of the COPD Assessment Test. Eur Respir J 2009;34:648-54.

18. Spruit MA, Vanderhoven-Augustin I, Janssen PP, et al. Integration of pulmonary rehabilitation in COPD. Lancet 2008;371:12-13.

19. Metsemakers JF, Hoppener P, Knottnerus JA, et al. Computerized health information in The Netherlands: a registration network of family practices. Br J Gen Pract 1992;42:102-6.

20. Spruit MA, Singh SJ, Garvey C, et al. An official American Thoracic Society/European Respiratory Society statement: key concepts and advances in pulmonary rehabilitation. Am J Respir Crit Care Med 2013;188:e13-64.

21. Munnik P, Zanen P, Lammers JW. A comparison of lung function equipment with emphasis on interchangeability and methods. Physiol Meas 2006;27:445-55.

22. Charlson M, Szatrowski TP, Peterson J, et al. Validation of a combined comorbidity index. J Clin Epidemiol 1994;47:1245-51.

23. van der Molen T, Miravitlles M, Kocks JW. COPD management: role of symptom assessment in routine clinical practice. Int J Chron Obstruct Pulmon Dis 2013;8:461-71.

24. Janssen DJ, Spruit MA, Uszko-Lencer NH, et al. Symptoms, comorbidities, and health care in advanced chronic obstructive pulmonary disease or chronic heart failure. J Palliat Med 2011;14:735-43.

25. Wilke S, Smid DE, Spruit MA, et al. The 2014 Updated GOLD Strategy: a comparison of the various scenarios. J COPD F 2014;1:212-20.

26. Zigmond AS, Snaith RP. The hospital anxiety and depression scale. Acta Psychiatr Scand 1983;67:361-70.

27. Mesquita R, Janssen DJ, Wouters EF, et al. Within-day test-retest reliability of the Timed Up \& Go test in patients with advanced chronic organ failure. Arch Phys Med Rehabil 2013;94:2131-8.

28. Janssen DJ, Wouters EF, Schols JM, et al. Care dependency independently predicts two-year survival in outpatients with advanced chronic organ failure. J Am Med Dir Assoc 2013;14:194-8.

29. Schols AM, Wouters EF, Soeters PB, et al. Body composition by bioelectricalimpedance analysis compared with deuterium dilution and skinfold anthropometry in patients with chronic obstructive pulmonary disease. Am J Clin Nutr 1991;53:421-4.

30. Rutten EP, Spruit MA, Wouters EF. Critical view on diagnosing muscle wasting by single-frequency bio-electrical impedance in COPD. Respiratory medicine 2006;27:445-55.

31. Hernandes NA, Wouters EF, Meijer K, et al. Reproducibility of 6-minute walking test in patients with COPD. Eur Resp J 2011;38:261-7.

32. van't Hul A, Gosselink R, Kwakkel G. Constant-load cycle endurance performance: testretest reliability and validity in patients with COPD. J Cardiopulm Rehabil 2003;23:143-50.

33. Pitta F, Troosters T, Probst VS, et al. Quantifying physical activity in daily life with questionnaires and motion sensors in COPD. Eur Resp J 2006;27:1040-55.

34. Nieuwenhuizen MG, de Groot S, Janssen TW, et al. Canadian Occupational Performance Measure performance scale: Validity and responsiveness in chronic pain. Journal of rehabilitation research and development 2014;51:727-46. 
35. Kon SS, Canavan JL, Jones SE, et al. Minimum clinically important difference for the COPD Assessment Test: a prospective analysis. Lancet Respir Med 2014;2:195-203.

36. Herland K, Akselsen JP, Skjonsberg OH, et al. How representative are clinical study patients with asthma or COPD for a larger "real life" population of patients with obstructive lung disease? Respir Med 2005;99:11-19.

37. Stoilkova A, Wouters EF, Spruit MA, et al. The relationship between coping styles and clinical outcomes in patients with COPD entering pulmonary rehabilitation. Copd 2013;10:316-23.

38. Franssen FM, Broekhuizen R, Janssen PP, et al. Limb muscle dysfunction in COPD: effects of muscle wasting and exercise training. Medicine and science in sports and exercise 2005;37:2-9.

39. Sin DD, Man SF. Why are patients with chronic obstructive pulmonary disease at increased risk of cardiovascular diseases? The potential role of systemic inflammation in chronic obstructive pulmonary disease. Circulation 2003;107:1514-19.

40. Alberti KG, Eckel RH, Grundy SM, et al. Harmonizing the metabolic syndrome: a joint interim statement of the International Diabetes Federation Task Force on Epidemiology and Prevention; National Heart, Lung, and Blood Institute; American Heart Association; World Heart Federation; International Atherosclerosis Society; and International Association for the Study of Obesity. Circulation 2009;120:1640-5.

41. Jones PW. Health status measurement in chronic obstructive pulmonary disease. Thorax 2001;56:880-7.

42. De Soomer K, Claus L, Heyndrickx R, et al. Office spirometry: (un) reliability of some handheld spirometers. European Respiratory Society International Congress; Bercelona, Spain, 2013.

43. Houben $\mathrm{CH}$, Spruit MA, Wouters EF, et al. A randomised controlled trial on the efficacy of advance care planning on the quality of end-of-life care and communication in patients with COPD: the research protocol. BMJ Open 2014;4:e004465.

44. Nakken N, Janssen DJA, van den Bogaart EHA, et al. An observational, longitudinal study on the home environment of people with chronic obstructive pulmonary disease: the research protocol of the Home Sweet Home study. BMJ Open 2014;4:e006098.

45. Auffray C, Charron D, Hood L. Predictive, preventive, personalized, participatory medicine: back to the future. Genome Med 2010;2:57.

Reproduced from [The impact of cardiovascular comorbidities on COPD Assessment Test (CAT) and its responsiveness to pulmonary rehabilitation in patients with moderate to very severe COPD: the protocol of the Chance study. Smid DE, Wilke S, Jones PW, Muris JWM, Wouters EFM, Franssen FME, Spruit MA. 5(7), e007536, 2015] with permission from BMJ Publishing Group Ltd. 


\section{SUPPLEMENTARY MATERIAL}

\section{Sample size calculation}

The original sample size calculation:

A sample size calculation for continuous response variables was performed with the available data from literature (Jones et al. Eur Respir Journal 2009). Three sample size calculations were performed, due to the differences in CAT scores were expected to be different between tertiary care COPD patients; tertiary care COPD patients and, primary care and secondary care COPD patients; and tertiary care COPD patients and non-COPD controls.

The mean of non-COPD controls is estimated on 5 units of the CAT. A minimal difference of 5 units with COPD patients resulted that the lowest mean of the CAT for COPD patients should be 10 units (this is a proportion of 0.25 of the maximum of 40 units of the CAT).

\section{Sample size calculation for tertiary care COPD patients:}

The sample size calculation to compare tertiary care patients is based on detecting a minimal difference of 4 units of the CAT (4/40 is a proportion of 0.10 of the maximum of 40 units of the CAT).

For this sample size calculations was used:

Power $1-\beta=.80$

Significance level $\alpha=.05$

Formula:

$\mathrm{N}=\left\{\left(\mathrm{z}_{\alpha / 2}+\mathrm{z}_{1-\beta}\right)^{2} *\right.$ pmean $\left.*\left(1-\mathrm{p}_{\text {mean }}\right) *(1+\mathrm{r})\right\} /\left\{\mathrm{d}^{2} * \mathrm{r}\right\}$

$z_{\alpha / 2}=1.96$ (for two sided $\alpha=0.05$ )

$\mathrm{z}_{1-\beta}=0.84($ for $1-\beta=0.80)$

$\mathrm{p}_{\text {mean }}=\left(\mathrm{r} *\right.$ p $\left._{\text {copd patient }}+\mathrm{p}_{\text {copd patient }}\right) /(\mathrm{r}+1)$ gives $(1 * 0.25+0.25) /(1+1)=0.25$

pcopd patient $=0.25$

difference $\mathrm{d}=0.10$

ratio $\mathrm{r}=1$

$\mathrm{N}=\left\{(1.96+0.84)^{2} * 0.25 *(1-0.25) *(1+1)\right\} /\left(0.10^{2} * 1\right)$ resulted in an $\mathrm{n}=294$ $\approx 300$.

So, the total tertiary care patients group should consist $2 * 300$ tertiary care patients. The GOLD II and GOLD III tertiary care patients group will consist in 300 patients and the GOLD IV tertiary care patients will also consist of 300 patients. 


\section{Chapter 2}

Sample size calculation for comparing primary care and secondary care COPD patients with tertiary care COPD patients:

The sample size calculation to compare tertiary care patients with primary care and secondary care is based on detecting a minimal difference between 4.5 and 5 units of the CAT (4.5/40 is a proportion of 0.11 of the maximum of 40 units of the CAT and 5/40 is a proportion of 0.13 of the maximum of 40 units of the CAT).

For the sample size calculation with 4.5 units difference was used:

Power $1-\beta=.80$

Significance level $\alpha=.05$

Formula:

$\mathrm{N}=\left\{\left(\mathrm{z}_{\alpha / 2}+\mathrm{z}_{1-\beta}\right)^{2 *} \mathrm{p}_{\text {mean }} *\left(1-\mathrm{p}_{\text {mean }}\right) *(1+\mathrm{r})\right\} /\left\{\mathrm{d}^{2} * \mathrm{r}\right\}$

$\mathrm{z}_{\alpha / 2}=1.96$ (for two sided $\alpha=0.05$ )

$\mathrm{z}_{1-\beta}=0.84$ (for $1-\beta=0.80$ )

$\mathrm{p}_{\text {mean }}=\left(\mathrm{r} * \mathrm{p}_{\text {copd patient }}+\mathrm{p}_{\text {copd patient }}\right) /(\mathrm{r}+1)$ gives $(1 * 0.25+0.25) /(1+1)=0.25$

Pcopd patient $=0.25$

difference $\mathrm{d}=0.11$

ratio $r=1$

$\mathrm{N}=\left\{(1.96+0.84)^{2} * 0.25 *(1-0.25) *(1+1)\right\} /(0.112 * 1)$ resulted in an $\mathrm{n}=232.3$ $\approx 235$

For the sample size calculation with 5 units difference was used:

Power $1-\beta=.80$

Significance level $\alpha=.05$

Formula:

$\mathrm{N}=\left\{\left(\mathrm{z}_{\alpha / 2}+\mathrm{z}_{1-\beta}\right)^{2 *} \mathrm{p}_{\text {mean }} *\left(1-\mathrm{p}_{\text {mean }}\right) *(1+\mathrm{r})\right\} /\left\{\mathrm{d}^{2} * \mathrm{r}\right\}$

$z_{\alpha / 2}=1.96$ (for two sided $\alpha=0.05$ )

$z_{1-\beta}=0.84$ (for $1-\beta=0.80$ )

$\mathrm{p}_{\text {mean }}=\left(\mathrm{r} * \mathrm{p}_{\text {copd patient }}+\mathrm{p}_{\text {copd patient }}\right) /(\mathrm{r}+1)$ gives $(1 * 0.25+0.25) /(1+1)=0.25$

popd patient $=0.25$

difference $\mathrm{d}=0.13$

ratio $\mathrm{r}=1$

$\mathrm{N}=\left\{(1.96+0.84)^{2} * 0.25 *(1-0.25) *(1+1)\right\} /(0.132 * 1)$ resulted in an $\mathrm{n}=188.2$ $\approx 190$. 
The total tertiary care COPD patients group and the combination of the primary care and secondary care COPD patients consist between 190 and 235 patients for this analyse. Therefore for this study 200 primary care and secondary care COPD patients will be included. A sample of the tertiary care patients of 200 patients will be used for these analyses.

Sample size calculation for comparing non-COPD controls with tertiary care COPD patients:

The sample size calculation is based on detecting a minimal difference of 5 units of the CAT ( $5 / 40$ is a proportion of 0.125 of the maximum of 40 units of the CAT) between COPD patients ( 3 groups) and non-COPD controls ( 2 groups). The sample size calculation is repeated with COPD patients as one group and nonCOPD controls as one group.

The mean of non-COPD control is estimated on 5 units of the CAT. A minimal difference of 5 units with COPD patients resulted that the lowest mean of the CAT for COPD patients should be 10 units (this is a proportion of 0.25 of the maximum of 40 units of the CAT).

For this sample size calculations was used:

Power $1-\beta=.80$

Significance level $\alpha=.05$

Formula:

$\mathrm{N}=\left\{\left(\mathrm{z}_{\alpha / 2}+\mathrm{z}_{1-\beta}\right)^{2 *}\right.$ p $\left._{\text {mean }} *\left(1-\mathrm{p}_{\text {mean }}\right) *(1+\mathrm{r})\right\} /\left\{\mathrm{d}^{2} * \mathrm{r}\right\}$

$z_{\alpha / 2}=1.96$ (for two sided $\alpha=0.05$ )

$\mathrm{z}_{1-\beta}=0.84($ for $1-\beta=0.80)$

$\mathrm{p}_{\text {mean }}=\left(\mathrm{r} * \mathrm{p}_{\text {copd patient }}+\mathrm{p}_{\text {non-copd control }}\right) /(\mathrm{r}+1)$ gives $(1.5 * 0.25+0.125) /(1.5+1)=$

$0.5 / 2.5=0.20$

$\mathrm{p}_{\text {copd patient }}=0.25$

pnon-copd control $=0.125$

difference $\mathrm{d}=0.25-0.125=0.125$

ratio $\mathrm{r}=1.5$

$\mathrm{N}=\left\{(1.96+0.84)^{2} * 0.20 *(1-0.20) *(1+1.5)\right\} /\left(0.125^{2} * 1.5\right)$ resulted in an $\mathrm{n}=$ $133.8 \approx 134$. Based on this calculation the total non-COPD control group should consist 134 participants and the total COPD group should consist $1.5 * 133.8=$ $200.7 \approx 201$ patients. 


\section{Chapter 2}

For this sample size calculations was used:

Power $1-\beta=.80$

Significance level $\alpha=.05$

Formula:

$\mathrm{N}=\left\{\left(\mathrm{z}_{\alpha / 2}+\mathrm{z}_{1-\beta}\right)^{2 *}\right.$ pmean $\left.*\left(1-\mathrm{p}_{\text {mean }}\right) *(1+\mathrm{r})\right\} /\left\{\mathrm{d}^{2} * \mathrm{r}\right\}$

$z_{\alpha / 2}=1.96$ (for two sided $\alpha=0.05$ )

$\mathrm{z}_{1-\beta}=0.84$ (for $1-\beta=0.80$ )

$\mathrm{p}_{\text {mean }}=\left(\mathrm{r} * \mathrm{p}_{\text {copd patient }}+\mathrm{p}_{\text {non-copd control }}\right) /(\mathrm{r}+1)$ gives $(1 * 0.25+0.125) /(1+1)=$

$0.375 / 2=0.19$

popd patient $=0.25$

phon-copd control $=0.125$

difference $\mathrm{d}=0.25-0.125=0.125$

ratio $r=1$

$\mathrm{N}=\left\{(1.96+0.84)^{2} * 0.19 *(1-0.19) *(1+1)\right\} /\left(0.125^{2} * 1\right)$ resulted in an $\mathrm{n}=$ $152.88 \approx 153$. Based on this calculation the total non-COPD control group should consist 153 participants and the total COPD group should consist 153 patients.

The total tertiary care COPD patients group and the non-COPD control group should consist between 134 and 153 patients for this analyse. Therefore for this study 150 non-COPD controls will be included. A minimum sample of 150 tertiary care patients will be used for these analyses.

\section{Adjustments to the sample size calculation:}

There are some concerns regarding the initial sample size calculation. The following reasons underline the adequacy and sufficiency of a smaller sample size, regarding tertiary care patients $(n=500)$, for the current study.

1. The sample size calculation was based on the out-dated international COPD GOLD 2007 guideline which classified COPD patients into four groups (GOLD I to IV), based on the degree of airflow limitation. However, the 2011 GOLD strategy started classifying patients in four groups based on the combination of the degree of airflow limitation and the number of exacerbations in the past twelve months and health status/severity of symptoms. This new classification has further been elaborated and described in the latest WHO COPD GOLD 2015 document. Consequently, these substantial changes impact the original foundation of the subgroups: it was outdated and a new composition was necessary. 
2. One objective of the current study is to study the impact of cardiovascular comorbidities on CAT-scores. An interim analyses showed that a sample size between $n=4322$ and $n=46044$ was necessary to detect differences in CAT-scores between patients with and without cardiovascular comorbidities (table 1). However, this sample size is not reasonable and it is not meaningful for the current study to include 600 patients anymore.

Table 1. Sample size calculation based on available data (baseline data of tertiary care patients)

\begin{tabular}{llll}
\hline & $\mathbf{n}$ & $\begin{array}{l}\text { Baseline CAT- } \\
\text { score (mean) }\end{array}$ & $\begin{array}{l}\text { Baseline CAT-score } \\
\text { (standard deviation) }\end{array}$ \\
\hline Cardiovascular comorbidity & 192 & 21.13 & 6.77 \\
No cardiovascular comorbidity & 221 & 21.63 & 6.55 \\
Total sample size & 4322 & & \\
\hline \hline Impaired ejection fraction & 65 & 21.54 & 7.11 \\
No impaired ejection fraction & 350 & 21.38 & 6.56 \\
Total sample size & 46044 & & \\
\hline
\end{tabular}

The sample size has been calculated with the program $G^{*}$ power 3.1.9. [Friedman et al. "Fundamentals of Clinical Trails" (3 $3^{\text {rd }}$ edition) 1998; Faul et al. Behavior Research Methods 2007].

The performed test is: $\mathrm{t}$-test mean difference between two independent means (two groups) with a power of 0.80 and $\alpha$-error: 0.05 .

3. Furthermore, a minimal clinically important differences of 2 points for the CAT has been established (Kon et al. Lancet Respir Med 2014). This was not available at the time of the initial sample size calculation. A second interim analyses revealed that GOLD II, GOLD III and GOLD IV patients following rehabilitation showed a clinically relevant improvement of their health status (table 2). Thus, it is possible to detect clinically relevant changes with the present available data.

Table 2. Sample size calculation based on available data (change in CAT-score, longitudinal data (before and after rehabilitation) of tertiary care patients

\begin{tabular}{llll}
\hline GOLD stage & $\mathbf{n}$ & $\begin{array}{l}\text { Change in CAT score } \\
\text { (mean) }\end{array}$ & $\begin{array}{l}\text { Change in CAT score } \\
\text { (standard deviation) }\end{array}$ \\
\hline 2 & 95 & -2.61 & 6.94 \\
3 & 102 & -3.50 & 6.88 \\
4 & 56 & -2.98 & 7.69 \\
\hline
\end{tabular}




\section{Chapter 2}

4. However, using these data (table 2) to re-calculate the sample size, a sample of $\mathrm{n}=3084$ was needed (table 3). This is due to small differences in variances. As mentioned earlier, this sample size is not reasonable and meaningful for the current study.

Table 3. Sample size calculation based on available data (change in CAT-score, longitudinal data (before and after rehabilitation) of tertiary care patients

\begin{tabular}{lllll}
\hline GOLD stage & $\mathbf{n}$ & $\begin{array}{l}\text { Change in CAT } \\
\text { score (mean) }\end{array}$ & $\begin{array}{l}\text { Change in CAT } \\
\text { score (standard } \\
\text { deviation) }\end{array}$ & \\
\hline 2 & 95 & -2.61 & 6.94 & \\
3 & 102 & -3.50 & 6.88 & 39.260 \\
4 & 56 & -2.98 & 7.69 & 12553.072 \\
\hline Between variance & & & & \\
Within variance & & & & \\
\hline Total sample size & 3084 & & & \\
\hline
\end{tabular}

The sample size has been calculated with the program G* power 3.1.9. [Friedman et al. "Fundamentals of Clinical Trails" (3 $3^{\text {rd }}$ edition) 1998; Faul et al. Behavior Research Methods 2007].

The performed test is: F-test; ANOVA: fixed effects omnibus, one-way, with a power of 0.80 and $\alpha$-error: 0.05 .

5. During the period we requested approval of the local medical ethical committee to adjust the sample size calculation, nearly 500 tertiary care patients were included in the study. Due to the unfeasible amount of patients needed after a recalculation of the sample size, we suggested a study sample of 500 patients. Some observational research has been published studying the change of CAT in patients with COPD following pulmonary rehabilitation. The sample sizes in these studies varied between $n=118$ and $n=377$ (e.g. Dodd et al. Thorax 2011, Dodd et al. COPD 2012, Kon et al. Respiration 2013) underlying the sufficiency of 500 patients for the current study. 


\section{Chapter 3}

How to determine an impaired health status in COPD? Results from a population-based study

Dionne E. Smid, Martijn A. Spruit, Dorly J.H. Deeg, Martijn Huisman, Jan Poppelaars, Emiel F.M. Wouters, Frits M.E. Franssen 


\section{ABSTRACT}

Background Chronic obstructive pulmonary disease (COPD) is associated with a significantly impaired health status and lost work productivity across all degrees of airflow limitation. The current study investigated whether an impaired health status is better represented by the recommended COPD Assessment Test (CAT) cut-point of 10 points, or the $95^{\text {th }}$ percentile of CAT score in a non-COPD population. Additionally, the impact of COPD on health status in a Dutch population, after stratification for work status, was measured.

Methods Demographics, clinical characteristics, post-bronchodilator spirometry, and CAT were assessed in subjects from the Longitudinal Aging Study Amsterdam (LASA), a large Dutch population-based study. Normative values for CAT score were described by percentiles using the mean, standard deviation, median and range.

Results In total, 810 COPD and non-COPD subjects (50.4\% male, mean age $60.5 \pm 2.9$ years) were analyzed. Significant differences were observed in CAT scores between non-COPD and COPD subjects $(6.7 \pm 5.2$ vs. 9.5 $\pm 5.9, \mathrm{p}<0.001$ respectively). The proportion of COPD subjects with an impaired health status differed between applying the CAT $\geq 10$ cut-point (50.0\%) and applying the $95^{\text {th }}$ percentile of CAT in non-COPD subjects ( $>18$ cut-point; 7.6\%). Higher CAT scores were seen in working COPD patients compared to working non-COPD subjects $(9.3 \pm 5.2$ vs. $6.0 \pm 4.6, \mathrm{p}<0.001)$.

Conclusion We suggest a CAT cut-point of $>18$ points to indicate an impaired health status in COPD. This would imply an adaptation of the current GOLD classification of the disease. 


\section{INTRODUCTION}

Chronic obstructive pulmonary disease (COPD) is a lung disease characterized by persistent respiratory symptoms and chronic airflow limitation (1). In addition to the pulmonary manifestations, COPD often provokes symptoms of anxiety and depression and causes limitations in daily life. In addition, a recent international patient survey revealed that $6 \%$ to $52 \%$ of working age patients are completely prevented from working due to their COPD (2). The impact of these restrictions is often underestimated (3,4). The COPD Assessment Test (CAT) is a simple patient-completed questionnaire, developed to quantify the impact of COPD on health status, focusing on daily symptoms and activities (5). Patients with an impaired health status experience a high burden of symptoms (6).

The Global initiative for chronic Obstructive Lung Disease (GOLD) strategy describes an impaired health status as a CAT total score of $\geq 10$ points, which is derived from the St. George respiratory questionnaire (SGRQ) cut-point of $\geq 25$ points (1). Previous studies determined normative values for other health-related measurements, e.g. echocardiographic measurements, according to the $95^{\text {th }}$ percentile in a reference population $(7,8)$. Defining abnormalities based on percentile values will account for an asymmetric distribution and the range of abnormality present within a population (9). With the current GOLD CAT cutpoint of $\geq 10$ points, only a minority of primary care COPD patients has a normal health status $(6,10)$. Moreover, previous research showed that an impaired health status, derived from the current GOLD CAT cut-point, already occurs in half of the current or former smokers without airway obstruction (11). This highlights the importance of understanding what an abnormal CAT value is, as it consequently also influences treatment choices in these patients. The large proportion of patients with an impaired health status resulting from the current GOLD CAT cut-point, raises the question if deriving abnormal values from the 95 $5^{\text {th }}$ percentile of CAT in a non-COPD population would give a better representation of reality, as suggested for several countries (12-14).

While the societal burden of COPD is considerable, the impact of sociodemographic characteristics, such as work status on health status is largely unknown. Less ability to participate in society and not being able to work are important concepts in an impaired health status (15). Previous research showed comparable CAT scores between a working COPD population and a working non-COPD population (12). 


\section{Chapter 3}

The primary aim of this study was to investigate which cut-off value represents an abnormal CAT score for non-COPD subjects in a Dutch population. The secondary aim was to measure the impact of COPD on health status in a Dutch population, after stratification for work status.

\section{METHODS}

Current data are collected from a subsample of the Longitudinal Aging Study Amsterdam (LASA), a large population-based study (16). The study was initiated by the Dutch Ministry of Welfare, Health and Culture to determine consequences and predictors of aging, focusing on physical, emotional, cognitive and social functioning in late life. Ethical approval for the LASA study was given by the Medical Ethics Committee of the VU University Medical Centre Amsterdam (METC number 2012/361).

\section{Population}

Subjects aged between 55-65 years were randomly sampled from 11 municipalities of three culturally different geographic regions (Amsterdam, Zwolle and Oss) in the Netherlands. Subjects were drawn from the population registers and subsequently interviewed by trained persons in their homes. To comprise the original sample, no in- or exclusion criteria were outlined in the LASA study. However, individuals who did not completed the medical interview and/or did not performed a spirometry were not included in the analyses.

\section{Measurements}

Between November 2012 and November 2013, subjects received a baseline interview assessing demographics, smoking history, work status, self-reported diseases and post-bronchodilator spirometry (forced expiratory volume in the first second, $\mathrm{FEV}_{1}$, and forced vital capacity, FVC). The spirometry was conducted with a Vmax Vyntus SPIRO - USB PC Spirometer from CareFusion (Höchberg, Germany), 15 minutes after inhalation of $200 \mu \mathrm{g}$ salbutamol (Airomir autohaler, Teva). Global Lung function Initiative (GLI) reference values were applied. Instead of managing the GOLD suggested fixed cut-off point for obstruction $\left(\mathrm{FEV}_{1} / \mathrm{FVC}\right.$ ratio $\left.<0.7\right)$, a $\mathrm{FEV}_{1} / \mathrm{FVC}$ ratio after bronchodilator lower than the $5^{\text {th }}$ percentile (from reference values) was applied to define airway obstruction (17). Patients with COPD were divided into four groups; spirometric grade $1\left(\mathrm{FEV}_{1} \geq\right.$ 80\%); spirometric grade 2 ( $\mathrm{FEV}_{1}$ 50-79\%); spirometric grade 3 ( $\mathrm{FEV}_{1} 30-49 \%$ ); and spirometric grade $4\left(\mathrm{FEV}_{1}<30 \%\right)$, based on the GOLD strategy 2017 (1). 
Additionally, health status was assessed with the CAT. The CAT is an eight-item patient-completed questionnaire, designed to measure health status in patient with COPD. Item scores range from 0 to 5 points, whereby the total score varies between 0 (best health status) and 40 points (worst health status) (5). An impaired health status was defined with the CAT $\geq 10$ cut-point and $95^{\text {th }}$ percentile of the non-COPD population.

\section{Statistics}

Descriptive statistics, including means (standard deviation, SD) and median (interquartile range, IQR), were applied. Categorical variables were described as frequencies. CAT normative values were described by percentiles using mean (SD), median and range. First, the calculation of normative values was performed in the whole non-COPD population. All variables were tested for normality with the Kolmogorov-Smirnov test. Differences between non-COPD subjects and COPD patients were assessed by performing an independent Student's t-test, when normally distributed. Otherwise, a Mann-Whitney $U$ test and two-independentsamples Tests were done to compare the two groups. When appropriate, a post hoc least significance difference multiple comparisons was performed. A KruskalWallis test was assessed for not-normally distributed variables and a Chi-square test was applied for categorical variables. Similar analyses were performed to compare working and non-working groups. A p-value of less than 0.05 was considered statistically significant. All statistics were done using SPSS V.20.0.

\section{RESULTS}

In total, 810 subjects (50.4\% male, mean age 60.5 (2.9) years) were included, 68 $(8.4 \%)$ of which had a chronic airflow limitation: 18 GOLD spirometric grade 1; 43 GOLD spirometric grade 2; 5 GOLD spirometric grade 3; and 2 GOLD spirometric grade 4 (see figure 1 for flowchart). Twenty-seven of the COPD subjects $(40 \%)$ were previously diagnosed with a respiratory disease; $10(37 \%)$ received COPD treatment from a general practitioner, 7 (26\%) received COPD treatment from a specialist and $10(37 \%)$ received no treatment. The non-COPD and COPD groups were similar regarding age, gender, BMI and comorbidities. Non-COPD subjects were less often current smokers and had a higher $\mathrm{FEV}_{1} \%$ predicted than subjects with COPD (Table 1). 


\section{Chapter 3}

Table 1. Baseline characteristics of study participants

\begin{tabular}{|c|c|c|c|}
\hline & $\begin{array}{l}\text { non-COPD } \\
\text { subjects }(n=742)\end{array}$ & $\begin{array}{l}\text { COPD subjects } \\
(n=68)\end{array}$ & p-value \\
\hline Men, n (\%) & $372(50.1)$ & $36(52.9)$ & 0.658 \\
\hline Age, years & $60.4(2.9)$ & $60.9(2.8)$ & 0.227 \\
\hline BMI, $\mathrm{kg} / \mathrm{m}^{2}$ & $26.6(23.8-29.5)^{a}$ & $26.0(23.3-28.9)^{\mathrm{h}}$ & 0.407 \\
\hline Current smoker, n (\%) & $120(16.2)$ & $28(41.2)$ & $<0.001^{*}$ \\
\hline Packyears, n & $11.7(16.9)$ & $28.5(25.5)$ & $<0.001^{*}$ \\
\hline $\mathrm{FEV}_{1}, \%$ predicted & $99.5(90.4-109.6)^{\mathrm{b}}$ & $67.6(60.4-80.4)$ & $<0.001^{*}$ \\
\hline $\mathrm{FEV}_{1} / \mathrm{FVC}, \%$ & $79.9(75.7-83.2)$ & $61.6(54.2-64.3)$ & $<0.001^{*}$ \\
\hline \multicolumn{4}{|l|}{ Self-reported diseases } \\
\hline - Heart disease, $\mathrm{n}(\%)$ & $77(10.4)$ & $12(17.6)$ & 0.067 \\
\hline - Arteries disease or abnormalities, n (\%) & $22(3.0)$ & $4(5.9)$ & 0.191 \\
\hline - $\quad$ Diabetes, n $(\%)$ & $57(7.7)$ & $5(7.4)$ & 0.922 \\
\hline - Cerebrovascular accident, $\mathrm{n}(\%)$ & $16(2.2)$ & $2(2.9)$ & 0.674 \\
\hline - Osteoarthritis, n (\%) & $307(41.4)$ & $24(35.3)$ & 0.329 \\
\hline - $\quad$ Rheumatoid arthritis, n (\%) & $59(8.0)$ & $5(7.4)$ & 0.861 \\
\hline - $\quad$ Cancer, n $(\%)$ & $67(9.0)$ & $7(10.3)$ & 0.729 \\
\hline - Other chronic disease, $\mathrm{n}(\%)$ & $248(33.4)$ & $17(25.0)$ & 0.156 \\
\hline CAT total score, points & $6.7(5.2)^{\mathrm{c}}$ & $9.5(5.9)^{\mathrm{i}}$ & $<0.001^{*}$ \\
\hline - CAT cough, points & $1.2(1.0)$ & $1.7(1.2)$ & $<0.001^{*}$ \\
\hline - CAT phlegm, points & $0.0(0.0-1.0)$ & $1.0(0.0-2.0)$ & $<0.001^{*}$ \\
\hline - CAT chest tightness, points & $0.0(0.0-1.0)$ & $0.0(0.0-1.0)$ & 0.214 \\
\hline - CAT breathlessness during activities, points & $1.2(1.2)^{\mathrm{d}}$ & $2.1(1.6)$ & $<0.001^{*}$ \\
\hline - CAT activity at home, points & $0.0(0.0-0.0)$ & $0.0(0.0-1.0)$ & 0.195 \\
\hline - CAT confidence in leaving home, points & $0.0(0.0-0.0)^{\mathrm{e}}$ & $0.0(0.0-0.0)^{j}$ & 0.099 \\
\hline - CAT sleep, points & $1.4(1.4)^{\mathrm{f}}$ & $1.4(1.5)^{\mathrm{k}}$ & 0.995 \\
\hline - CAT energy, points & $1.3(1.2)^{g}$ & $1.3(1.2)^{1}$ & 0.974 \\
\hline Subjects with CAT $\geq 10$ points, $\mathrm{n}(\%)$ & $165(22.8)^{c}$ & $33(50.0)^{\mathrm{i}}$ & $<0.001^{*}$ \\
\hline Subjects with CAT $>18$ points, $\mathrm{n}(\%)$ & $28(3.9)^{\mathrm{c}}$ & $5(7.6)^{\mathrm{i}}$ & 0.150 \\
\hline SR-physician's respiratory diagnosis, yes(n) & $46(6.2)$ & $27(39.7)$ & $<0.001^{*}$ \\
\hline Treatment for respiratory diagnosis, yes(n) & $30(4.0)$ & $17(25.0)$ & $<0.001^{*}$ \\
\hline
\end{tabular}

Values expressed as mean (SD), median (IQR), number of patients (n) or proportion $(\%) .{ }^{*}=\mathrm{p} \leq 0.05$ $\mathrm{a}=2$ participants missing, ${ }^{\mathrm{b}}=1$ participant missing, ${ }^{\mathrm{c}}=19$ participants missing, ${ }^{\mathrm{d}}=3$ participants missing, $\mathrm{e}=15$ participants missing, $\mathrm{f}=10$ participants missing, $\mathrm{g}=2$ participants missing, $\mathrm{h}=1$ participant missing, $\mathrm{i}=2$ participants missing, $\mathrm{j}=1$ participant missing, $\mathrm{k}=2$ participants missing, $\mathrm{l}=1$ participant missing. Abbreviations: BMI, Body Mass Index, $\mathrm{FEV}_{1}$, forced expiratory volume in the first second; FVC, Forced Vital Capacity; SR, Self-reported; COPD, Chronic Obstructive Pulmonary Disease; CAT, COPD Assessment Test. 


\section{COPD versus non-COPD}

CAT total scores were significantly lower in non-COPD subjects than in COPD subjects. COPD subjects had significantly higher scores on CAT questions related to cough, phlegm and breathlessness during activities (Table 1). CAT values of non-COPD subjects ranged from 0 to 29 points, with the $95^{\text {th }}$ percentile at 18 points (Table 2). When applying the CAT $\geq 10$ cut-point, $50.0 \%$ of COPD subjects had an impaired health status and when using a CAT $>18$ cut-point $7.6 \%$ of COPD subjects had an impaired health status, see Table 2.

Table 2. CAT normative values for COPD and non-COPD subjects

\begin{tabular}{|c|c|c|}
\hline & $\mathbf{N}=$ & non-COPD subjects $^{\mathrm{a}+\mathrm{b}}$ \\
\hline Mean CAT (SD) & 723 & $6.7(5.2)$ \\
\hline Median & 723 & 6.00 \\
\hline Range CAT (min-max) & 723 & $0-29$ \\
\hline CAT $5^{\text {th }}$ percentile & 723 & 0.00 \\
\hline CAT $10^{\text {th }}$ percentile & 723 & 1.00 \\
\hline CAT $25^{\text {th }}$ percentile & 723 & 3.00 \\
\hline CAT $75^{\text {th }}$ percentile & 723 & 9.00 \\
\hline CAT 90th percentile & 723 & 14.00 \\
\hline \multirow[t]{2}{*}{ CAT 95th percentile } & 723 & 18.00 \\
\hline & $\mathbf{N}=$ & COPD subjects ${ }^{c}$ \\
\hline Mean CAT (SD) & 66 & $9.5(5.9)$ \\
\hline Median & 66 & 9.50 \\
\hline Range CAT (min-max) & 66 & $0-27$ \\
\hline CAT $5^{\text {th }}$ percentile & 66 & 0.00 \\
\hline CAT $10^{\text {th }}$ percentile & 66 & 2.70 \\
\hline CAT $25^{\text {th }}$ percentile & 66 & 4.75 \\
\hline CAT $75^{\text {th }}$ percentile & 66 & 13.25 \\
\hline CAT 90th percentile & 66 & 17.30 \\
\hline CAT 95th percentile & 66 & 19.65 \\
\hline
\end{tabular}

$\mathrm{a}=11$ participants missing, $\mathrm{b}=8$ participants missing, $\mathrm{c}=2$ participants missing.

Abbreviations: COPD, Chronic Obstructive Pulmonary Disease; CAT, COPD Assessment Test; SD, Standard Deviation.

Work status

As shown in Figure 1, CAT total scores were significantly lower in non-COPD subjects with a job, compared to non-COPD subjects without a job, $\mathrm{p}<0.001$. No significant differences were observed between a working and non-working COPD population, $\mathrm{p}<0.741$. Moreover, significantly higher CAT scores were observed in a working population with COPD in comparison to a working population without COPD, $\mathrm{p}<0.001$. 
A. non-COPD population

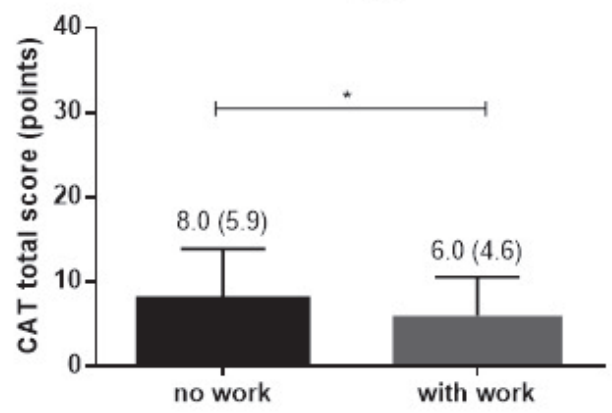

B.

COPD population

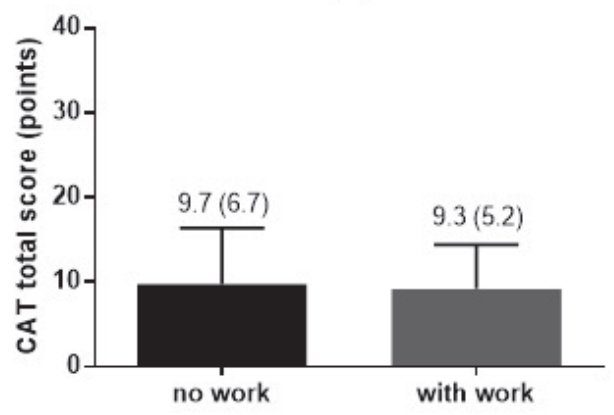

C.

Working population

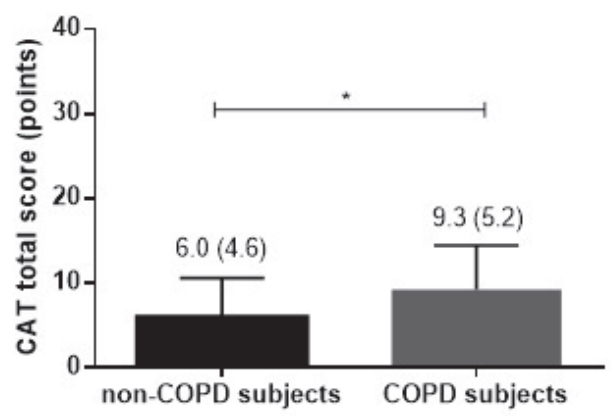

Figure 1. CAT stratified by work status. A) working population versus non-working population in non-COPD subjects, B) working population versus non-working population in patients with COPD and C) non-COPD subjects versus patients with COPD in a working population.

Abbreviations: CAT, COPD Assessment Test; COPD, Chronic Obstructive Pulmonary Disease 


\section{DISCUSSION}

This is the first study examining normative values for CAT performed in a Dutch population. It shows that approximately $20 \%$ of the non-COPD subjects had an impaired health status according to the current cut-point suggested by GOLD (CAT $\geq 10$ points). Based on the $95^{\text {th }}$ percentile of the CAT in a non-COPD population, a new CAT cut-point of $>18$ points was suggested to indicate an impaired health status. No significant differences in CAT score were found between a working and non-working COPD population. Normative values should be taken into account when applying the refined GOLD assessment to Dutch COPD patients in clinical practice.

In accordance with previous research (18), the current study showed that patients with COPD had significantly more symptoms of cough, phlegm and breathlessness during activities. Reported mean CAT total scores in COPD subjects vary between 7.3 points $( \pm 5.2[\mathrm{n}=67$, Japan] $), 16.6$ points $(95 \% \mathrm{CI}=15.5$ $16.8[\mathrm{n}=806$, Arabic countries]) and 20.9 points (95\% CI $=16.9-22.2[\mathrm{n}=229$, Turkey]) (12-14). A mean CAT of 9.5 points was observed in the current study. Moreover, a value of 18 points was found as the $95^{\text {th }}$ percentile of CAT total scores in non-COPD subjects, resulting in $7.6 \%$ of the COPD patients with an impaired health status. Previous studies showed that the $95^{\text {th }}$ percentile of CAT total scores in non-COPD subjects varies between 14 points ( $n=1266$, Japan), 16 points ( $n=500$, Canada), 21 points $(n=2863$, Arabic countries) and 28 points ( $\mathrm{n}=872$, Turkey) (12-14). Differences in disease severity, demographics, comorbidities, care setting, religion, culture and socio-economic factors may account for the observed variation (19-22). When comparing disease severity between studies, airflow obstruction was equivalent (12-14). Furthermore, not all previously performed studies measured comorbidities, and if they did, often other diseases were assessed, making a comparison difficult. Indeed, Nishimura and colleagues showed that a working population is often more active during the day (12), resulting in a better health status and less symptoms (23). Moreover, the use of a CAT cut-point of $>18$ points is supported by the study of Casanova and colleagues, stating that a CAT cut point of $>18$ points more comprehensively categorizes patients with COPD according to the GOLD classification and more adequately predicts all-cause mortality (24).

While the current study found differences in CAT scores between a working and non-working non-COPD population, no significant differences were found between a working and non-working COPD population. In addition, COPD patients with a job still had significantly higher CAT scores than non-COPD 
subjects with a job. So, it is possible that having a job solely improves heath status (to a certain extent) in a general population, but this does not account for COPD patients. Previous research indicates that variation between multiple populations can also be explained by differences in quality of life between countries (25). Defining influences of the other variables (demographics, care setting, religion, culture and socio-economic factors) goes beyond the scope of this study.

Another important factor to consider, when describing normative values, is the impact of comorbidities. In the current study, approximately $10 \%$ of the nonCOPD subjects reported a heart disease, presumably leading to a higher CAT total score. However, there are several reasons for not excluding comorbidities in the non-COPD group. First, a study from Gupta and colleagues indicated that only depression, myocardial infarction, angina and/or pneumonia influence CAT score (26). Another study showed that solely gastro-esophageal reflux disease and depression have impact on CAT (27). However, not all these comorbidities were assessed. Therefore, we were not able to determine these influences. Also, comorbidities in the current study were self-reported. The study of Triest and colleagues showed a poor agreement between objectively identified and chart-based comorbidities in patients with COPD (28), resulting in unreliable outcomes. Finally, as patients with COPD also experience many comorbidities (29), it would be unrealistic to compare patients with completely healthy individuals. Subsequently, the current results showed no differences in comorbidities between subjects with or without COPD. This indicates that comorbidities are not specifically related to COPD, making them valuable for normative values of the CAT.

\section{Limitations}

There are some limitations to this study. First, selection bias could have occurred, indicating that people with lack of motivation or with a worse health condition are less willing to participate. These people may also be less willing to perform a lung function test, leading to more favorable outcomes. However, we tried to minimize selection bias by randomly selecting the participants. Second, participants were between the age of 55-65 years. Despite the limited variance in age, results are in accordance with previous research in other countries. Therefore, it is expected that the results are representative, though one should be careful in generalizing to other age groups. Third, comorbidities and a former diagnosis of COPD were selfreported. Also, COPD was defined as a self-reported diagnosis of chronic bronchitis, asthma, emphysema, or COPD. Initially, it is a disadvantage that the diagnosis is self-reported as it is less accurate than the original doctor diagnosis. Besides that, no distinction was made between various respiratory diseases. This 
makes it impossible to specify whether the participant was diagnosed with chronic bronchitis, asthma, emphysema or COPD.

\section{CONCLUSION}

A new CAT cut-point of $>18$ points is suggested to indicate an impaired health status in patients with COPD, as approximately one in five non-COPD subjects has abnormal CAT scores according to current international standards. These normative values should be taken into account when applying the updated GOLD assessment to Dutch COPD patients in clinical practice. 


\section{REFERENCES}

1. Vogelmeier CF, Criner GJ, Martinez FJ, et al. Global Strategy for the Diagnosis, Management, and Prevention of Chronic Obstructive Lung Disease 2017 Report: GOLD Executive Summary. AJRCCM. 2017.

2. Foo J, Landis SH, Maskell J, Oh YM, van der Molen T, Han MK, et al. Continuing to Confront COPD International Patient Survey: Economic Impact of COPD in 12 Countries. PloS one. 2016;11(4):e0152618.

3. ZuWallack R. How are you doing? What are you doing? Differing perspectives in the assessment of individuals with COPD. Copd. 2007;4(3):293-7.

4. Rennard S, Decramer M, Calverley PM, et al. Impact of COPD in North America and Europe in 2000: subjects' perspective of Confronting COPD International Survey. Eur Respir J. 2002;20(4):799-805.

5. Jones PW, Harding G, Berry P, Wiklund I, Chen WH, Kline Leidy N. Development and first validation of the COPD Assessment Test. Eur Respir J. 2009;34(3):648-54.

6. Vestbo J, Hurd SS, Agusti AG, et al. Global strategy for the diagnosis, management, and prevention of chronic obstructive pulmonary disease: GOLD executive summary. Am J Respir Crit Care Med. 2013;187(4):347-65.

7. Evans BJ, Stevenson SJ. The Pattern Glare Test: a review and determination of normative values. Ophthalmic Physiol Opt. 2008;28(4):295-309.

8. Echocardiographic Normal Ranges Meta-Analysis of the Left Heart C. Ethnic-Specific Normative Reference Values for Echocardiographic LA and LV Size, LV Mass, and Systolic Function: The EchoNoRMAL Study. JACC Cardiovasc Imaging. 2015;8(6):656-65.

9. Recommendations for Cardiac Chamber Quantification by Echocardiography in Adults: An Update from the American Society of Echocardiography and the European Association of, Cardiovascular Imaging. Eur Heart J Cardiovasc Imaging. 2016;17(4):412.

10. Jones PW, Adamek L, Nadeau G, Banik N. Comparisons of health status scores with MRC grades in COPD: implications for the GOLD 2011 classification. Eur Respir J. 2013;42(3):647-54.

11. Woodruff PG, Barr RG, Bleecker E, et al. Clinical Significance of Symptoms in Smokers with Preserved Pulmonary Function. N Engl J Med. 2016;374(19):1811-21.

12. Nishimura K, Mitsuma S, Kobayashi A, et al. COPD and disease-specific health status in a working population. Respir res. 2013;14(1):61.

13. Pinto LM, Gupta N, Tan W, et al. Derivation of normative data for the COPD assessment test (CAT). Respir res. 2014;15(1):68.

14. Jones PW, Shahrour N, Nejjari C, et al. Psychometric evaluation of the COPD assessment test: data from the BREATHE study in the Middle East and North Africa region. Respir med. 2012;106 Suppl 2:S86-99.

15. Andenaes R, Bentsen SB, Hvinden K, Fagermoen MS, Lerdal A. The relationships of self-efficacy, physical activity, and paid work to health-related quality of life among patients with chronic obstructive pulmonary disease (COPD). J Multidiscip Healthc. 2014;7:239-47.

16. Huisman M, Poppelaars J, van der Horst M, et al. Cohort profile: the Longitudinal Aging Study Amsterdam. Int J Epidemiol. 2011;40(4):868-76. 
17. Quanjer PH, Brazzale DJ, Boros PW, Pretto JJ. Implications of adopting the Global Lungs Initiative2012 all-age reference equations for spirometry. Eur Respir J. 2013;42(4):1046-54.

18. Kart L, Akkoyunlu ME, Bayram M, et al. COPD: an underdiagnosed disease at hospital environment. Wien Klin Wochenschr. 2014;126(3-4):73-8.

19. Office of the Surgeon General (US); Center for Mental Health Services (US); National Institute of Mental Health (US). Mental Health: Culture, Race, and Ethnicity: A Supplement to Mental Health: A Report of the Surgeon General. Rockville (MD): Substance Abuse and Mental Health Services Administration (US); 2001 Aug. Chapter 2 Culture Counts: The Influence of Culture and Society on Mental Health. Available from: http://www.ncbi.nlm.nih.gov/books/NBK44249/.

20. Brewer G, Robinson S, Sumra A, Tatsi E, Gire N. The Influence of Religious Coping and Religious Social Support on Health Behaviour, Health Status and Health Attitudes in a British Christian Sample. J Relig Health. 2015;54(6):2225-34.

21. Negewo NA, McDonald VM, Gibson PG. Comorbidity in chronic obstructive pulmonary disease. Respir Investig. 2015;53(6):249-58.

22. Ferre A, Fuhrman C, Zureik M, et al. Chronic bronchitis in the general population: influence of age, gender and socio-economic conditions. Respir Med. 2012;106(3):467-71.

23. Waschki B, Kirsten AM, Holz O, et al. Disease Progression and Changes in Physical Activity in Patients with Chronic Obstructive Pulmonary Disease. Am J Respir Crit Care Med. 2015:192(3):295-306.

24. Casanova C, Marin JM, Martinez-Gonzalez C, de Lucas-Ramos P, Mir-Viladrich I, Cosio B, et al. Differential Effect of Modified Medical Research Council Dyspnea, COPD Assessment Test, and Clinical COPD Questionnaire for Symptoms Evaluation Within the New GOLD Staging and Mortality in COPD. Chest. 2015;148(1):159-68.

25. Al Moamary MS, Tamim HM, Al-Mutairi SS, et al. Quality of life of patients with chronic obstructive pulmonary disease in the Gulf Cooperation Council countries. Saudi Med J. 2012;33(10):1111-7.

26. Gupta N, Pinto L, Benedetti A, et al. The COPD Assessment Test: can it discriminate across COPD subpopulations? Chest. 2016.

27. Miyazaki M, Nakamura H, Chubachi S, et al. Analysis of comorbid factors that increase the COPD assessment test scores. Respir res. 2014;15:13.

28. Triest FJ, Franssen FM, Spruit MA, Groenen MT, Wouters EF, Vanfleteren LE. Poor agreement between chart-based and objectively identified comorbidities of COPD. Eur Respir J. 2015;46(5):1492-5.

29. Vanfleteren LE, Spruit MA, Groenen M, et al. Clusters of comorbidities based on validated objective measurements and systemic inflammation in patients with chronic obstructive pulmonary disease. Am J Respir Crit Care Med. 2013;187(7):728-35.

Reproduced with permission from the Netherlands Journal of Medicine: Smid DE, Spruit MA, Deeg DJH, Huisman M, Poppelaars J, EF MW, et al. How to determine an impaired health status in COPD: Results from a population-based study. Neth J Med. 2017;75(4):151-7. 
SUPPLEMENTARY MATERIAL

\begin{tabular}{|c|c|c|}
\hline $\begin{array}{l}\text { Total number LASA cohort: } \\
\qquad \mathrm{n}=1023\end{array}$ & $\begin{array}{l}\mathrm{n}=121 \\
\mathrm{n}=7\end{array}$ & $\begin{array}{l}\text { Participant refused medical interview } \\
\text { Not contacted for medical interview }\end{array}$ \\
\hline$\sqrt{<-}$ & $\mathrm{n}=1$ & Decreased \\
\hline $\begin{array}{l}\text { Total number including } \\
\text { medical interview: } \\
\mathrm{n}=889\end{array}$ & $\begin{array}{l}\mathrm{n}=18 \\
\mathrm{n}=15 \\
\mathrm{n}=6\end{array}$ & $\begin{array}{l}\text { No spirometry due to physical reasons } \\
\text { Spirometer did not work/parts missing } \\
\text { Participant refused spirometry }\end{array}$ \\
\hline 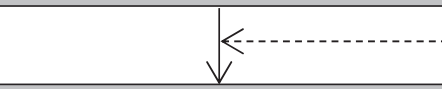 & $\begin{array}{l}n=6 \\
n=5\end{array}$ & $\begin{array}{l}\text { No medication available to perform spirometry } \\
\text { Limited time, unable to perform spirometry }\end{array}$ \\
\hline $\begin{array}{l}\text { Total number of patients } \\
\text { with required data: } \\
\qquad \mathrm{n}=810\end{array}$ & $\begin{array}{l}n=4 \\
n=1 \\
n=24\end{array}$ & $\begin{array}{l}\text { Environment not suitable to perform spirometry } \\
\text { Demographic data missing, unable to } \\
\text { calculate reference values } \\
\text { Unknown }\end{array}$ \\
\hline
\end{tabular}

Figure E1. Flow diagram of subject inclusion

Abbreviations: LASA, Longitudinal Aging Study Amsterdam 


\section{Chapter 4}

\section{The physical, mental and social impact of COPD in a population based sample}

Dionne E. Smid, Martijn A. Spruit, Dorly J.H. Deeg, Martijn Huisman, Jan Poppelaars, Emiel F.M. Wouters, Frits M.E. Franssen 


\section{ABSTRACT}

Introduction The burden of COPD is mainly studied in highly-selected patient samples. This study aims to examine the features of subjects with COPD in a Dutch population-based sample and compare their physical status, mental status, and social status to non-COPD subjects.

Methods The current study made use of the Longitudinal Aging Study Amsterdam (LASA). Demographics, clinical characteristics, self-reported diseases, post-bronchodilator spirometry, physical status (i.e. physical subscale of SF-12 and 6-meter walking speed test), mental status (i.e. CAT; COPD Assessment test and EQ5D; EuroQuol 5D and its Visual Analogue Scale) and social status (i.e. having a partner and instrumental/emotional support) were assessed.

Results 810 subjects $(50.5 \%$ male, mean age $60.5 \pm 2.9$ years) were included. Subjects with COPD ( $\mathrm{n}=68$, mean $\mathrm{FEV}_{1} 67.6$ [IQR 60.4-80.4] \%) had a slower walking speed than non-COPD subjects, $\mathrm{p}=0.033$. COPD subjects rated their health and life worse (physical subscale of SF-12: 15 [IQR 16.0-19.0] vs. 18 [IQR 11.0-17.0] points, EQ5D VAS: 75 [IQR 70.0-90.0] vs. 80 points [IQR 65.0-85.5], respectively), had a more impaired disease-specific health status (CAT: $9.5 \pm 5.9$ vs. $6.7 \pm 5.2$, respectively), less frequently had a partner (69\% vs. 84\%, respectively) and less often received emotional support ( $24 \%$ vs. $36 \%$, respectively) compared to nonCOPD subjects, for all $\mathrm{p}<0.001$.

Conclusion In a population based sample, subjects with COPD have a reduced physical performance, a more impaired disease specific health status and are socially deprived compared to non-COPD subjects. These impairments need to be taken into consideration when setting up a management program for mild COPD. 


\section{INTRODUCTION}

In 2015, Global Lungs Initiative (GLI) reference values were implemented in the chronic obstructive pulmonary disease (COPD) guidelines of the Dutch society for primary care in the Netherlands (1). Currently, a $\mathrm{FEV}_{1} / \mathrm{FVC}$ ratio after bronchodilator lower than the $5^{\text {th }}$ percentile (from reference values), instead of the fixed cut-off point $\left(\mathrm{FEV}_{1} / \mathrm{FVC}\right.$ ratio $\left.<0.7\right)$, is used to define chronic airflow limitation (2). Understanding of the clinical characteristics of subjects diagnosed with COPD according to these new reference values is limited. Moreover, most studies aimed at investigating the burden of COPD were performed in selected patient populations. Subjects without a significant smoking history $(>15$ pack years) and subjects with other comorbidities (expressing similar symptoms as COPD) are often excluded from these studies (3). In addition, subjects with COPD visiting a chest physician or referred for pulmonary rehabilitation were more frequently represented in existing literature, than undiagnosed subjects meeting the spirometric criteria for COPD or subjects with COPD who receive treatment from a general practitioner (GP) $(3,4)$. While undiagnosed subjects seem to be healthier than subjects with a diagnosis of obstructive lung disease, still an impaired health status, impaired functional status and increased risk of death was observed compared to non-COPD subjects $(5,6)$. This highlights the importance of increasing our understanding of COPD in a broader population without exclusion of patients with mild to moderate COPD, a smoking history of $<15$ pack years and/or specific comorbidities, and allows us to question the generalizability and clinical significance of previous studies.

COPD is a common lung disease characterized by persistent airflow limitation. Moreover, COPD is now recognized as a multicomponent disease. It also affects systems and organs outside the lungs, the so-called systemic effects of COPD (e.g. weight loss, muscle dysfunction, cardiovascular disease) (7). Systemic effects of COPD relate to physical, mental and social impairments. For instance, previous research indicates that subjects with COPD have a lower physical activity level, already occurring early in the disease process, a substantially impaired lower limb muscle- and handgrip strength and a lower endurance capacity in comparison with non-COPD subjects (8-10). Additionally, it was shown that subjects with COPD have a worse mental status compared to non-COPD subjects: more symptoms of anxiety and depression, a lower quality of life, more cognitive dysfunction and more symptoms of fatigue (11-14). While it is shown that the diagnosis of COPD has social consequences $(15,16)$, little is known about how these consequences express in daily living (e.g. personal network size, frequency of daily support or satisfaction with received help). Therefore, the current study had the following 
aims: 1) to study the features (e.g. age, gender, smoking history, lung function, comorbidities) of subjects with COPD in a Dutch population-based sample and 2) to compare physical status, mental status, and social status in a population-based sample of COPD subjects with non-COPD subjects from the same population.

\section{METHODS}

Current data are part of the Longitudinal Aging Study Amsterdam (LASA), a large population-based study designed to determine predictors and consequences of physical, emotional, cognitive and social functioning in late life. Ethical approval for the LASA study was given by the Medical Ethics Committee of the VU University Medical Center Amsterdam (METC number 2012/361). Extended information of the LASA study design has been published previously (17).

\section{Participants}

Subjects aged between 55-65 years were recruited between November 2012 and November 2013. Subjects were randomly sampled from 11 municipality registers in the regions Amsterdam, Zwolle and Oss in the Netherlands. They received information about the study by letter, were contacted by phone and, when approved, subsequently interviewed in their home environment. Other than age, no in- or exclusion criteria were defined. All subjects gave written informed consent before entering the study. Only data from subjects who completed the post-bronchodilator spirometry were included in the current analysis. The details about recruitment and assessment have been described in the previously published protocol (17).

\section{Measurements}

Demographics, smoking history, blood pressure, self-reported comorbid diseases (heart diseases, peripheral artery diseases, diabetes, CVA, incontinence, osteoarthritis, rheumatoid arthritis, cancer and other chronic diseases) and medical history were recorded. Subjects were questioned if they had chronic bronchitis, emphysema or COPD. A post-bronchodilator spirometry (forced expiratory volume in the first second, $\mathrm{FEV}_{1}$, and forced vital capacity, FVC) was performed to assess COPD. The spirometry was conducted with a Vmax Vyntus SPIRO USB PC Spirometer from CareFusion (Höchberg, Germany), 15 minutes after inhalation of $200 \mu \mathrm{g}$ salbutamol. Additionally, the following spirometry errors were registered: insufficient number (less than 3) successful forced tests, two highest $\mathrm{FEV}_{1}$ values were not within $150 \mathrm{ml}$, two highest FVC values were not within 150 $\mathrm{ml}$, a (maximal volume) exhalation time of less than 6 seconds and a combination of multiple errors (18). COPD was defined according to the lower limit of normal 
(LLN) (19). Subjects with COPD were divided in traditional GOLD grades for airflow limitation; grade 1 ( $\mathrm{FEV}_{1}>80 \%$ predicted), grade 2 ( $\mathrm{FEV}_{1} 50-80 \%$ predicted), grade 3 ( $\mathrm{FEV}_{1} 30-50 \%$ predicted) or grade 4 ( $\mathrm{FEV}_{1}<30 \%$ predicted). Physical, mental and social status were assessed as follows:

- Physical status: self-reported health, number of falls in the past year, experience of pain, sleep quality, self-reported sedentary behavior, handgrip strength, 6-meter walking 6 speed and use of aids during daily life

- Mental status: cognitive test, 15 Words Test, 15WT (20); overall life satisfaction; mood status, Hospital Anxiety and Depression Scale - Anxiety subscale, HADS-A and Center for Epidemiologic Studies Depression Scale, CES-D (21); disease specific health status, COPD assessment test, CAT (22); generic health status, EuroQuol 5D and its Visual Analogue Scale, EQ5D VAS (23), and 12-Item Short Form Health Survey, SF-12 (24)

- Social status: the interviewer asked questions about having a partner yes or no, marital status, daily support from partner, personal network size, received instrumental and emotional support, loneliness (measured using the De Jong Gierveld loneliness scale (25)), personal, domestic or personal help and employment (17)

\section{Data availability}

LASA data are available for research. To obtain data, researchers need to submit an analysis proposal that is evaluated by the LASA Steering Group. The LASA Steering Group has adopted a policy of open sharing of data with interested researchers for specific research questions on aging-related issues. More information on data requests can be found at the study website: www.lasa-vu.nl.

\section{Statistics}

Descriptive statistics were applied, including mean and standard deviation (SD), median and interquartile range (IQR), and/or proportions, as appropriate. Categorical variables were described as absolute numbers and frequencies.

Variables were tested for normality with a Skewness and Kurtosis test. Subjects with and without COPD were compared. A Mann-Whitney U test and one-way analysis of variances (ANOVA) were applied for normally distributed variables. When appropriate, post hoc least significance difference (LSD) multiple comparisons were performed. A Kruskal-Wallis test was assessed for not-normally distributed variables and a Chi-square test was applied for categorical variables. A p-value of less than or equal to 0.05 was considered statistically significant. Statistics were performed with SPSS V.20.0. 


\section{Chapter 4}

\section{RESULTS}

In total, 889 subjects were included in the measurement wave in 2012/13. Of those, 810 subjects completed spirometry (see appendix Figure E1 for flow-chart), of which 742 subjects $(91.6 \%)$ had a $\mathrm{FEV}_{1} / \mathrm{FVC}$ above the $5^{\text {th }}$ percentile and 68 subjects $(8.4 \%)$ fulfilled the diagnostic criterion for chronic airflow limitation; 18 GOLD grade 1; 43 GOLD grade 2; 5 GOLD grade 3; and 2 GOLD grade 4. Of these 68 subjects with COPD, 27 subjects (40\%) were previously diagnosed with a respiratory disease (self-reported). Features of the study subjects are presented in Table 1.

Table 1. Features of study subjects

\begin{tabular}{|c|c|c|}
\hline & Non-COPD subjects & COPD subjects \\
\hline $\mathrm{N}$ & 742 & 68 \\
\hline Men, n (\%) & $372(50.1)$ & $36(52.9)$ \\
\hline Age, years & $60.4(2.9)$ & $60.9(2.8)$ \\
\hline Current smoker, n (\%) & $120(16.2)^{*}$ & $28(41.2)$ \\
\hline Packyears, n & $3.9(0.0-18.8)^{*}$ & $23.6(10.2-41.1)$ \\
\hline $\mathrm{FEV}_{1} \%$ predicted & $99.5(90.4-109.6)^{*}$ & $67.6(60.4-80.4)$ \\
\hline $\mathrm{FEV}_{1} / \mathrm{FVC}, \%$ & $79.9(75.7-83.2)^{*}$ & $61.6(54.2-64.3)$ \\
\hline $\mathrm{BMI}, \mathrm{kg} / \mathrm{m} 2$ & $26.6(23.8-29.5)$ & $26.0(23.3-28.9)$ \\
\hline Systolic blood pressure, / $\mathrm{mm} \mathrm{Hg}$ & $136.0(123.0-149.0)$ & $134.0(125.0-149.8)$ \\
\hline Diastolic blood pressure, $/ \mathrm{mm} \mathrm{Hg}$ & $83.0(75.0-90.0)$ & $81.5(75.0-91.0)$ \\
\hline Number of SR-comorbidities, points & $1.5(1.4)$ & $1.7(1.4)$ \\
\hline - $\quad$ Respiratory diseases, n (\%) & $46(6.2)^{*}$ & $27(39.7)$ \\
\hline - Heart diseases, $\mathrm{n}(\%)$ & $77(10.4)$ & $12(17.6)$ \\
\hline - Peripheral artery diseases, $\mathrm{n}(\%)$ & $22(3.0)$ & $4(9.8)$ \\
\hline - $\quad$ Diabetes, $\mathrm{n}(\%)$ & $57(7.7)$ & $5(12.2)$ \\
\hline$-\quad$ CVA, n $(\%)$ & $16(2.2)$ & $2(4.9)$ \\
\hline - Incontinence, $\mathrm{n}(\%)$ & $118(15.9)$ & $10(14.7)$ \\
\hline - Osteoarthritis, n (\%) & $307(41.4)$ & $24(35.3)$ \\
\hline - $\quad$ Rheumatoid arthritis, $\mathrm{n}(\%)$ & $59(8.0)$ & $5(7.4)$ \\
\hline - $\quad$ Cancer, n $(\%)$ & $67(9.0)$ & $7(10.3)$ \\
\hline - Other chronic diseases, n $(\%)$ & $248(33.4)$ & $17(25.0)$ \\
\hline Number of medications & $1.0(0.0-2.0)^{*}$ & $2.0(0.0-4.8)$ \\
\hline
\end{tabular}

Values expressed as mean (SD), median (IQR) or number of patients (\%).

${ }^{*}=\mathrm{p} \leq 0.05$ versus group COPD patients

Abbreviations: $\mathrm{FEV}_{1}$, forced expiratory volume in the first second; FVC, forced vital capacity; BMI, body mass index; FFMI, fat free mass index; SR, Self-Reported. 
Features of the COPD subjects

Subjects with and without COPD were comparable concerning age, gender distribution, BMI and comorbidities. Noticeable, a high percentage of incontinence (non-COPD subjects: $15.9 \%$, and COPD subjects: $14.7 \%$ ) was found in both groups. However, COPD subjects were more often current smoker, had more pack years, a worse lung function and used more medication than non-COPD subjects (Table 1).

\section{Physical status}

COPD subjects rated their physical health worse $(\mathrm{p}<0.001)$ and walked more slowly on a distance of 6 meters $(p=0.033)$ compared to non-COPD subjects, see Table 2. Number of falls in the last year, experience of pain, sleep quality, selfreported sedentary behaviour, handgrip strength and use of aids in daily life were comparable between groups. However, noteworthy was the high percentage of pain (non-COPD subjects: $27.4 \%$, and COPD subjects: $31.3 \%$ ) experience in both groups.

Table 2. Physical status of the study subjects divided in patients with and without COPD

\begin{tabular}{lll}
\hline & Non-COPD subjects & COPD subjects \\
\hline SR health & $13(1.8)$ & \\
- Poor, n (\%) & $72(9.7)^{*}$ & $2(2.9)$ \\
- Sometimes good, n (\%) & $125(16.8)$ & $13(19.1)$ \\
- Fair, n (\%) & $406(54.7)$ & $31(42.1)$ \\
- Good, n (\%) & $126(17.0)$ & $7(10.3)$ \\
- Excellent, n (\%) & $18.0(16.0-19.0)^{*}$ & $15.0(11.0-17.0)$ \\
SF-12 physical health, points & $1.0(1.0-2.0)$ & $1.0(1.0-2.3)$ \\
Number of falls last year & $189(27.4)$ & $20(31.3)$ \\
Experience pain during day, n (\%) & & \\
Sleep quality & $25(3.6)$ & $4(6.2)$ \\
- Very bad, n (\%) & $88(12.6)$ & $9(13.8)$ \\
- Somewhat bad, n (\%) & $294(42.1)$ & $26(40.0)$ \\
- Somewhat good, n(\%) $(\%)$ & $26(40.0)$ \\
- Very good, n (\%) & $283(38.1)$ & $8(12.3)$ \\
No sleeping problems, n (\%) & $97(13.9)$ & $780.0(600.0-1140.0)$ \\
SR sedentary behaviour, minutes & $775.0(570.0-1020.0)$ & $33.4(11.6)$ \\
Handgrip strength right, kg/force & $32.7(13.0)$ & $32.5(12.7)$ \\
Handgrip strength left, kg/force & $32.3(12.9)$ & $6.0(5.0-7.0)$ \\
Walking speed 6 meters test, seconds & $6.0(5.0-7.0)^{*}$ & $3(4.4)$ \\
Use of aids in daily life, n & $17(2.3)$ & \\
\hline
\end{tabular}

Values expressed as mean (SD), median (IQR) or number of patients (\%).

${ }^{*}=\mathrm{p} \leq 0.05$ versus group COPD patients.

Abbreviations: SR, Self-Reported. 


\section{Chapter 4}

\section{Mental status}

A large proportion of subjects with COPD had neither a positive nor a negative view on their overall life. Moreover, COPD subjects had a more impaired diseasespecific health status and rated their health less positive than non-COPD subjects (Table 3). Cognitive status, depressive symptoms, symptoms of anxiety, generic health status and mental status were comparable between groups.

Table 3. Mental status of the study subjects divided in patients with and without COPD

\begin{tabular}{lll}
\hline & Non-COPD subjects & COPD subjects \\
\hline 15WT & $23.0(19.0-27.0)$ & $22.5(18.0-26.0)$ \\
- Learning memory, points & $75.0(60.0-88.9)$ & $72.7(54.3-85.7)$ \\
- First retention, points & $72.7(60.0-86.7)$ & $73.9(58.5-85.4)$ \\
- Second retention, points & $13.0(11.0-15.0)$ & $13.0(11.0-16.0)$ \\
CES-D, points & $4.0(3.0-5.0)$ & $4.0(3.0-5.0)$ \\
HADS-A, points & & \\
Life satisfaction & $3(0.4)$ & $1(1.5)$ \\
- Very dissatisfied, n (\%) & $16(2.2)$ & $2(2.9)$ \\
- Dissatisfied, n (\%) & $91(12.3)^{*}$ & $14(20.6)$ \\
- Neutral, n (\%) & $472(67.5)$ & $41(60.3)$ \\
- Satisfied, n (\%) & $109(15.6)$ & $6(8.8)$ \\
- Very satisfied, n (\%) & $6.7(5.2)^{*}$ & $9.5(5.9)$ \\
CAT, points & $1.0(1.0-1.0)$ & $1.0(1.0-2.0)$ \\
EQ5D & $1.0(1.0-1.0)$ & $1.0(1.0-1.0)$ \\
- Mobility, points & $1.0(1.0-1.0)$ & $1.0(1.0-2.0)$ \\
- Self-care, points & $1.0(1.0-1.0)$ & $1.0(1.0-2.0)$ \\
- Usual activities, points & $1.0(1.0-1.0)$ & $1.0(1.0-1.0)$ \\
- Pain/discomfort, points & $80.0(70.0-90.0)^{*}$ & $75.0(65.0-85.5)$ \\
- Anxiety/depression, points & $23.0(20.0-24.00)$ & $21.0(18.0-24.0)$ \\
VAS, points &
\end{tabular}

Values expressed as mean (SD), median (IQR) or number of patients (\%).

$*=\mathrm{p} \leq 0.05$ versus group COPD patients

Abbreviations: 15WT, 15 words test; CES-D, Center for Epidemiologic Studies Depression Scale; HADS-A, Hospital Anxiety and Depression Scale - Anxiety Scale; CAT, COPD assessment test; EQ5D, EuroQuol 5D; VAS, Visual Analogue Scale; SF-12, 12-Item Short Form Health Survey.

\section{Social status}

Subjects with COPD less frequently had a partner and, when having a partner, they were less often 'very satisfied' with the daily support they received from their partner than non-COPD subjects. Additionally, COPD subjects perceived less often emotional support compared to non-COPD subjects (Table 4). Marital status, personal network size, instrumental support, loneliness, receiving help and employment status were comparable between groups. 
Table 4. Social status of the study subjects divided in patients with and without COPD

\begin{tabular}{|c|c|c|}
\hline & Non-COPD subjects & COPD subjects \\
\hline Partner, yes (\%) & $622(83.8)^{*}$ & $47(69.1)$ \\
\hline Married, yes (\%) & $535(72.1)$ & $45(66.2)$ \\
\hline \multicolumn{3}{|l|}{ Daily support partner } \\
\hline - No partner/no answer, n (\%) & $118(18.3)^{*}$ & $22(32.4)$ \\
\hline - $\quad$ Very dissatisfied, n (\%) & $4(0.5)$ & $1(1.5)$ \\
\hline - $\quad$ Dissatisfied, n (\%) & $8(1.1)$ & $1(1.5)$ \\
\hline - A little dissatisfied, $\mathrm{n}(\%)$ & $39(5.3)$ & $5(7.4)$ \\
\hline - $\quad$ Satisfied, n (\%) & $330(44.5)$ & $26(38.2)$ \\
\hline - $\quad$ Very satisfied, n (\%) & $190(27.2)^{*}$ & $10(14.7)$ \\
\hline Personal network size, number & $19.0(13.0-28.0)$ & $16.0(11.0-25.5)$ \\
\hline \multicolumn{3}{|l|}{ Instrumental support } \\
\hline - $\quad$ No support, n (\%) & $90(12.1)$ & $10(14.7)$ \\
\hline - $\quad$ Seldom, n (\%) & $400(53.9)$ & $35(51.5)$ \\
\hline - Sometimes, n (\%) & $231(31.2)$ & $21(30.9)$ \\
\hline - $\quad$ Often, n $(\%)$ & $21(2.8)$ & $2(2.9)$ \\
\hline \multicolumn{3}{|l|}{ Emotional support } \\
\hline - $\quad$ No support, n (\%) & $18(2.4)$ & $4(5.9)$ \\
\hline - $\quad$ Seldom, n (\%) & $94(12.7)$ & $10(14.7)$ \\
\hline - $\quad$ Sometimes, n (\%) & $360(48.5)$ & $38(55.9)$ \\
\hline - Often, $\mathrm{n}(\%)$ & $270(36.4)^{*}$ & $16(23.5)$ \\
\hline \multicolumn{3}{|l|}{ Loneliness } \\
\hline - Emotional, yes (\%) & $222(29.9)$ & $25(36.8)$ \\
\hline - $\quad$ Social, yes $(\%)$ & $277(37.3)$ & $25(36.8)$ \\
\hline - General, yes (\%) & $353(47.6)$ & $33(48.5)$ \\
\hline \multicolumn{3}{|l|}{ Help } \\
\hline - $\quad$ Personal, yes (\%) & $9(1.2)$ & $0(0.0)$ \\
\hline - Domestic, yes $(\%)$ & $128(17.3)$ & $12(17.6)$ \\
\hline - $\quad$ Nursing, yes (\%) & $9(1.2)$ & $1(1.5)$ \\
\hline Having a paid job, n $(\%)$ & $478(64.4)$ & $37(54.4)$ \\
\hline
\end{tabular}

Values expressed as mean (SD), median (IQR) or number of patients (\%).

${ }^{*}=\mathrm{p} \leq 0.05$ versus group COPD patients

\section{DISCUSSION}

This is the first study that specifically studied physical, mental and social status in subjects with and without COPD from a population-based sample, aged between 55 to 65 years. Despite a mild-to-moderate degree of airflow limitation, subjects with COPD had significant impairments in specific measures of physical, mental and social status compared to non-COPD subjects. 
The impact of COPD on physical, mental and/or social status was demonstrated in multiple studies, including mostly subjects with moderate to very severe COPD recruited at outpatient clinics $(9,10,12,13,15)$. This, however, may limit the external validity of these findings towards subjects living with COPD in the general population. The current study is the first to show that COPD subjects with a mean age of 60 years and a mild-to-moderate degree of airflow limitation have a deteriorated physical, mental and social status, compared to non-COPD subjects. The fact that the subjects with and without COPD had a comparable age, gender distribution, BMI and equal number of self-reported comorbidities, suggests that the presence of mild-to-moderate COPD may be the main driver of these impairments.

\section{Physical, mental and social impact of COPD}

Corresponding to the current study, a high prevalence of subjects experiencing pain and incontinence is found in former research (26-28). Subsequently, previous studies showed that physical performance is reduced in subjects with COPD compared to non-COPD subjects $(29,30)$. In addition, the present study shows that subjects with mild to moderate COPD, already have a slower walking speed and report lower values on self-rated health compared to non-COPD subjects. On the other hand, physical measurements, like sedentary behavior, handgrip strength, number of falls or use of daily aids were comparable in the current study. Though, we should take into account that only a distribution was made in disease severity based on $\mathrm{FEV}_{1} \%$ predicted, while degree of emphysema can also influence physical status $(31,32)$. However, this still raises the question what causes these specific impairments in physical status, while other physical parameters were comparable between groups. Possibly, differences in self-rated health between subjects with and without COPD could be explained by influences of subjective/self-perceived measurement of physical status, e.g. personal fulfillment or expectations (33). Also, it can be hypothesized that subjects already experience dyspnea and/or fatigue during daily activities at the early stage of the disease (34). Vanfleteren and colleagues indicate that lower physical activity can be caused by the nature of symptom development and adaptations to minimize dyspnea provocation (35). These questions need to be addressed in future studies. Nevertheless, subjects with a relatively preserved lung function, diagnosed with COPD, experience physical symptoms. This is supported by previous research, indicating that patients with preclinical COPD are physically more inactive than smoking non-COPD peers (8). Also, there is growing evidence of significant respiratory morbidity in smokers with preserved spirometry (36).

With regard to mental status, in line with previous literature $(6,11)$, a more impaired disease specific health status is observed in subjects with COPD and they rated their 
health worse than non-COPD subjects. However, it should be taken into account that the instruments used to assess health status (CAT, EQ5D and VAS) largely focus on the patients' personal perspective on bodily sensations and limitations in daily living. These measurements direct less attention to emotional consequences, accentuating the influence of daily limitations and need for adequate management of COPD. Furthermore, no significant differences were observed with cognitive function and mood status between the two groups, while previous literature implies that subjects with COPD have more symptoms of anxiety and depression and more cognitive dysfunction compared to non-COPD controls $(12,13)$. Contradictory results can be explained by the fact that studies were performed within a more severe COPD population, not representing the general COPD population. Overall, the current results indicate that the largest proportion of subjects with COPD from a general population barely experience mental symptoms.

New insights were gained relating to social consequences of COPD. Subjects with COPD less frequently had a partner, rated daily support from their partner less positive and did not receive emotional support as often as non-COPD subjects. As the current study shows no differences in personal network size and feelings of loneliness between subjects with and without COPD, it appears that the shortage of emotional support does not directly depend on the number of people in their network. This leads to the assumption that subjects with COPD have a higher need of emotional support, which is also found in previous research (37). A lower rate for received support may be explained by the fact that subjects with COPD and their partner or caregiver are confronted with multiple limitations in daily living and often have different perceptions on the disease (38). Another study shows that, in order to cope with the disease, partners of COPD subjects are very important for the patient (39).

\section{Possible consequences for clinical practice}

Healthcare professionals should be aware of the fact that subjects with mild COPD in the general population may experience specific impairments in physical, mental and social status. This needs to be taken into consideration when setting up an COPD management program and/or a program to monitor disease progression. Concerning physical status, this can for example be applied by giving education about influence of COPD on physical status or provide physiotherapy/ physical activity coaching, if necessary, at an early stage of the disease. Results with regard to mental status imply that a large proportion of COPD subjects does no experience psychological symptoms. This may suggest that these subjects would sufficiently benefit from a management program with a lower intensity, and presumably lower healthcare costs (40). Assessment of physical, mental and social 
status at the start of treatment may detect these subjects. The cost-effectiveness remains to be established however. This would also give the opportunity to detect COPD subjects with higher needs for social support and provide information to prevent deterioration. Therefore, when necessary, it is suggested to involve the closely related social system of subjects with COPD (e.g. partner, children or other caregivers) in COPD care programs. For example, psychotherapeutic interventions can be applied to improve health status among COPD subjects and their system (31). However, whether and to what extent these suggestions influence physical, mental or social status remains to be determined.

The present Dutch healthcare guidelines provide comprehensive directives about COPD management implemented by general practitioners, i.e. focusing on airflow limitation, general deterioration, symptoms and health status (41). The results of the current study support the guidelines, as airflow limitation and specific measures of physical and mental status differed significantly between subjects with and without COPD. However, no specific healthcare can be provided in the large proportion of undiagnosed COPD subjects. As the current study shows that COPD has impact on specific aspects of all three areas (physical, mental and social), the necessity of detecting COPD in the general population is emphasized. In the current healthcare system, detection of COPD mainly consists of performing post-bronchodilator spirometry $(42,43)$. Other studies suggest that we should, for example, increase awareness of COPD in smokers (4) or apply specifically developed questionnaires assessing symptoms (44) to uncover COPD in the general population. Based on the current results, it is recommended to, in addition to the current guidelines, assess functional and health status in subjects with an increased risk for COPD (e.g. high number of pack-years/current smokers). Moreover, instruments have to be quick and easy to implement into clinical practice $(45,46)$. Assessment of functional status and health status should be performed for diagnostic purposes and assess the impact of the COPD.

\section{Limitations}

A limitation of the current study is that a relatively small number of subjects with COPD participated in the current study. However, this was expected based on previously published prevalence rates of COPD in a general population $(47,48)$. Second, the current population is slightly younger than the population examined in previous studies (49). However, despite the limited variance in age, general features are in accordance with previous research. Therefore, it is expected that the results are representative, although one should be careful in generalizing to other age groups. It should be noticed that the current population also gives the opportunity to show that clear differences are present between subjects with and without 
COPD in this age group. Third, a history of respiratory diseases was defined as self-reported chronic bronchitis, asthma, emphysema, or COPD. Initially, it is a disadvantage that the diagnosis is self-reported as it is less accurate than the original doctor diagnosis. Moreover, no distinction was made between the various respiratory diseases. This makes it impossible to specify whether the subject was diagnosed with chronic bronchitis, asthma, emphysema or COPD, which may indicate even more underdiagnosis of COPD than already reported in the current study. Finally, measurements were conducted cross-sectionally, not providing the possibility to determine the causal direction between the physical, mental and social impact and COPD. Therefore, it is possible for the causal direction to go the other way, where symptoms are prior to COPD. However, previous longitudinal research suspects otherwise (50).

\section{CONCLUSION}

Subjects with mild-to-moderate COPD from a general population sample in the Netherlands showed some specific impairments in measures of physical, mental and social status compared to non-COPD subjects. These impairments need to be taken into consideration when setting up an COPD management program. Complementary to the current COPD care, it is suggested to diagnose COPD in the general population by performing spirometry and measuring functional status and health in subjects with an increased risk 


\section{REFERENCES}

1. Quanjer PH, Brazzale DJ, Boros PW, Pretto JJ. Implications of adopting the Global Lungs Initiative 2012 all-age reference equations for spirometry. The European respiratory journal. 2013;42(4):1046-54.

2. Vogelmeier CF et al. Global Strategy for the Diagnosis, Management, and Prevention of Chronic Obstructive Lung Disease 2017 Report: GOLD Executive Summary. American journal of respiratory and critical care medicine. 2017.

3. Herland K, Akselsen JP, Skjonsberg OH, Bjermer L. How representative are clinical study patients with asthma or COPD for a larger "real life" population of patients with obstructive lung disease? Respiratory medicine. 2005;99(1):11-9.

4. Mun SY et al. Awareness of chronic obstructive pulmonary disease in current smokers: a nationwide survey. The Korean journal of internal medicine. 2015;30(2):191-7.

5. Martinez $\mathrm{CH}$ et al. Undiagnosed Obstructive Lung Disease in the United States. Associated Factors and Long-term Mortality. Annals of the American Thoracic Society. 2015;12(12):1788-95.

6. Coultas DB, Mapel D, Gagnon R, Lydick E. The health impact of undiagnosed airflow obstruction in a national sample of United States adults. American journal of respiratory and critical care medicine. 2001;164(3):372-7.

7. Agusti A. Systemic effects of chronic obstructive pulmonary disease: what we know and what we don't know (but should). Proceedings of the American Thoracic Society. 2007;4(7):522-5.

8. Van Remoortel $\mathrm{H}$ et al. Daily physical activity in subjects with newly diagnosed COPD. Thorax. 2013;68(10):962-3.

9. Ju C, Chen R. Factors associated with impairment of quadriceps muscle function in Chinese patients with chronic obstructive pulmonary disease. PloS one. 2014;9(2):e84167.

10. Leong DP et al. Prognostic value of grip strength: findings from the Prospective Urban Rural Epidemiol-ogy (PURE) study. Lancet. 2015;386(9990):266-73.

11. Peruzza $S$ et al. Chronic obstructive pulmonary disease (COPD) in elderly subjects: impact on functional status and quality of life. Respiratory medicine. 2003;97(6):612-7.

12. Bratek A et al. Depressiveness, symptoms of anxiety and cognitive dysfunctions in patients with asthma and chronic obstructive pulmonary disease (COPD): possible associations with inflammation markers: a pilot study. J Neural Transm. 2014.

13. Wong TS et al. Depressive disorders in older patients with chronic obstructive pulmonary disease (COPD) in Hong Kong: a controlled study. Aging \& mental health. 2014;18(5):588-92.

14. Antoniu SA, Petrescu E, Stanescu R, Anisie E, Boiculese L. Impact of fatigue in patients with chronic obstructive pulmonary disease: results from an exploratory study. Therapeutic advances in respiratory disease. 2016;10(1):26-33.

15. Johnson JL, Campbell AC, Bowers M, Nichol AM. Understanding the social consequences of chronic obstructive pulmonary disease: the effects of stigma and gender. Proc Am Thorac Soc. 2007;4(8):680-2. 
16. Janssen DJ, Wouters EF, Spruit MA. Psychosocial consequences of living with breathlessness due to advanced disease. Curr Opin Support Palliat Care. 2015;9(3):232-7.

17. Hoogendijk EO et al. The Longitudinal Aging Study Amsterdam: cohort update 2016 and major findings. Eur J Epidemiol. 2016;31(9):927-45.

18. Miller MR et al. Standardisation of spirometry. The European respiratory journal. 2005;26(2):319-38.

19. Swanney MP et al. Using the lower limit of normal for the FEV1/FVC ratio reduces the misclassification of airway obstruction. Thorax. 2008;63(12):1046-51.

20. Saan RJ, Deelman BG. De 15-Woorden Tests A en B. (Een voorlopige handleiding). Groningen: afd Neuropsychologie, AZG (interne publicatie). 1986.

21. Radloff LS. The CES-D Scale: A self-report depression scale for research in the general population. Appl Psychol Meas. 1977;3:385-401.

22. Jones PW et al. Development and first validation of the COPD Assessment Test. The European respiratory journal. 2009;34(3):648-54.

23. Brettschneider $\mathrm{C}$ et al. Validity and responsiveness of the EQ-5D in assessing and valuing health status in patients with somatoform disorders. Health and quality of life outcomes. 2013;11:3.

24. Ware JE, Kosinski M, Keller SD, editors. SF-12: How to score the SF-12 Physical and Mental Health Summary Scales. Boston. 1995 (key publication).

25. van Tilburg TG, de Jong Gierveld J. [Reference standards for the loneliness scale]. Tijdschr Gerontol Geriatr. 1999;30(4):158-63.

26. Janssen DJ, Wouters EF, Parra YL, Stakenborg K, Franssen FM. Prevalence of thoracic pain in patients with chronic obstructive pulmonary disease and relationship with patient characteristics: a cross-sectional observational study. BMC pulmonary medicine. 2016;16:47.

27. Burge AT et al. Prevalence and impact of urinary incontinence in men with chronic obstructive pulmonary disease: a questionnaire survey. Physiotherapy. 2016.

28. Cooper $\mathrm{J}$ et al. Prevalence of female urinary incontinence and its impact on quality of life in a cluster population in the United Kingdom (UK): a community survey. Prim Health Care Res Dev. 2015;16(4):377-82.

29. Vaes AW et al. Changes in physical activity and all-cause mortality in COPD. The European respiratory journal. 2014;44(5):1199-209.

30. De Buyser SL et al. Physical func-tion measurements predict mortality in ambulatory older men. European journal of clinical investigation. 2013;43(4):379-86.

31. Chen R, Chen R, Chen X, Chen L. Effect of endurance training on expiratory flow limitation and dynamic hyperinflation in patients with stable chronic obstructive pulmonary disease. Intern Med J. 2014;44(8):791-800.

32. Cheng $\mathrm{T}$ et al. Obvious emphysema on computed tomography during an acute exacerbation of chronic obstructive pulmonary disease predicts a poor prognosis. Intern Med J. 2015;45(5):517-26.

33. Leidy NK. Subjective measurement of activity in chronic obstructive pulmonary disease. Copd. 2007;4(3):243-9.

34. Vaes AW et al. Task-related oxygen uptake during domestic activities of daily life in patients with COPD and healthy elderly subjects. Chest. 2011;140(4):970-9. 


\section{Chapter 4}

35. Soumagne $\mathrm{T}$ et al. Asymptomatic subjects with airway obstruction have significant impairment at exercise. Thorax. 2016;71(9):804-11.

36. Woodruff PG et al. Clinical Significance of Symptoms in Smokers with Preserved Pulmonary Function. N Engl J Med. 2016;374(19):1811-21.

37. Hand C, Law M, McColl MA, Hanna S, Elliott S. An examination of social support influences on participation for older adults with chronic health conditions. Disability and rehabilitation. 2014;36(17):1439-44.

38. Nakken $\mathrm{N}$ et al. Informal caregivers of patients with COPD: Home Sweet Home? Eur Respir Rev. 2015;24(137):498-504.

39. Binder $\mathrm{M}$ et al. [Helpful and stressful factors in coping with COPD in patients and their partners - a qualitative study]. Praxis (Bern 1994). 2014;103(2):75-83.

40. Newman S, Steed L, Mulligan K. Self-management interventions for chronic illness. Lancet. 2004;364(9444):1523-37.

41. Geijer RM et al. [The NHG guidelines 'Adult asthma' and 'COPD']. Nederlands tijdschrift voor geneeskunde. 2015;159:A9076.

42. Ferguson GT, Enright PL, Buist AS, Higgins MW. Office spirometry for lung health assessment in adults: A consensus statement from the National Lung Health Education Program. Chest. 2000;117(4):1146-61.

43. Soriano JB, Zielinski J, Price D. Screening for and early detection of chronic obstructive pulmonary disease. Lancet. 2009;374(9691):721-32.

44. Dirven JA et al. Early detection of COPD in general practice: implementation, workload and socioeconomic status. A mixed methods observational study. Primary care respiratory journal: journal of the General Practice Airways Group. 2013;22(3): 338-43.

45. Bisca GW, Morita AA, Hernandes NA, Probst VS, Pitta F. Simple lower limb functional tests in patients with Chronic Obstructive Pulmonary Disease: a systematic review. Archives of physical medicine and rehabilitation. 2015.

46. Ringbaek T, Martinez G, Lange P. A comparison of the assessment of quality of life with CAT, CCQ, and SGRQ in COPD patients participating in pulmonary rehabilitation. Copd. 2012;9(1):12-5.

47. Buist AS et al. International variation in the prevalence of COPD (the BOLD Study): a population-based prevalence study. Lancet. 2007;370(9589):741-50.

48. Atsou K, Chouaid C, Hejblum G. Variability of the chronic obstructive pulmonary disease key epidemiological data in Europe: systematic review. BMC medicine. 2011;9:7.

49. Rennard SI. The Promise of Observational Studies (ECLIPSE, SPIROMICS, and COPDGene) in Achieving the Goal of Personalized Treatment of Chronic Obstructive Pulmonary Disease. Semin Respir Crit Care Med. 2015;36(4):478-90.

50. de Torres JP et al. The importance of symptoms in the longitudinal variability of clusters in COPD patients: A validation study. Respirology. 2017. 
SUPPLEMENTARY MATERIAL

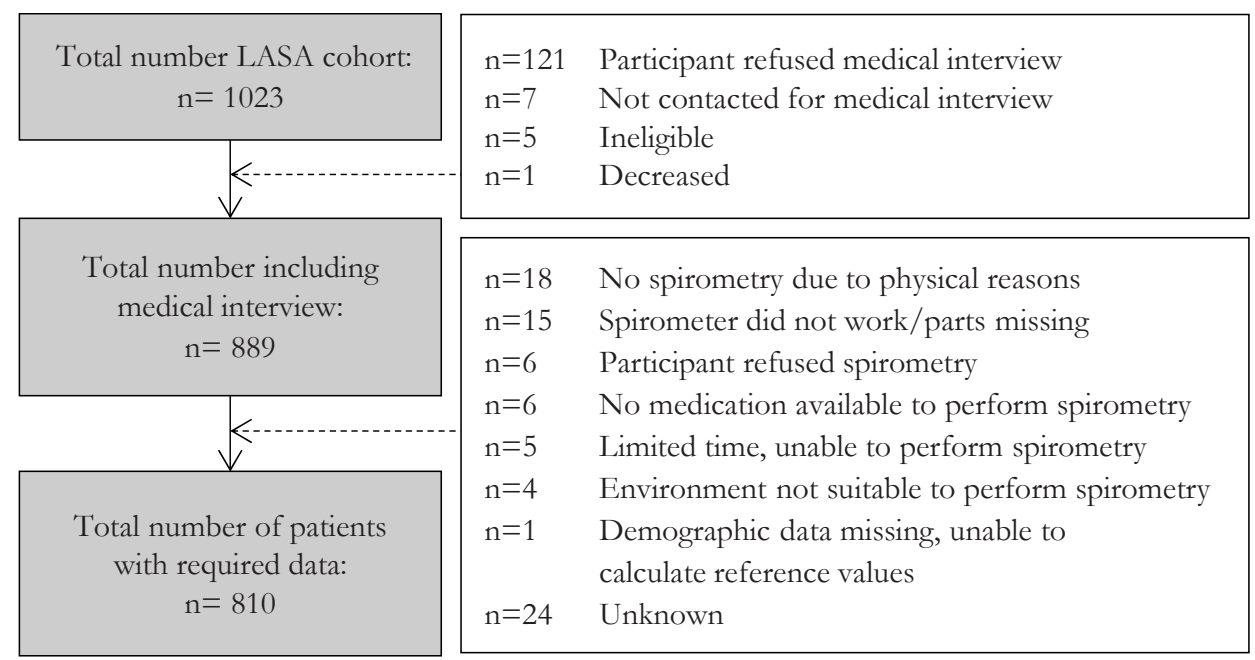

Figure E1. Flow diagram of subject inclusion

Abbreviations: LASA, Longitudinal Aging Study Amsterdam 



\section{Chapter 5}

\section{Burden of COPD in patients treated in different care settings in the Netherlands}

Dionne E. Smid, Martijn A. Spruit, Sarah Houben-Wilke, Jean W.M. Maris, Gernot G.U. Rohde, Emiel F.M. Wouters, Frits M.E. Franssen 


\section{ABSTRACT}

Introduction Care for patients with chronic obstructive pulmonary disease (COPD) can be provided in primary, secondary or tertiary care. Whether and to what extent patients with COPD treated in various healthcare settings differ in disease burden and healthcare utilization remains unknown. Therefore, daily symptoms, functional mobility, mood status, health status and healthcare utilization were compared between COPD patients in various care settings, to explore possibilities for healthcare-optimization.

Methods Current data are part of the Chance study. Demographics, functional mobility (Care Dependency Scale (CDS); Timed-Up-and-Go (TUG) test), mood status (Hospital Anxiety and Depression scale (HADS)), health status (COPD Assessment test (CAT); Clinical COPD questionnaire (CCQ); COPD specific St. George Respiratory questionnaire (SGRQ-C)), received treatments and severity of physical and psychological symptoms were assessed in subjects with and without COPD.

Results 836 subjects (100 primary care patients, 100 secondary care patients, 518 tertiary care patients and 118 non-COPD subjects) were included. The burden of disease significantly increased from primary care to tertiary care. However, in all three healthcare settings a high percentage of patients with an impaired health status was observed (i.e. CAT 10 points, 68.0\% vs. $91.0 \%$ vs. $94.5 \%$, respectively). Furthermore, many patients treated in secondary care remain highly symptomatic despite treatment, while others with low burden of disease would allow for de-intensification of care.

Conclusion This study revealed important shortcomings and challenges for the care of COPD patients in the Netherlands. It emphasizes the need for detailed patient characterization and more individualized treatment, independent of the healthcare setting. 


\section{INTRODUCTION}

Chronic obstructive pulmonary disease (COPD) is one of the most prevalent noncommunicable diseases worldwide, associated with substantial morbidity and mortality (1). Population-based studies estimated that about $10 \%$ of the adult population has at least a moderate degree of chronic airflow limitation (2). Healthcare for patients with COPD varies between jurisdictions, mostly due to local policies and conditions (3-5). In most jurisdictions, however, patients with COPD can receive primary care, secondary care and/or tertiary care (6). While the majority of patients with established COPD is treated in primary care (7), most of the current understanding of the heterogeneous pulmonary and systemic features of COPD and the burden of disease is based on cohorts of patients recruited in secondary and/or tertiary care (8). Also the degree of overlap as potential differences in real-life burden of disease and healthcare utilization between care settings is mostly unexplored. Vest and colleagues found no differences in demographics and smoking history between primary and secondary care patients (9). Additionally, Herland and colleagues reported no differences in amount of comorbidities between primary and secondary care patients (10). In contrast, Kruis and colleagues showed that COPD patients participating in large pharmaceuticallysponsored studies differed substantially in lung function, health status and exacerbation frequency from primary care patients (11). More studies comparing relevant patient-related outcomes of patients with COPD in different healthcare settings are lacking. Thus, external validity of previously performed COPD studies conducted in secondary and/or tertiary care is mostly unknown (11), as is the true burden of disease in primary care. Although differences in the degree of chronic airflow limitation may partially account for differences between care settings, it is well recognized that lung function is a poor predictor of patient-related outcomes in COPD (12,13). A better understanding of the clinical characteristics and healthcare consumption of patients with COPD treated in various care settings will help clinicians and healthcare policy makers in the development of tools for integrated assessment of burden of disease, decision taking regarding intensity of monitoring of patients, and allocation of patients.

The aim of the present study was to compare burden of disease and healthcare utilization between patients with COPD treated in primary care, secondary care or tertiary care and explore possibilities for optimization of care. A priori, we hypothesized that there is substantial overlap in daily symptoms, functional mobility, mood status, health status and healthcare utilization between patients in primary, secondary and tertiary care setting, but that patients in tertiary care have the highest disease burden. 


\section{METHODS}

The current data are part of the Chance study, an observational longitudinal study concerning the clinical, physiological and psychosocial determinants of health status in a broad sample of patients with COPD and non-COPD controls (14). The Medical Ethical Committee of the Maastricht University Medical Centre (Maastricht, The Netherlands) approved the study (METC 11-3-070), which is registered at the Netherlands National Trial Register (NTR 3416).

\section{Study sample}

Patients with COPD (defined as post-bronchodilator forced expiratory volume in the first second $\left(\mathrm{FEV}_{1}\right)$ / forced vital capacity $\left.(\mathrm{FVC})<0.7\right)$ were recruited at eight general practices (GPs, primary care) in the Southern part of the Netherlands, at the outpatient pulmonary clinic of the Maastricht University Medical Centre, the Netherlands (secondary care) and at the highly-specialized pulmonary rehabilitation centre CIRO in Horn, the Netherlands (tertiary care). Primary care COPD patients were recruited from the Registration Network of Family Practices (RNH), initiated by Maastricht University (15). Patients were eligible for participation if they received COPD treatment from a GP only. Consecutive patients visiting the secondary care setting were eligible if they had their regular check-ups with a chest physician in the hospital, optionally in combination with treatment by a GP. Patients derived from RNH, who were both being treated by a GP and a chest physician, were also considered eligible for inclusion in the secondary care group. Tertiary care patients were recruited and assessed during a pre-rehabilitation assessment in CIRO, after referral by a chest physician. Non-COPD subjects were recruited at the same GPs as the primary care COPD patients. They were eligible if they had no history of respiratory diseases, heart failure, malignancies within the past 5 years or other clinically relevant disease which may influence health status according to the principal investigator. Non-COPD subjects, primary care and secondary care patients were assessed during a single home visit. All patients gave written informed consent. Details about other in- and exclusion criteria, recruitment and assessment have been described in the study protocol (14).

\section{Measurements}

Demographics, general characteristics, smoking history, degree of dyspnea (modified Medical Research Council, mMRC) (16), resting oxygen saturation, body mass index (BMI), body composition (bioelectrical impedance assessment, BIA; fat-free mass index, FFMI) (17), comorbidities (Charlson Comorbidity Index, CCI) (18), frequency of exacerbations and hospitalizations twelve months prior to inclusion and medical history and medications were assessed. Post-bronchodilator spirometry (FEV 1 and 
FVC) in primary care patients, secondary care patients and non-COPD subjects was performed with a handheld SpiroPro (Jaeger/Cardinal Health, Hoechberg, Germany) in the home setting. Lung function in tertiary care patients was assessed with standardized spirometry equipment of Masterlab (CareFusion, Hoechberg, Germany) (19). Patients with COPD were divided into the four updated GOLD groups; based on the degree of airflow limitation and number of exacerbations in the past 12 months (A/B vs. C/D) and the severity of symptoms, based on CAT score (A/C vs. $B / D)(20)$. Burden of disease was determined according to the amount and severity of daily symptoms, functional mobility, mood status and health status. Functional mobility was assessed with the Care Dependency Scale (CDS) (21) and Timed Upand-Go (TUG) test (22). Mood status was measured with the Hospital Anxiety and Depression Scale (HADS) (23). Disease-specific health status was assessed using the COPD Assessment Test (CAT) (24), the Clinical COPD Questionnaire (CCQ) (25) and the COPD-specific version of the St George's Respiratory Questionnaire (SGRQ-C) (26). Additionally, a questionnaire concerning the type and amount of received care and a questionnaire about the degree of physical and psychological selfperceived symptoms were assessed $(14,27)$.

\section{Statistics}

The sample size calculation has previously been described in the published protocol (14). Results are presented as mean and standard deviation (SD), median and interquartile range (IQR), and/or proportions, as appropriate. Categorical variables were described as absolute numbers and frequencies. To gain insight in the burden of disease, internationally accepted cut-offs for high symptoms or abnormal values were applied: $\mathrm{mMRC}$ score $\geq 2$, CAT $\geq 10$, CCQ $>1$, SGRQ $>25$ (20), HADS $\geq 10$ (23), BMI $<18.5$ or $\geq 25 \mathrm{~kg} / \mathrm{m}^{2}$ (28) and FFMI $<5 \%$ percentile (29). All variables were tested for normality with the KolmogorovSmirnov test. Normally distributed variables were assessed by a one-way analysis of variances (ANOVA). When appropriate, post hoc least significance difference (LSD) multiple comparisons were performed. Not-normally distributed variables were assessed with a Kruskal-Wallis test. A Chi-square test was applied for categorical variables. All statistics were done using SPSS V.20.0. A p-value equal to or less than 0.01 was considered statistically significant.

\section{RESULTS}

In total, 836 subjects $(55.9 \%$ male, mean age $64.4( \pm 8.6)$ years $)$ were included, of which 100 primary care COPD patients, 100 secondary care COPD patients, 518 tertiary care COPD patients and 118 non-COPD subjects. Patient characteristics, 
daily symptoms, functional mobility, mood status and health status of these four groups are presented in Table 1.

\section{COPD versus non-COPD}

Patients with COPD had significantly more pack years, a worse lung function and more comorbidities than non-COPD subjects. They also experienced more daily symptoms and had a worse functional mobility. Moreover, a worse mood status and health status were observed in patients with COPD compared to non-COPD subjects (Table 1). Furthermore, COPD subjects used more (pulmonary and nonpulmonary) medications and more healthcare resources compared to non-COPD subjects (Table 2).

\section{Characteristics of COPD patients in various healthcare settings}

Fig. 1 shows the associations between the degree of airflow limitation and functional status (A), mood status (B) and health status (C) for COPD patients in the various care settings. For complementary variables see appendix (Fig. A1). On average, tertiary care patients were located at the upper left side of the figures, indicating more severe airflow limitation and higher disease burden, while primary care patients were found at the lower right side of the figures, indicating a relatively good lung function and low disease burden. However, a large degree of overlap between care settings was shown. Boxplots were created to get a better view of the observed overlap between the different healthcare settings (Fig. A2).

\section{Burden of disease in primary care}

As shown in Table 1, primary care patients had the lowest amount of pack years, less severe degree of airflow limitation, higher oxygen saturation at rest, the least daily symptoms and best functional status compared to secondary and tertiary care patients. Nonetheless, more than half of the primary care patients was overweight or obese and $20 \%$ had low fat-free mass. These patients were more often current smokers. Moreover, 68\% of primary care patients were highly symptomatic (quadrant B/D), based on CAT cut-off as proposed by GOLD. Alternatively, 11\% of primary care patients fulfilled diagnostic criteria for high risk GOLD quadrants $\mathrm{C} / \mathrm{D}$, mostly based on a high exacerbation frequency ( $8 \%$ of patients). None of the primary care patients was hospitalized for COPD in the previous year. Sixty-five percent of primary care patients used a prescription for medication containing long-acting bronchodilators and 40\% used ICS (Table 2). The majority of patients had no or very infrequent visits with their general practitioner. In general, primary care patients often did not receive treatment by a physiotherapist, dietician, psychologist and/or occupational therapist. 


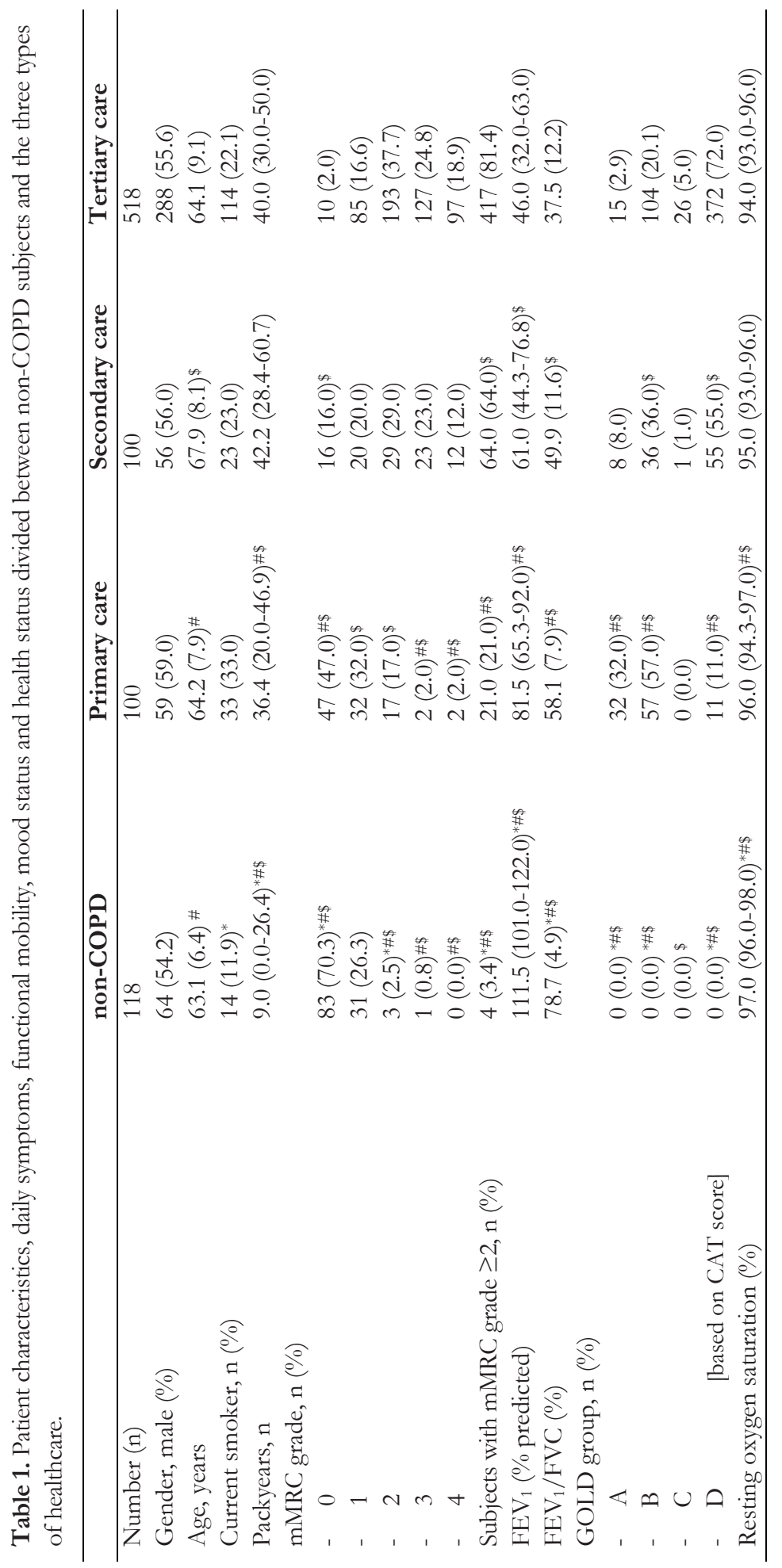




\section{Chapter 5}

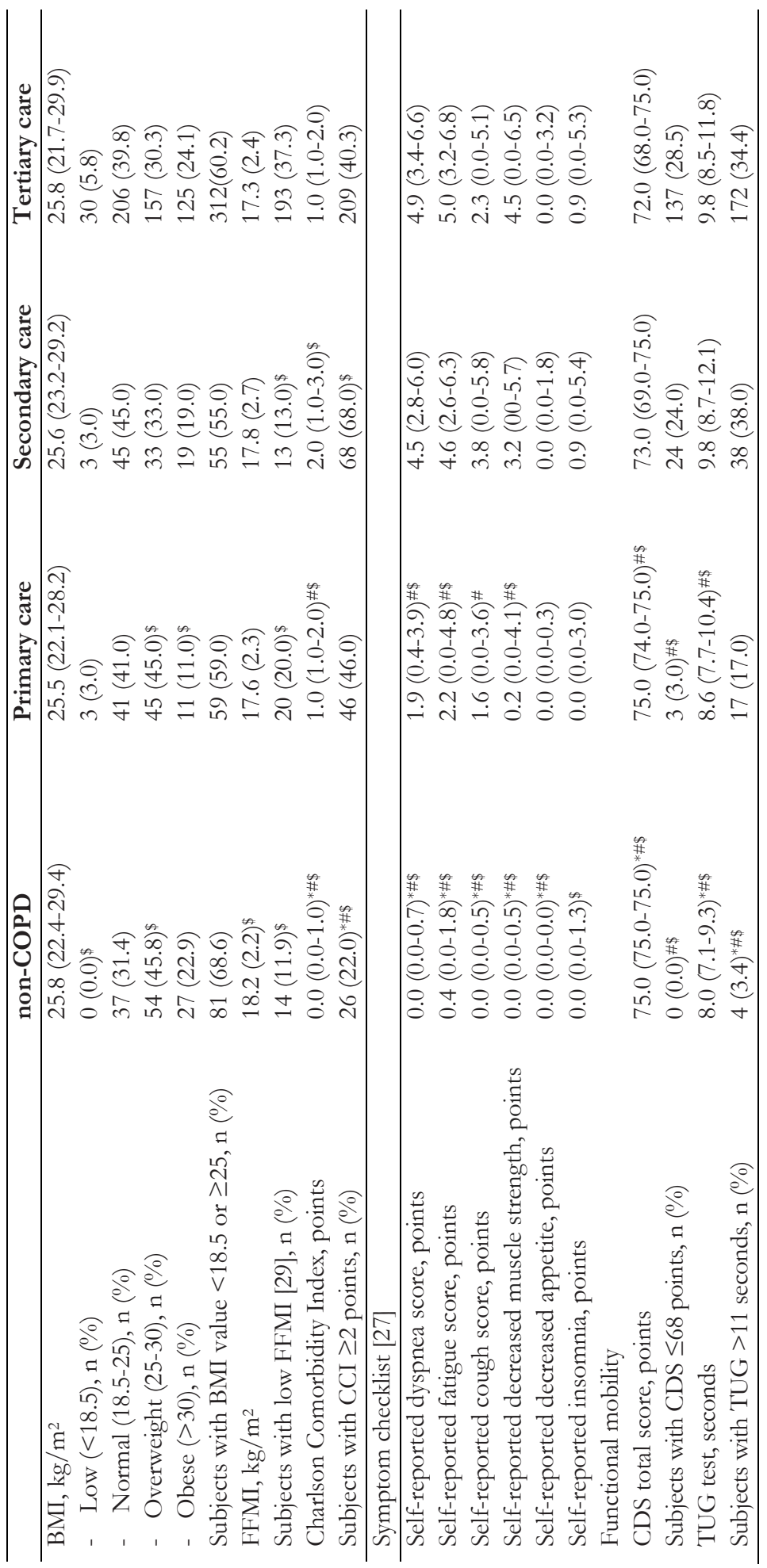




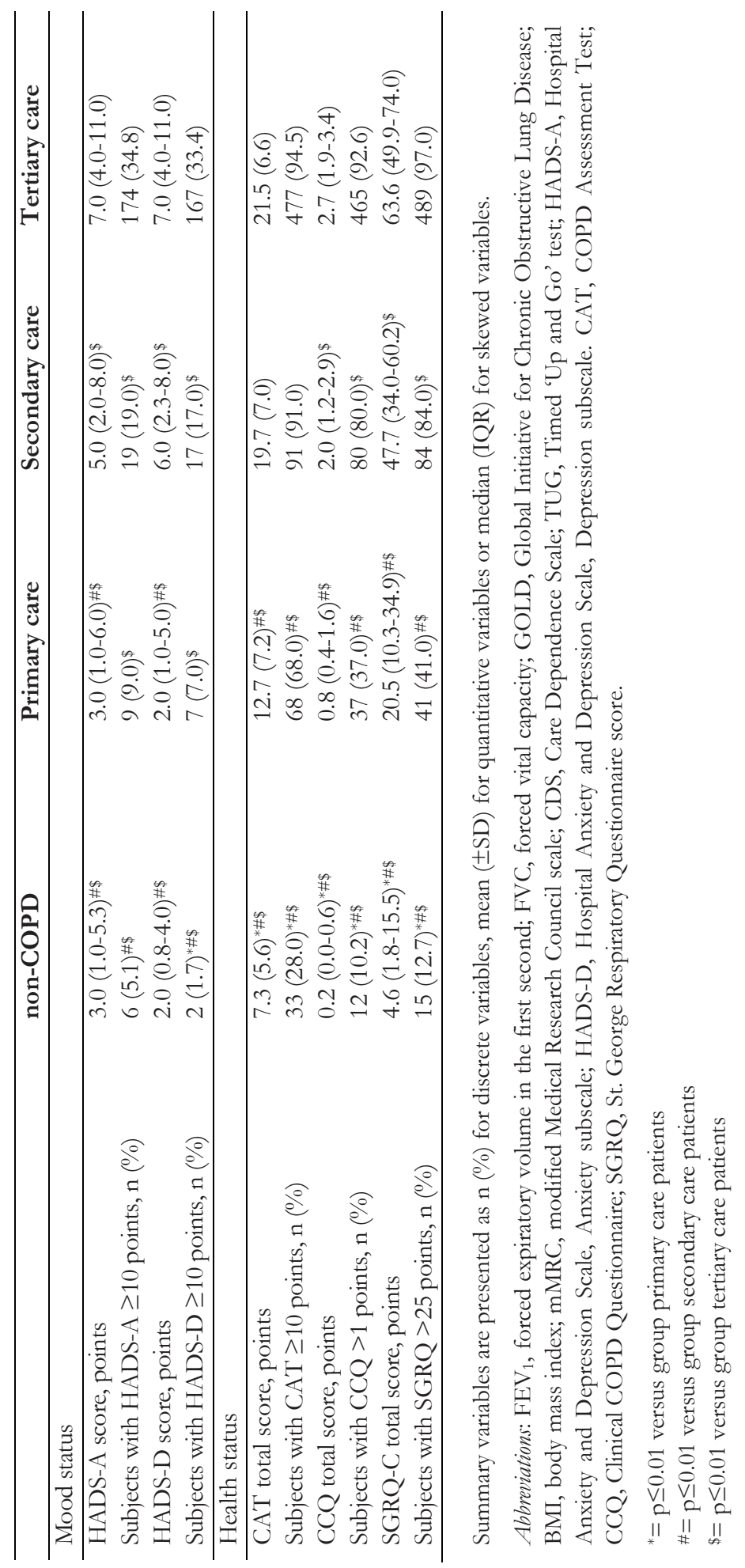




\section{Chapter 5}

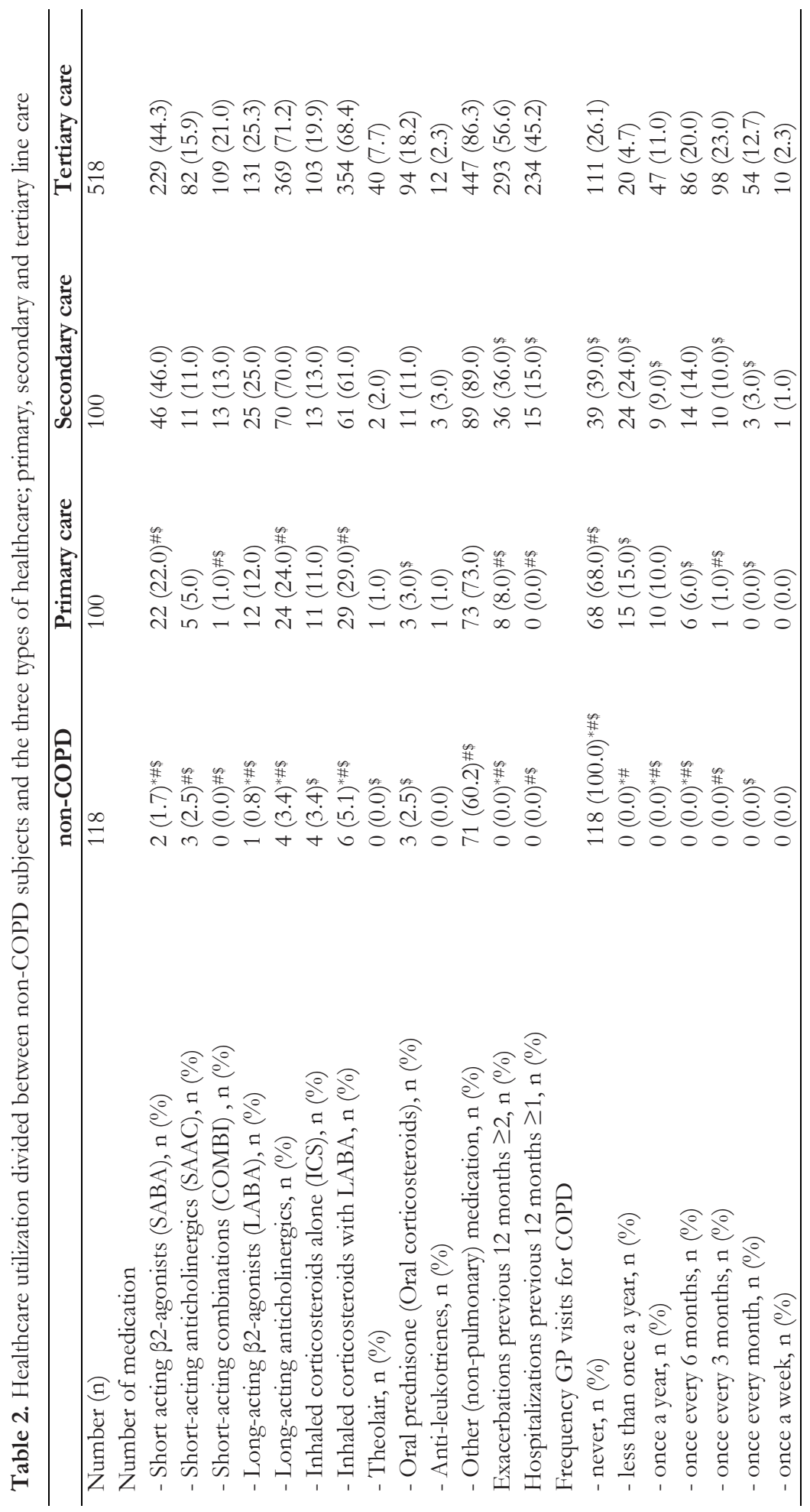




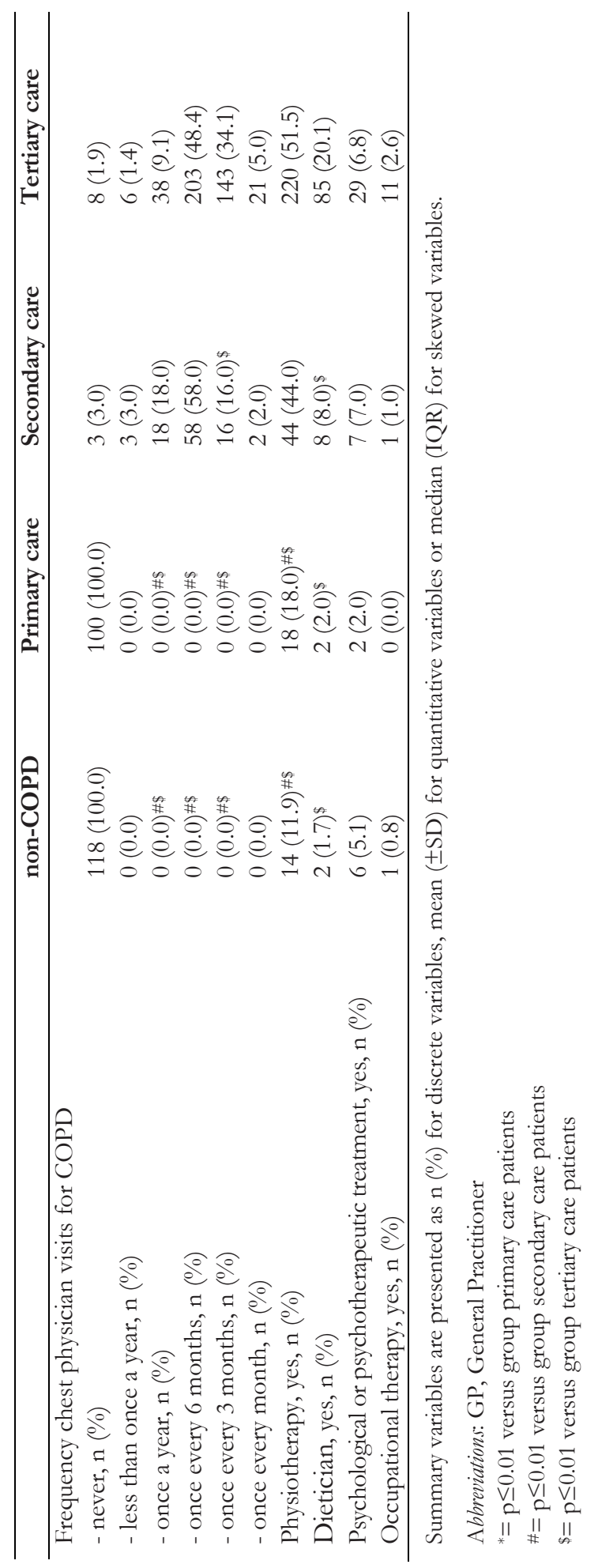


Chapter 5
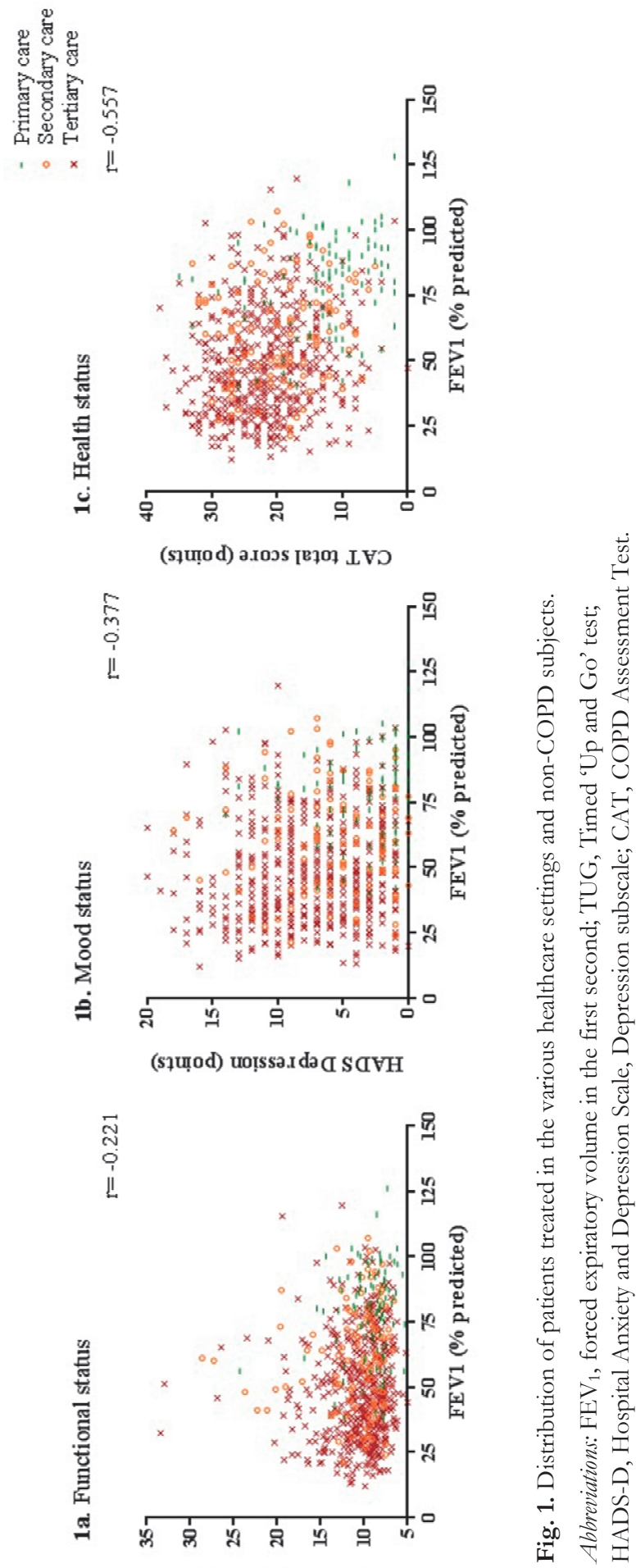

(spuoวəs) วuฺฺฺ 


\section{Burden of disease in secondary care}

Secondary care patients were the oldest and had the highest comorbidity score. Beyond $90 \%$ was categorized as highly symptomatic and almost a quarter was a current smoker. More than half of secondary care patients were categorized as high risk according to GOLD, with $36 \%$ of them having frequent exacerbations. As shown in Table 2, the largest proportion of secondary care patients used long-acting bronchodilators and $74 \%$ of them had inhaled corticosteroids. The majority of patients had a visit with their chest physician at least every six months. While psychological symptoms, abnormalities in body weight or body composition and reduced functional mobility were commonly observed, less than $10 \%$ of patients consulted a psychologist or dietician and less than half of the patients had physiotherapy.

\section{Burden of disease in tertiary care}

Smoking status and number of pack years were comparable between secondary and tertiary care patients. Though, tertiary care patients were the most dyspneic (as measured with the mMRC), had the worst lung function, and had the highest proportion of patients with low FFMI. More than three quarters of these patients were categorized as high risk according to GOLD; $57 \%$ of them had frequent exacerbations, while almost half of them was hospitalized for COPD in the previous year. Nearly $90 \%$ of the tertiary care patients used ICS. The use of oral corticosteroids for maintenance treatment was also common. Approximately half of the tertiary care patients consulted a physiotherapist before referral for pulmonary rehabilitation. Subsequently it is shown that, while one third of patients had significant symptoms of anxiety or depression, less than $10 \%$ of patients had consulted a psychologist. Even though mood status and health status (measured with CCQ and SGRQ) decreased significantly from primary care to tertiary care setting, mean CAT scores were comparable between secondary and tertiary care (Table 1).

\section{DISCUSSION}

In this analysis of studying the burden of disease and healthcare utilization in COPD patients treated in primary, secondary and tertiary care setting in the Netherlands, we were able to show that substantial burden of disease is present in primary care, where COPD management is mostly symptom driven and nonpharmacologic management of COPD is uncommon. Despite frequent consultations with a chest physician and broad prescription of inhaled therapies aimed at risk reduction, most secondary care patients were highly symptomatic and many of them had frequent exacerbations. Tertiary care patients had the highest 
burden of disease, mainly indicated by reduced mood and health status rather than increased functional limitation. The current results have implications for the generalizability of previous studies performed in different care settings and uncover possibilities for optimization of care.

Previous studies indicated that primary care patients have an impaired health status across all severities of COPD, a large proportion of patients are current smokers and the majority experiences symptoms of cough and dyspnea $(9,12)$. These findings are in accordance with the results of the current study. Additionally, Herland and colleagues observed only minor differences in demographics and burden of smoking between primary care patients and secondary care patients (10). Another study demonstrated that patients who visit a chest physician have a worse lung function and more frequent hospitalizations compared to primary care patients (9). This is in line with the findings of the current study. However, the present study additionally showed significantly more comorbidities, a higher amount of medications, more daily symptoms and a worse functional mobility, mood status and health status in secondary care patients compared to primary care patients. This is in contrast with (10) or supplementary to previous studies $(9,10,12)$. Studies comparing patients in secondary and tertiary care settings were previously lacking.

\section{Focus on primary care}

In the present study, 21\% of primary care COPD patients had severe to very severe dyspnea, 68\% had an impaired health status and $8 \%$ of them had frequent exacerbations. Also, low fat-free mass and overweight/obesity were very common in primary care COPD patients. At the same time, these patients were more often current smokers and had very infrequent visits with their GP. Only a limited number of patients received treatment from primary allied healthcare professionals. This suggests that current management of COPD is not very effective and suboptimal. Previous studies also implied that primary care patients receive little to no education on how to adapt their behaviour to their illness in the current healthcare management (30). Similar shortcomings were observed by a study performed in the United Kingdom (31). Dutch primary care COPD guidelines advise to provide smoking cessation, stimulate physical activity, offer dietary consultation when necessary, give breathing exercises, provide psychosocial help when necessary and offer an individually-based drug treatment (32). We conclude that these guidelines are not fully implemented by the GPs who participated in the current study. Despite possible regional differences (33), we expect that these results will be comparable to other parts of the Netherlands (34). 


\section{Focus on secondary care}

Secondary care patients had a higher burden of disease than primary care patients, as indicated by a more severe degree of airflow limitation, more symptoms of dyspnea, an impaired health status, worse mood status and more frequent exacerbations and hospitalizations, despite more extensive pharmacotherapy and consultations at the outpatient respiratory clinic. While emphasizing the limitations of currently available COPD pharmacotherapies, solely $9 \%$ of secondary care patients was low-symptomatic and only a minority of them had frequent exacerbations or hospitalizations. Thus, it is questionable whether and to what extent patients are allocated according to the Dutch national guidelines for COPD patients. These guideline state that patients should be referred to secondary or tertiary care when diagnostic problems (e.g. discrepancy between the severity of chronic obstruction and the subjective burden, COPD at young age and/or abnormal low FFMI) or insufficient progress in treatment goals (e.g. GOLD III or IV, quickly progressing COPD or more than 2 exacerbations per year) occur (32).

\section{Focus on tertiary care}

Patients referred for tertiary care pulmonary rehabilitation had the worst lung function and the highest number of exacerbations and hospitalizations. Symptoms of dyspnea were most pronounced, mood status and health status were more impaired, and low muscle mass was more common in this population. Remarkably, functional mobility was comparable to secondary care patients, as were daily symptoms, amount of pack years, oxygen saturation in rest, BMI and amount of medications. Although the present analysis is crosssectional, the current results suggest that symptoms of dyspnea, mood status and/or health status are important reasons for referral to pulmonary rehabilitation. Former studies also observed a high grade of dyspnea and impaired mood status and health status at the start of pulmonary rehabilitation (35-37). While the GOLD strategy for the management of COPD recommends pulmonary rehabilitation for all patients who get short of breath when walking on their own pace on level ground (8), no specific criteria for referral to pulmonary rehabilitation are currently available. Noteworthy, tertiary care patients had lower Charlson comorbidity scores compared to patients in secondary care. Probably, this is a result of under-diagnosis of comorbid diseases in COPD (38) and limitations of the index, since common COPD comorbidities such as mood disorders, osteoporosis and obesity are not reflected by the Charlson score (18). 


\section{What can we learn from these data?}

At the time of data acquisition of the current study (2012-2014) the latest national guidelines for COPD management by primary care physicians was introduced for more than 5 years. These guidelines mainly focused on airflow limitation, general deterioration and exacerbations (32). In 2015, the national guidelines were updated, extending the focus on symptoms, health status and poor nutritional status (39). Indeed, the current study highlights the importance of impaired health status as a reason to change intensity of care, as it was shown that tertiary care patients have the worst mood and health status. The updated guidelines also describe that more self-management should be provided in primary care. Complementary to this advice, we recommend that GPs should (be able to) refer patients with high disease burden for nonpharmacologic treatments or pulmonary rehabilitation, as this treatment appears to have a moderate to very good effect in $89.5 \%$ of the patients. This results in substantial improvements in functional mobility, health status and respiratory symptoms $(40,41)$. Subsequently, the updated guidelines advise to refer patients back to primary care solely when the reason(s) for referral and/or diagnostics have been addressed and/or when the chest physician is not able to contribute to reducing the disease burden. However, the absence of recent exacerbations and a low burden of disease should also be included. The most important shortcoming however, is the fact that there are solely guidelines available in primary care, while we aim for an integrated healthcare system. Guidelines should be constructed for all three healthcare settings.

Despite the fact that a structured, proactive approach has proven to reduce the burden of chronic diseases (42), current healthcare for patients with a chronic disease is often acute and reactive (43). Implementing disease management programs would improve chronic care and make it proactive and planned. An example of a disease management program applied in the Netherlands is the Chronic Care Model (CCM). This program clusters self-management support, health care organization, decision support, community linkages, delivery system design, clinical information systems and integration of the first five components (44). The most optimal approach would be to perform a complete assessment of every COPD patient during their first consultation, as already currently performed in tertiary care. Following, a patient should be referred to the most suitable type of healthcare, based on the comprehensive diagnostic assessment and needs of the individual. In addition, the acute setting of hospitalization of exacerbation should trigger physicians to reflect on the disease severity and burden of COPD in individual patients. Actually, this approach might lower the costs of COPD care, as proactive care results in less emergency or unscheduled visits, lower rates of hospitalizations and a shorter length of hospital utilization (45). However, based 
on the current data, neither the cost-effectiveness of such an approach can be shown nor can it be compared with possible stepped-care approach (46). To be able to construct a protocol and optimize individual healthcare, it is necessary to measure exacerbation and hospitalization history, daily symptoms, functional status, mood status and health status in all three healthcare settings (for diagnostic purposes, possible referral and/or merely as monitoring). Suggested instruments, easy to implement into clinical practice, are the mMRC dyspnea scale and symptom checklist for daily symptoms $(27,47)$, the TUG test, gait speed test or sitto-stand test for functional status (48), the HADS for mood status and the CAT or CCQ for health status (49).

\section{Limitations}

The generalizability of the current results needs to be considered, as participating GPs were merely located in the Southern part of the Netherlands. In addition, the tertiary care group consisted of a larger number of patients than the other groups, which does not reflect the allocation of patients in real-life. However, the baseline characteristics of our study population were comparable to those in previously published cohorts of COPD populations in different care settings $(11,50,51)$. Gender distribution, degree of airway obstruction and health status were comparable to a primary care population (11), secondary care population (50) and tertiary care population (51). Whether the provided care differs between various regions in the Netherlands and between countries remains unknown. Though, previous research also indicates shortcomings in implementation of healthcare guidelines in the UK (52) and USA (53). Another consideration is that several tests were measured differently in non-COPD subjects, primary care patients and secondary care patients (home environment) compared to tertiary care patients (clinical setting), as also described in the previously published protocol (14). Solely spirometry was measured with different equipment. Though, both devices are valid and reliable (19), and spirometry was mainly performed to confirm/exclude diagnoses and characterize patients with COPD. Thus, it is very unlikely to majorly have influenced the results. Subsequently, measurements were conducted crosssectionally, not providing the possibility to determine causality between burden of disease and care settings. Also, while primary and secondary care patients were assessed while being chronically managed, tertiary care patients were included ahead of treatment in tertiary care. Thus, it can be anticipated that disease burden would improve and allied healthcare utilization would increase in these patients after pulmonary rehabilitation. Finally, functional mobility was measured by TUG and CDS; since all participants were assessed in their home environment, no six minute walk test or other exercise tests were performed. 


\section{Chapter 5}

\section{CONCLUSION}

This study confirmed that the burden of disease gradually increases from COPD patients treated in primary and secondary care to those treated in tertiary care. It also revealed the need for additional interventions in secondary care patients who remain symptomatic despite pharmacologic and non-pharmacologic treatment, while another proportion of low symptomatic secondary care patients would allow for de-intensification of care. This study emphasizes the need for detailed characterization of individuals with COPD and for a more tailored treatment, independent of the healthcare setting. 


\section{REFERENCES}

1. I. Sommer, U. Griebler, P. Mahlknecht, K. Thaler, K. Bouskill, G. Gartlehner, S. Mendis, Socioeconomic inequalities in non-communicable diseases and their risk factors: an overview of systematic reviews, BMC Public Health 15 (1) (2015) 914.

2. L.E. Vanfleteren, F.M. Franssen, G. Wesseling, E.F. Wouters, The prevalence of chronic obstructive pulmonary disease in Maastricht, The Netherlands, Respir. Med. 106 (6) (2012) 871-874.

3. M.A. Spruit, F. Pitta, C. Garvey, R.L. ZuWallack, C.M. Roberts, E.G. Collins, R. Goldstein, R. McNamara, P. Surpas, K. Atsuyoshi, J.L. Lopez-Campos, I. Vogiatzis, J.E. Williams, S. Lareau, D. Brooks, T. Troosters, S.J. Singh, S. Hartl, E.M. Clini, E.F. Wouters, Differences in content and organisational aspects of pulmonary rehabilitation programmes, Eur. Respir. J. 43 (5) (2014) 1326-1337.

4. S. Tanday, Basic deficiencies noted in COPD care in England and wales, Lancet Respir. Med. 3 (3) (2015) 183.

5. S. Nardini, I. Annesi-Maesano, M. Del Donno, M. Delucchi, G. Bettoncelli, V. Lamberti, C. Patera, M. Polverino, A. Russo, C. Santoriello, P. Soverina. The AIMAR recommendations for early diagnosis of chronic obstructive respiratory disease based on the WHO/GARD model, Multidiscip. Respir. Med. 9 (1) (2014) 46.

6. National Institute for Health and Clinical Excellence (NICE). Management of chronic obstructive pulmonary disease in adults in primary and secondary care. Chronic obstructive pulmonary disease. [website: http://www.nice.org.uk/guidance/cg101/ resources/guidance-chronic-obstructive-pulmonarydisease-pdf. Updated: July 2014. Acces Date: 1-12-2015].

7. E.W. Bischoff, T.R. Schermer, H. Bor, P. Brown, C. van Weel, W.J. van den Bosch, Trends in COPD prevalence and exacerbation rates in Dutch primary care, Br. J. Gen. Pract. 59 (569) (2009) 927-933.

8. J. Vestbo, S.S. Hurd, A.G. Agusti, P.W. Jones, C. Vogelmeier, A. Anzueto, P.J. Barnes, L.M. Fabbri, F.J. Martinez, M. Nishimura, R.A. Stockley, D.D. Sin, R. RodriguezRoisin, Global strategy for the diagnosis, management, and prevention of chronic obstructive pulmonary disease: GOLD executive summary, Am. J. Respir. Crit. Care Med. 187 (4) (2013) 347-365.

9. S. Vest, L. Moll, M. Petersen, T.F. Buch, D.M. Bruun, M. Rask, A. Wester, A. Linneberg, Results of an outpatient multidisciplinary COPD rehabilitation programme obtained in two settings: primary and secondary health care, Clin. Respir. J. 5 (2) (2011) 84-91.

10. K. Herland, J.P. Akselsen, O.H. Skjonsberg, L. Bjermer, How representative are clinical study patients with asthma or COPD for a larger "real life" population of patients with obstructive lung disease? Respir. Med. 99 (1) (2005) 11-19.

11. A.L. Kruis, B. Stallberg, R.C. Jones, I.G. Tsiligianni, K. Lisspers, T. van der Molen, J.W. Kocks, N.H. Chavannes, Primary care COPD patients compared with large pharmaceutically-sponsored COPD studies: an UNLOCK validation.

12. P.W. Jones, G. Brusselle, R.W. Dal Negro, M. Ferrer, P. Kardos, M.L. Levy, T. Perez, J.J. Soler Cataluna, T. van der Molen, L. Adamek, N. Banik, Patient centred assessment 
of COPD in primary care: experience from a crosssectional study of health-related quality of life in Europe, Prim. Care Respir. J. 21 (3) (2012) 329-336.

13. M.A. Spruit, M.L. Watkins, L.D. Edwards, J. Vestbo, P.M. Calverley, V. Pinto, Plata, B.R. Celli, R. Tal-Singer, E.F. Wouters, Determinants of poor 6-min walking distance in patients with COPD: the ECLIPSE cohort, Respir. Med. 104 (6) (2010) 849-857.

14. D.E. Smid, S. Wilke, P.W. Jones, J.M.W. Muris, E.F. Wouters, F.M. Franssen, M.A. Spruit, Impact of cardiovascular comorbidities on COPD Assessment Test (CAT) and its responsiveness to pulmonary rehabilitation in patients with moderate to very severe COPD: protocol of the Chance study, BMJ Open 5 (7) (2015) e007536.

15. J.F. Metsemakers, P. Hoppener, J.A. Knottnerus, R.J. Kocken, C.B. Limonard, Unlocking patients' records in general practice for research, medical education and quality assurance: the registration network family practices, Int. J. Biomed. Comput. 42 (1e2) (1996) 43-50.

16. D.A. Mahler, C.K. Wells, Evaluation of clinical methods for rating dyspnea, Chest 93 (3) (1988) 580-586.

17. A.M. Schols, E.F. Wouters, P.B. Soeters, K.R. Westerterp, Body composition by bioelectrical-impedance analysis compared with deuterium dilution and skinfold anthropometry in patients with chronic obstructive pulmonary disease, Am. J. Clin. Nutr. 53 (2) (1991) 421-424.

18. M.E. Charlson, P. Pompei, K.L. Ales, C.R. MacKenzie, A new method of classifying prognostic comorbidity in longitudinal studies: development and validation, J. Chronic Dis. 40 (5) (1987) 373-383.

19. P. Munnik, P. Zanen, J.W. Lammers, A comparison of lung function equipment with emphasis on interchangeability and methods, Physiol. Meas. 27 (6) (2006) 445-455.

20. Global Strategy For The Diagnosis, Management, and Prevention of Chronic, Obstructive Pulmonary Disease. [website: www.goldcopd.com] Updated: Decemer 2015. Acces Date: 15-3-2016.

21. D.J. Janssen, E.F. Wouters, J.M. Schols, M.A. Spruit, Care dependency independently predicts two-year survival in outpatients with advanced chronic organ failure, J. Am. Med. Dir. Assoc. 14 (3) (2013) 194-198.

22. R. Mesquita, D.J. Janssen, E.F. Wouters, J.M. Schols, F. Pitta, M.A. Spruit, Withinday test-retest reliability of the timed "up \& go" test in patients with advanced chronic organ failure, Arch. Phys. Med. Rehabil. 94 (11) (2013) 2131-2138.

23. A.S. Zigmond, R.P. Snaith, The hospital anxiety and depression scale, Acta Psychiatr. Scand. 67 (6) (1983) 361-370.

24. P.W. Jones, G. Harding, P. Berry, I. Wiklund, W.H. Chen, N. Kline Leidy, Development and first validation of the COPD assessment test, Eur. Respir. J. 34 (3) (2009) 648-654.

25. T. van der Molen, B.W. Willemse, S. Schokker, N.H. ten Hacken, D.S. Postma, E.F. Juniper, Development, validity and responsiveness of the clinical COPD questionnaire, Health Qual. Life Outcomes 1 (2003) 13.

26. P.W. Jones, F.H. Quirk, C.M. Baveystock, The St George's respiratory questionnaire, Respir. Med. 85 (Suppl B) (1991) 25-31 discussion 33-7.

27. D.J. Janssen, E.F. Wouters, J.M. Schols, M.A. Spruit, Self-perceived symptoms and care needs of patients with severe to very severe chronic obstructive pulmonary 
disease, congestive heart failure or chronic renal failure and its consequences for their closest relatives: the research protocol, BMC Palliat. Care 7 (2008) 5.

28. WHO, Obesity: Preventing and Managing the Global Epidemic. Report of a WHO Consultation, 2000. WHO Technical Report Series 894.

29. F.M. Franssen, E.P. Rutten, M.T. Groenen, L.E. Vanfleteren, E.F. Wouters, M.A. Spruit, New reference values for body composition by bioelectrical impedance analysis in the general population: results from the UK Biobank, J. Am. Med. Dir. Assoc. 15 (6) (2014) 448, 441-446.

30. A.L. Kruis, N. Smidt, W.J. Assendelft, J. Gussekloo, M.R. Boland, M. Rutten-van Molken, N.H. Chavannes, Integrated disease management interventions for patients with chronic obstructive pulmonary disease, Cochrane Database Syst. Rev. 10 (2013) CD009437.

31. D. Price, D. West, G. Brusselle, K. Gruffydd-Jones, R. Jones, M. Miravitlles, A. Rossi, C. Hutton, V.L. Ashton, R. Stewart, K. Bichel, Management of COPD in the UK primary-care setting: an analysis of real-life prescribing patterns, Int. J. Chron. Obstruct Pulmon Dis. 9 (2014) 889-904.

32. I.J.M. Smeele, C. Van Weel, C.P. Van Schayck, T. Van der Molen, B. Thoonen, T. Schermer, A.P.E. Sachs, J.W.M. Muris, N.H. Chavannes, B.G.M. Kolnaar, M.H. Grol, RMM G. NHG-Standaard COPD, Huisarts Wet. 50 (8) (2007).

33. M. van Noordt, J. van der Zee, P.P. Groenewegen, Regional variation in hospital admission rates in The Netherlands, Belgium, northern France, NordrheinWestfalen, Gesundheitswesen 54 (4) (1992) 173-178.

34. G.P. Westert, F.G. Schellevis, D.H. de Bakker, P.P. Groenewegen, J.M. Bensing, J. van der Zee, Monitoring health inequalities through general practice: the second dutch national survey of general practice, Eur. J. public health 15 (1) (2005) 59-65.

35. J.W. Dodd, L. Hogg, J. Nolan, H. Jefford, A. Grant, V.M. Lord, C. Falzon, R. Garrod, C. Lee, M.I. Polkey, P.W. Jones, W.D. Man, N.S. Hopkinson, The COPD assessment test (CAT): response to pulmonary rehabilitation. A multicentre, prospective study, Thorax 66 (5) (2011) 425-429.

36. S.S. Kon, J.L. Canavan, S.E. Jones, C.M. Nolan, A.L. Clark, M.J. Dickson, B.M. Haselden, M.I. Polkey, W.D. Man, Minimum clinically important difference for the COPD assessment test: a prospective analysis, Lancet Respir. Med. 2 (3) (2014) 195-203.

37. M.I. Pumar, C.R. Gray, J.R. Walsh, I.A. Yang, T.A. Rolls, D.L. Ward, Anxiety and depression-Important psychological comorbidities of COPD, J. Thorac. Dis. 6 (11) (2014) 1615-1631.

38. F.J. Triest, F.M. Franssen, M.A. Spruit, M.T. Groenen, E.F. Wouters, L.E. Vanfleteren, Poor agreement between chart-based and objectively identified comorbidities of COPD, Eur. Respir. J. 46 (5) (2015) 1492-1495.

39. R.M. Geijer, M.K. Tuut, J.C. in't Veen, B.D. Broekhuizen, N.H. Chavannes, I.J. Smeele, The NHG guidelines 'adult asthma' and 'COPD', Ned. Tijdschr. Geneeskd. 159 (2015) A9076.

40. M.A. Spruit, I.M. Augustin, L.E. Vanfleteren, D.J. Janssen, S. Gaffron, H.J. Pennings, F. Smeenk, W. Pieters, J.J. van den Bergh, A.J. Michels, M.T. Groenen, E.P. Rutten, E.F. Wouters, F.M. Franssen, Differential response to pulmonary rehabilitation in COPD: multidimensional profiling, Eur. Respir. J. 46 (6) (2015) 1625-1635. 
41. L. Nici, R. ZuWallack, Pulmonary rehabilitation for patients with chronic airways obstruction, J. Allergy Clin. Immunol. Pract. 3 (4) (2015) 512-518.

42. J.M. Cramm, A.P. Nieboer, The chronic care model: congruency and predictors among patients with cardiovascular diseases and chronic obstructive pulmonary disease in The Netherlands, BMC Health Serv. Res. 12 (2012) 242.

43. C. Lenfant, Shattuck lectureeclinical research to clinical practiceelost in translation? N. Engl. J. Med. 349 (9) (2003) 868-874.

44. G. Norris, Risk sharing strategies for disease management programs, Dis. Manag. 6 (3) (2003) 139-141.

45. S.G. Adams, P.K. Smith, P.F. Allan, A. Anzueto, J.A. Pugh, J.E. Cornell, Systematic review of the chronic care model in chronic obstructive pulmonary disease prevention and management, Arch. Intern. Med. 167 (6) (2007) 551-561.

46. E.F. van den Akker, A.J. van 't Hul, N.H. Chavannes, G.J. Braunstahl, A. van Bruggen, M.P. Rutten-van Molken, et al., Development of an integral assessment approach of health status in patients with obstructive airway diseases: the CORONA study, Int. J. chronic Obstr. Pulm. Dis. 10 (2015) 2413-2422.

47. T. van der Molen, M. Miravitlles, J.W. Kocks, COPD management: role of symptom assessment in routine clinical practice, Int. J. Chron. Obstruct Pulmon Dis. 8 (2013) 461-471.

48. G.W. Bisca, A.A. Morita, N.A. Hernandes, V.S. Probst, F. Pitta, Simple lower limb functional tests in patients with chronic obstructive pulmonary disease: a systematic review, Arch. Phys. Med. Rehabil. 96 (12) (2015) 2221-2230.

49. T. Ringbaek, G. Martinez, P. Lange, Comparison of the assessment of quality of life with CAT, CCQ, and SGRQ in COPD patients participating in pulmonary rehabilitation, COPD 9 (1) (2012) 12-15.

50. A. Agusti, P.M. Calverley, B. Celli, H.O. Coxson, L.D. Edwards, D.A. Lomas, W. MacNee, B.E. Miller, S. Rennard, E.K. Silverman, R. Tal-Singer, E. Wouters, J.C. Yates, J. Vestbo, Characterisation of COPD heterogeneity in the ECLIPSE cohort, Respir. Res. 11 (2010) 122.

51. W.A. Altenburg, N.H. ten Hacken, L. Bossenbroek, H.A. Kerstjens, M.H. de Greef, J.B. Wempe, Short- and long-term effects of a physical activity counselling programme in COPD: a randomized controlled trial, Respir. Med. 109 (1) (2015) 112-121.

52. A. Worth, H. Pinnock, M. Fletcher, G. Hoskins, M.L. Levy, A. Sheikh, Systems for the management of respiratory disease in primary care-an international series: United Kingdom, Prim. care Respir. J. J. General Pract. Airw. Group 20 (1) (2011) 23-32.

53. M.K. Han, C.H. Martinez, D.H. Au, J. Bourbeau, C.M. Boyd, R. Branson, et al., Meeting the challenge of COPD care delivery in the USA: a multiprovider perspective, Lancet Respir. Med. (2016), http://dx.doi.org/10.1016/S2213-2600(16)00094-1. Published online ahead of print.

Reproduced with permission from Respiratory Medicine: Smid DE, Spruit MA, Houben-Wilke S, Muris JW, Rohde GG, Wouters EF, et al. Burden of COPD in patients treated in different care settings in the Netherlands. Respiratory medicine. 2016;118:76-83. (doi: 10.1016/j.rmed.2016.07.015) 


\section{SUPPLEMENTARY MATERIAL}

\section{Figure legends}

Figure A.1. Distribution of patients treated in the various healthcare settings

Abbreviations: $\mathrm{FEV}_{1}$, forced expiratory volume in the first second; mMRC, modified Medical Research Council scale; CCI, Charlson Comorbidity Index; CDS, Care Dependence Scale; TUG, Timed 'Up and Go' test; HADS-A, Hospital Anxiety and Depression Scale, Anxiety subscale; HADS-D, Hospital Anxiety and Depression Scale, Depression subscale. CAT, COPD Assessment Test; CCQ, Clinical COPD Questionnaire; SGRQ, St. George Respiratory Questionnaire score.

Figure A.2. Boxplots of patients treated in the various healthcare settings

Abbreviations: $\mathrm{FEV}_{1}$, forced expiratory volume in the first second; mMRC, modified Medical Research Council scale; CCI, Charlson Comorbidity Index; CDS, Care Dependence Scale; TUG, Timed 'Up and Go' test; HADS-A, Hospital Anxiety and Depression Scale, Anxiety subscale; HADS-D, Hospital Anxiety and Depression Scale, Depression subscale. CAT, COPD Assessment Test; CCQ, Clinical COPD Questionnaire; SGRQ, St. George Respiratory Questionnaire score. 

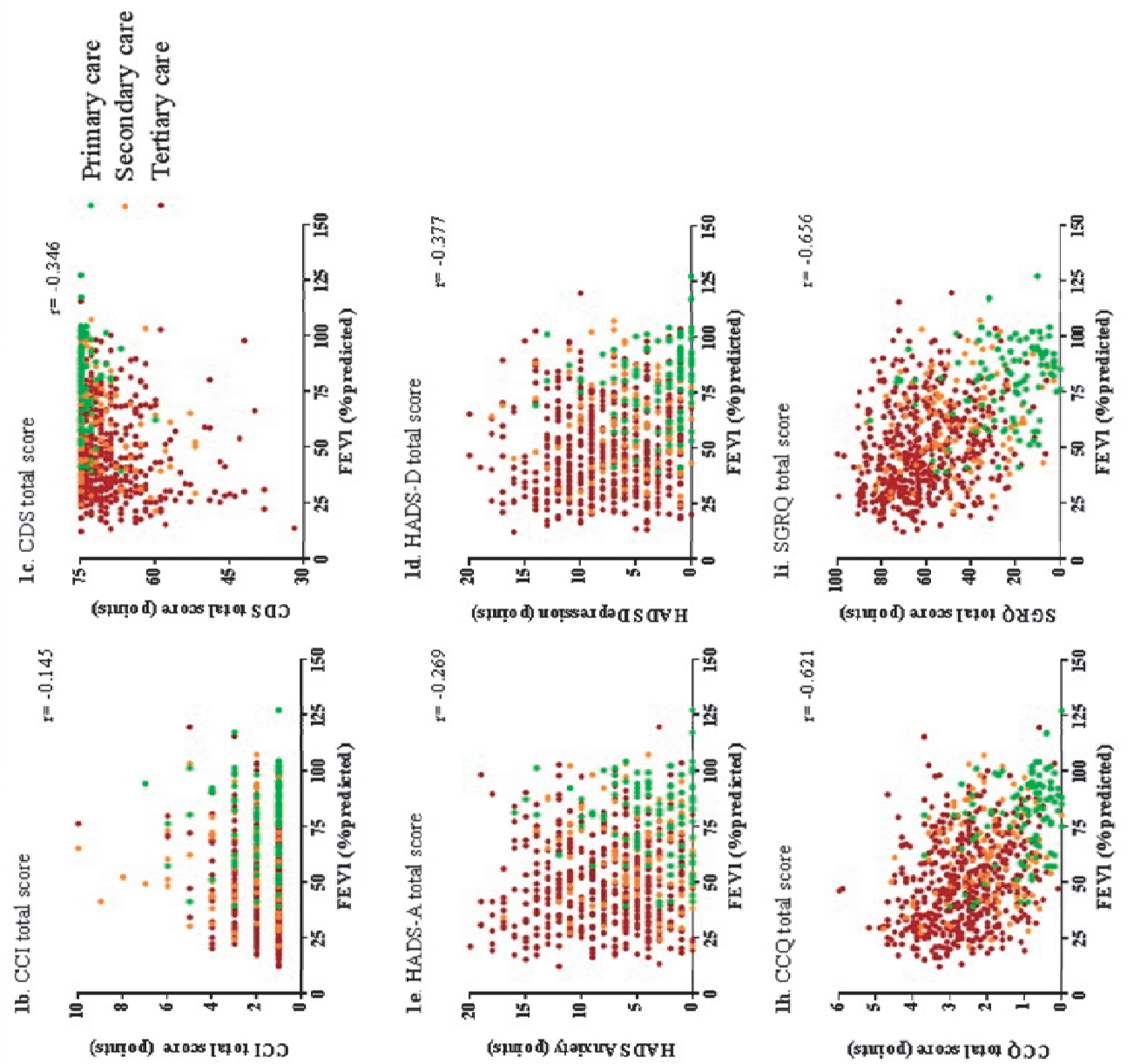

D0
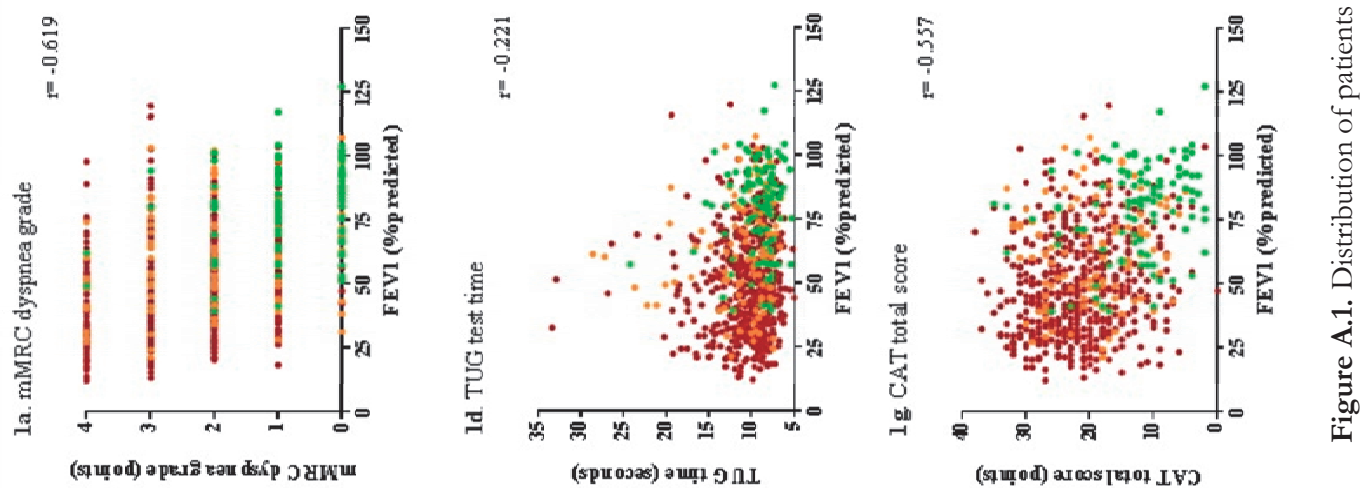

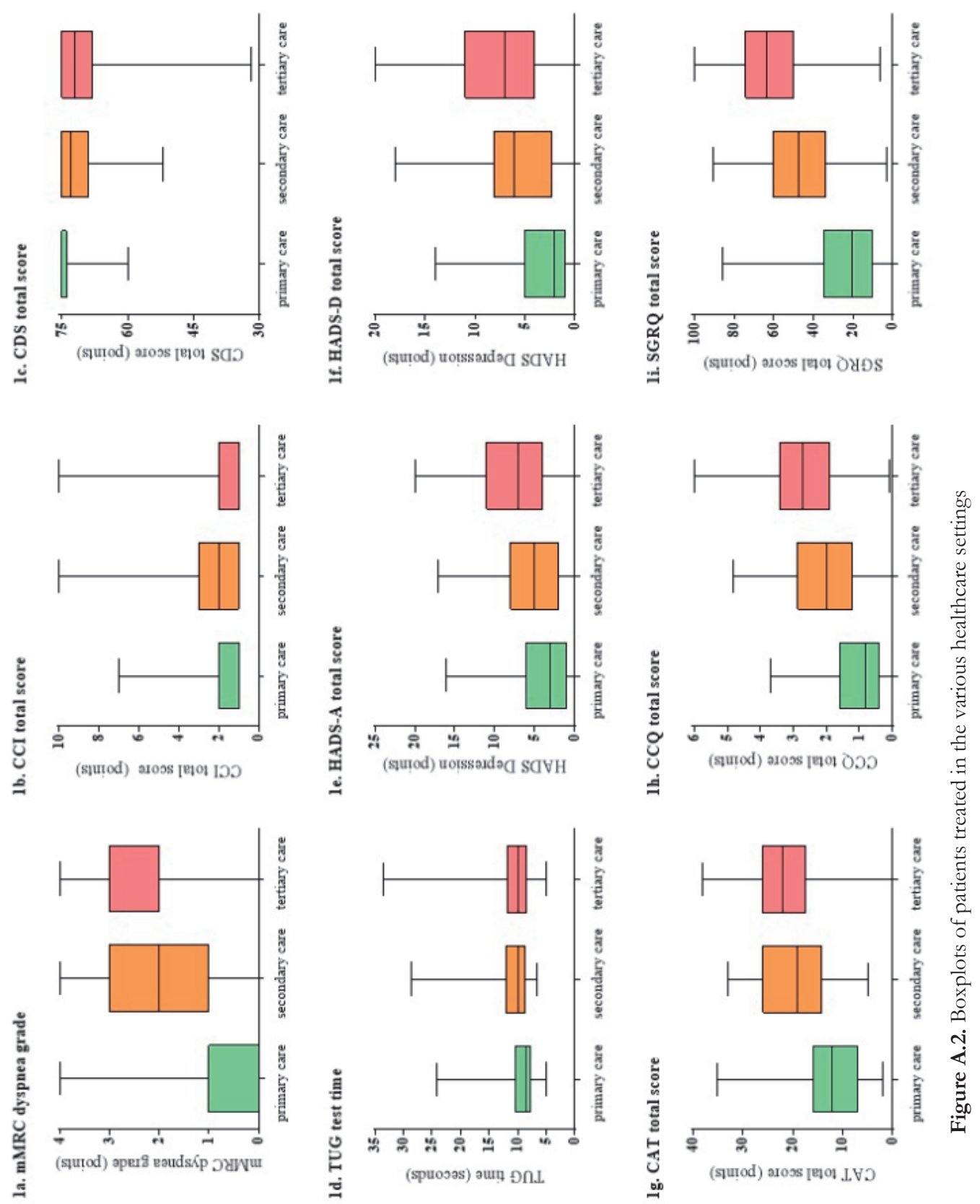



\section{Chapter 6}

Responsiveness and MCID estimates for
CAT, CCQ, and HADS in patients with COPD undergoing pulmonary rehabilitation: a prospective analysis

Dionne E. Smid, Frits M.E. Franssen, Sarah Houben-Wilke, Lowie E.G.W. Vanfleteren, Daisy J.A. Janssen, Emiel F.M. Wouters, and Martijn A. Spruit 


\section{ABSTRACT}

Objectives Pulmonary rehabilitation enhances health status and mood status in patients with chronic obstructive pulmonary disease (COPD). The aim was to determine the responsiveness of St. George's Respiratory Questionnaire (SGRQ), COPD Assessment Test (CAT), COPD Clinical Questionnaire (CCQ), and Hospital Anxiety and Depression Scale (HADS) to pulmonary rehabilitation in patients with COPD, and estimate minimum clinically important differences (MCIDs) for CAT, CCQ, and HADS.

Design A prospective analysis. MCIDs were estimated with anchor-based (anchor: SGRQ) and distribution-based methods. Newly estimated MCIDs were compared to known MCID estimates from a systematic literature search.

Setting Newly estimated MCIDs were calculated in patients treated in pulmonary rehabilitation.

Participants A subsample of 419 individuals with COPD (55.4\% male, mean age $64.3 \pm 8.8$ years) were included from the Chance study.

Measurements Health status was measured with SGRQ, CAT, and CCQ, before and after pulmonary rehabilitation. Mood status was assessed using HADS.

Results 419 patients with COPD (forced expiratory volume in the first second $37.3 \% \pm 12.1 \%$ predicted) completed pulmonary rehabilitation. SGRQ $(-9.1 \pm 14.0$ points $)$, CAT $(-3.0 \pm 6.8$ points $)$, CCQ $(-0.6 \pm 0.9$ points $)$, HADSAnxiety (-1.7 \pm 3.7 points), and HADS-Depression $(-2.1 \pm 3.7$ points $)$ improved significantly. New MCIDs were estimated for CAT (range: -3.8 to -1.0 points), CCQ (range: -0.8 to -0.2 points), HADS-Anxiety (range: -2.0 to -1.1 points), and HADS-Depression (range: -1.8 to -1.4 points).

Conclusions The SGRQ, CAT, CCQ, and HADS are responsive to pulmonary rehabilitation in patients with COPD. We propose MCID estimates ranging between -3.0 and -2.0 points for CAT; -0.5 and -0.3 points for CCQ, -1.8 and -1.3 points for HADS-Anxiety, and -1.7 and -1.5 points for HADS-Depression. 


\section{INTRODUCTION}

Patients with chronic obstructive pulmonary disease (COPD) have an impaired health status and more symptoms of anxiety and depression compared to healthy peers (1), both negatively affecting prognosis and healthcare utilization $(2,3)$.

Pulmonary rehabilitation is the best available means to improve health status and mood status in patients with COPD who are symptomatic despite otherwise optimal therapy at the start of the program (4). Changes in health status and mood status are assessed using questionnaires $(5,6)$, such as the St. George's Respiratory Questionnaire (SGRQ), the COPD Assessment Test (CAT), the COPD Clinical Questionnaire (CCQ), and the Hospital Anxiety and Depression Scale (HADS).

The minimal clinically important difference (MCID) is defined as the smallest difference in a measurable clinical parameter that indicates a meaningful change in the condition for better or for worse, as perceived by the patient, clinician, or investigator (7). An MCID can be used to assess the efficacy of specific therapies (8), to assist in interpreting statistical significant results (9), and to perform a sample size calculation (10). In addition, recent research showed that clinically relevant changes in health status are able to estimate the likelihood of hospital-free survival (11). Anchor- and distribution-based approaches can both be used for MCID estimation $(9,12)$.

In patients with COPD, MCIDs for SGRQ, CAT, CCQ, and HADS have been estimated following pulmonary rehabilitation (13-19), after a COPD exacerbation (16-20), or after an observational period with "usual care" $(5,16)$. One study used distribution-based methods (5), 2 studies applied anchor-based methods $(14,15)$, and 5 studies used both methods (13,16-20). The methods used to estimate the MCID, study context, and/or studied population can partially explain the observed variance in MCID estimates $(21,22)$. Therefore, multiple studies are necessary. This study aimed 1) to determine the responsiveness of SGRQ, CAT, CCQ, and HADS following a comprehensive pulmonary rehabilitation program in patients with COPD and 2) to estimate MCIDs for CAT, CCQ, and HADS using anchor-based and distribution-based methods, and comparing the newly estimated MCIDs with known MCID estimates from previous studies. 


\section{METHODS}

The current study is part of the Chance study [Medical Ethical Committee of the Maastricht University Medical Centre, the Netherlands (METC 11-3-070); Netherlands National Trial Register (NTR 3416)] (23).

\section{Study Population}

Patients were recruited between April 2012 and September 2014. Patients with mild to very severe COPD referred for a pulmonary rehabilitation program in the CIRO Rehabilitation Network were recruited during their routine prerehabilitation assessment at CIRO in Horn, the Netherlands. They had to be between the ages of 40 and 85 years and have a diagnosis of COPD according to GOLD guidelines. Extended information (e.g., inclusion and exclusion criteria, sample size calculation) of the Chance study has previously been published (23). All patients gave written informed consent prior to inclusion in the study.

\section{Intervention}

CIRO provides a state-of-the-art interdisciplinary pulmonary rehabilitation program for patients with COPD. The program consists of educational sessions, psychosocial counseling, supervised physical exercise training, nutritional counseling, occupational therapy, and COPD exacerbation management (8), in line with the 2013 American Thoracic Society/European Respiratory Society (ATS/ERS) Statement (4). Pulmonary rehabilitation took place inpatient (8 weeks, 5 sessions per week; total of 40 sessions) or outpatient ( 8 weeks, 3 sessions per week, followed by 8 weeks, 2 sessions per week; total 40 sessions), as described before (8). During the pre- and post-rehabilitation assessments, a careful characterization of patients with COPD was performed (8).

\section{Measurements}

Demographics, body mass index, body composition (fat-free mass index), smoking history, oxygen saturation at rest, and degree of dyspnea (modified Medical Research Council) were assessed before and after rehabilitation. Spirometry [forced expiratory volume in the first second $\left(\mathrm{FEV}_{1}\right)$ and forced vital capacity $\left.(\mathrm{FVC})\right]$ was performed with standardized spirometer equipment of Masterlab (24), 15 minutes after inhalation of $200 \mathrm{mg}$ salbutamol. COPD was defined as postbronchodilator $\mathrm{FEV}_{1} / \mathrm{FVC}$ smaller than 0.7 , in which patients were divided in GOLD stages; grade 1, mild ( $\mathrm{FEV}_{1} \geq 80 \%$ ); grade 2, moderate (FEV $150 \%$-79\%); grade 3, severe $\left(\mathrm{FEV}_{1} 30 \%-49 \%\right)$; and grade 4, very severe $\left(\mathrm{FEV}_{1}<30 \%\right)$. Health status was assessed with the Dutch version of the COPD-specific SGRQ (range: 0-100 
points), CAT (range: $0-40$ points), and CCQ (range: $0-6$ points). Mood status was assessed with the HADS (range: 0-21 points) (6). A decrease in points is equivalent to an improved health status and/or reduction in symptoms of anxiety or depression, respectively. Additionally, functional exercise performance was assessed with the 6-minute walking distance (6MWD) test according to ATS/ERS standard (25), including 2 tests at baseline.

\section{Statistics}

Results are presented as mean and standard deviation (SD), median and interquartile range, and/or proportions, as appropriate. Continuous variables were tested for normality. Differences following pulmonary rehabilitation were assessed using chi-square tests, dependent sample t tests, McNemar test, or Mann-Whitney $\mathrm{U}$ tests, as appropriate. Pearson product-moment correlations were calculated between changes in outcomes measures. Only data from participants who completed pulmonary rehabilitation were included in the analysis. To estimate effect size, a Cohen $\mathrm{d}$ was calculated using the mean difference and SD before and after pulmonary rehabilitation.

As it is recommended to use a triangulation to measure MCID (9), both anchorbased and distribution-based methods were used. The change in SGRQ total score was used as anchor. To decide whether a variable could be compared to the anchor, the correlation coefficient had to be at least 0.3 (9). Subsequently, a linear regression and receiver operating characteristic (ROC) curves analysis, including the area under the curve and Mann-Whitney-Wilcoxon test, were performed. In the linear regression analysis CAT, CCQ, and HADS were used as dependent variables and the anchor (change in SGRQ total score of -4.0 points) was used as the independent variable (26). The change in CAT, CCQ, and HADS score cutoffs that best discriminated between patients who improved their health status by the anchor and those who did not was defined as the MCID. To determine the MCID with the distribution-based approach, at first one-half SD was calculated. Then, the standard error of measurement (SEM) was calculated using the equation

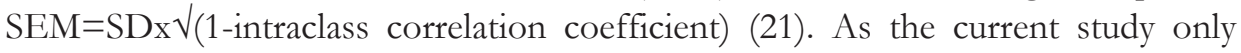
measured the CAT, CCQ, and HADS once, the intraclass correlation coefficient was derived from the former literature [CAT, 0.80; CCQ, 0.94; HADS-Anxiety (HADS-A), 0.78; and HADS-Depression (HADS-D), 0.86] (27-29). To estimate the MCID of the current study, the mean of all MCID estimates was calculated. New MCID estimates and known estimated MCIDs were compared, to verify known MCID estimates or to suggest a new MCID value or range. A posteriori, an MCID value or range was determined by calculating the mean [ $95 \%$ confidence 


\section{Chapter 6}

interval (CI)] of all known and new MCID estimates. A p-value $\leq 0.01$ was considered statistically significant. All statistics were done using SPSS V.20.0.

\section{RESULTS}

A total of 518 patients volunteered to participate and attended the prerehabilitation assessment, of whom 99 (19.1\%) did not complete the pulmonary rehabilitation program (see Figure A1). Differences between completers and noncompleters are presented in Table A1.

\section{Before and after rehabilitation}

Changes following pulmonary rehabilitation were analyzed in 419 patients with COPD (55.4\% male): 32 GOLD 1; 152 GOLD 2; 148 GOLD 3; and 87 GOLD 4. Demographics are presented in Table 1. Patients were on average overweight, had a poor health status, and had an impaired functional exercise performance. Fat-free mass index, the degree of dyspnea, and functional exercise performance improved significantly following pulmonary rehabilitation compared to baseline (all p <0.01). Moreover, patients had a significantly better health status and mood status postrehabilitation (both $\mathrm{p}<0.01$; Table 2). The SGRQ, CAT, CCQ, and HADS had a small to moderate effect size $(\mathrm{d}=0.45-0.62$; Table 2$)$.

Table 1. Demographics of the patients who completed pulmonary rehabilitation

\begin{tabular}{ll}
\hline General characteristics & \\
\hline Number (n) & 419 \\
Gender, male (\%) & $232(55.4)$ \\
Age, years & $64.3(8.8)$ \\
Level of education, n (\%) & \\
- Intermediate vocational education or lower, n & $349(86.2)$ \\
- Secondary general education or higher, n & $56(13.8)$ \\
Current smoker, n (\%) & $79(18.9)$ \\
Pack years, n & $40.0(30.0-50.0)$ \\
LTOT, n (\%) & $104(24.8)$ \\
Inpatient/outpatient rehabilitation, $\%$ & $62.5 / 37.5$ \\
\hline
\end{tabular}

Summary variables are presented as $\mathrm{n}(\%)$ for discrete variables, mean \pm SD for quantitative variables or median (IQR) for skewed variables, ${ }^{*}=14$ missing.

Abbreviations: LTOT, Long Term Oxygen Therapy 
Table 2. Patient characteristics pre- and post-pulmonary rehabilitation.

\begin{tabular}{|c|c|c|c|c|c|}
\hline & $\begin{array}{l}\text { Pre- } \\
\text { rehabilitation }\end{array}$ & $\begin{array}{l}\text { Post- } \\
\text { rehabilitation }\end{array}$ & $\begin{array}{l}\text { Mean } \\
\text { change }\end{array}$ & $\begin{array}{l}\text { Cohen's } \\
d\end{array}$ & $\begin{array}{l}\mathrm{P} \text { - } \\
\text { value }\end{array}$ \\
\hline $\mathrm{BMI}, \mathrm{kg} / \mathrm{m}^{2}$ & $26.2(5.7)$ & $26.4(5.4)$ & $0.2(2.3)$ & 0.04 & 0.064 \\
\hline FFMI, $\mathrm{kg} / \mathrm{m}^{2}$ & $17.0(2.4)$ & $17.1(2.3)$ & $0.1(0.9)$ & 0.06 & 0.001 \\
\hline $\mathrm{FEV}_{1}(\%$ pred $)$ & $48.9(20.0)$ & $48.3(19.9)$ & $-0.5(7.5)$ & -0.02 & 0.160 \\
\hline $\mathrm{FEV}_{1} / \mathrm{FVC}(\%)$ & $37.3(12.1)$ & $37.0(12.1)$ & $-0.3(1.1)$ & -0.04 & 0.123 \\
\hline Oxygen saturation in rest $(\%)$ & $94.0(93.0-96.0)$ & $95.0(93.0-96.0)$ & $0.4(2.3)$ & 0.19 & $<0.001$ \\
\hline mMRC grade $\geq 2, \mathrm{n}(\%)$ & $334(80.7)$ & $200(69.9)$ & $-0.3(1.1)$ & -0.38 & $<0.001$ \\
\hline SGRQ-C total score, points & $60.1(17.1)$ & $50.9(17.4)$ & $-9.1(14.0)$ & -0.58 & $<0.001$ \\
\hline CAT total score, points & $21.5(6.6)$ & $18.5(6.9)$ & $-3.0(6.8)$ & -0.45 & $<0.001$ \\
\hline CCQ total score, points & $2.6(1.0)$ & $2.0(1.0)$ & $-0.6(0.9)$ & -0.62 & $<0.001$ \\
\hline HADS-A score, points & $7.5(4.4)$ & $5.8(4.2)$ & $-1.7(3.7)$ & -0.45 & $<0.001$ \\
\hline HADS-D score, points & $7.4(4.2)$ & $5.3(3.9)$ & $-2.1(3.7)$ & -0.54 & $<0.001$ \\
\hline 6MWD, meters & $424.0(124.4)$ & $457.4(122.1)$ & $22.9(66.8)$ & 0.27 & $<0.001$ \\
\hline
\end{tabular}

Summary variables are presented as $\mathrm{n}(\%)$ for discrete variables, mean \pm SD for quantitative variables or median $(\mathrm{IQR})$ for skewed variables, ${ }^{*}=5$ missing values.

Abbreviations: $\mathrm{FEV}_{1}$, forced expiratory volume in the first second; FVC, forced vital capacity; BMI, body mass index; FFMI, Fat Free Mass Index; mMRC, modified Medical Research Council scale; CAT, COPD Assessment Test; CCQ, Clinical COPD Questionnaire; SGRQ-C, COPD specific St. George Respiratory Questionnaire score; HADS-A, Hospital Anxiety and Depression Scale, Anxiety subscale; HADS-D, Hospital Anxiety and Depression Scale, Depression subscale.

\section{MCID Estimation for CAT}

The CAT MCID, measured with ROC curve, was established on -3.5 points (Figure A2-A). With linear regression analysis, the CAT MCID was estimated on -1.7 points $(\mathrm{r}=0.555$, Figure 1A). When applying the distribution-based method, the estimate for significant improvement in CAT total score using 0.5.SD was -3.4 points and using SEM was -2.9 points. This resulted in a mean estimated MCID of -2.9 points (range: -3.5 to -1.7 points).

\section{MCID Estimation for CCQ}

The estimated CCQ MCID for the ROC curve (Figure A2-B) as well as linear regression was -0.4 points $(r=0.605$, Figure $1 \mathrm{~B})$. With distribution-based methods, the estimate for significant improvement in CCQ total score was -0.5 points (based on $0.5 \cdot \mathrm{SD}$ ) and -0.2 (based on SEM), resulting in a mean estimated MCID of -0.4 points (range: -0.5 to -0.2 points). 


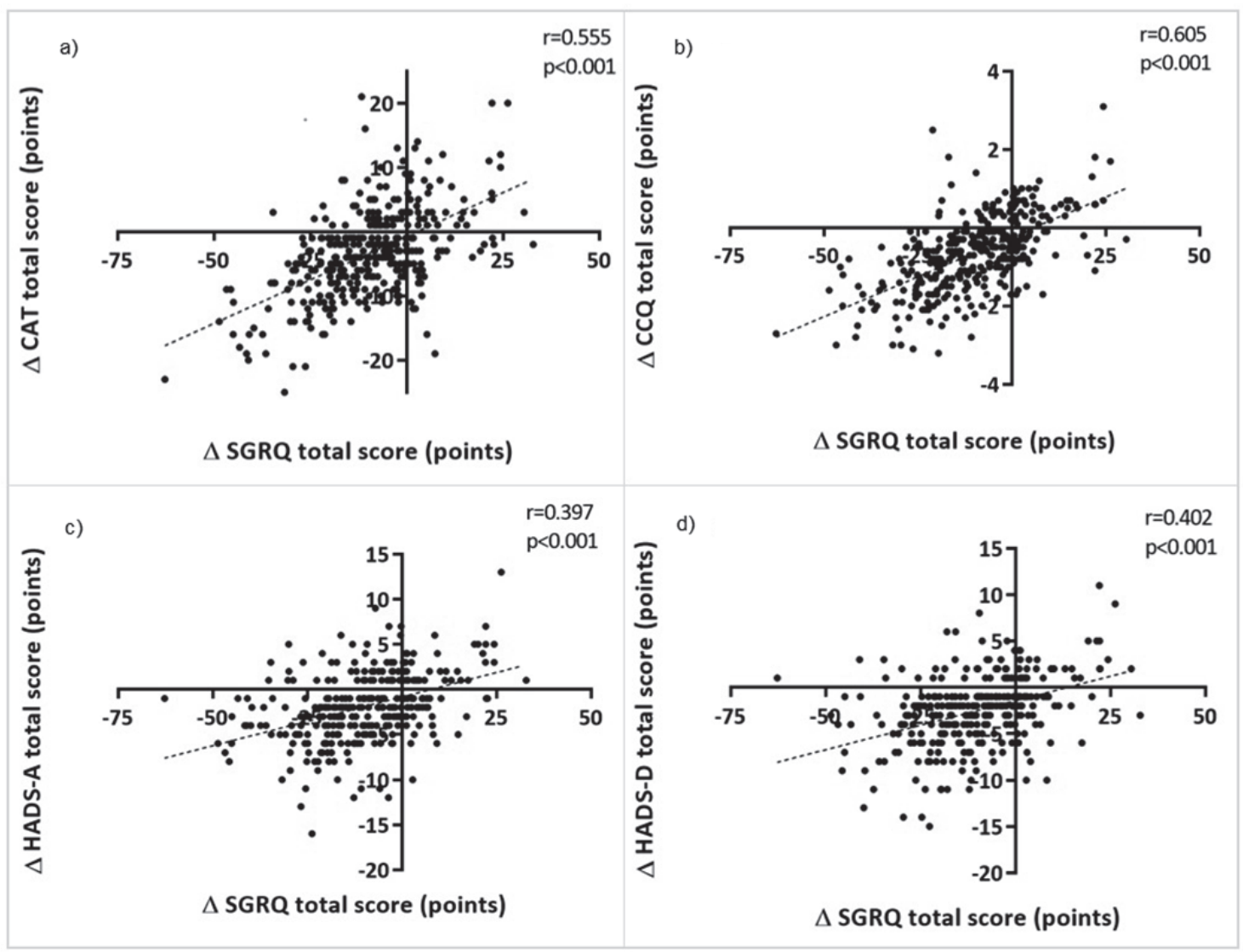

Figure 1. Association between the changes in CAT score (A), CCQ score (B), HADS-A score (C), HADS-D score (D), and the change in SGRQ score. CAT, COPD Assessment Test; CCQ, Clinical COPD Questionnaire; SGRQ, St. George Respiratory Questionnaire; HADS-A, Hospital Anxiety and Depression Scale, Anxiety subscale; and HADS-D, Hospital Anxiety and Depression Scale, Depression subscale.

\section{MCID Estimation for HADS-A}

The HADS-A MCID, measured with the ROC curve, was established at -1.5 points (Figure A2-C). The MCID, measured with linear regression, was estimated at -1.1 points ( $r=0.397$, Figure $1 \mathrm{C})$. The estimate for significant improvement with $0.5 \cdot \mathrm{SD}$ resulted in an MCID of -1.8 points, and based on the SEM equation, in -2.0 points. This indicates a mean estimated MCID of -1.6 points (range: -2.0 to -1.1 points).

MCID Estimation for HADS-D

The HADS-D MCID based on ROC curve was observed on -1.5 points (Figure A2-D) and based on linear regression, -1.6 points $(r=0.402$, Figure $1 D)$. With the 
0.5.SD distribution-based method, -1.8 points was observed as the MCID. The SEM distribution-based method estimated the HADS MCID at -1.6 points. Thus, the mean estimated MCID was -1.6 points (range: -1.8 to -1.5 points).

\section{Summary of current and existing MCID estimates}

We performed a systematic computerized search to identify all studies performed on MCID estimation of the CAT, CCQ, and HADS in patients with COPD (see Table A2). Known CAT MCIDs ranged from -3.8 to -1.0 points; CCQ ranged from -0.8 to -0.2 points; and HADS-A/D ranged from -1.7 to -1.3 points (Figure 2). Based on the known MCIDs and newly estimated MCIDs, the 95\% CI was calculated for each questionnaire, giving anchor-based MCIDs an equal or higher weight than the distribution-based MCIDs (see Table A3). This resulted in a CAT MCID ranging between -3.0 and -2.0 points (mean: -2.5 points); for CCQ ranging between -0.5 and -0.3 points (mean: -0.4 points); for HADS-A ranging from -1.8 to -1.3 points (mean: -1.6 points); and for HADS-D ranging between -1.7 and -1.5 points (mean: -1.6 points).

\section{DISCUSSION}

The present study confirmed that SGRQ, CAT, CCQ, and HADS are responsive to pulmonary rehabilitation in patients with mild to very severe COPD. The MCID for CAT (as derived from the original data) ranged between -3.5 and -1.7 points (mean MCID: -2.9 points), for CCQ between -0.5 and -0.2 points (mean MCID: -0.4 points), for HADS-A between -2.0 and -1.1 points (mean MCID: -1.6 points), and for HADS-D between -1.8 and -1.5 points (mean MCID: -1.6 points). Based on the known MCID estimates from the literature and the new MCID estimates, we propose that the estimated CAT MCID ranges between -3.0 and -2.0 points. Moreover, we propose an MCID range of -0.5 to -0.3 points for CCQ, -1.8 to -1.3 points for HADS-A, and -1.7 to -1.5 points for HADS-D.

\section{Responsiveness}

The responsiveness of the SGRQ, CAT, CCQ, and HADS ( $d=-0.45$ to -0.62 ) to pulmonary rehabilitation is comparable with previous research, indicating an effect size of -0.33 to -0.37 for the SGRQ, -0.19 to -0.40 for the CAT, and -0.39 to -0.43 for the CCQ $(14,15,17,18)$. 

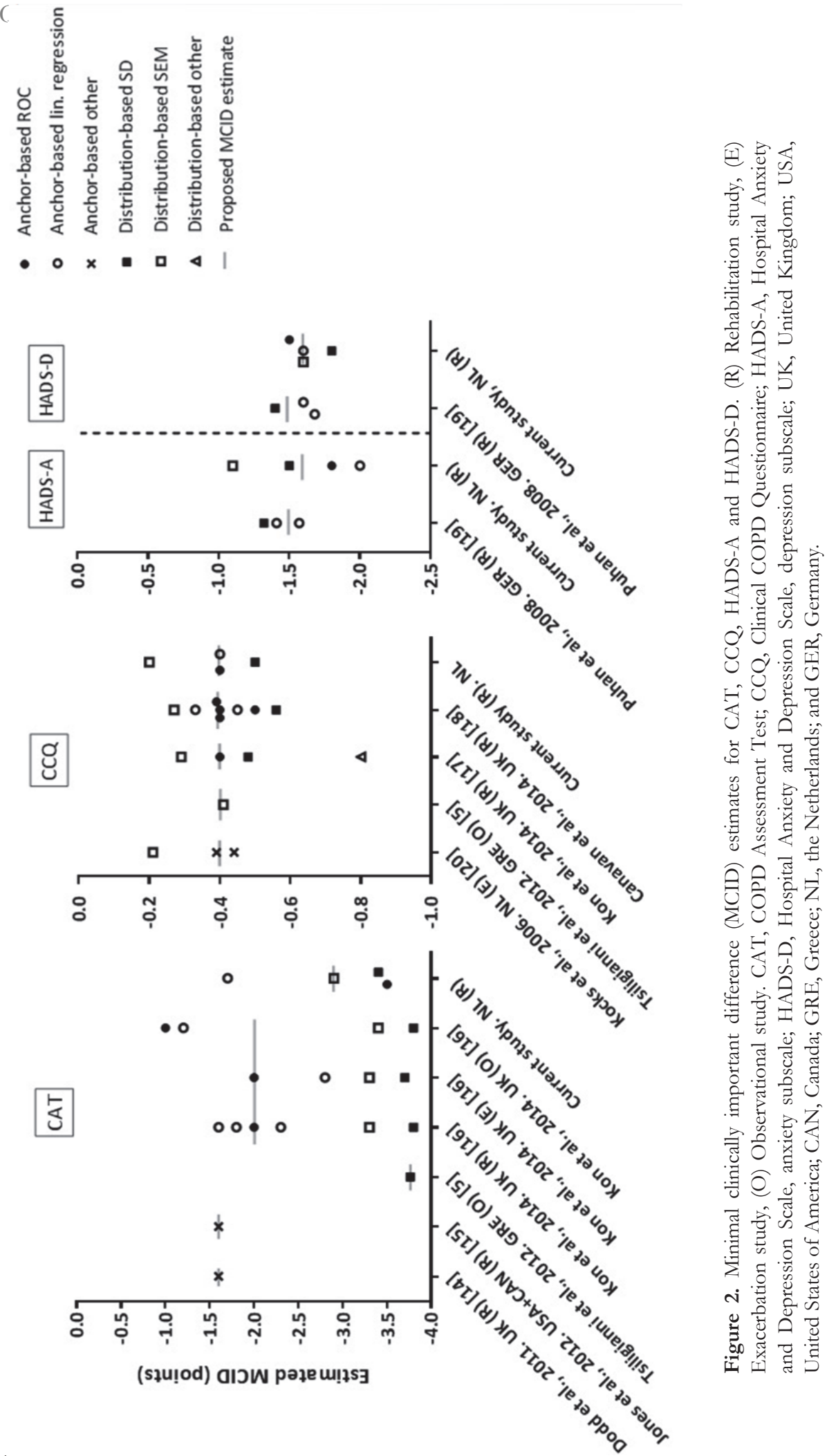


\section{MCID Estimate}

The current mean CCQ MCID estimate (-0.4 points) is identical to those estimated by Kon and colleagues ( $n=261 ;-0.4$ points), Canavan and colleagues ( $n=138 ;-0.4$ points), Kocks and colleagues ( $\mathrm{n}=168 ;-0.4$ points), and Tsiligianni and colleagues $(\mathrm{n}=90 ;-0.4$ points) $(5,17,18,20)$. Also, the current mean HADS-A/D MCID estimates (both -1.6 points) are very similar to those reported by Puhan and colleagues ( $n=88 ;-1.5$ points) (19). So, it seems reasonable to conclude that a change of -0.4 points in CCQ and a change of -1.5 points in HADS-A/D can be defined as clinically relevant. Indeed, the $95 \%$ CI of all available CCQ and HADSA/D MCIDs is rather small (Table A3).

The mean CAT MCID estimate of the current study (-2.9 points) is larger than the MCID estimated by Dodd and colleagues ( $\mathrm{n}=261,-1.6$ points), Jones and colleagues ( $\mathrm{n}=131,-1.6$ points), and Kon and colleagues ( $\mathrm{n}=876,-2.0$ points) (1416). Previous studies indicate that the MCID estimate could be influenced by the type of intervention (e.g., pulmonary rehabilitation, follow-up after exacerbation, or a usual care observational period) (21,30). Even though MCID estimation was done following 6-8 weeks of pulmonary rehabilitation, the program of the current study was more extensive than the program applied in previous studies (14-16). Indeed, the response of the SGRQ, CAT, CCQ, and HADS to pulmonary rehabilitation in the current study was larger than in previously reported studies $(31,32)$. This could explain why MCID estimates of previous studies were smaller than that of the current study. Additionally, it is shown that baseline severity may influence the MCID estimate because of regression to the mean, floor and ceiling effects, and more room for improvement in patients with a worse baseline value (33). Nevertheless, baseline CAT scores of previous studies were comparable to the baseline scores of the current study (14-16).

Statistical methods used may explain, at least in part, the differences between MCID estimates. For example, Kon and colleagues reported that the CAT MCID estimate ranged from -1.8 points (anchor-based) to -3.6 points (distribution-based) (16). The distribution based MCID of Kon and colleagues is comparable to the distribution-based CAT MCID estimate of Tsiligianni and colleagues (-3.8 points) and the mean distribution-based CAT MCID estimate of the current study (-3.2 points) (5). This could be explained by methodologic differences, as distributionbased methods are sample specific (derived from sample size and distribution), whereas anchor based methods are derived from the patient's perspective $(12,21)$. Whether and to what extent anchor-based MCIDs should have a different weight than distribution-based MCIDs remains unknown. As anchor-based methods are derived from the patients' perspective (12), anchor-based approach should perhaps 
have a higher weight. However, no previous literature has been published about how to distribute the weight among different measurement methods. Therefore, the mean MCIDs (95\% CI) were calculated with an equal weight for anchor-based and distribution-based MCIDs (1:1), and after increasing the weight for anchorbased MCIDs (i.e., 2:1 and 3:2).

Former studies also indicate that context and population characteristics may influence MCID estimates $(9,34)$. Age, gender and education are strong predictors of health status (35), resulting in a differential change in response to pulmonary rehabilitation and MCID estimate. However, only 2 studies (with comparable MCID estimates) implemented their study in the same country $(14,16)$, and not all studies registered educational level or socioeconomic status. Therefore, we were not able to define the influence of population characteristics on current MCID estimates.

Nonetheless, MCID estimates of the CCQ and HADS-A/D were rather comparable between studies, despite all possible influences (e.g., type of intervention, baseline characteristics, statistical methods, and population characteristics) and limitations of estimating the MCID. This may indicate that the CAT is more sensitive for external influences than CCQ and HADS-A/D, and therefore it is not reliable to determine one single value as the CAT MCID estimate.

\section{Methodological considerations}

It should be taken into account that the AUC for the SGRQ versus the CAT, CCQ, and HADS was below 0.7, which makes us question whether these instruments are able to make a valid distinction between those who improved by at least 4 points on the SGRQ and those who did not. Furthermore, 19\% of the patients did not complete the pulmonary rehabilitation program. However, this is very similar to previous studies $(16,36)$. Non-completers had slightly worse baseline values compared with patients who completed pulmonary rehabilitation. Whether this would have affected current results remains unknown. Third, patients were solely recruited in a pulmonary rehabilitation centre, resulting in a selected group of COPD patients. This should be considered when applying results to other populations. Moreover, Schunemann and colleagues discussed the necessity to achieve a correlation of minimally 0.5 before applying a regression analysis, for example, to prevent a wide range in MCIDs (37). For CAT and CCQ, this value was achieved. Although the correlation between the SGRQ and HADS was found to be between 0.3 and 0.5 , a small range could be estimated. In addition, as the CAT, CCQ, and HADS were only measured once, the intraclass correlation 
coefficient to measure the MCID based on SEM was derived from previous studies. Although we do not expect it to significantly influence the current results, using an intraclass correlation coefficient from the same sample as the SD would have been more reliable. Finally, current results give an estimation of the MCID in CAT, CCQ, and HADS. It should be used as an indicative value, rather than an absolute cut-off point between achieving benefit or not (13).

\section{CONCLUSION}

The present study showed that SGRQ, CAT, CCQ, and HADS are responsive to pulmonary rehabilitation in patients with moderate to very severe COPD. We propose an MCID range for CAT of -3.0 to -2.0 points; for CCQ, -0.5 to -0.3 points; for HADS-A, -1.8 to -1.3 points, and for HADS-D, -1.7 to -1.5 points. 


\section{REFERENCES}

1. Bratek A, Zawada K, Beil-Gawelczyk J, et al. Depressiveness, symptoms of anxiety and cognitive dysfunctions in patients with asthma and chronic obstructive pulmonary disease (COPD): Possible associations with inflammation markers: A pilot study. J Neural Transm 2015;122:S83-S91.

2. Marin JM, Cote CG, Diaz O, et al. Prognostic assessment in COPD: Health related quality of life and the BODE index. Respir Med 2011;105:916-921.

3. Panagioti M, Scott C, Blakemore A, et al. Overview of the prevalence, impact, and management of depression and anxiety in chronic obstructive pulmonary disease. Int J Chron Obstruct Pulmon Dis 2014;9:1289-1306.

4. Spruit MA, Singh SJ, Garvey C, et al. An official American Thoracic Society/European Respiratory Society statement: Key concepts and advances in pulmonary rehabilitation. Am J Respir Crit Care Med 2013;188:e13-e64.

5. Tsiligianni IG, van der Molen T, Moraitaki D, et al. Assessing health status in COPD. A head-to-head comparison between the COPD assessment test (CAT) and the clinical COPD questionnaire (CCQ). BMC Pulm Med 2012;12:20.

6. Zigmond AS, Snaith RP. The hospital anxiety and depression scale. Acta Psychiatr Scand 1983;67:361-370.

7. Kiley JP, Sri Ram J, Croxton TL, et al. Challenges associated with estimating minimal clinically important differences in COPD The NHLBI perspective. COPD 2005;2:43-46.

8. Spruit MA, Augustin IM, Vanfleteren LE, et al. Differential response to pulmonary rehabilitation in COPD: Multidimensional profiling. Eur Respir J 2015;46:1625-1635.

9. Revicki D, Hays RD, Cella D, et al. Recommended methods for determining responsiveness and minimally important differences for patient-reported outcomes. J Clin Epidemiol 2008;61:102-109.

10. Halme AS, Fritel X, Benedetti A, et al. Implications of the minimal clinically important difference for health-related quality-of-life outcomes: A comparison of sample size requirements for an incontinence treatment trial. Value Health 2015;18:292-298.

11. Wilke S, Jones PW, Mullerova $\mathrm{H}$, et al. One-year change in health status and subsequent outcomes in COPD. Thorax 2015;70:420-425.

12. Jones PW, Beeh KM, Chapman KR, et al. Minimal clinically important differences in pharmacological trials. Am J Respir Crit Care Med 2014;189:250-255.

13. Jones PW. St. George's Respiratory Questionnaire: MCID. COPD 2005;2:75-79.

14. Dodd JW, Hogg L, Nolan J, et al. The COPD assessment test (CAT): Response to pulmonary rehabilitation. A multicentre, prospective study. Thorax 2011;66: 425-429.

15. Jones PW, Harding G, Wiklund I, et al. Tests of the responsiveness of the COPD assessment test following acute exacerbation and pulmonary rehabilitation. Chest 2012;142:134-140.

16. Kon SS, Canavan JL, Jones SE, et al. Minimum clinically important difference for the COPD Assessment Test: A prospective analysis. Lancet Respir Med 2014;2: 195-203.

17. Kon SS, Dilaver D, Mittal M, et al. The Clinical COPD Questionnaire: Response to pulmonary rehabilitation and minimal clinically important difference. Thorax 2014;69:793-798. 
18. Canavan JL, Dilaver D, Clark AL, et al. Clinical COPD Questionnaire in patients with chronic respiratory disease. Respirology 2014;19:1006-1012.

19. Puhan MA, Frey M, Buchi S, et al. The minimal important difference of the Hospital Anxiety and Depression Scale in patients with chronic obstructive pulmonary disease. Health Qual Life Outcomes 2008;6:46.

20. Kocks JW, Tuinenga MG, Uil SM, et al. Health status measurement in COPD: The minimal clinically important difference of the clinical COPD questionnaire. Respir Res 2006;7:62.

21. Wright A, Hannon J, Hegedus EJ, et al. Clinimetrics corner: A closer look at the minimal clinically important difference (MCID). JMan Manip Ther 2012;20:160-166.

22. Terwee CB, Roorda LD, Dekker J, et al. Mind the MIC: Large variation among populations and methods. J Clin Epidemiol 2010;63:524-534.

23. Smid DE, Wilke S, Jones PW, et al. Impact of cardiovascular comorbidities on COPD Assessment Test (CAT) and its responsiveness to pulmonary rehabilitation in patients with moderate to very severe COPD: Protocol of the Chance study. BMJ Open 2015;5:e007536.

24. Munnik P, Zanen P, Lammers JW. A comparison of lung function equipment with emphasis on interchangeability and methods. Physiol Meas 2006;27: 445-455.

25. Holland AE, Spruit MA, Troosters T, et al. An official European Respiratory Society/American Thoracic Society technical standard: Field walking tests in chronic respiratory disease. Eur Respir J 2014;44:1428-1446.

26. Brant R, Sutherland L, Hilsden R. Examining the minimum important difference. Stat Med 1999;18:2593-2603.

27. Jones PW, Harding G, Berry P, et al. Development and first validation of the COPD Assessment Test. Eur Respir J 2009;34:648-654.

28. van der Molen T, Willemse BW, Schokker S, et al. Development, validity and responsiveness of the Clinical COPD Questionnaire. Health Qual Life Outcomes 2003;1:13.

29. Reda AA. Reliability and validity of the Ethiopian version of the Hospital Anxiety and Depression Scale (HADS) in HIV infected patients. PloS One 2011; 6:e16049.

30. Pepin V, Laviolette L, Brouillard C, et al. Significance of changes in endurance shuttle walking performance. Thorax 2011;66:115-120.

31. Gupta N, Pinto LM, Morogan A, et al. The COPD assessment test: A systematic review. Eur Respir J 2014;44:873-884.

32. McCarthy B, Casey D, Devane D, et al. Pulmonary rehabilitation for chronic obstructive pulmonary disease. Cochrane Database Syst Rev 2015:CD003793.

33. Copay AG, Subach BR, Glassman SD, et al. Understanding the minimum clinically important difference: A review of concepts and methods. Spine J 2007;7: 541-546.

34. Lauridsen $\mathrm{HH}$, Hartvigsen J, Manniche C, et al. Responsiveness and minimal clinically important difference for pain and disability instruments in low back pain patients. BMC Musculoskelet Disord 2006;7:82.

35. Mroczek B, Sitko Z, Augustyniuk K, et al. Socioeconomic indicators shaping quality of life and illness acceptance in patients with chronic obstructive pulmonary disease. Adv Exp Med Biol 2015;861:19-30. 
36. Bjoernshave B, Korsgaard J, Nielsen CV. Does pulmonary rehabilitation work in clinical practice? A review on selection and dropout in randomized controlled trials on pulmonary rehabilitation. Clin Epidemiol 2010;2:73-83.

37. Schünemann HJ, Griffith L, Jaeschke R, et al. Evaluation of the minimal important difference for the feeling thermometer and the St. George's Respiratory Questionnaire in patients with chronic airflow obstruction. J Clin Epidemiol 2003;56:1170-1176.

Reproduced with permission from JAMDA: Smid DE, Franssen FM, Houben-

Wilke S, Vanfleteren LE, Janssen DJ, Wouters EF, et al. Responsiveness and MCID Estimates for CAT, CCQ, and HADS in Patients with COPD Undergoing Pulmonary Rehabilitation: A Prospective Analysis. Journal of the American Medical Directors Association. 2017; 18(1):53-8 (doi: 10.1016/j.jamda.2016.08.002.) 


\section{SUPPLEMENTARY MATERIAL}

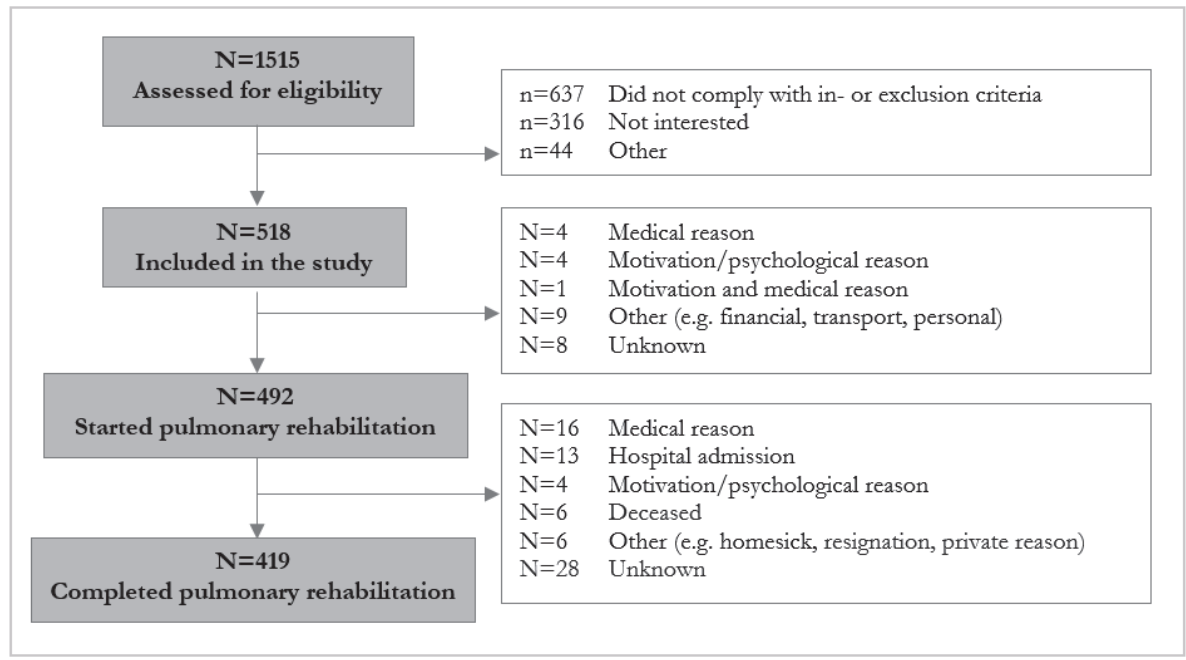

Figure A1. Flow-chart subject participation 
A. $\mathrm{AUC}=0.61$

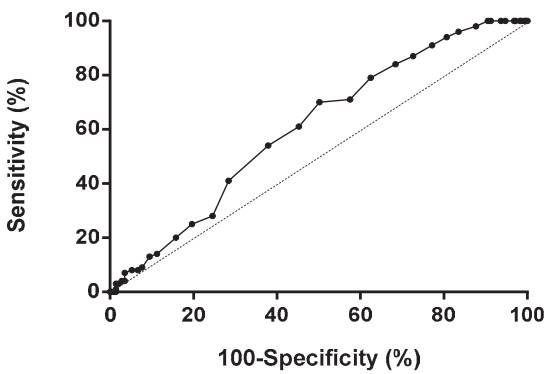

B.

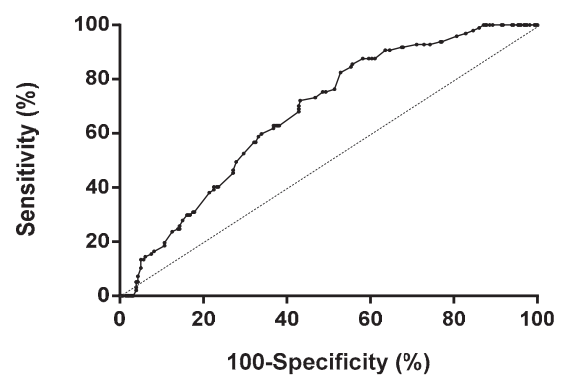

C.

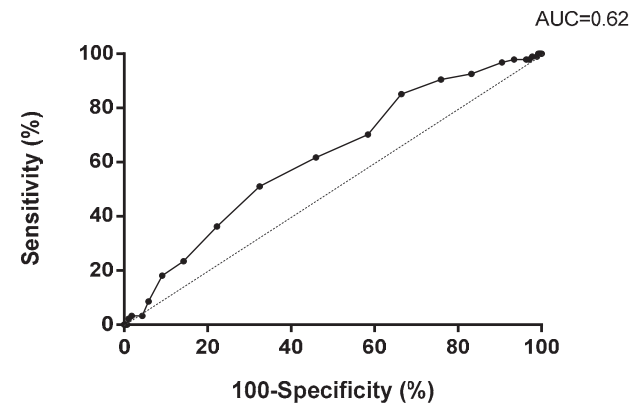

D.

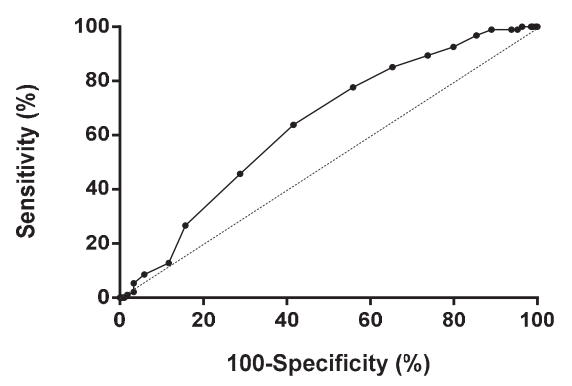

Figure A2. Receiver operator characteristic curves with a change of -4.0 points on the st. George respiratory questionnaire as anchor to estimate the MCID on the CAT (A), CCQ (B), HADS-A (C) and HADS-D (D) AUC $=$ Area under the curve 
Table A1. Baseline characteristics completers versus non-completers of pulmonary rehabilitation.

\begin{tabular}{llll}
\hline & Completers (n=419) & Non-completers (n=99) & P-value \\
\hline Gender, male (\%) & $232(55.4)$ & $56(56.6)$ & 0.829 \\
Age, years & $64.3(8.8)$ & $63.2(10.3)$ & 0.274 \\
Current smoker, n (\%) & $79(18.9)$ & $35(35.7)$ & $<0.001$ \\
Pack years, n & $40.0(30.0-50.0)$ & $40.0(30.0-51.0)$ & 0.468 \\
BMI, kg/m² & $26.2(5.7)$ & $26.2(6.3)$ & 0.926 \\
FFMI, kg/m² & $17.0(2.4)$ & $17.0(2.6)$ & 0.812 \\
FEV $/ \%$ pred) & $48.9(20.0)$ & $47.3(20.1)$ & 0.490 \\
FEV $/$ FVC $(\%)$ & $37.3(12.1)$ & $38.4(12.9)$ & 0.418 \\
Oxygen saturation $(\%)$ & $94.0(93.0-96.0)$ & $94.0(92.0-96.0)$ & 0.345 \\
mMRC grade $\geq 2$, n $(\%)$ & $334(80.7)$ & $83(84.7)$ & 0.014 \\
CAT total score, points & $21.5(6.6)$ & $21.7(6.9)$ & 0.826 \\
CCQ total score, points & $2.6(1.0)$ & $2.8(1.1)$ & 0.042 \\
SGRQ-C total score, points & $60.1(17.1)$ & $65.4(18.1)$ & 0.007 \\
HADS-A score, points & $7.5(4.4)$ & $9.0(4.9)$ & 0.004 \\
HADS-D score, points & $7.4(4.2)$ & $8.0(4.9)$ & 0.210 \\
6MWD, meters & $431.1(123.7)$ & $393.0(123.3)$ & 0.007 \\
\hline
\end{tabular}

Summary variables are presented as $\mathrm{n}(\%)$ for discrete variables, mean $\pm \mathrm{SD}$ for quantitative variables or median (IQR) for skewed variables.

Abbreviations: $\mathrm{FEV}_{1}$, forced expiratory volume in the first second; FVC, forced vital capacity; BMI, body mass index; FFMI, Fat Free Mass Index; mMRC, modified Medical Research Council scale; CAT, COPD Assessment Test; CCQ, Clinical COPD Questionnaire; SGRQ-C, COPD specific St. George Respiratory Questionnaire score; HADS-A, Hospital Anxiety and Depression Scale, Anxiety subscale; HADS-D, Hospital Anxiety and Depression Scale, Depression subscale 
Chapter 6

Table A2. Literature search

\begin{tabular}{|c|c|c|c|c|}
\hline Questionnaire: & Key words: & Search results: & Relevant articles: & $\begin{array}{l}\text { Additional } \\
\text { Articles*: }\end{array}$ \\
\hline $\begin{array}{l}\text { COPD } \\
\text { Assessment test }\end{array}$ & $\begin{array}{l}\text { (((((Minimum Clinically } \\
\text { Important Difference) OR } \\
\text { Minimal Clinically } \\
\text { Important Difference) OR } \\
\text { minimal important } \\
\text { difference) OR minimum } \\
\text { important difference) OR } \\
\text { MCID)) AND (COPD } \\
\text { assessment test OR CAT) }\end{array}$ & 44 articles & $\begin{array}{l}\text { 1. Dodd, Thorax } \\
2011 \\
\text { 2. Tsiligianni, BMC } \\
\text { Pulm Med } \\
2012 \\
\text { 3. Kon, the Lancet } \\
\text { Resp Med } 2014\end{array}$ & $\begin{array}{l}\text { Jones, } \\
\text { Chest } \\
2012\end{array}$ \\
\hline $\begin{array}{l}\text { Clinical COPD } \\
\text { questionnaire }\end{array}$ & $\begin{array}{l}\text { (((((Minimum Clinically } \\
\text { Important Difference) OR } \\
\text { Minimal Clinically } \\
\text { Important Difference) OR } \\
\text { minimal important } \\
\text { difference) OR minimum } \\
\text { important difference) OR } \\
\text { MCID)) AND (Clinical } \\
\text { COPD questionnaire OR } \\
\text { CCQ) }\end{array}$ & 64 articles & $\begin{array}{l}\text { 1. Kocks, Respir } \\
\text { Res } 2006 \\
\text { 2. Tsiligianni, BMC } \\
\text { Pulm Med } \\
2012 \\
\text { 3. Kon, Thorax } \\
2014 \\
\text { 5. Canavan, } \\
\text { Respirology } \\
\text { 2014 }\end{array}$ & \\
\hline $\begin{array}{l}\text { Hospital Anxiety } \\
\text { and Depression } \\
\text { Scale }\end{array}$ & $\begin{array}{l}\text { ((((((Minimum Clinically } \\
\text { Important Difference) OR } \\
\text { Minimal Clinically } \\
\text { Important Difference) OR } \\
\text { minimal important } \\
\text { difference) OR minimum } \\
\text { important difference) OR } \\
\text { MCID)) AND (Hospital } \\
\text { Anxiety and Depression } \\
\text { Scale OR HADS) }\end{array}$ & 15 articles & $\begin{array}{l}\text { 1. Puhan, Health } \\
\text { Qual Life } \\
\text { Outcomes } 2008\end{array}$ & \\
\hline
\end{tabular}

The computerized search was performed in the database Medline/PubMed for reports published till December 2015. * Reference lists and citations of included articles were searched to identify additional articles that may contain information on the topic of interest. 
Table A3. 95\% Confidence interval (CI) for CAT, CCQ and HADS based on various distributions

\begin{tabular}{|c|c|c|c|c|c|}
\hline & \multirow[b]{2}{*}{ Distrubution } & \multirow[b]{2}{*}{ Mean } & \multicolumn{2}{|c|}{$95 \%$ Confidence Interval for Mean } & \multirow[t]{2}{*}{ MCID Range } \\
\hline & & & Lower Bound & Upper Bound & \\
\hline \multirow[t]{3}{*}{$\overline{\mathrm{CAT}}$} & 1 & -2.6 & -3.0 & -2.2 & \\
\hline & 2 & -2.4 & -2.7 & -2.0 & -3.0 to -2.0 \\
\hline & 3 & -2.4 & -2.7 & -2.2 & \\
\hline \multirow[t]{3}{*}{ CCQ } & 1 & -0.4 & -0.5 & -0.3 & \\
\hline & 2 & -0.4 & -0.4 & -0.4 & -0.5 to -0.3 \\
\hline & 3 & -0.4 & -0.4 & -0.4 & \\
\hline \multirow[t]{3}{*}{ HADS-A } & 1 & -1.5 & -1.8 & -1.3 & \\
\hline & 2 & -1.6 & -1.8 & -1.4 & -1.8 to -1.3 \\
\hline & 3 & -1.6 & -1.7 & -1.4 & \\
\hline \multirow[t]{3}{*}{ HADS-D } & 1 & -1.6 & -1.7 & -1.5 & \\
\hline & 2 & -1.6 & -1.7 & -1.5 & -1.7 to -1.5 \\
\hline & 3 & -1.6 & -1.7 & -1.5 & \\
\hline
\end{tabular}

$1=$ Original values; equal weight to anchor-based MCIDs as distribution-based MCIDs

$2=$ Distribution based on $2 / 3$ anchor-based MCIDs and $1 / 3$ distribution-based MCIDs

(double weight on anchor-based MCIDs)

$3=$ Distribution based on $3 / 5$ anchor-based MCIDs and 2/5 distribution-based MCIDs

(60\% anchor based; $40 \%$ distribution based)

Abbreviations: CAT, COPD Assessment Test; CCQ, Clinical COPD Questionnaire; HADS-A, Hospital Anxiety and Depression Scale, Anxiety subscale; HADS-D, Hospital Anxiety and Depression Scale, Depression subscale 



\section{Chapter 7}

\section{The 2014 updated GOLD strategy: \\ a comparison of the various scenarios}

Sarah Wilke,* Dionne E. Smid,* Martijn A. Spruit, Daisy J A. Janssen, Jean W. M. Muris, Thys van der Molen, Marjan van den Akker, Paul W. Jones, Emiel F.M. Wouters, and Frits M.E. Franssen *Joint first author JCOPDF, 2014 Jul. 1(2) 


\section{ABSTRACT}

Background The 2014 updated Global initiative for chronic Obstructive Lung Disease (GOLD) strategy added the St. George's Respiratory Questionnaire (SGRQ) as the fourth possible symptoms measure. The impact of the suggested tools for symptoms of COPD and the different definitions of future risk on the frequency distribution and clinical characteristics of the GOLD groups remain unknown.

Methods Demographic and clinical characteristics were assessed in 542 patients with COPD (57.7\% male, age 64.6 [9.0] years, FEV 1 54.7 [22.3]\% predicted). Health status was assessed by the COPD-specific SGRQ and symptoms of anxiety and depression by the Hospital Anxiety and Depression Scale, anxiety (HADS-A) and depression (HADS-D) subscale. Cohen's Kappa was used to assess agreement between groups.

Results Level of agreement in frequency distribution using the modified Medical Research Council dyspnea (mMRC) scale $\geq 2$, COPD Assessment Test (CAT) $\geq 10$, Clinical COPD Questionnaire (CCQ) $\geq 1$ and SGRQ $\geq 25$ was moderate to very good. Best agreement was reached between CCQ and SGRQ (K $=0.838$ or $0.851, \mathrm{p}<0.001)$. Patients classified in mMRC GOLD A reported higher SGRQ scores, higher HADS-A and HADS-D scores compared to patients classified in CAT GOLD A or SGRQ GOLD A. Outcomes were comparable between the risk assessment groups.

Conclusions Choice of the symptom measure impacts GOLD groups more than choice of the exacerbation risk assessment. Health care professionals should be aware that patients are heterogeneous in terms of health status and symptoms of anxiety and depression based on the symptom measure used. 


\section{INTRODUCTION}

The 2007 Global initiative for chronic Obstructive Lung Disease (GOLD) statement classified COPD patients into 4 groups (GOLD stages I to IV), based on the degree of airflow limitation (1). This parameter, however, is only poorly-tomoderately associated with disease activity and progression, extra-pulmonary features and comorbidities, and prognosis in COPD patients (2-4). Therefore, the 2011 GOLD strategy started classifying patients in 4 new groups (GOLD groups A to D) based on the combination of the degree of airflow limitation and the number of exacerbations in the past 12 months (A/B vs. C/D); and the severity of symptoms (A/C vs. B/D) (Table 1). To assess the severity of symptoms, the GOLD strategy recommends new, simple and reliable assessment tools, designed for use in routine daily clinical practice (5).

Jones and colleagues were the first to study the impact of the choice of symptom measure (modified Medical Research Council dyspnea, mMRC scale or COPD Assessment Test, CAT) on the frequency distribution and clinical characteristics of the GOLD groups (6). The current mMRC cut-point of grade $\geq 2$ did not match with the current CAT cut-point of $\geq 10$ points (6). Thus, the choice of symptom measure clearly influences the new GOLD classification $(6,7)$, and in turn, the necessity for refinement of the current mMRC and/ or CAT cut-points was suggested.

The 2013 GOLD strategy added the Clinical COPD Questionnaire (CCQ) as the third possibility to classify patients to the low (A/C) or high (B/D) symptom group. Moreover, the number of COPD hospitalizations in the past 12 months (cut-point: $\geq 1$ hospitalizations) was added as the third criterion to classify patients as GOLD low (A/B) or high (C/D) risk (8). Casanova and colleagues showed that the symptom measure (i.e. mMRC, CAT or CCQ) used "can substantially alter group assignment” (9). Since the St. George's Respiratory Questionnaire (SGRQ) is the most documented measure and commonly used in COPD studies, the 2014 updated GOLD strategy added the SGRQ (cut-point: $\geq 25$ points) as a fourth possibility to grade symptoms (10). To date, the impact of all of these introduced assessment tools on the frequency distribution and clinical characteristics of the GOLD groups remain unknown. Therefore, the aims of the present study were: 1) to investigate the impact of the 4 different assessment tools for symptoms (mMRC, CAT, CCQ or SGRQ) and different definitions of future risk (degree of airflow limitation/ $\geq 2$ COPD exacerbations, and degree of airflow limitation/ $\geq 1$ hospitalization for COPD exacerbation) on the frequency distribution of GOLD groups A to D; and 2) to study differences in health status, functional mobility, 


\section{Chapter 7}

symptoms of anxiety and depression, and self-reported comorbidities between the

GOLD groups using these different scenarios. We hypothesized a priori that the symptom measures impact the GOLD distribution as well as the clinical characteristics of the GOLD groups.

Table 1. Overview GOLD strategies

I $\quad$ II III

GOLD

$\mathrm{FEV}_{1} \geq 80 \%$ pred $\mathrm{FEV}_{1} \geq 50 \%$ pred $\mathrm{FEV}_{1} \geq 30 \%$ pred $\quad \mathrm{FEV}_{1}<30 \%$ pred

2007 $<80 \%$ pred $\quad<50 \%$ pred

\begin{tabular}{|c|c|c|c|c|c|}
\hline & & $\mathbf{A}$ & B & C & $\mathbf{D}$ \\
\hline \multirow{4}{*}{$\begin{array}{l}\text { GOLD } \\
2011\end{array}$} & GOLD 2007 or & GOLD I or II & GOLD I or II & GOLD III or IV & GOLD III or IV \\
\hline & $\begin{array}{l}\text { Exacerbation } \\
\text { historya }\end{array}$ & $0-1$ exacerbations & $0-1$ exacerbations & $\geq 2$ exacerbations & $\geq 2$ exacerbations \\
\hline & mMRC grade & $0-1$ & $\geq 2$ & $0-1$ & $\geq 2$ \\
\hline & CAT, points & $<10$ & $\geq 10$ & $<10$ & $\geq 10$ \\
\hline \multirow{6}{*}{$\begin{array}{l}\text { GOLD } \\
2013\end{array}$} & GOLD 2007 or & GOLD I or II & GOLD I or II & GOLD III or IV & GOLD III or IV \\
\hline & $\begin{array}{l}\text { Exacerbation } \\
\text { historya }\end{array}$ & $0-1$ exacerbations & $0-1$ exacerbations & $\geq 2$ exacerbations & $\geq 2$ exacerbations \\
\hline & $\begin{array}{l}\text { GOLD } 2007 \text { or } \\
\text { Hospitalization } \\
\text { historya }\end{array}$ & $\begin{array}{l}\text { GOLD I or II } \\
\text { No } \\
\text { hospitalizations }\end{array}$ & $\begin{array}{l}\text { GOLD I or II } \\
\text { No } \\
\text { hospitalizations }\end{array}$ & $\begin{array}{l}\text { GOLD III or IV } \\
\geq 1 \text { hospitalizations }\end{array}$ & $\begin{array}{l}\text { GOLD III or IV } \\
\geq 1 \text { hospitalizations }\end{array}$ \\
\hline & mMRC grade or & $0-1$ & $\geq 2$ & $0-1$ & $\geq 2$ \\
\hline & CAT, points or & $<10$ & $\geq 10$ & $<10$ & $\geq 10$ \\
\hline & CCQ, points & $<1$ & $\geq 1$ & $<1$ & $\geq 1$ \\
\hline \multirow{7}{*}{$\begin{array}{l}\text { GOLD } \\
2014\end{array}$} & GOLD 2007 or & GOLD I or II & GOLD I or II & GOLD III or IV & GOLD III or IV \\
\hline & $\begin{array}{l}\text { Exacerbation } \\
\text { historya }\end{array}$ & $0-1$ exacerbations & $0-1$ exacerbations & $\geq 2$ exacerbations & $\geq 2$ exacerbations \\
\hline & $\begin{array}{l}\text { GOLD } 2007 \text { or } \\
\text { Hospitalization } \\
\text { history }^{a}\end{array}$ & $\begin{array}{l}\text { GOLD I or II } \\
\text { No } \\
\text { hospitalizations }\end{array}$ & $\begin{array}{l}\text { GOLD I or II } \\
\text { No } \\
\text { hospitalizations }\end{array}$ & $\begin{array}{l}\text { GOLD III or IV } \\
\geq 1 \text { hospitalizations }\end{array}$ & $\begin{array}{l}\text { GOLD III or IV } \\
\geq 1 \text { hospitalizations }\end{array}$ \\
\hline & mMRC grade or & $0-1$ & $\geq 2$ & $0-1$ & $\geq 2$ \\
\hline & CAT, points or & $<10$ & $\geq 10$ & $<10$ & $\geq 10$ \\
\hline & CCQ, points & $<1.0-1.5$ & $\geq 1.0-1.5$ & $<1.0-1.5$ & $\geq 1.0-1.5$ \\
\hline & SGRQ, points & $<25$ & $\geq 25$ & $<25$ & $\geq 25$ \\
\hline
\end{tabular}

a If there is a discrepancy between the risk group as classified by airflow limitation or exacerbation history, the GOLD strategy suggests to use the parameter with worst future risk. 


\section{METHODS}

\section{Design}

The current cross-sectional analyses are part of an ongoing prospective observational study about determinants of health status assessed with CAT in a broad sample of COPD patients. The Medical Ethical Committee of the Maastricht University Medical Centre+ Maastricht, the Netherlands (METC 11-3-070) approved this study, which was registered at the Dutch Trial Register (NTR 3416).

\section{Study Population}

Patients were eligible to participate if they had a primary diagnosis of COPD and if they were clinically stable for at least 4 weeks preceding enrollment. Patients were excluded if they had a history of other lung diseases, had undergone lung surgery or had a malignancy within the last 5 years. All patients gave written informed consent.

Patients were recruited in primary, secondary and tertiary care settings between April 2012 and April 2014. Primary care patients only received treatment by their general practitioner and never contacted a chest physician or were previously treated in tertiary care. Secondary care patients were only treated by a chest physician but were not previously treated in tertiary care. Primary and secondary care patients were recruited through general practitioner practices selected from the Registration Network of Family Practices, RNH (11). Tertiary care patients were recruited at $\mathrm{CIRO}+$, a centre for pulmonary rehabilitation in Horn, the Netherlands, during their pre-rehabilitation assessment.

\section{Measurements}

Primary and secondary care patients were assessed during home visits, while tertiary care patients were measured during an inpatient pre-rehabilitation assessment (12). Demographics, body mass index (BMI), smoking status, number of exacerbations and hospitalizations during the last 12 months, use of long-term oxygen therapy, current medication, post-bronchodilator spirometry (forced expiratory volume in 1 second, [FEV 1 , and forced vital capacity, [FVC]), mMRC dyspnea grade, functional mobility (Timed Up and Go [TUG] test) and selfreported comorbidities (Charlson Comorbidity Index) were assessed (13-15). Symptoms of anxiety and depression were assessed by using the Hospital Anxiety and Depression Scale, consisting of an anxiety subscale (HADS-A) and depression subscale (HADS-D) (16, 17). In addition, disease-specific health status was assessed using the CAT, the CCQ and the COPD-specific version of the SGRQ 
(SGRQ-C) (18-20). SGRQ scores were used to assess differences in health status between the various scenarios.

\section{Statistics}

Allocation to GOLD groups was made using $\mathrm{mMRC} \geq 2$ vs. CAT $\geq 10$ or CCQ $\geq 1$ or SGRQ $\geq 25$ and degree of airflow limitation/ $\geq 2$ exacerbations vs. degree of airflow limitation/ $\geq 1$ hospitalization in the previous 12 months. Bivariate correlations (Pearson's product-moment correlation) between mMRC, CAT, CCQ and SGRQ scores were assessed. Cohen's Kappa was used to assess agreement between the frequencies of patients classified into GOLD groups A to D using the different cut-points. Kappa values were categorized as having poor $(<0.0)$, slight (0.00-0.20), fair (0.21-0.40), moderate (0.41-0.60), substantial (0.61-0.80), and very good (0.81-1.00) agreement (21). Patient characteristics were compared between GOLD groups A to D using univariate analysis of variance for continuous variables, followed by post hoc least significance difference (LSD) multiple comparisons, or Kruskal-Wallis test followed by Mann-Whitney U test, as appropriate. Categorical variables were compared using Chi- Square tests. The same statistics were used to compare patient characteristics and health status, symptoms of anxiety and depression, the TUG test, and self-reported comorbidities between GOLD groups. For other tests, the independent sample ttest or Mann-Whitney U test were used, as appropriate. All statistical analyses were performed using SPSS for Windows, Version 19.0. A p-value $\leq 0.01$ was interpreted as statistically significant.

\section{RESULTS}

\section{Patient Characteristics}

In total, 542 patients with moderate to very severe COPD were included. Characteristics of the study population are presented in Table 2.

\section{The Impact of Symptom Measure on Frequency Distribution}

The mMRC, CAT, CCQ and SGRQ scores were moderately to strongly correlated, with the best relationship being between the CCQ and SGRQ ( $\mathrm{r}=0.853, \mathrm{p}<0.001$ ) (e-Figure 1). Using the cut-points selected, the majority of the patients were classified as GOLD D, irrespective of the symptom measure used (Figure 1).

The agreement of classification (Kappa values) into low (A/C) or high (B/D) symptom GOLD groups using the mMRC, CAT, CCQ or SGRQ scores is 
summarized in Table 3 . There was a moderate to substantial agreement $(\mathrm{K}=0.602$ or $0.626, \mathrm{p}<0.001)$ between mMRC and CAT and very good agreement $(\mathrm{K}=0.838$ or $0.851, \mathrm{p}<0.001)$ between CCQ and SGRQ scores.

Table 2. Patient characteristics

\begin{tabular}{ll}
\hline General characteristics & \\
\hline Men, $\mathrm{n}(\%)$ & $313(57.7)$ \\
Age, years & $64.6(9.0)$ \\
Current smoker, n (\%) & $132(24.4)$ \\
Packyears, $\mathrm{n}$ & $42.6(28.0)$ \\
FEV $\%$ predicted & $54.7(22.3)$ \\
FEV ${ }_{1} / \mathrm{FVC}, \%$ & $42.2(13.7)$ \\
BMI, $\mathrm{kg} / \mathrm{m}^{2}$ & $26.1(5.3)$ \\
Exacerbations previous 12 months $\geq 2, \mathrm{n}(\%)$ & $256(47.2)$ \\
Hospitalizations previous 12 months $\geq 1, \mathrm{n}(\%)$ & $187(34.5)$ \\
Charlson Comorbidity Index, points & $1.8(1.2)$ \\
mMRC, grade & $2.1(1.2)$ \\
CAT, points & $19.9(7.3)$ \\
CCQ, points & $2.3(1.1)$ \\
SGRQ total, points & $53.1(21.6)$ \\
HADS-A, points & $6.8(4.4)$ \\
HADS-D, points & $6.5(4.3)$ \\
TUG test, seconds & $10.3(3.6)$ \\
Primary care patients, $\mathrm{n}(\%)$ & $63(11.6)$ \\
Secondary care patients, $\mathrm{n}(\%)$ & $97(17.9)$ \\
Tertiary care patients, $\mathrm{n}(\%)$ & $382(70.5)$ \\
\hline
\end{tabular}

$\mathrm{n}=542$. Values expressed as mean (standard deviation) or number of patients (n), proportion (\%).

Abbreviations: $\mathrm{FEV}_{1}$, forced expiratory volume in the first second; BMI, body mass index; $\mathrm{mMRC}$, modified Medical Research Council scale; CAT, COPD Assessment Test; CCQ, Clinical COPD Questionnaire; SGRQ, St. George Respiratory Questionnaire score; TUG, Timed 'Up and Go' test; HADS-A, Hospital Anxiety and Depression Scale, Anxiety subscale; HADS-D, Hospital Anxiety and Depression Scale, Depression subscale; ${ }^{a} \mathrm{n}=534$

\section{The Impact of Symptom Measure on Clinical Characteristics}

On average, GOLD B/D patients had worse disease-specific health status scores compared to GOLD A/C patients, with worst (=highest) health status scores in GOLD D groups (Figure 2, e-Table 1a and e-Table 1b). mMRC GOLD A patients had a significantly worse health status compared to CAT GOLD A, CCQ GOLD A and SGRQ GOLD A patients. mMRC GOLD B, CCQ GOLD B and SGRQ GOLD B patients reported significantly worse health status compared to CAT GOLD B patients. In GOLD C and D groups, however, mean SGRQ scores were 
comparable between the symptom measures mMRC, CAT and CCQ. mMRC GOLD C and CAT GOLD C patients reported worse health status compared to SGRQ GOLD C patients (Figure 2).
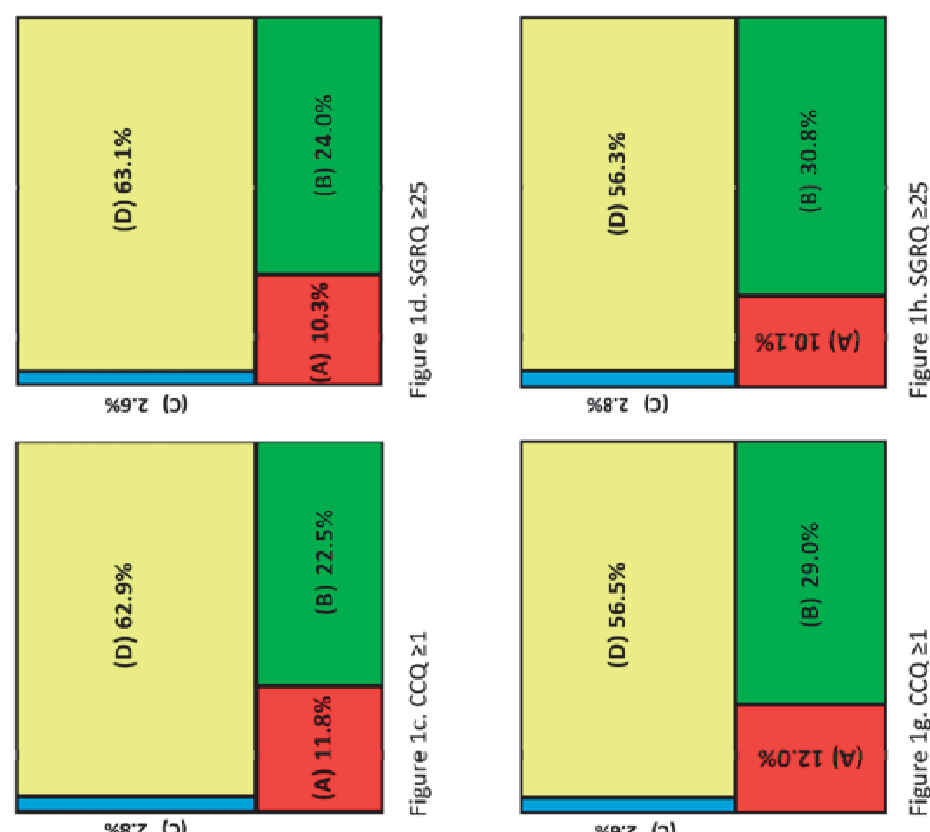

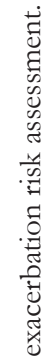
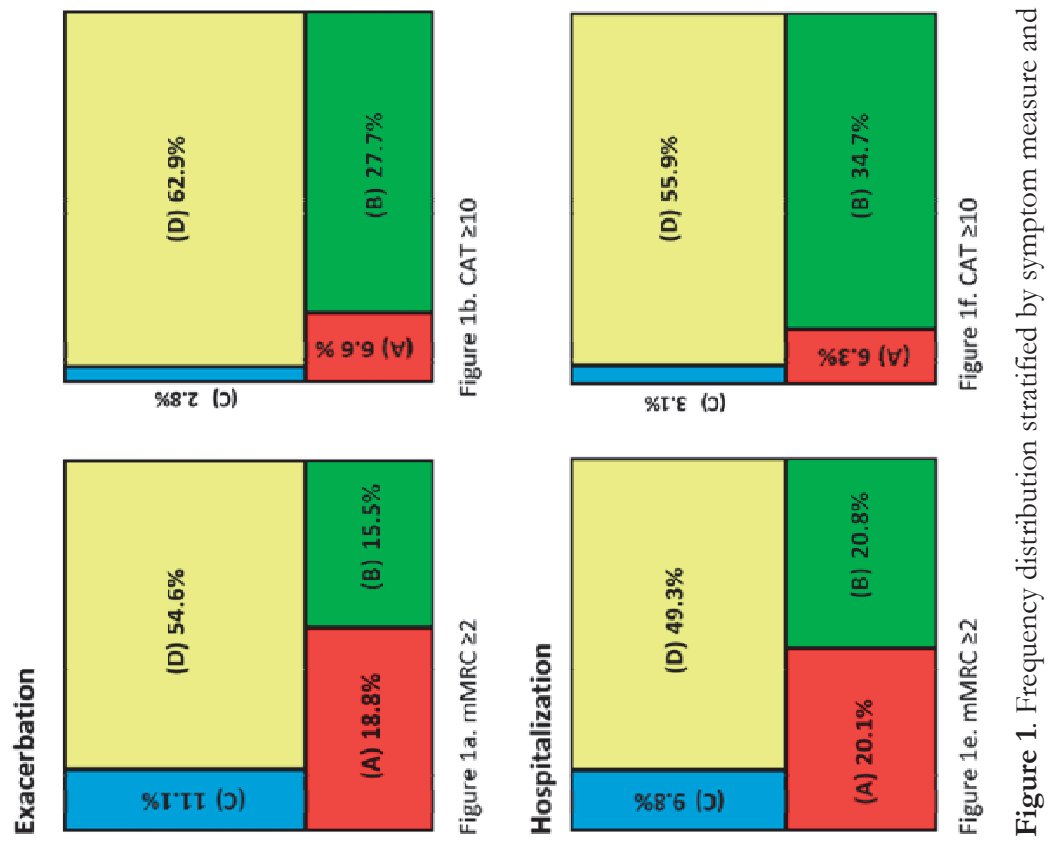
Table 3. Cohen's Kappa between symptom measures and same risk assessments

\begin{tabular}{|c|c|c|c|}
\hline \multicolumn{4}{|c|}{ Exacerbation history/degree of airflow limitation as risk assessment } \\
\hline & CAT & CCQ & SGRQ \\
\hline mMRC & 0.602 & 0.694 & 0.678 \\
\hline CAT & - & 0.806 & 0.787 \\
\hline CCQ & - & - & 0.838 \\
\hline \multicolumn{4}{|c|}{ Hospitalization history/degree of airflow limitation as risk assessment } \\
\hline & CAT & CCQ & SGRQ \\
\hline mMRC & 0.626 & 0.712 & 0.698 \\
\hline CAT & - & 0.820 & 0.803 \\
\hline CCQ & - & - & 0.851 \\
\hline
\end{tabular}

All results: $\mathrm{p}<0.001$

On average, GOLD B/D patients needed more time to complete the TUG test compared to GOLD A/C patients, with worst impairment in GOLD D patients. mMRC GOLD B patients and SGRQ GOLD B patients reported more comorbidities compared to mMRC GOLD A, C and D patients and SGRQ A and $\mathrm{D}$ patients, respectively (e-Table $1 \mathrm{a}$ and e-Table1b). There were no differences in the number of self-reported comorbidities and time needed to complete the TUG test between GOLD groups using mMRC, CAT, CCQ or SGRQ (Figure 2). On average, GOLD B/D patients reported significantly higher HADS-A and HADSD scores compared to GOLD A/C patients (e-Table 1a and e-Table 1b). mMRC GOLD A patients had higher (=worse) HADS-A and HADS-D scores compared to CAT GOLD A and SGRQ GOLD A patients.

\section{The Impact of Exacerbation Risk. Assessment on Frequency Distribution}

Table 4 shows that there is substantial agreement between the classifications using the exacerbation history and hospitalization history as risk assessment.

\section{The Impact of Exacerbation Risk. Assessment on Clinical Characteristics}

In general, the impact of choice of symptom cut-point measure on demographic and clinical characteristics was similar for both exacerbation risk assessment groups (Figure 2, e-Table 1a and e-Table 1b). Health status, physical mobility, symptoms of anxiety and depression and self-reported comorbidities were comparable between both exacerbation risk assessment groups (Figure 2). 
Chapter 7
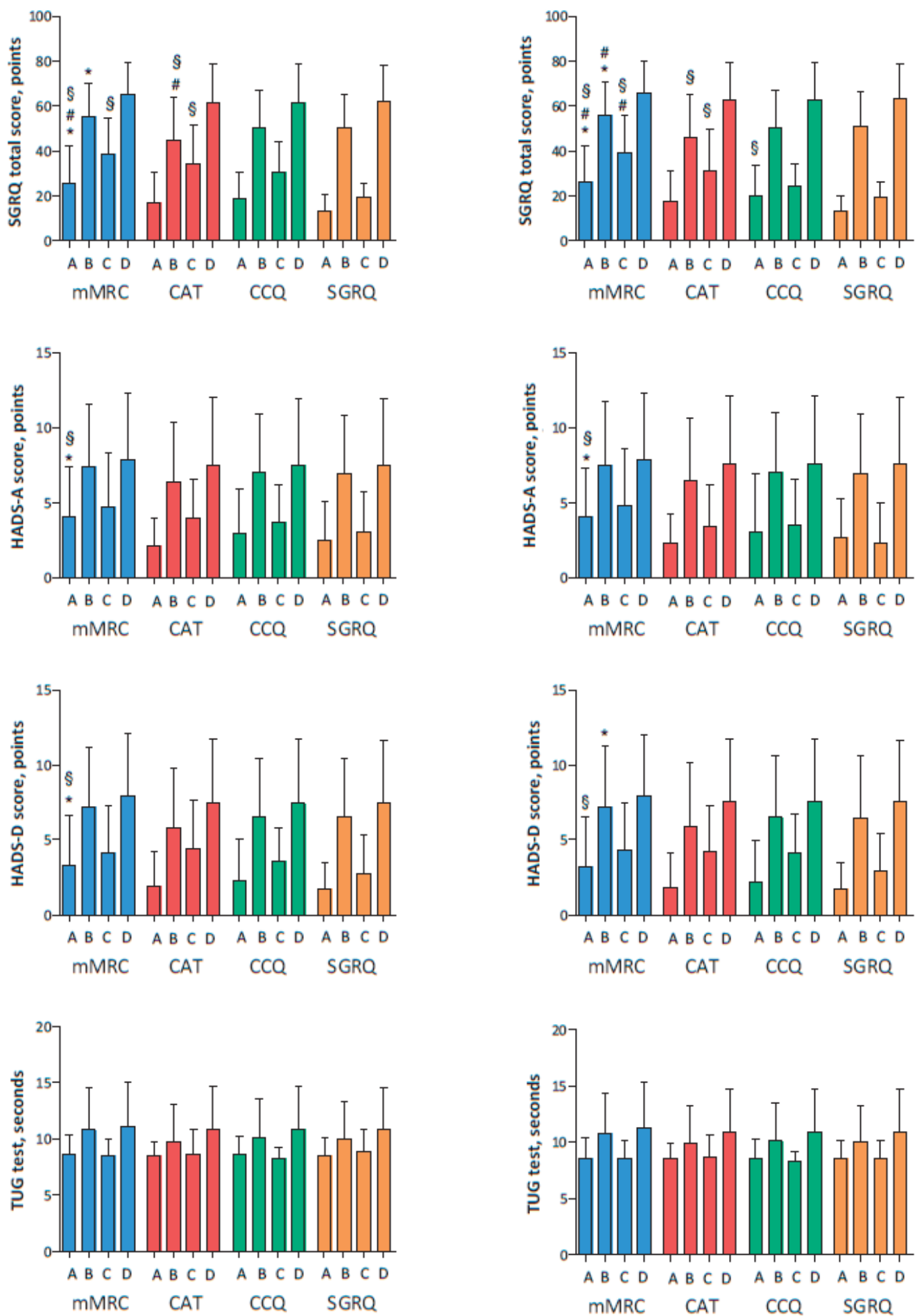

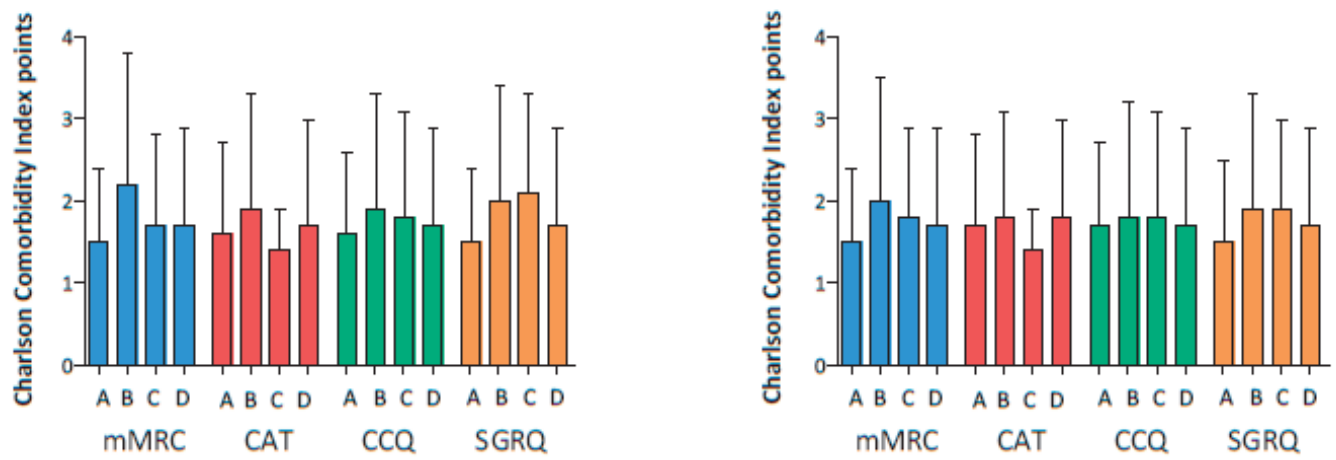

Figure 2. Health status as assessed by a) SGRQ, b) symptoms of anxiety (HADS-A) and c) depression (HADS-D), d) functional mobility (TUG test) and e) self-reported comorbidities (Charlson Comorbidity Index) stratified by symptom measure and exacerbation risk assessment (left column: degree of airflow limitation/exacerbation history; right column: degree of airflow limitation/hospitalization history). Significances are only described for comparison between similar GOLD groups using different symptom measures (e.g. mMRC GOLD A versus CAT GOLD A versus CCQ GOLD A versus SGRQ GOLD A. For significances within each symptom measure see online supplementary table E1a and $\mathrm{E} 1 \mathrm{~b}) .{ }^{*} \mathrm{p} \leq 0.01$ versus CAT; $\# \mathrm{p} \leq 0.01$ versus CCQ; $\$ \mathrm{p} \leq 0.01$ versus SGRQ

Table 4. Cohen's Kappa between different risk assessments and same symptom measures

\begin{tabular}{l|lllll}
\hline \multicolumn{2}{c}{} & \multicolumn{4}{c}{ Degree of airflow limitation/hospitalization } \\
\cline { 3 - 6 } \multicolumn{2}{c}{$\begin{array}{l}\text { Degree of } \\
\text { airflow }\end{array}$} & mMRC & CAT & CCQ & SGRQ \\
limitation/ & CAT & 0.801 & - & - & - \\
exacerbation & CCQ & - & 0.764 & - & - \\
\hline
\end{tabular}

All results: $\mathrm{p}<0.001$

\section{DISCUSSION}

\section{Key Findings}

This is the first study investigating the impact of the 4 GOLD-recommended symptom measures (mMRC, CAT, CCQ and SGRQ) and the 2 measures for exacerbation risk (exacerbation and hospitalization history) on the frequency distribution of GOLD groups A to D, and their clinical characteristics in COPD patients. It shows that the choice of symptom measure influences the frequency distribution of the new GOLD groups more than the measures for exacerbation risk. Moreover, health status and psychological symptoms differ between different 
outcome measures used to identify high and low symptom patients, in particular in GOLD groups A and B. Thus, our hypothesis that the symptom measures impact the GOLD distribution as well as the clinical characteristics of the GOLD groups is partly confirmed.

\section{The Impact of Symptom Measure on Frequency Distribution}

The distribution of patients between GOLD groups A/C or B/D was dependent on the choice of symptom measure. As suggested before (6), this is not surprising since CAT, CCQ and SGRQ cover a broad variety of symptoms and have been developed differently compared to mMRC $(18,19)$. The current study extends previous reports and shows that the mMRC cut-point of $\geq 2$ gives an overrepresentation of patients classified in groups A and C compared with cut-points of the CAT, CCQ and SGRQ $(6,22)$. In addition, previous studies only included primary and secondary care patients, while the majority of patients in the current analyses were recruited in tertiary care $(22,23)$. As suggested before, the distribution of patients across GOLD groups seems to differ by sample population (23). The results also show that the impact of the choice of symptom measure is most pronounced in the low risk groups GOLD A/B. Probably, the impact of severe airflow limitation or exacerbations/hospitalizations on health status is more pronounced in the high-risk groups GOLD C/D, compared to the low-risk groups GOLD A/B, which may overwhelm the impact of choice of symptom measure in the high-risk groups. The current study found a similar degree of agreement between mMRC and CAT compared to previous studies and showed even a better agreement between mMRCCCQ and CAT-CCQ with best agreement between CCQ-SGRQ $(6,9,22)$. However, the current study extends previous findings (24) showing a similarly strong relationship between CAT and CCQ $(r=0.771, \mathrm{p}<0.001)$ and the best relationship between CCQ and SGRQ (r=0.853, p < 0.001) (e-Figure 1).

Patients with a CAT score $\geq 10$ points experience a negative impact of their disease on their daily lives (25). Jones and colleagues showed that the classification of low symptom patients were approximately equivalent using the cut-points of mMRC grade $\geq 1$ and CAT score $\geq 10$ (6). Other studies suggest a CAT cut-point of 22 points or 13 points to determine low symptom groups which correspond with an mMRC cut-point of 2 or more $(23,26)$. However, the choice of an adequate cutpoint remains debatable: the updated GOLD 2014 guidelines suggest a cut-point for the CCQ between 1.0-1.5 points (9), while the current study suggests a CCQ cut-point of $\geq 0.6$ points and an mMRC grade of $\geq 1$ matching with a CAT cutpoint of $\geq 10$ points to reach the best agreement (e-Figure 2 and e-Figure 3 ). The classification is important since treatment is recommended according to the classification of the disease described in the GOLD guidelines. Although, the CAT 
and CCQ are both useful tools to assess patients' experience of COPD (24), it has been suggested to be challenging using both tools in clinical practice (27). Kim and colleagues suggested using the worse score on CAT or mMRC to allocate patients to GOLD groups A/C or B/D (22), like the procedure for exacerbation risk assessment. However, if this procedure is applied in the current study, only $4.8 \%$ of all patients are classified in GOLD groups A/C of which most of them are classified in the low risk group A. Therefore, this procedure probably gives an underestimation of low symptom patients (GOLD A/C).

\section{The Impact of Symptom Measure on Clinical Characteristics}

Furthermore, the current study shows that patients classified as GOLD group A/C using $\mathrm{mMRC}$ reported a worse health status as compared to CAT or CCQ assessed patients. This supports and extends previous findings (6). Interestingly, in mMRC GOLD B, CCQ GOLD B and SGRQ GOLD B groups, patients reported a worse health status compared with CAT GOLD B patients. Furthermore, mMRC GOLD A patients reported higher HADS-A and HADS-D scores compared to CAT GOLD A and SGRQ GOLD A patients. Previously, dyspnea and CAT scores have been associated with symptoms of anxiety and depression (28-30). Since mMRC GOLD A patients reported worse health status scores (Figure 2, e-Table $1 \mathrm{a}$ and e-Table $1 \mathrm{~b}$ ), it is reasonable that those patients also report higher HADS scores.

The current study identified significantly more self-reported comorbidities in mMRC GOLD B and SGRQ GOLD B/C compared to mMRC GOLD A, C and $\mathrm{D}$ and SGRQ A or D patients, respectively, while there were no differences in selfreported comorbidities between the GOLD groups when using the alternative GOLD-recommended symptom measures. Although previous studies also showed the highest prevalence of comorbidities in GOLD B $(31,32)$, the present results once again emphasize the importance of the choice of symptom measure. In addition, these studies only used the mMRC to categorize symptoms while the current study considered all various scenarios $(31,32)$.

Finally, the choice of risk assessment did not impact the frequency distribution or the clinical characteristics which is in line with a recently published report suggesting a $4.2 \%$ shift from low risk patients to high risk patients, independent of the symptom measure used (23). While the authors concluded that the meaning was clinically uncertain (23), the present study indicates that both measures for risk assessment are comparable. 


\section{Chapter 7}

\section{Limitations}

There are a number of aspects that need to be taken into consideration regarding the current study. The proportion of patients from primary $(11.6 \%)$, secondary $(17.9 \%)$ and tertiary $(70.5 \%)$ care is not equally distributed, which may limit the external validity of the current findings. Furthermore, the current findings need to be interpreted in the light of the number of comparisons that were made in the present study (33). Nonetheless, multiple findings in the same direction, rather than a single statistically significant result, suggest that these are not due to chance alone. Future studies are necessary to further assess the impact of the use of mMRC, CAT, CCQ and SGRQ on prognosis in all groups and to provide recommendations for disease management.

\section{CONCLUSION}

In contrast to the possibilities to assess future risk, the 4 possible symptom measures have an impact upon the distribution of patients between the new GOLD groups. This is especially seen in the low-risk GOLD groups A and B, in terms of impact on health status and psychological symptoms. Health care professionals should be aware that patients differ in terms of health status and symptoms of anxiety and depression based on the symptom measure used. 


\section{REFERENCES}

1. Rabe KF, Hurd S, Anzueto A, Barnes PJ, Buist SA, Calverley P, et al. Global strategy for the diagnosis, management, and prevention of chronic obstructive pulmonary disease: GOLD executive summary. Am J Respir Crit Care Med. 2007;176(6):532-55.

2. Vanfleteren LE, Spruit MA, Groenen M, Gaffron S, van Empel VP, Bruijnzeel PL, et al. Clusters of comorbidities based on validated objective measurements and systemic inflammation in patients with chronic obstructive pulmonary disease. Am J Respir Crit Care Med. 2013;187(7):728-35.

3. Spruit MA, Polkey MI, Celli B, Edwards LD, Watkins ML, Pinto-Plata V, et al. Predicting outcomes from 6-minute walk distance in chronic obstructive pulmonary disease. Journal of the American Medical Directors Association. 2012;13(3):291-7.

4. Graat-Verboom L, van den Borne BE, Smeenk FW, Spruit MA, Wouters EF. Osteoporosis in COPD outpatients based on bone mineral density and vertebral fractures. Journal of bone and mineral research : the official journal of the American Society for Bone and Mineral Research. 2011;26(3):561- 8.

5. Vestbo J, Hurd SS, Agusti AG, Jones PW, Vogelmeier C, Anzueto A, et al. Global strategy for the diagnosis, management, and prevention of chronic obstructive pulmonary disease: GOLD executive summary. Am J Respir Crit Care Med. 2013;187(4):347-65.

6. Jones PW, Adamek L, Nadeau G, Banik N. Comparisons of health status scores with MRC grades in COPD: implications for the GOLD 2011 classification. The European respiratory journal: official journal of the European Society for Clinical Respiratory Physiology. 2013;42(3):647-54.

7. Han MLK, Muellerova H, Curran-Everett D, Dransfield MT, Washko GR, Regan EA, et al. GOLD 2011 disease severity classification in COPDGene: a prospective cohort study. The Lancet Respiratory Medicine. 2012;1(1):43-50.

8. Agusti A, Hurd S, Jones P, Fabbri LM, Martinez F, Vogelmeier C, et al. FAQs about the GOLD 2011 assessment proposal of COPD: a comparative analysis of four different cohorts. The European respiratory journal: official journal of the European Society for Clinical Respiratory Physiology. 2013;42(5):1391-401.

9. Casanova C, Marin JM, Martinez-Gonzalez C, de Lucas-Ramos P, Mir-Viladrich I, Cosio B, et al. New GOLD classification: longitudinal data on group assignment. Respiratory research. 2014;15:3.

10. (GOLD) GIfCOLD. Global Strategy for the Diagnosis, Management and Prevention of COPD. http://wwwgoldcopdorg/. 2014.

11. Metsemakers JF, Hoppener P, Knottnerus JA, Kocken RJ, Limonard CB. Computerized health information in The Netherlands: a registration network of family practices. The British journal of general practice: the journal of the Royal College of General Practitioners. 1992;42(356):102-6.

12. Spruit MA, Pennings HJ, Janssen PP, Does JD, Scroyen S, Akkermans MA, et al. Extra-pulmonary features in COPD patients entering rehabilitation after stratification for MRC dyspnea grade. Respiratory medicine. 2007;101(12):2454-63. 
13. Mahler DA, Wells CK. Evaluation of clinical methods for rating dyspnea. Chest. 1988;93(3):580-6.

14. Mesquita R, Janssen DJ, Wouters EF, Schols JM, Pitta F, Spruit MA. Within-day testretest reliability of the Timed Up \& Go test in patients with advanced chronic organ failure. Archives of 105 physical medicine and rehabilitation. 2013;94(11):2131-8.

15. Charlson ME, Pompei P, Ales KL, MacKenzie CR. A new method of classifying prognostic comorbidity in longitudinal studies: development and validation. Journal of chronic diseases. 1987;40(5):373-83.

16. Zigmond AS, Snaith RP. The hospital anxiety and depression scale. Acta psychiatrica Scandinavica. 1983;67(6):361-70.

17. Puhan MA, Frey M, Buchi S, Schunemann HJ. The minimal important difference of the hospital anxiety and depression scale in patients with chronic obstructive pulmonary disease. Health and quality of life outcomes. 2008;6:46.

18. Jones PW, Harding G, Berry P, Wiklund I, Chen WH, Kline Leidy N. Development and first validation of the COPD Assessment Test. The European respiratory journal : official journal of the European Society for Clinical Respiratory Physiology. 2009;34(3):648-54.

19. van der Molen T, Willemse BW, Schokker S, ten Hacken NH, Postma DS, Juniper EF. Development, validity and responsiveness of the Clinical COPD Questionnaire. Health and quality of life outcomes. 2003;1:13.

20. Jones PW, Quirk FH, Baveystock CM. The St George's Respiratory Questionnaire. Respiratory medicine. 1991;85 Suppl B:25-31; discussion 3-7.

21. Landis JR, Koch GG. The measurement of observer agreement for categorical data. Biometrics. 1997;33:159-74.

22. Kim S, Oh J, Kim YI, Ban HJ, Kwon YS, Oh IJ, et al. Differences in classification of COPD group using COPD assessment test (CAT) or modified Medical Research Council (mMRC) dyspnea scores: a cross-sectional analyses. BMC pulmonary medicine. 2013;13:35.

23. Jones PW, Nadeau G, Small M, Adamek L. Characteristics of a COPD population categorized using the GOLD framework by health status and exacerbations. Respiratory medicine. 2014;108(1):129-35.

24. Tsiligianni IG, van der Molen T, Moraitaki D, Lopez I, Kocks JW, Karagiannis K, et al. Assessing health status in COPD. A head-to-head comparison between the COPD assessment test (CAT) and the clinical COPD questionnaire (CCQ). BMC pulmonary medicine. 2012;12:20.

25. Jones PW, Tabberer M, Chen WH. Creating scenarios of the impact of COPD and their relationship to COPD Assessment Test (CAT) scores. BMC pulmonary medicine. 2011;11:42.

26. Pillai AP, Turner AM, Stockley RA. Global Initiative for Chronic Obstructive Lung Disease 2011 symptom/risk assessment in alpha1-antitrypsin deficiency. Chest. 2013;144(4):1152-62.

27. Langhammer A, Jones R. Usefulness of the COPD assessment test (CAT) in primary care. Primary care respiratory journal : journal of the General Practice Airways Group. 2013;22(1):8-9. 
28. Janssen DJ, Spruit MA, Leue C, Gijsen C, Hameleers H, Schols JM, et al. Symptoms of anxiety and depression in COPD patients entering pulmonary rehabilitation. Chronic respiratory disease. 2010;7(3):147-57.

29. Nagata K, Tomii K, Otsuka K, Tachikawa R, Takeshita J, Tanaka K, et al. Evaluation of the chronic obstructive pulmonary disease assessment test for measurement of health-related quality of life in patients with interstitial lung disease. Respirology. 2012;17(3):506-12.

30. Hilmarsen CW, Wilke S, Engan H, Spruit MA, Rodenburg J, Janssen DJ, et al. Impact of symptoms of anxiety and depression on COPD Assessment Test scores. The European respiratory journal : official journal of the European Society for Clinical Respiratory Physiology. 2014;43(3):898-900.

31. Lange P, Marott JL, Vestbo J, Olsen KR, Ingebrigtsen TS, Dahl M, et al. Prediction of the clinical course of chronic obstructive pulmonary disease, using the new GOLD classification: a study of the general population. Am J Respir Crit Care Med. 2012;186(10):975-81.

32. Agusti A, Edwards LD, Celli B, Macnee W, Calverley PM, Mullerova H, et al. Characteristics, stability and outcomes of the 2011 GOLD COPD groups in the ECLIPSE cohort. The European respiratory journal : official journal of the European Society for Clinical Respiratory Physiology. 2013;42(3):636-46.

33. Perneger TV. What's wrong with Bonferroni adjustments. BMJ. 1998;316(7139):1236-8.

Reprinted with permission from Chronic Obstructive Pulmonary Diseases: Journal of the COPD Foundation 2014; 1 [2]:212-220. (doi: http//dx.doi.org/ 10.15326/jcopdf.1.2.2014.0135) Copyright 2014 COPD Foundation. 


\section{SUPPLEMENTARY MATERIAL}

E-table 1A. Clinical characteristics by GOLD groups/different scenarios - degree of airflow limitation/exacerbations as risk assessment

\begin{tabular}{|c|c|c|c|c|}
\hline & \multicolumn{4}{|c|}{ mMRC } \\
\hline & $\overline{\mathbf{A}}$ & B & $\mathbf{C}$ & $\mathbf{D}$ \\
\hline Gender, male $(\%)^{a}$ & $44(64.7)$ & $34(68.0)$ & $18(52.9)$ & $104(56.5)$ \\
\hline Age, years & $62.6(9.1)^{*}$ & $65.9(8.7)^{\#}$ & $59.0(8.9)^{\$}$ & $64.5(8.6)$ \\
\hline Current smoker, $\mathrm{n}(\%)^{\mathrm{b}}$ & $15(22.1)$ & $16(32.0)$ & $11(32.4)$ & $42(22.8)$ \\
\hline Packyears, $\mathrm{n}^{\mathrm{b}}$ & $36.1(19.3)^{*}$ & $51.0(29.9) \#$ & $32.5(15.6)$ & $42.5(28.4)$ \\
\hline $\mathrm{FEV}_{1}(\% \text { pred })^{\mathrm{b}}$ & $77.1(17.9)^{* \# \$}$ & $67.4(12.4) \# \$$ & $48.2(17.0)^{\$}$ & $41.2(17.8)$ \\
\hline $\mathrm{FEV}_{1} / \mathrm{FVC}^{\mathrm{a}, \mathrm{b}}$ & $55.4(10.8)^{* \# \$}$ & $50.5(9.2) \# \$$ & $38.8(10.2) \$$ & $34.3(11.6)$ \\
\hline $\mathrm{BMI}, \mathrm{kg} / \mathrm{m}^{2}$ & $27.1(4.9)^{\# \$}$ & $28.3(5.9)^{\# \$}$ & $24.3(4.6) \$$ & $25.5(5.4)$ \\
\hline Exacerbations previous 12 months, $\mathrm{n}^{\mathrm{b}}$ & $0.3(0.5)^{\# \$}$ & $0.3(0.5) \# \$$ & $2.1(1.4)$ & $3.1(2.5)$ \\
\hline Hospitalizations previous 12 months, $\mathrm{n}^{\mathrm{b}}$ & $0.1(0.3) \# \$$ & $0.2(0.5) \# \$$ & $0.6(0.9)$ & $1.1(1.4)$ \\
\hline Charlson Comorbidity Index, points ${ }^{b}$ & $1.6(1.2)^{*}$ & $2.2(1.8) \# \$$ & $1.5(1.1)^{\$}$ & $1.6(1.0)$ \\
\hline mMRC, points ${ }^{b}$ & $0.5(0.5)^{* \# \$}$ & $2.5(0.7) \# \$$ & $0.9(0.3)^{\$}$ & $2.9(0.8)$ \\
\hline CAT total score, points ${ }^{a}$ & $12.4(5.9)^{* \# \$}$ & $21.3(6.2)^{\#}$ & $16.6(6.4) \$$ & $22.2(6.2)$ \\
\hline CCQ total score, points ${ }^{\mathrm{a}, \mathrm{b}}$ & $1.0(0.7)^{* \# \$}$ & $2.3(1.0) \# \$$ & $1.7(0.8) \$$ & $2.8(0.9)$ \\
\hline SGRQ-C total score, pointsa & $26.4(17.0)^{* \# \$}$ & $56.0(14.7) \# \$$ & $40.7(16.9)^{\$}$ & $65.2(14.6)$ \\
\hline TUG test, seconds ${ }^{\mathrm{b}}$ & $8.5(1.6) * \$$ & $10.4(3.0)^{\#}$ & $8.2(1.5) \$$ & $10.9(3.4)$ \\
\hline HADS-A score, points, $\mathrm{b}$ & $4.0(3.3) * \$$ & $7.3(4.4)^{\#}$ & $4.4(3.4)^{\$}$ & $8.2(4.5)$ \\
\hline \multirow[t]{3}{*}{ HADS-D score, points ${ }^{\mathrm{b}}$} & $3.3(3.6) * \$$ & $7.0(3.7)^{\#}$ & $3.9(3.2) \$$ & $8.0(4.3)$ \\
\hline & \multicolumn{4}{|c|}{ CAT } \\
\hline & $\overline{\mathbf{A}}$ & $\mathbf{B}$ & $\mathrm{C}$ & $\mathbf{D}$ \\
\hline Gender, male $(\%)^{a}$ & $16(69.6)$ & $62(65.3)$ & $9(81.8)$ & $113(54.6)$ \\
\hline Age, years & $59.7(9.8)^{* \$}$ & $65.0(8.6)$ & $66.0(7.1)$ & $63.5(9.0)$ \\
\hline Current smoker, $\mathrm{n}(\%)^{\mathrm{b}}$ & $4(17.4)$ & $27(28.4)$ & $2(18.2)$ & $51(24.6)$ \\
\hline Packyears, $\mathrm{n}^{\mathrm{b}}$ & $31.1(16.7)^{* \$}$ & $45.1(26.4)$ & $39.3(32.4)$ & $41.0(26.8)$ \\
\hline $\mathrm{FEV}_{1}(\% \text { pred })^{\mathrm{b}}$ & $83.6(18.8)^{* \# \$}$ & $70.4(14.8)^{\# \$}$ & $45.5(20.6)$ & $42.1(17.7)$ \\
\hline $\mathrm{FEV}_{1} / \mathrm{FVC}^{\mathrm{a}, \mathrm{b}}$ & $60.2(9.3)^{* \# \$}$ & $51.7(10.0) \# \$$ & $35.5(12.3)$ & $35.0(11.5)$ \\
\hline BMI, $\mathrm{kg} / \mathrm{m}^{2}$ & $27.1(4.5)$ & $27.8(5.6)$ & $25.3(4.0)^{\$}$ & $25.3(5.3)$ \\
\hline Exacerbations previous 12 months, $\mathrm{n}^{\mathrm{b}}$ & $0.1(0.3) \# \$$ & $0.3(0.5)^{\# \$}$ & $2.5(1.4)$ & $3.0(2.4)$ \\
\hline Hospitalizations previous 12 months, $\mathrm{n}^{\mathrm{b}}$ & $0.1(0.3) \# \$$ & $0.1(0.4)^{\# \$}$ & $1.2(1.1)$ & $1.0(1.4)$ \\
\hline Charlson Comorbidity Index, points ${ }^{\mathrm{b}}$ & $1.7(1.2)$ & $1.9(1.6)$ & $1.4(0.5)$ & $1.6(1.1)$ \\
\hline mMRC, points & $0.5(0.7)^{* \# \$}$ & $1.5(1.2)^{\$}$ & $1.7(1.1)^{\$}$ & $2.6(1.0)$ \\
\hline CAT total score, points ${ }^{a}$ & $6.0(2.4) * \$$ & $18.6(6.1)^{\# \$}$ & $7.0(2.6) \$$ & $22.1(5.7)$ \\
\hline CCQ total score, points $\mathrm{s}^{\mathrm{a}, \mathrm{b}}$ & $0.5(0.4)^{* \# \$}$ & $1.8(1.0)^{\$}$ & $1.3(0.7)^{\$}$ & $2.7(0.9)$ \\
\hline SGRQ-C total score, points ${ }^{a}$ & $17.4(14.4)^{* \# \$}$ & $44.2(19.9) \$$ & $36.4(17.3)^{\$}$ & $62.7(16.4)$ \\
\hline TUG test, seconds ${ }^{\mathrm{b}}$ & $8.3(1.0) * \$$ & $9.6(2.6)^{\$}$ & $8.7(2.5)^{\$}$ & $10.6(3.4)$ \\
\hline HADS-A score, points ${ }^{\mathrm{a}, \mathrm{b}}$ & $2.0(1.9)^{* \# \$}$ & $6.2(4.1) \$$ & $4.2(2.6) \$$ & $7.8(4.5)$ \\
\hline HADS-D score, points & $1.6(2.6)^{* \# \$}$ & $5.7(4.0)^{\$}$ & $4.7(3.0)^{\$}$ & $7.5(4.5)$ \\
\hline
\end{tabular}




\begin{tabular}{|c|c|c|c|c|}
\hline & \multicolumn{4}{|c|}{ CCQ } \\
\hline & $\mathbf{A}$ & $\mathbf{B}$ & $\mathrm{C}$ & $\mathrm{D}$ \\
\hline Gender, male $(\%)^{\mathrm{c}}$ & $30(65.2)$ & $48(66.7)$ & $7(70.0)$ & $115(55.3)$ \\
\hline Age, years & $62.2(8.9)$ & $65.1(9.0)$ & $61.3(6.7)$ & $63.7(9.0)$ \\
\hline Current smoker, $\mathrm{n}(\%)^{\mathrm{d}}$ & $8(17.4)$ & $23(31.9)$ & $2(20.0)$ & $51(24.5)$ \\
\hline Packyears, $\mathrm{n}^{\mathrm{d}}$ & $33.7(17.4)^{*}$ & $48.1(28.1)$ & $33.1(13.6)$ & $41.3(27.5)$ \\
\hline $\mathrm{FEV}_{1}(\%$ pred $) \mathrm{c,d}$ & $80.3(18.4)^{* \# \$}$ & $68.3(13.2)^{\$}$ & $57.6(21.4)^{\$}$ & $41.6(17.4)$ \\
\hline $\mathrm{FEV}_{1} / \mathrm{FVC}^{\mathrm{d}}$ & $57.5(10.2)^{* \# \$}$ & $50.7(9.7)^{\$}$ & $44.0(13.0)^{\$}$ & $34.6(11.3)$ \\
\hline BMI, $\mathrm{kg} / \mathrm{m}^{2}$ & $26.5(4.2)$ & $28.4(5.9)^{\# \$}$ & $24.5(4.5)$ & $25.4(5.3)$ \\
\hline Exacerbations previous 12 months, $\mathrm{n}^{\mathrm{d}}$ & $0.2(0.4) \# \$$ & $0.3(0.5)^{\# \$}$ & $1.6(1.6)^{\$}$ & $3.0(2.4)$ \\
\hline Hospitalizations previous 12 months, $\mathrm{n}^{\mathrm{d}}$ & $0.0(0.2)^{* \# \$}$ & $0.2(0.5) \$$ & $0.4(0.7)$ & $1.1(1.4)$ \\
\hline Charlson Comorbidity Index, points d & $1.7(1.4)$ & $1.9(1.6)$ & $1.7(1.3)$ & $1.6(1.0)$ \\
\hline mMRC, points ${ }^{d}$ & $0.5(0.6)^{* \# \$}$ & $1.9(1.1) \# \$$ & $1.0(0.8)^{\$}$ & $2.7(1.0)$ \\
\hline CAT total score, points ${ }^{c}$ & $9.9(4.5) * \$$ & $20.2(6.1) \# \$$ & $11.8(6.5)^{\$}$ & $21.8(6.2)$ \\
\hline CCQ total score, points ${ }^{c}$ & $0.5(0.3)^{* \# \$}$ & $2.2(0.9) \# \$$ & $0.8(0.3)^{\$}$ & $2.8(0.9)$ \\
\hline SGRQ-C total score, points ${ }^{d}$ & $19.4(12.7)^{* \# \$}$ & $51.4(16.3) \#$ & $31.9(16.3)^{\$}$ & $62.8(16.2)$ \\
\hline TUG test, seconds ${ }^{\mathrm{d}}$ & $8.4(1.6)^{* \$}$ & $9.9(2.7)$ & $8.5(1.2)^{\$}$ & $10.6(3.4)$ \\
\hline HADS-A score, pointc & $3.2(3.3)^{* \$}$ & $6.8(4.0)^{\#}$ & $3.7(2.9)^{\$}$ & $7.8(4.5)$ \\
\hline \multirow[t]{3}{*}{ HADS-D score, points ${ }^{d}$} & $2.4(3.1)^{* \# \$}$ & $6.5(3.8)^{\#}$ & $3.3(2.0)^{\$}$ & $7.6(4.4)$ \\
\hline & \multicolumn{4}{|c|}{ SGRQ } \\
\hline & $\mathbf{A}$ & $\mathbf{B}$ & $\mathrm{C}$ & $\mathbf{D}$ \\
\hline Gender, male $(\%)^{\mathrm{c}}$ & $24(68.6)$ & $54(56.1)$ & $3(50.0)$ & $119(56.1)$ \\
\hline Age, years & $62.6(8.1)$ & $64.6(9.4)$ & $61.7(7.5)$ & $63.7(8.9)$ \\
\hline Current smoker, $\mathrm{n}(\%)^{\mathrm{d}}$ & $8(22.9)$ & $23(27.7)$ & $0(0.0)$ & $53(25.0)$ \\
\hline Packyears, $\mathrm{n}^{\mathrm{d}}$ & $31.1(16.1) * \$$ & $47.4(27.1)^{\$}$ & $35.4(10.5)$ & $41.1(27.4)$ \\
\hline $\mathrm{FEV}_{1}(\%$ pred $) \mathrm{c,d}$ & $81.8(16.4)^{* \# \$}$ & $69.3(15.1)^{\$}$ & $52.7(21.0)$ & $42.0(7.7)$ \\
\hline $\mathrm{FEV}_{1} / \mathrm{FVC}^{\mathrm{d}}$ & $59.8(7.2)^{* \# \$}$ & $50.6(10.3) \$$ & $43.7(12.7)$ & $34.8(11.4)$ \\
\hline BMI, $\mathrm{kg} / \mathrm{m}^{2}$ & $26.6(3.1)$ & $28.1(6.0) \$$ & $26.4(5.3)$ & $25.3(5.3)$ \\
\hline Exacerbations previous 12 months, $\mathrm{n}^{\mathrm{d}}$ & $0.2(0.4) \# \$$ & $0.3(0.5) \# \$$ & $1.3(0.8) \$$ & $3.0(2.4)$ \\
\hline Hospitalizations previous 12 months, $\mathrm{n}^{\mathrm{d}}$ & $0.1(0.2) \# \$$ & $0.2(0.5) \# \$$ & $0.7(0.8)$ & $1.0(1.4)$ \\
\hline Charlson Comorbidity Index, points ${ }^{\mathrm{d}}$ & $1.5(1.0)^{* \#}$ & $2.0(1.6) \$$ & $2.3(1.5)$ & $1.6(1.0)$ \\
\hline mMRC, points ${ }^{d}$ & $0.3(0.5) * \#$ & $1.8(1.1) \# \$$ & $0.8(0.8) \$$ & $2.6(1.0)$ \\
\hline CAT total score, points ${ }^{c}$ & $9.1(4.3) * \$$ & $19.1(6.5) \#$ & $9.8(6.0) \$$ & $21.7(6.3)$ \\
\hline CCQ total score, pointsc & $0.6(0.3) * \$$ & $2.0(1.0) \# \$$ & $0.9(0.5) \$$ & $2.7(0.9)$ \\
\hline SGRQ-C total score, points ${ }^{\mathrm{d}}$ & $12.9(6.5)^{* \# \$}$ & $49.9(15.6) \# \$$ & $20.1(6.9)^{\$}$ & $62.6(16.1)$ \\
\hline TUG test, seconds ${ }^{d}$ & $8.2(1.4)^{* \$}$ & $9.8(2.6)$ & $8.3(1.9)$ & $10.6(3.4)$ \\
\hline HADS-A score, point ${ }^{c}$ & $2.2(2.1) * \$$ & $6.7(4.1)^{\#}$ & $2.3(2.6) \$$ & $7.7(4.5)$ \\
\hline HADS-D score, points ${ }^{d}$ & $1.3(1.5) * \$$ & $6.4(3.9) \# \$$ & $2.3(2.0) \$$ & $7.5(4.4)$ \\
\hline
\end{tabular}

${ }^{*}=\mathrm{p} \leq 0.05$ versus group $\mathrm{B}, \#=\mathrm{p} \leq 0.05$ versus group $\mathrm{C}, \$=\mathrm{p} \leq 0.05$ versus group $\mathrm{D}$

$a=$ non parametric test for group "mMRC", b= non parametric test for group "CAT"

$c=$ non parametric test for group "CCQ", d= non parametric test for group "SGRQ" 
E-table 1B. Clinical characteristics by GOLD groups/different scenarios - degree of airflow limitation/hospitalizations as risk assessment

\begin{tabular}{|c|c|c|c|c|}
\hline & \multicolumn{4}{|c|}{ mMRC } \\
\hline & $\mathbf{A}$ & $\mathbf{B}$ & $\mathrm{C}$ & $\mathbf{D}$ \\
\hline Gender, male $(\%)^{\mathrm{b}}$ & $39(54.9)$ & $37(61.7)$ & $23(74.2)$ & $101(58.0)$ \\
\hline Age, years & $62.8(8.6)^{\#}$ & $64.2(8.9)^{\#}$ & $58.2(9.7)^{\$}$ & $65.0(8.6)$ \\
\hline Current smoker, $\mathrm{n}(\%)^{\mathrm{b}}$ & $15(21.1)$ & $18(30.0)$ & $11(35.5)$ & $40(23.0)$ \\
\hline Packyears, $\mathrm{n}^{\mathrm{b}}$ & $36.0(19.8)^{*}$ & $46.7(29.0)^{\#}$ & $32.4(13.7)$ & $43.5(28.9)^{\$}$ \\
\hline $\mathrm{FEV}_{1}(\% \text { pred })^{\mathrm{b}}$ & $77.4(17.4)^{* \# \$}$ & $68.2(13.7) \# \$$ & $44.7(13.5)$ & $39.4(16.0)^{\$}$ \\
\hline $\mathrm{FEV}_{1} / \mathrm{FVCb}^{\mathrm{b}}$ & $55.4(10.6)^{* \# \$}$ & $50.0(9.8) \# \$$ & $37.1(8.9)$ & $33.6(11.1) \$$ \\
\hline $\mathrm{BMI}, \mathrm{kg} / \mathrm{m}^{2 \mathrm{a}, \mathrm{b}}$ & $26.6(4.8)$ & $28.1(56.3) \# \$$ & $25.3(5.4)$ & $25.4(5.2)$ \\
\hline Exacerbations previous 12 months, $\mathrm{n}^{\mathrm{b}}$ & $0.5(0.9)^{\# \$}$ & $0.9(1.2) \#$ & $1.6(1.5)$ & $3.1(2.6)^{\$}$ \\
\hline Hospitalizations previous 12 months, $\mathrm{n}^{\mathrm{b}}$ & $0.0(0.0)^{\# \$}$ & $0.0(0.0)^{\# \$}$ & $0.9(0.9)$ & $1.2(1.4)$ \\
\hline Charlson Comorbidity Index, points & $1.5(1.2)^{*}$ & $1.9(1.6)$ & $1.5(1.1)$ & $1.6(1.1)$ \\
\hline mMRC, points ${ }^{\mathrm{a}, \mathrm{b}}$ & $0.5(0.5)^{* \# \$}$ & $2.4(0.6) \#$ & $0.9(0.3)$ & $3.0(0.8)^{\$}$ \\
\hline CAT total score, pointsa & $13.0(6.4)^{* \# \$}$ & $21.3(5.8)^{\#}$ & $15.5(6.2)$ & $22.3(6.3)^{\$}$ \\
\hline CCQ total score, points & $1.0(0.8)^{* \# \$}$ & $2.3(0.9) \# \$$ & $1.7(0.8)$ & $2.9(0.9)^{\$}$ \\
\hline SGRQ-C total score, points & $27.0(16.7)^{* \# \$}$ & $54.8(15.0) \# \$$ & $40.9(17.9)$ & $66.1(14.0)^{\$}$ \\
\hline TUG test, seconds ${ }^{b}$ & $8.4(1.5) * \$$ & $10.3(2.8) \#$ & $8.4(1.6)$ & $11.0(3.5)^{\$}$ \\
\hline HADS-A score, point ${ }^{\mathrm{a}, \mathrm{b}}$ & $3.9(3.3) * \$$ & $7.4(4.6) \#$ & $4.5(3.6)$ & $8.2(4.4)^{\$}$ \\
\hline HADS-D score, points ${ }^{b}$ & $3.2(3.6)^{* \# \$}$ & $6.8(4.1)^{\# \$}$ & $4.3(3.1)$ & $8.2(4.2)^{\$}$ \\
\hline
\end{tabular}

\begin{tabular}{|c|c|c|c|c|}
\hline & \multicolumn{4}{|c|}{ CAT } \\
\hline & $\mathbf{A}$ & $\mathbf{B}$ & $\mathrm{C}$ & $\mathbf{D}$ \\
\hline Gender, male $(\%)^{\mathrm{b}}$ & $14(63.6)$ & $62(56.9)$ & $11(91.7)$ & $113(58.5)$ \\
\hline Age, years & $59.5(9.5)^{*}$ & $64.2(8.4)$ & $65.7(8.0)$ & $63.8(9.1)$ \\
\hline Current smoker, $\mathrm{n}(\%)^{\mathrm{b}}$ & $3(13.6)$ & $30(27.5)$ & $3(25.0)$ & $48(24.9)$ \\
\hline Packyears, $\mathrm{n}^{\mathrm{b}}$ & $29.9(17.7)^{*} \$$ & $43.1(25.6)$ & $40.6(29.7)$ & $41.9(27.4)$ \\
\hline $\mathrm{FEV}_{1}(\% \text { pred })^{\mathrm{b}}$ & $84.2(18.8)^{* \# \$}$ & $71.0(15.0)^{\# \$}$ & $47.5(21.1)$ & $39.8(15.3)$ \\
\hline $\mathrm{FEV}_{1} / \mathrm{FVC}^{\mathrm{b}}$ & $59.8(10.1)^{* \# \$}$ & $1.6(10.1) \# \$$ & $38.2(14.1)$ & $33.9(10.6)$ \\
\hline BMI, $\mathrm{kg} / \mathrm{m}^{2 \mathrm{a}, \mathrm{b}}$ & $26.7(4.6)$ & $27.4(5.8)^{\$}$ & $26.2(4.2)$ & $25.3(5.2)$ \\
\hline Exacerbations previous 12 months, $\mathrm{n}^{\mathrm{b}}$ & $0.3(1.1)^{* \# \$}$ & $0.8(1.1) \#$ & $1.9(1.3)$ & $2.9(2.6)$ \\
\hline Hospitalizations previous 12 months, $\mathrm{n}^{\mathrm{b}}$ & $0.0(0.0) \# \$$ & $0.0(0.0) \# \$$ & $1.3(1.0)$ & $1.2(1.4)$ \\
\hline Charlson Comorbidity Index, points ${ }^{b}$ & $1.6(1.2)$ & $1.7(1.5)$ & $1.4(0.5)$ & $1.6(1.1)$ \\
\hline mMRC, pointsa,b & $0.5(0.7)^{* \# \$}$ & $1.5(1.1)^{\$}$ & $1.7(1.1)^{\$}$ & $2.7(1.0)$ \\
\hline CAT total score, pointsa & $6.0(2.5) * \$$ & $19.0(5.9)^{\# \$}$ & $7.0(2.5)^{\$}$ & $22.1(5.9)$ \\
\hline CCQ total score, points & $0.5(0.4)^{* \# \$}$ & $1.8(1.0)^{\$}$ & $1.2(0.7)^{\$}$ & $2.8(0.9)$ \\
\hline SGRQ-C total score, points & $17.5(14.9)^{* \# \$}$ & $44.2(19.3)^{\$}$ & $34.7(17.1)^{\$}$ & $64.0(15.7)$ \\
\hline TUG test, seconds ${ }^{\mathrm{b}}$ & $8.1(1.0)^{*} \$$ & $9.5(2.5) \$$ & $8.9(2.3) \$$ & $10.7(3.4)$ \\
\hline HADS-A score, point ${ }^{\mathrm{a}, \mathrm{b}}$ & $2.3(2.0) * \$$ & $6.2(4.3) \# \$$ & $3.5(2.9)^{\$}$ & $7.9(4.4)$ \\
\hline HADS-D score, points ${ }^{b}$ & $1.5(2.6)^{* \# \$}$ & $5.5(4.2)^{\$}$ & $4.6(3.1)^{\$}$ & $7.8(4.3)$ \\
\hline
\end{tabular}




\begin{tabular}{|c|c|c|c|c|}
\hline & \multicolumn{4}{|c|}{ CCQ } \\
\hline & $\mathbf{A}$ & B & $\mathbf{C}$ & $\mathbf{D}$ \\
\hline Gender, male $(\%) \mathrm{d}$ & $30(62.5)$ & $46(55.4)$ & $7(87.5)$ & $117(59.4)$ \\
\hline Age, years & $62.5(8.4)$ & $64.0(9.0)$ & $59.3(9.1)$ & $64.1(9.0)$ \\
\hline Current smoker, $\mathrm{n}(\%)^{\mathrm{d}}$ & $8(16.7)$ & $25(30.1)$ & $2(25.0)$ & $49(24.9)$ \\
\hline Packyears, $\mathrm{n}^{\mathrm{d}}$ & $33.6(17.7)^{*} \$$ & $45.2(27.5)$ & $33.6(9.9)$ & $42.2(27.9)$ \\
\hline $\mathrm{FEV}_{1}(\%$ pred $)$ & $80.9(17.7)^{* \# \$}$ & $68.8(14.0) \#$ & $48.6(15.9)$ & $39.9(15.7)$ \\
\hline $\mathrm{FEV}_{1} / \mathrm{FVCd}$ & $57.7(9.8)^{* \# \$}$ & $50.2(10.0) \# \$$ & $39.3(10.8)$ & $33.9(10.8)$ \\
\hline $\mathrm{BMI}, \mathrm{kg} / \mathrm{m}^{2 \mathrm{c}}$ & $26.0(3.9)$ & $28.0(6.2) \$$ & $27.2(6.3)$ & $25.3(5.1)$ \\
\hline Exacerbations previous 12 months, $\mathrm{n}^{\mathrm{d}}$ & $0.4(0.9) * \$$ & $0.9(1.1) \$$ & $0.8(07) \$$ & $2.9(2.5)$ \\
\hline Hospitalizations previous 12 months, $\mathrm{n}^{\mathrm{d}}$ & $0.0(0.0)^{\# \$}$ & $0.0(0.0) \# \$$ & $0.8(0.7)$ & $1.2(1.4)$ \\
\hline Charlson Comorbidity Index, points ${ }^{\mathrm{d}}$ & $1.7(1.4)$ & $1.7(1.5)$ & $1.8(1.4)$ & $1.6(1.1)$ \\
\hline mMRC, points ${ }^{\mathrm{c}, \mathrm{d}}$ & $0.5(0.7)^{*}$ & $1.9(1.0) \# \$$ & $0.9(0.8) \$$ & $2.7(1.0)$ \\
\hline CAT total score, points & $10.3(5.0) * \$$ & $20.6(5.7)^{\#}$ & $9.4(5.1) \$$ & $21.7(6.4)$ \\
\hline CCQ total score, points, $\mathrm{d}$ & $0.6(0.3) * \$$ & $2.2(0.8) \# \$$ & $0.7(0.3) \$$ & $2.8(0.9)$ \\
\hline SGRQ-C total score, points ${ }^{\mathrm{c}, \mathrm{d}}$ & $21.1(14.8) * \$$ & $50.5(16.2) \# \$$ & $24.6(9.2)^{\$}$ & $63.8(15.6)$ \\
\hline TUG test, seconds ${ }^{\mathrm{d}}$ & $8.4(1.6)^{* \$}$ & $9.8(2.6)^{\$}$ & $8.5(1.0) \$$ & $10.7(3.4)$ \\
\hline HADS-A score, point ${ }^{c, d}$ & $3.2(3.2) * \$$ & $6.9(4.3) \#$ & $3.8(4.0) \$$ & $7.8(4.4)$ \\
\hline HADS-D score, points ${ }^{\mathrm{d}}$ & $2.3(2.9)^{* \# \$}$ & $6.3(4.2) \$$ & $4.3(2.8)^{\$}$ & $7.7(4.3)$ \\
\hline
\end{tabular}

\begin{tabular}{|c|c|c|c|c|}
\hline & \multicolumn{4}{|c|}{ SGRQ } \\
\hline & A & B & $\mathrm{C}$ & $\mathbf{D}$ \\
\hline Gender, male $(\%) \mathrm{d}$ & $22(64.7)$ & $54(55.7)$ & $5(71.4)$ & $119(60.1)$ \\
\hline Age, years & $62.7(7.8)$ & $63.7(9.1)$ & $61.3(9.0)$ & $64.1(9.0)$ \\
\hline Current smoker, $\mathrm{n}(\%)^{\mathrm{d}}$ & $7(20.6)$ & $26(26.8)$ & $1(14.3)$ & $50(25.3)$ \\
\hline Packyears, $\mathrm{n}^{\mathrm{d}}$ & $31.2(16.4) * \$$ & $44.4(26.5)$ & $33.8(10.6)$ & $42.1(27.8)$ \\
\hline $\mathrm{FEV}_{1}(\%$ pred $)$ & $82.4(16.2)^{* \# \$}$ & $70.0(15.3)^{\# \$}$ & $53.7(19.0)$ & $39.7(15.5)$ \\
\hline $\mathrm{FEV}_{1} / \mathrm{FVCd}^{\mathrm{d}}$ & $60.1(7.2)^{* \# \$}$ & $50.4(10.4)^{\$}$ & $44.6(11.8)^{\$}$ & $33.7(10.7)$ \\
\hline BMI, $\mathrm{kg} / \mathrm{m}^{2 \mathrm{c}}$ & $26.5(3.2) \$$ & $27.6(6.2)$ & $26.7(4.7)$ & $25.3(5.2)$ \\
\hline Exacerbations previous 12 months, $\mathrm{n}^{\mathrm{d}}$ & $0.3(0.5) * \# \$$ & $0.9(1.2)^{\$}$ & $1.0(0.8)^{\$}$ & $2.9(2.6)$ \\
\hline Hospitalizations previous 12 months, $\mathrm{n}^{\mathrm{d}}$ & $0.0(0.0) \# \$$ & $0.0(0.0)^{\# \$}$ & $0.9(0.7)$ & $1.2(1.4)$ \\
\hline Charlson Comorbidity Index, points ${ }^{\mathrm{d}}$ & $1.5(1.0)$ & $1.8(1.5)$ & $2.1(1.5)$ & $1.6(1.1)$ \\
\hline mMRC, points ${ }^{c, d}$ & $0.2(0.5) * \# \$$ & $1.8(1.0)^{\# \$}$ & $0.9(0.7)^{\$}$ & $2.7(1.0)$ \\
\hline CAT total score, points & $9.2(4.4) * \$$ & $19.5(6.2)^{\# \$}$ & $9.0(5.4)^{\$}$ & $21.7(6.4)$ \\
\hline CCQ total score, points ${ }^{\mathrm{c}, \mathrm{d}}$ & $0.6(0.4) * \$$ & $2.0(1.0)^{\# \$}$ & $0.7(0.3)^{\$}$ & $2.8(0.9)$ \\
\hline SGRQ-C total score, points ${ }^{c, d}$ & $12.6(6.3)^{* \# \$}$ & $49.2(15.5)^{\# \$}$ & $20.5(6.5)^{\$}$ & $63.8(15.5)$ \\
\hline TUG test, seconds ${ }^{\mathrm{d}}$ & $8.2(1.4) * \$$ & $9.7(2.6)^{\$}$ & $8.3(1.7)^{\$}$ & $10.7(3.4)$ \\
\hline HADS-A score, point ${ }^{c, d}$ & $2.4(2.2) * \$$ & $6.6(4.2)^{\# \$}$ & $1.4(2.1)^{\$}$ & $7.8(4.4)$ \\
\hline HADS-D score, points ${ }^{\mathrm{d}}$ & $1.3(1.4) * \$$ & $6.1(4.2)^{\# \$}$ & $2.4(2.1)^{\$}$ & $7.8(4.2)$ \\
\hline
\end{tabular}

${ }^{*}=\mathrm{p} \leq 0.05$ versus group $\mathrm{B},{ }^{*}=\mathrm{p} \leq 0.05$ versus group $\mathrm{C}, \$=\mathrm{p} \leq 0.05$ versus group $\mathrm{D}$

$\mathrm{a}=$ non parametric test for group "mMRC", $\mathrm{b}=$ non parametric test for group "CAT"

$\mathrm{c}=$ non parametric test for group "CCQ", $\mathrm{d}=$ non parametric test for group "SGRQ" 
a)

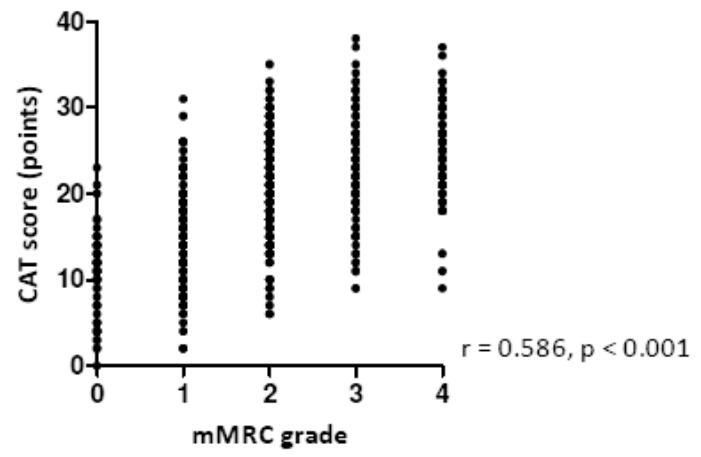

b)

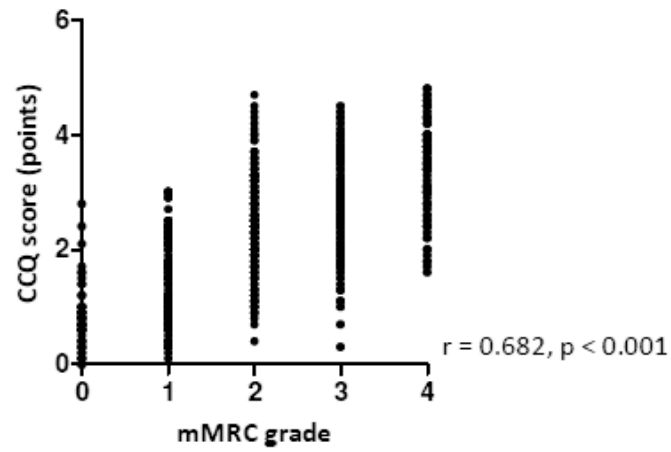

c)

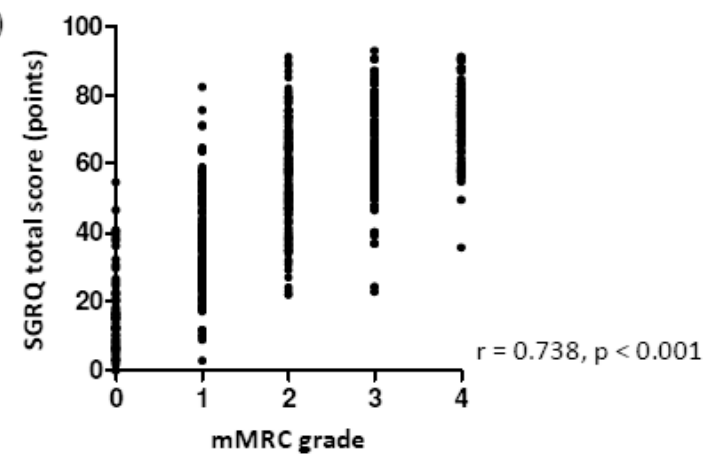

d)

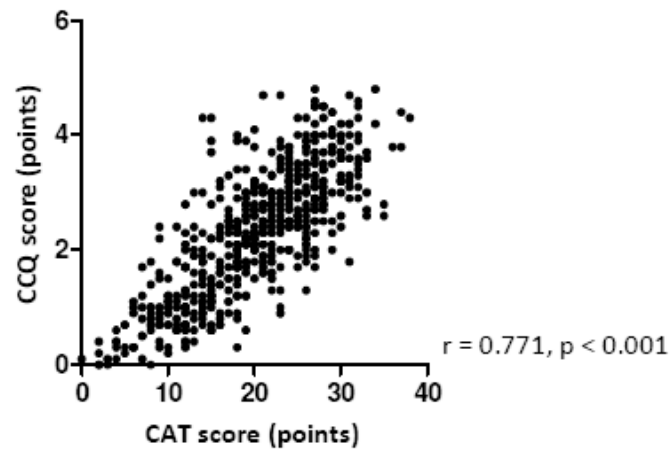

e)

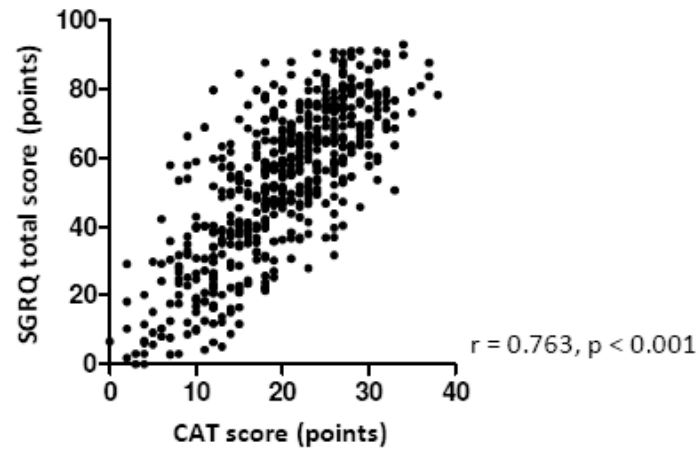

f)

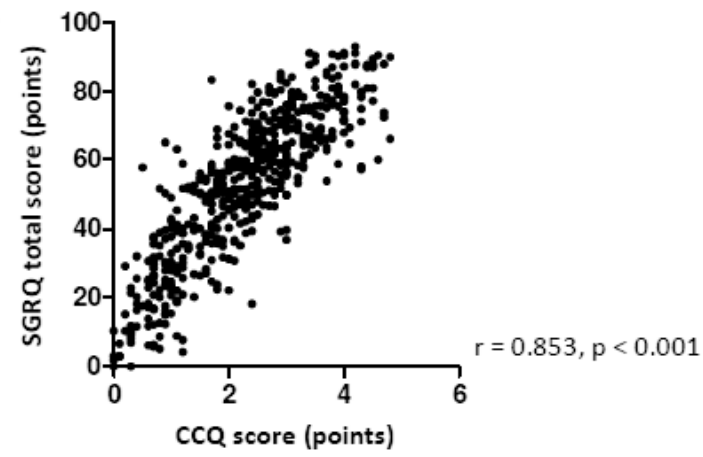

E-figure 1. Pearson Correlation between a) mMRC and CAT; b) mMRC and CCQ; c) mMRC and SGRQ; d) CAT 


\section{Exacerbation}

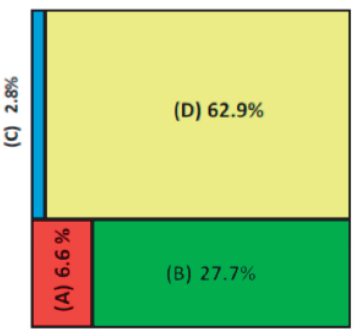

e-Figure 2a. CAT $\geq 10$

Hospitalization

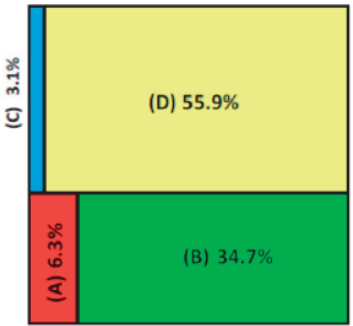

e-Figure 2e. CAT $\geq 10$

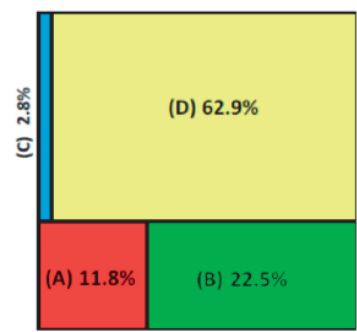

e-Figure $2 \mathrm{~b} . \mathrm{CCQ} \geq 1, \mathrm{~K}=0.806$

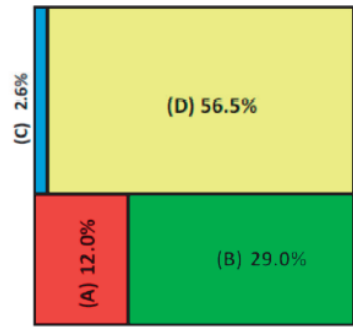

e-Figure 2f. $C C Q \geq 1, K=0.820$

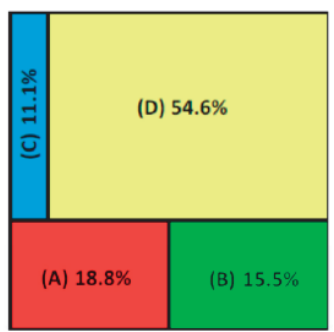

e-Figure 2c. CCQ $\geq 1.5, K=0.689$

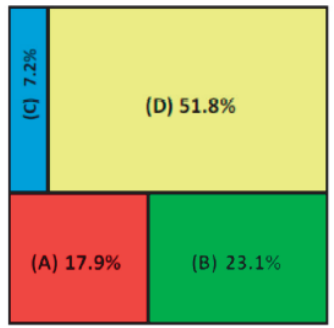

e-Figure $2 \mathrm{~g}$. $C C Q \geq 1.5, \mathrm{~K}=0.710$

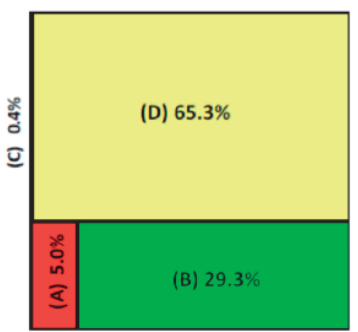

e-Figure 2 d. $C C Q \geq 0.6, K=0.868$

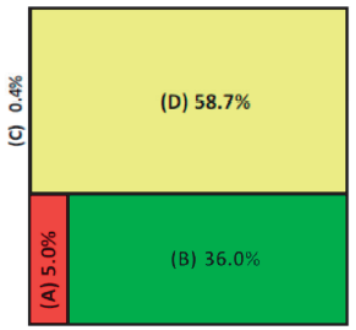

e-Figure $2 \mathrm{~h}$. CCQ $\geq 0.6, \mathrm{~K}=0.878$

E-figure 2. Frequency distribution stratified by symptom measure and exacerbation risk assessment using alternative cut-points for CCQ.

\section{Exacerbation}

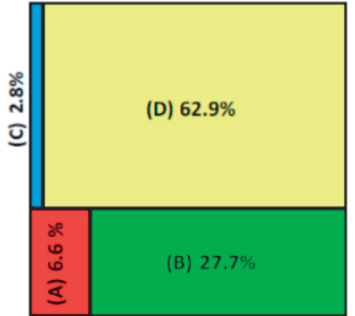

e-Figure 3a. CAT $\geq 10$

\section{Hospitalization}

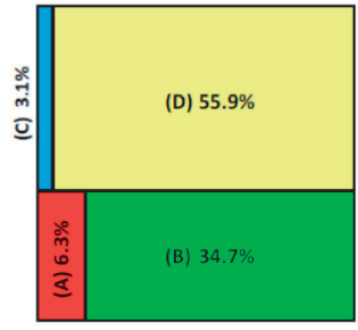

e-Figure 3e. CAT $\geq 10$

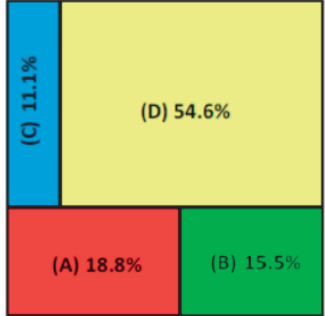

e-Figure 3b. $m M R C \geq 2, K=0.602$

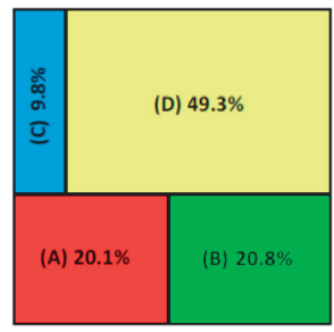

e-Figure 3f. $m M R C \geq 2, K=0.626$

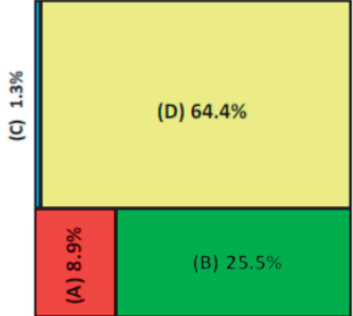

e-Figure $3 c$. $m M R C \geq 1, K=0.765$

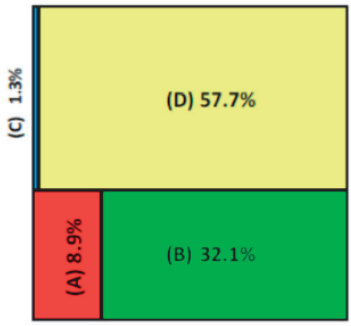

e-Figure $3 \mathrm{~g} . \mathrm{mMRC} \geq 1, \mathrm{~K}=0.782$

E-figure 3. Frequency distribution stratified by symptom measure and exacerbation risk assessment using alternative cut-points for mMRC 

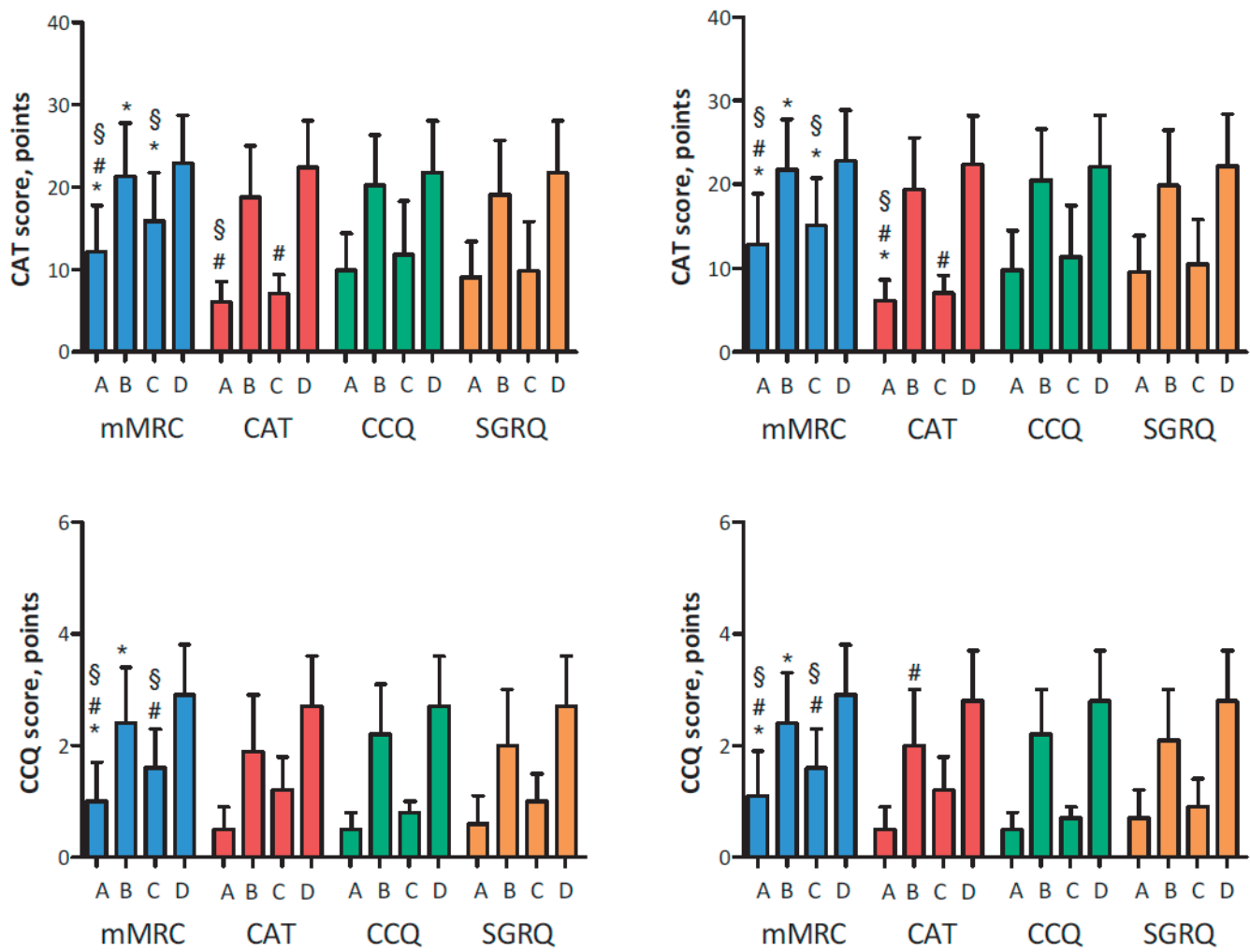

E-figure 4. Health status as assessed by a) CAT and b) CCQ (left column: degree of airflow limitation/exacerbation history; right column: degree of airflow limitation/hospitalization history). Significances are only described for comparison between similar GOLD groups using different symptom measures (e.g. mMRC GOLD A versus CAT GOLD A versus CCQ GOLD A versus SGRQ GOLD A. For significances within each symptom measure please see online supplementary table E1a and $\mathrm{E} 1 \mathrm{~b}) .{ }^{*} \mathrm{p} \leq 0.01$ versus $\mathrm{CAT} ; \# \mathrm{p} \leq 0.01$ versus CCQ; $\mathrm{S} \leq 0.01$ versus SGRQ 


\section{Chapter 8}

\section{Redefining Cut-Points for High Symptom Burden of the Global Initiative for Chronic Obstructive Lung Disease Classification in 18,577 Patients with Chronic Obstructive Pulmonary Disease}

Dionne E Smid, Frits ME Franssen, Maria Gonik, Marc Miravitlles, Ciro Casanova, Borja G Cosio, Pilar de Lucas-Ramos, Jose M Marin, Cristina Martinez, Isabel Mir, Joan B Soriano, Juan P de Torres, Alvar Agusti, Nart B Atalay, Julia Billington, Afroditi K Boutou, Stefanie Brighenti-Zogg, Emma Chaplin, Samantha

Coster, James W Dodd, Selina Dürr, Alberto Fernandez-Villar, Miriam TJ

Groenen, Miguel Guimarães, Karel Hejduk, Victoria Higgins, Nicholas S Hopkinson, Nobuyuki Horita, Sarah Houben-Wilke, Daisy JA Janssen, Melissa Jehn, Rudolf Joerres, Annika Karch, Julia L Kelly, Yu-Il Kim, Hiroshi Kimura, Vladimir Koblizek, Janwillem H Kocks, Samantha SC Kon, Namhee Kwon, Inês

Ladeira, Sang-Do Lee, Joerg D Leuppi, Nicholas Locantore, José L LopezCampos, William D-C Man, Lana Maricic, Laura Mendoza, David Miedinger, Florin Mihaltan, Seigo Minami, Thys van der Molen, Trevor J Murrells, Nienke

Nakken, Yu Nishijima, Ian J Norman, Barbora Novotna, Denis E O'Donnell, Yoshitaka Ogata, Eanes D Pereira, James Piercy, David Price, Chaicharn Pothirat, Natya Raghavan, Thomas Ringbaek, Dimitar Sajkov, Naseh Sigari, Sally Singh, Mark Small, Guilherme F da Silva, Rebecca J Tanner, Ioanna G Tsiligianni, Baykal Tulek, Nikolaos Tzanakis, Lowie EGW Vanfleteren, Henrik Watz, Katherine A Webb, Emiel FM Wouters, Guogang G Xie, Masanori Yoshikawa and Martijn A Spruit 


\section{ABSTRACT}

Background Patients with chronic obstructive pulmonary disease (COPD) can be classified into groups $\mathrm{A} / \mathrm{C}$ or $\mathrm{B} / \mathrm{D}$ based on symptom intensity. Different threshold values for symptom questionnaires can result in misclassification and, in turn, different treatment recommendations. The primary aim was to find the best fitting cut-points for Global initiative for chronic Obstructive Lung Disease (GOLD) symptom measures, with a modified Medical Research Council dyspnea grade of 2 or higher as point of reference.

Methods After a computerized search, data from 41 cohorts and whose authors agreed to provide data were pooled. COPD studies were eligible for analyses if they included, at least age, sex, postbronchodilator spirometry, modified Medical Research Council, and COPD Assessment Test (CAT) total scores.

Main outcomes Receiver operating characteristic curves and the Youden index were used to determine the best calibration threshold for CAT, COPD Clinical Questionnaire, and St. Georges Respiratory Questionnaire total scores. Following, GOLD A/B/C/D frequencies were calculated based on current cut-points and the newly derived cut-points.

Findings A total of 18,577 patients with COPD [72.0\% male; mean age: 66.3 years (standard deviation 9.6)] were analyzed. Most patients had a moderate or severe degree of airflow limitation (GOLD spirometric grade 1, 10.9\%; grade 2, $46.6 \%$; grade 3, 32.4\%; and grade 4, 10.3\%). The best calibration threshold for CAT total score was 18 points, for COPD Clinical Questionnaire total score 1.9 points, and for St. Georges Respiratory Questionnaire total score 46.0 points.

Conclusions The application of these new cut-points would reclassify about one-third of the patients with COPD and, thus, would impact on individual disease management. Further validation in prospective studies of these new values are needed. 


\section{INTRODUCTION}

The Global initiative for chronic Obstructive Lung Disease (GOLD) is a recent practice strategy on the diagnosis, prevention, and management of chronic obstructive pulmonary disease (COPD) (1). Patients with COPD are classified based on postbronchodilator spirometry into grade I (forced expiratory volume in the first second, $\mathrm{FEV}_{1} \geq 80 \%$ predicted), grade II (FEV $50 \%$ to $<80 \%$ predicted), grade III ( $\mathrm{FEV}_{1} 30 \%$ to $<50 \%$ predicted), or grade $\mathrm{IV}\left(\mathrm{FEV}_{1}<30 \%\right.$ predicted). Additionally, patients are classified in groups $A$ to $D$ for specific therapeutic recommendations based on the degree of symptoms (low vs high), and the history of exacerbations and hospitalizations.

High symptoms are determined using various questionnaires: the modified Medical Research Council scale (mMRC, grade 2 or higher), the COPD Clinical Questionnaire (CCQ) total score (1 point or higher), the COPD Assessment test (CAT) total score (10 points or higher), and the St. Georges Respiratory Questionnaire (SGRQ) total score (25 points or higher) (1).

The choice of symptom questionnaire impacts the classification of patients with COPD in GOLD A/C or B/D groups (2-5). mMRC only focusses on the impact of dyspnea, the most common symptom of patients with COPD. The other symptom questionnaires also take other aspects of health-related quality of life into consideration. Therefore, the CAT, CCQ, or SGRQ may be preferred over MMRC. However, mMRC is easy to obtain, and, it is the most frequently used in clinical practice and studies, and is suggested to be used to categorize patients into symptom severity groups for the purpose of treatment $(1,6)$.

Previous studies suggest that the current cut-points need proper validation (4,7-10). Indeed, the GOLD Scientific Committee recognized that a calibration of the current cut-points of the symptom measures is an important topic that needs to be addressed in the next major revision of the GOLD document (10). Then again, the former threshold values for mMRC, SGRQ, and CAT are still used in the GOLD 2017 strategy (1). Interestingly, the GOLD document indicates that multidimensional scores like CAT do not categorize patients into symptom severity groups for the purpose of treatment, suggesting a central role of mMRC for patient classification. Therefore, new classification schemes should be benchmarked against mMRC.

The primary aim of this patient-level pooled analysis was to find best fitting cutpoints for GOLD symptom measures, with a mMRC dyspnea grade of 2 or higher as the point of reference. Following, the impact of the newly derived cut-points of all questionnaires on the frequency distribution of the GOLD staging was studied. 


\section{METHODS}

This is a pooled analysis of concurrent cohort studies assessing mMRC and multidimensional evaluation systems in COPD. To identify the original cohorts, we performed a computerized search in the database Medline/Pubmed for reports published from the first CAT publication (September 2009) to June 2015 (11). D.S., S.H-W., or M.S. approached the corresponding authors to gather information about their readiness to partake and the availability of a minimum required set of individual data of patients with COPD, including age, sex, postbronchodilator $\mathrm{FEV}_{1}$, CAT total score, and mMRC dyspnea grade. All participants within their respective studies gave their informed written consent to participate in the original study, and each study was approved by their respective ethics committee.

\section{Measurements}

The individual demographics and clinical characteristics [sex, age (years), height (m), weight (kg), smoking status (current/former/never), pack years, use of longterm oxygen therapy (yes/no), FEV 1 (liters), $\mathrm{FEV}_{1}$ (\% predicted), $\mathrm{FEV}_{1} / \mathrm{FVC}(\%)$, mMRC dyspnea grade, CAT total score (points), CCQ total score (points), SGRQ total score (points), and number of COPD exacerbations and/or hospitalizations in the last 12 months] were provided from each dataset. All data were pooled, and the dataset was cleaned.

\section{Statistics}

Mean (standard deviation), median (interquartile range), or proportions were calculated, whatever appropriate. Pearson product moment correlations between mMRC dyspnea grade, CAT total score, CCQ total score, and SGRQ total score were performed. A r-value of $< \pm 0.20$ indicates no meaningful correlation; \pm 0.20 to \pm 0.34 , weak; \pm 0.35 to \pm 0.50 , moderate; and $> \pm 0.50$, strong correlation (12). Postbronchodilator $\mathrm{FEV}_{1}$ was used to classify patients into spirometric grades 1-4. Allocation to GOLD groups A-D was done using $m M R C \geq 2$, CAT $\geq 10$, CCQ $\geq 1$, and SGRQ $\geq 25$ in combination with exacerbations history. In addition, patients were re-allocated (if applicable) based on the newly derived cut-points in combination with exacerbations history.

Receiver operating characteristic (ROC) curves were used to reveal the cut-points for the GOLD symptom measures that discriminate best between the 2 clusters defined on mMRC dyspnea grade ( 2 or higher). ROC curve represented dependency between the sensitivity and specificity of the binary classification for different cut-points of the GOLD symptom measures. The cut-point, which satisfied the optimal criterion of the Youden index (13), was referred as the best 
calibration threshold. The optimal cut-points were calculated for CAT total score, CCQ total score, and SGRQ total score. A software environment R v 3.1.0 was used. The ROC function from the pROC package was used to visualize the ROC curves and calculate the best thresholds.

Graphs were created using GraphPad Prism v 6 (GraphPad Software Inc. San Diego, CA). Statistics were performed using SPSS for Windows, v 20.0 (IBM Corp, Armonk, NY). A P value of $\leq 0.01$ was interpreted as statistically significant, to obtain a greater statistical power than the usual $\mathrm{P}$ value of $<0.05$.

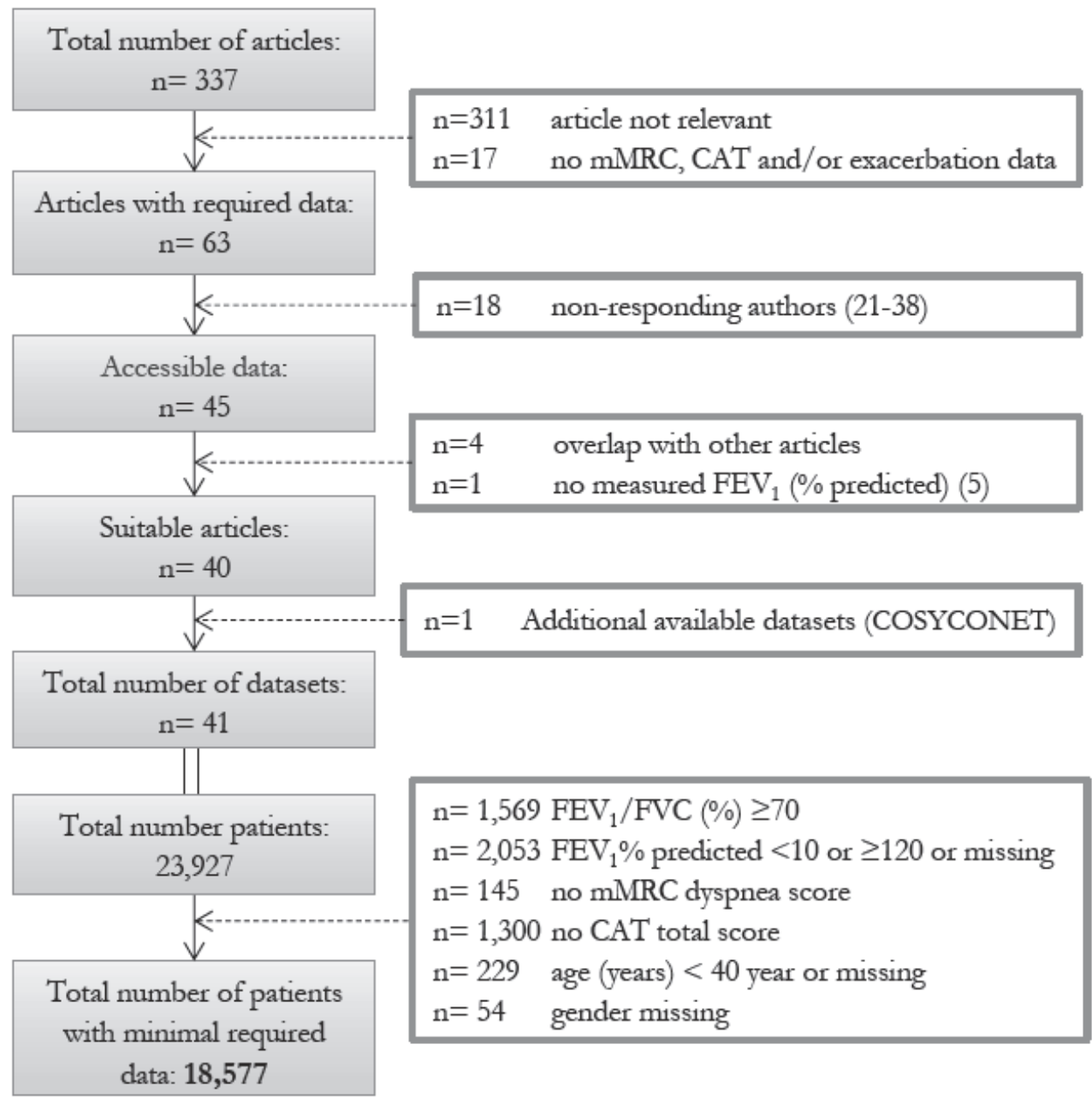

Figure E1. Flow diagram of subject inclusion 
Table 1. General characteristics per resource article

\begin{tabular}{|c|c|c|c|}
\hline \multirow{2}{*}{ Lead author } & \multicolumn{3}{|c|}{ Dataset resource } \\
\hline & $\begin{array}{l}\text { Agusti } \\
(39)\end{array}$ & $\begin{array}{l}\text { Billington } \\
(40)\end{array}$ & $\begin{array}{l}\text { Boutou } \\
\text { (41) }\end{array}$ \\
\hline Journal and year & $\begin{array}{l}\text { Qual Life Res, } \\
2015\end{array}$ & $\begin{array}{l}\text { COPD, } \\
2015\end{array}$ & $\begin{array}{l}\text { BMJ Open } \\
\text { Respir Res, } 2014\end{array}$ \\
\hline Country & Spain & UK & UK \\
\hline Cohort & GSK & & \\
\hline $\mathbf{N}$ & 110 & 61 & 703 \\
\hline Gender (male), n (\%) & $104(94.5)$ & $29(47.5)$ & $348(49.5)$ \\
\hline Age, years & $70.3(9.7)$ & $71.2(10.0)$ & $67.3(9.8)$ \\
\hline Current smoker, n (\%) & $28(25.5)$ & $32(52.5)$ & - \\
\hline Packyears & $40.0(24.6-54.3)^{\mathrm{a}}$ & - & - \\
\hline $\mathrm{BMI}, \mathrm{kg} / \mathrm{m}^{2}$ & - & $26.1(22.3-29.9)$ & $26.0(22.4-30.0)^{\mathrm{d}}$ \\
\hline $\mathrm{FEV}_{1}(\%$ pred.) & $63.6(20.0)$ & $65.4(15.8)$ & $49.2(18.8)$ \\
\hline $\mathrm{FEV}_{1} / \mathrm{FVC}(\%)$ & $54.0(11.2)^{\mathrm{b}}$ & $53.0(10.2)$ & $43.9(14.5)^{\mathrm{e}}$ \\
\hline LTOT, n (\%) & - & - & \\
\hline GOLD stage, n (\%) & & & \\
\hline$-\mathbf{I}$ & $24(21.8)$ & $12(19.7)$ & $45(6.4)$ \\
\hline - II & $57(51.8)$ & $39(63.9)$ & $289(41.1)$ \\
\hline - III & $24(21.8)$ & $9(14.8)$ & $246(35.0)$ \\
\hline - IV & $5(4.5)$ & $1(1.6)$ & $123(17.5)$ \\
\hline $\begin{array}{l}\text { Exacerbations previous } \\
12 \text { months } \geq 2, \mathrm{n}(\%)\end{array}$ & $9(8.2)$ & $41(67.2)$ & - \\
\hline $\begin{array}{l}\text { Hospitalizations previous } \\
12 \text { months } \geq 1 \text {, n (\%) }\end{array}$ & $6(5.5)$ & - & - \\
\hline $\begin{array}{l}\text { mMRC dyspnea grade } \\
\geq 2, \mathrm{n}(\%)\end{array}$ & $49(44.5)$ & $41(67.2)$ & $576(81.9)$ \\
\hline CAT total score, points & $16.3(8.2)$ & $14.8(6.8)$ & $21.2(7.5)$ \\
\hline CCQ total score, points & - & - & $3.1(1.2)^{\mathrm{f}}$ \\
\hline SGRQ total score, points & $44.5(24.1)^{c}$ & - & $47.3(16.4)^{g}$ \\
\hline
\end{tabular}

a 8 missing; b 1 missing; c 7 missing; d 190 missing; e 462 missing; f 522 missing; g 495 missing; h 11

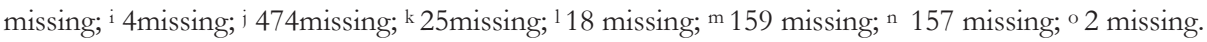

Values expressed as mean (SD), median (IQR) or number of patients (\%).

Abbreviations: $\mathrm{BMI}=$ body mass index; $\mathrm{CAT}=\mathrm{COPD}$ Assessment Test; $\mathrm{CCQ}=$ Clinical $\mathrm{COPD}$ Questionnaire; $\mathrm{FEV}_{1}=$ Forced Expiratory Volume in the first second; FVC= Forced Vital Capacity; GOLD = Global initiative for chronic Obstructive Lung Disease; LTOT= long-term oxygen therapy; $\mathrm{mMRC}=$ modified Medical Research Council dyspnoea scale; SGRQ $=$ St. George's Respiratory Questionnaire. 


\begin{tabular}{|c|c|c|c|c|c|c|}
\hline \multicolumn{7}{|c|}{ Dataset resource } \\
\hline De Torres & Casanova & Casanova & Chaplin & Dodd & Horita & Jehn \\
\hline$(42)$ & (43) & $(43)$ & $(44)$ & $(45)$ & $(46)$ & $(47)$ \\
\hline CHEST, & Respir & Chest, & J Cardiopulm & Thorax, & Clin & Environ \\
\hline 2014 & Res, 2014 & 2014 & $\begin{array}{l}\text { Rehabil Prev, } \\
2015\end{array}$ & 2011 & $\begin{array}{l}\text { Respir J, } \\
2013\end{array}$ & Health, 2013 \\
\hline \multicolumn{3}{|c|}{ Spain } & UK & UK & Japan & Germany \\
\hline \multicolumn{7}{|c|}{ CHAIN } \\
\hline \multicolumn{3}{|c|}{785} & 166 & 196 & 74 & 34 \\
\hline \multicolumn{3}{|c|}{$658(83.8)$} & $89(53.6)$ & $114(58.2)$ & $60(81.1)$ & $22(64.7)$ \\
\hline \multicolumn{3}{|c|}{$67.8(8.8)$} & $70.8(8.7)$ & $69.2(9.0)$ & $72.3(9.4)$ & $63.5(9.9)$ \\
\hline \multicolumn{3}{|c|}{$223(28.4)$} & - & - & $11(14.9)$ & $28(82.4)$ \\
\hline \multicolumn{3}{|c|}{$55.9(28.0)^{\mathrm{h}}$} & - & - & $51.6(30.4)$ & $15.7(12.1)$ \\
\hline \multicolumn{3}{|c|}{$27.8(24.8-31.0)^{\mathrm{i}}$} & $27.7(7.0)^{\mathrm{k}}$ & $27.6(6.6)^{1}$ & $21.2(3.0)$ & $26.5(19.9-29.8)$ \\
\hline \multicolumn{3}{|c|}{$59.3(20.2)$} & $56.2(24.4)$ & $51.2(19.4)$ & $43.2(12.7)$ & $46.2(13.4)$ \\
\hline \multicolumn{3}{|c|}{$51.9(11.3)$} & - & - & $59.7(7.7)$ & $42.3(13.2)^{\circ}$ \\
\hline \multicolumn{3}{|c|}{$69(22.3) i$} & & - & $16(21.6)$ & $8(23.5)$ \\
\hline \multicolumn{3}{|c|}{$134(17.1)$} & 35 (21.1) & $16(8.2)$ & $0(0.0)$ & $0(0.0)$ \\
\hline \multicolumn{3}{|c|}{$377(48.0)$} & $55(33.1)$ & $86(43.9)$ & $20(27.0)$ & $14(41.2)$ \\
\hline \multicolumn{3}{|c|}{$231(29.4)$} & $50(30.1)$ & $65(33.2)$ & $42(56.8)$ & $15(44.1)$ \\
\hline \multicolumn{3}{|c|}{$43(5.5)$} & $26(15.7)$ & $29(14.8)$ & $12(16.2)$ & $5(14.7)$ \\
\hline \multicolumn{3}{|c|}{98 (12.5) } & - & - & - & $11(32.4)$ \\
\hline \multicolumn{3}{|c|}{89 (11.3) } & - & - & - & $20(58.8)$ \\
\hline \multicolumn{3}{|c|}{358 (45.6) } & 131 (78.9) & $148(75.5)$ & $35(47.3)$ & $16(47.1)$ \\
\hline \multicolumn{3}{|c|}{$12.1(7.6)$} & $21.8(7.6)$ & $20.2(7.5)$ & $11.1(7.9)$ & $19.1(5.7)$ \\
\hline \multicolumn{3}{|c|}{$1.6(1.1)$} & - & $2.9(1.2)^{\mathrm{m}}$ & - & - \\
\hline \multicolumn{3}{|c|}{ - } & - & $45.7(19.1)^{\mathrm{n}}$ & - & - \\
\hline
\end{tabular}




\begin{tabular}{|c|c|c|c|c|}
\hline & Dataset resource & & & \\
\hline Lead author & $\begin{array}{l}\text { Jones } \\
(2)\end{array}$ & $\begin{array}{l}\text { Karch } \\
(20)\end{array}$ & $\begin{array}{l}\text { Kelly } \\
(48)\end{array}$ & $\begin{array}{l}\text { Kim } \\
(49)\end{array}$ \\
\hline Journal and year & $\begin{array}{l}\text { ERJ, } \\
2013\end{array}$ & $\begin{array}{l}\text { Respir Med, } \\
2016\end{array}$ & $\begin{array}{l}\text { Respiration, } \\
2012\end{array}$ & $\begin{array}{l}\text { Pulm } \\
\text { Med, } 2013\end{array}$ \\
\hline Country & $\begin{array}{l}\text { Belgium, France, } \\
\text { UK, Germany, Italy, } \\
\text { the Netherlands and } \\
\text { Spain }\end{array}$ & Germany & UK & $\begin{array}{l}\text { South } \\
\text { Korea }\end{array}$ \\
\hline Cohort & HEED & COSYCONET & & - \\
\hline $\mathbf{N}$ & 1725 & 2258 & 219 & 238 \\
\hline Gender (male), n (\%) & $1251(72.5)$ & $1379(61.1)$ & $139(63.5)$ & $192(80.7)$ \\
\hline Age, years & $64.9(9.7)$ & $65.1(8.4)$ & $64.0(9.6)$ & $67.8(9.4)$ \\
\hline Current smoker, n (\%) & $737(42.7)$ & $561(24.8)$ & $28(12.8)$ & $51(21.4)$ \\
\hline Packyears & $38.4(19.2)^{a}$ & $41.2(22.0-63.0)^{\mathrm{g}}$ & $41.7(23.2)^{\mathrm{k}}$ & $27.9(26.2)$ \\
\hline $\mathrm{BMI}, \mathrm{kg} / \mathrm{m}^{2}$ & $27.0(4.9)^{\mathrm{b}}$ & $26.2(23.2-29.4)^{\mathrm{h}}$ & $25.2(5.4)^{1}$ & $22.9(3.2)^{\mathrm{m}}$ \\
\hline $\mathrm{FEV}_{1}(\%$ pred.) & $56.4(19.7)$ & $52.5(18.5)$ & $40.4(17.9)$ & $72.4(23.7)$ \\
\hline $\mathrm{FEV}_{1} / \mathrm{FVC}(\%)$ & $56.2(10.6)^{\mathrm{c}}$ & $51.3(11.0)$ & $36.9(12.7)$ & $54.5(11.8)$ \\
\hline LTOT, n (\%) & - & $436(19.3)$ & $32(14.6)$ & - \\
\hline GOLD stage, n (\%) & & & & \\
\hline$-I$ & $216(12.5)$ & $202(8.9)$ & $8(3.7)$ & 99 (41.6) \\
\hline - II & $827(47.9)$ & $956(42.3)$ & $45(20.5)$ & $92(38.7)$ \\
\hline - III & $540(31.3)$ & $856(37.9)$ & $96(43.8)$ & $38(16.0)$ \\
\hline- IV & $142(8.2)$ & $244(10.8)$ & $70(32.0)$ & $9(3.8)$ \\
\hline $\begin{array}{l}\text { Exacerbations previous } \\
12 \text { months } \geq 2, \mathrm{n}(\%)\end{array}$ & $451(29.9)^{\mathrm{d}}$ & $633(28.0)$ & $132(60.3)$ & $126(52.9)$ \\
\hline $\begin{array}{l}\text { Hospitalizations previous } \\
12 \text { months } \geq 1, \mathrm{n}(\%)\end{array}$ & $155(10.3)^{\mathrm{e}}$ & $453(20.1)^{\mathrm{i}}$ & - & - \\
\hline $\begin{array}{l}\text { mMRC dyspnea grade } \\
\geq 2, \mathrm{n}(\%)\end{array}$ & $751(43.5)$ & $1090(48.3)$ & $183(83.6)$ & $93(39.1)$ \\
\hline CAT total score, points & $17.7(8.4)$ & $18.1(7.4)$ & $23.1(8.1)$ & $16.0(9.3)$ \\
\hline CCQ total score, points & - & - & - & - \\
\hline SGRQ total score, points & $44.7(19.4)^{\mathrm{f}}$ & $43.6(19.9)^{j}$ & - & - \\
\hline
\end{tabular}

a 71 missing; b 6 missing; c 49 missing; d 151 missing; e 218 missing; 151 missing; 11 missing;

h 2 missing; i 2 missing; ${ }^{i} 12$ missing; ${ }^{k} 125$ missing; ${ }^{1} 8$ missing; ${ }^{m} 3$ missing; ${ }^{n} 7$ missing; ${ }^{\circ} 1$ missing; $\mathrm{p}$

3 missing; q 6 missing; r 125 missing; s 14 missing; t 5 missing; u 23 missing.

Values expressed as mean (SD), median (IQR) or number of patients (\%).

Abbreviations: $\mathrm{BMI}=$ body mass index; $\mathrm{CAT}=\mathrm{COPD}$ Assessment Test; $\mathrm{CCQ}=\mathrm{Clinical} \mathrm{COPD}$ Questionnaire; $\mathrm{FEV}_{1}=$ Forced Expiratory Volume in the first second; $\mathrm{FVC}=$ Forced Vital Capacity; GOLD $=$ Global initiative for chronic Obstructive Lung Disease; LTOT= long-term oxygen therapy; $\mathrm{mMRC}=$ modified Medical Research Council dyspnoea scale; SGRQ $=$ St. George's Respiratory Questionnaire. 


\begin{tabular}{|c|c|c|c|c|}
\hline \multicolumn{5}{|c|}{ Dataset resource } \\
\hline $\begin{array}{l}\text { Kon } \\
(50)\end{array}$ & $\begin{array}{l}\text { Kwon } \\
(51)\end{array}$ & $\begin{array}{l}\text { Lee } \\
(52)\end{array}$ & $\begin{array}{l}\text { Ladeira } \\
(53)\end{array}$ & $\begin{array}{l}\text { Lopez- } \\
\text { Campos (54) }\end{array}$ \\
\hline Thorax, 2014 & CHEST, 2013 & $\begin{array}{l}\text { Respir Med, } \\
2014\end{array}$ & $\begin{array}{l}\text { Rev Port } \\
\text { Pneumol, } 2015\end{array}$ & $\begin{array}{l}\text { Int J COPD, } \\
2015\end{array}$ \\
\hline the UK & $\begin{array}{l}\text { Indonesia, } \\
\text { Korea, Vietnam } \\
\text { and Hong Kong }\end{array}$ & $\begin{array}{l}\text { Australia, China, } \\
\text { Korea and } \\
\text { Taiwan }\end{array}$ & Portugal & Spain \\
\hline- & GSK & GSK & & On-Sint \\
\hline 260 & 303 & 321 & 82 & 499 \\
\hline $151(58.1)$ & $296(97.7)$ & $286(89.1)$ & $64(78.0)$ & 407 (81.6) \\
\hline $71.0(8.8)$ & $69.0(9.4)$ & $69.7(8.8)$ & $70.2(9.5)$ & $67.1(9.3)$ \\
\hline $31(11.9)$ & $53(17.5)$ & $62(19.3)$ & $17(20.7)$ & $115(23.0)^{\mathrm{p}}$ \\
\hline $41.1(29.5)$ & $30.0(20.0-50.0)$ & $40.0(25.0-60.0)$ & $41.5(20.0-75.0)$ & $38.3(20.6)$ \\
\hline $27.0(23.7-31.0)$ & $20.8(3.6)$ & $23.4(4.1)$ & $26.2(5.0)$ & $27.7(4.3) \mathrm{q}$ \\
\hline $50.1(20.6)$ & $49.9(18.0)$ & $50.6(19.3)$ & $44.8(16.3)$ & $58.7(18.4)$ \\
\hline $50.4(14.3)$ & $50.0(9.8)$ & $46.5(12.1)$ & $67.0(11.4)$ & $54.6(10.8)^{\mathrm{r}}$ \\
\hline $12(4.6)$ & - & - & $47(57.3)$ & $69(14.2)^{\mathrm{s}}$ \\
\hline $26(10.0)$ & $18(5.9)$ & $25(7.8)$ & $2(2.4)$ & $55(11.0)$ \\
\hline $96(36.9)$ & $131(43.2)$ & $121(37.7)$ & $22(26.8)$ & $304(60.9)$ \\
\hline $84(32.3)$ & $121(39.9)$ & $137(42.7)$ & $48(58.5)$ & $112(22.4)$ \\
\hline $54(20.8)$ & $33(10.9)$ & $38(11.8)$ & $10(12.2)$ & $28(5.6)$ \\
\hline $117(45.0)$ & $95(32.1)^{\mathrm{n}}$ & $153(47.7)$ & $26(31.7)$ & $309(62.6)^{t}$ \\
\hline- & - & - & $25(30.5)$ & $161(33.8)^{\mathrm{u}}$ \\
\hline $185(71.2)$ & $169(55.8)$ & $153(47.7)$ & $54(65.9)$ & $247(49.5)$ \\
\hline $20.7(7.9)$ & $17.8(8.1)$ & $14.8(8.0)$ & $17.3(8.2)$ & $18.4(7.6)$ \\
\hline $2.8(1.2)$ & - & - & - & - \\
\hline $49.3(16.4)$ & $45.4(17.8)^{\circ}$ & - & - & - \\
\hline
\end{tabular}




\begin{tabular}{|c|c|c|c|c|}
\hline \multirow{2}{*}{ Author } & \multicolumn{4}{|c|}{ Dataset resource } \\
\hline & $\begin{array}{l}\text { Manca } \\
(55)\end{array}$ & $\begin{array}{l}\text { Maricic } \\
(56)\end{array}$ & $\begin{array}{l}\text { Mendoza } \\
(57)\end{array}$ & $\begin{array}{l}\text { Mihaltan } \\
(58)\end{array}$ \\
\hline $\begin{array}{l}\text { Journal and year } \\
\text { published }\end{array}$ & $\begin{array}{l}\text { COPD, } \\
2014\end{array}$ & $\begin{array}{l}\text { Coll Antropol, } \\
2013\end{array}$ & $\begin{array}{l}\text { Eur Respir J, } \\
2015\end{array}$ & $\begin{array}{l}\text { Pneumologia, } \\
2015\end{array}$ \\
\hline Country & Spain & Croatia & Chile & Romania \\
\hline \multicolumn{5}{|l|}{ Cohort } \\
\hline $\mathbf{N}$ & 92 & 33 & 101 & 1082 \\
\hline Gender (male), n (\%) & $67(72.8)$ & $25(75.8)$ & $62(61.4)$ & $801(74.0)$ \\
\hline Age, years & $66.1(10.8)$ & $62.6(7.9)$ & $68.8(8.5)$ & $63.1(10.1)$ \\
\hline Current smoker, n (\%) & $4(4.3)$ & $12(36.4)^{\mathrm{a}}$ & - & $569(52.6)$ \\
\hline Packyears & $33.0(15.5-60.0)$ & $41.6(35.2)$ & $40.5(20.6)$ & - \\
\hline $\mathrm{BMI}, \mathrm{kg} / \mathrm{m}^{2}$ & $26.2(4.7)$ & $24.5(3.5)$ & $26.9(4.5)$ & - \\
\hline $\mathrm{FEV}_{1}(\%$ pred. $)$ & $48.6(17.2)$ & $67.5(16.9)$ & $66.1(19.5)$ & $56.6(17.8)$ \\
\hline $\mathrm{FEV}_{1} / \mathrm{FVC}(\%)$ & $47.3(11.6)$ & $57.3(7.9)$ & $55.0(9.5)$ & - \\
\hline LTOT, n (\%) & $7(7.6)$ & - & $3(3.0)$ & - \\
\hline \multicolumn{5}{|l|}{ GOLD stage, n (\%) } \\
\hline$-\mathbf{I}$ & $5(5.4)$ & $6(18.2)$ & $28(27.7)$ & $119(11.0)$ \\
\hline- II & $32(34.8)$ & $24(72.7)$ & $52(51.5)$ & $560(51.8)$ \\
\hline - III & $45(48.9)$ & $2(6.1)$ & $18(17.8)$ & $336(31.1)$ \\
\hline - IV & $10(10.9)$ & $1(3.0)$ & $3(3.0)$ & $67(6.2)$ \\
\hline $\begin{array}{l}\text { Exacerbations previous } \\
12 \text { months } \geq 2, \mathrm{n}(\%)\end{array}$ & $29(31.5)$ & - & - & $470(43.4)$ \\
\hline $\begin{array}{l}\text { Hospitalizations previous } \\
12 \text { months } \geq 1 \text {, n (\%) }\end{array}$ & $15(16.3)$ & - & - & - \\
\hline $\begin{array}{l}\text { mMRC dyspnea grade } \\
\geq 2, \mathrm{n}(\%)\end{array}$ & $51(55.4)$ & $6(18.2)$ & $49(48.5)$ & $665(61.5)$ \\
\hline CAT total score, points & $12.8(8.1)$ & $14.6(7.7)$ & $16.0(8.2)$ & $17.8(7.9)$ \\
\hline CCQ total score, points & - & - & - & - \\
\hline SGRQ total score, points & - & - & $42.8(18.4)$ & - \\
\hline
\end{tabular}

a 21 missing; b 145 missing; c 717 missing; d 28 missing; e 2 missing; f 153 missing; g 10 missing;

h 35 missing; i 2 missing; 1 missing; ${ }^{2} 29$ missing; 198 missing; m 98 missing; ${ }^{n} 1$ missing.

Values expressed as mean (SD), median (IQR) or number of patients (\%).

Abbreviations: $\mathrm{BMI}=$ body mass index; $\mathrm{CAT}=\mathrm{COPD}$ Assessment Test; $\mathrm{CCQ}=\mathrm{Clinical} \mathrm{COPD}$ Questionnaire; $\mathrm{FEV}_{1}=$ Forced Expiratory Volume in the first second; FVC= Forced Vital Capacity; GOLD = Global initiative for chronic Obstructive Lung Disease; LTOT= long-term oxygen therapy; mMRC $=$ modified Medical Research Council dyspnoea scale; SGRQ $=$ St. George's Respiratory Questionnaire. 
Redefining cut-points for high symptom burden

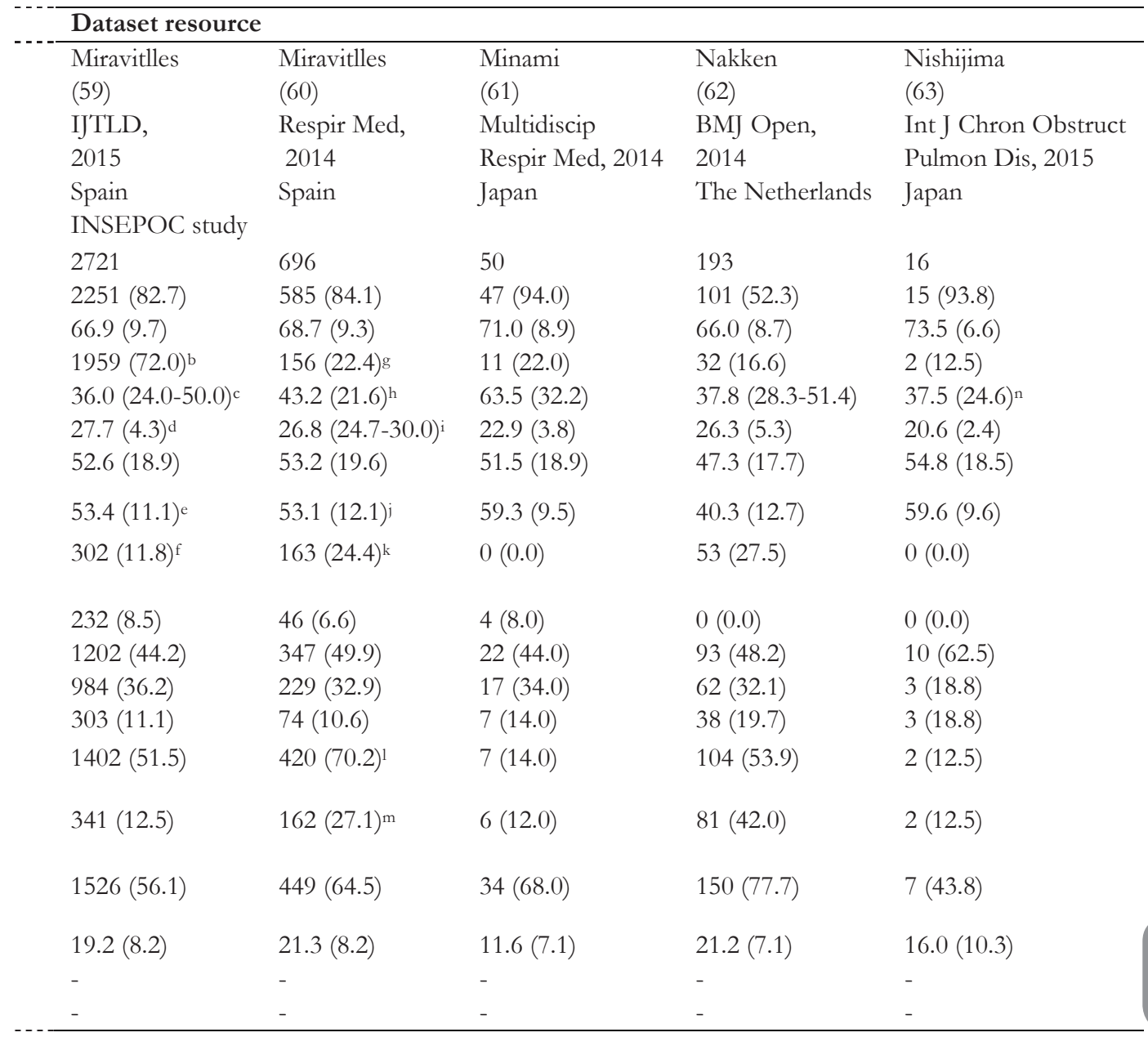




\begin{tabular}{|c|c|c|c|c|}
\hline & Dataset resource & & & \\
\hline Author & $\begin{array}{l}\text { Novotna } \\
\text { (64) }\end{array}$ & $\begin{array}{l}\text { Pothirat } \\
(65)\end{array}$ & $\begin{array}{l}\text { Pothirat } \\
(66)\end{array}$ & $\begin{array}{l}\text { Price } \\
(67)\end{array}$ \\
\hline $\begin{array}{l}\text { Journal and year } \\
\text { published }\end{array}$ & IJCOPD, 2014 & $\begin{array}{l}\text { BMC Pulm } \\
\text { Med, } 2014\end{array}$ & $\begin{array}{l}\text { Int J Chron } \\
\text { Obstruct Pulmon } \\
\text { Dis, } 2015\end{array}$ & Int J COPD, 2014 \\
\hline Country & The Czech republic & Thailand & Thailand & $\begin{array}{l}\text { US, France, Spain, } \\
\text { Germany, Italy, UK }\end{array}$ \\
\hline Cohort & $\begin{array}{l}\text { Czech Multicentre } \\
\text { Research Database } \\
\text { of COPD (CMRD) }\end{array}$ & & & $\begin{array}{l}\text { Adelphi Respiratory } \\
\text { DSP }\end{array}$ \\
\hline $\mathbf{N}$ & 514 & 97 & 153 & 1070 \\
\hline Gender (male), n (\%) & $374(72.8)$ & $80(82.5)$ & $89(58.2)$ & $734(68.6)$ \\
\hline Age, years & $67.3(8.1)$ & $70.7(8.2)$ & $71.5(8.5)$ & $64.6(10.4)$ \\
\hline Current smoker, n (\%) & $93(18.1)$ & $5(5.2)$ & - & $338(31.6)$ \\
\hline Packyears & $38.0(25.0-48.0)^{\mathrm{a}}$ & $34.0(19.0-59.5)$ & - & $32.0(20.0-48.0)^{\mathrm{d}}$ \\
\hline BMI, $\mathrm{kg} / \mathrm{m}^{2}$ & $27.2(5.9)$ & $20.9(3.5)$ & $20.2(3.9)$ & $26.4(23.4-29.4)^{\mathrm{e}}$ \\
\hline $\mathrm{FEV}_{1}(\%$ pred.) & $43.3(11.2)$ & $56.4(21.0)$ & $47.8(17.6)$ & $60.5(16.0)$ \\
\hline $\mathrm{FEV}_{1} / \mathrm{FVC}(\%)$ & $50.5(10.7)$ & $50.8(12.1)$ & $51.9(10.3)$ & - \\
\hline $\begin{array}{l}\text { LTOT, n (\%) } \\
\text { GOLD stage, n (\%) }\end{array}$ & $78(15.2)$ & - & - & $143(13.4)$ \\
\hline$-I$ & $0(0.0)$ & $14(14.4)$ & $10(6.5)$ & $112(10.5)$ \\
\hline- II & $168(32.7)$ & $42(43.3)$ & $58(37.9)$ & $711(66.4)$ \\
\hline - III & $278(54.1)$ & $27(27.8)$ & $61(39.9)$ & $203(19.0)$ \\
\hline - IV & $68(13.2)$ & $14(14.4)$ & $24(15.7)$ & $44(4.1)$ \\
\hline $\begin{array}{l}\text { Exacerbations previous } \\
12 \text { months } \geq 2 \text {, n (\%) }\end{array}$ & $162(31.5)$ & $13(13.4)$ & - & $356(33.4)^{\mathrm{f}}$ \\
\hline $\begin{array}{l}\text { Hospitalizations previous } \\
12 \text { months } \geq 1 \text {, n ( } \%)\end{array}$ & $141(27.4)$ & - & - & $150(14.0)^{g}$ \\
\hline $\begin{array}{l}\text { mMRC dyspnea grade } \\
\geq 2, \mathrm{n}(\%)\end{array}$ & $391(76.1)$ & $39(40.2)$ & $96(62.7)$ & $377(35.2)$ \\
\hline CAT total score, points & $16.6(7.8)$ & $12.3(7.3)$ & $12.4(7.3)$ & $20.6(8.5)$ \\
\hline CCQ total score, points & - & - & - & - \\
\hline SGRQ total score, points & $48.0(18.5)^{\mathrm{b}}$ & $38.3(20.7)$ & $42.1(21.0)^{\mathrm{c}}$ & - \\
\hline
\end{tabular}

a 57 missing; b 319 missing; c 3 missing; d 62 missing; e 37 missing; f 4 missing; 1 missing; h 2 missing;

i 8 missing; 13 missing; ${ }^{~} 113$ missing.

Values expressed as mean (SD), median (IQR) or number of patients (\%).

Abbreviations: $\mathrm{BMI}=$ body mass index; $\mathrm{CAT}=\mathrm{COPD}$ Assessment Test; $\mathrm{CCQ}=\mathrm{Clinical}$ COPD

Questionnaire; $\mathrm{FEV}_{1}=$ Forced Expiratory Volume in the first second; $\mathrm{FVC}=$ Forced Vital Capacity;

GOLD = Global initiative for chronic Obstructive Lung Disease; LTOT= long-term oxygen therapy; $\mathrm{mMRC}=$ modified Medical Research Council dyspnoea scale; SGRQ $=$ St. George's Respiratory Questionnaire. 


\begin{tabular}{|c|c|c|c|c|}
\hline \multicolumn{5}{|c|}{ Dataset resource } \\
\hline $\begin{array}{l}\text { Raghavan } \\
(68)\end{array}$ & $\begin{array}{l}\text { Ringbaek } \\
(69)\end{array}$ & $\begin{array}{l}\text { Da Silva } \\
(18)\end{array}$ & $\begin{array}{l}\text { Da Silva } \\
\text { (19) }\end{array}$ & $\begin{array}{l}\text { Sigari } \\
(70)\end{array}$ \\
\hline COPD, 2012 & COPD, 2012 & $\begin{array}{l}\text { Qual Life Res, } \\
2014\end{array}$ & $\begin{array}{l}\text { J Bras Pneumol, } \\
2013\end{array}$ & $\begin{array}{l}\text { Rheumatol Int, } \\
2015\end{array}$ \\
\hline Canada & Denmark & \multicolumn{2}{|c|}{ Brazil } & Iran \\
\hline \multicolumn{5}{|l|}{ COLD } \\
\hline 111 & 118 & & 50 & 78 \\
\hline $63(56.8)$ & $47(39.8)$ & & $(48.0)$ & $45(57.7)$ \\
\hline $64.3(10.6)$ & $68.2(9.6)$ & & $2(8.5)$ & $60.5(8.0)$ \\
\hline $21(18.9)$ & $22(18.6)^{\mathrm{i}}$ & & - & $27(34.6)$ \\
\hline $19.6(22.6)^{\mathrm{h}}$ & $41.7(22.6)^{j}$ & & - & $29.1(34.7)$ \\
\hline $27.2(24.3-30.8)$ & $24.8(5.8)$ & & $(5.1)$ & - \\
\hline $86.7(15.8)$ & $33.7(9.3)$ & 44. & (13.8) & $48.7(17.4)$ \\
\hline $65.0(60.0-67.6)$ & - & 48. & $(10.8)$ & $56.1(8.9)$ \\
\hline $0(0.0)$ & $4(3.4)$ & & - & $5(6.4)$ \\
\hline 77 (69.4) & $0(0.0)$ & & $(0.0)$ & $7(9.0)$ \\
\hline $32(28.8)$ & $6(5.1)$ & & $(36.0)$ & $28(35.9)$ \\
\hline $2(1.8)$ & $70(59.3)$ & & $(50.0)$ & $35(44.9)$ \\
\hline $0(0.0)$ & $42(35.6)$ & & $14.0)$ & $8(10.3)$ \\
\hline- & - & & - & $31(39.7)$ \\
\hline- & - & & - & $39(50.0)$ \\
\hline $8(7.2)$ & $118(100.0)$ & & $(50.0)$ & $70(89.7)$ \\
\hline $8.4(6.3)$ & $18.3(6.6)$ & & $3(9.9)$ & $25.1(8.7)$ \\
\hline- & - & & - & - \\
\hline - & $42.8(7.0)^{\mathrm{k}}$ & 44. & (20.4) & - \\
\hline
\end{tabular}




\begin{tabular}{|c|c|c|c|c|}
\hline \multirow[b]{2}{*}{ Author } & \multicolumn{4}{|l|}{ Dataset resource } \\
\hline & $\begin{array}{l}\text { Tsiligianni } \\
\text { (71) }\end{array}$ & $\begin{array}{l}\text { Tulek } \\
(72)\end{array}$ & $\begin{array}{l}\text { Jones } \\
(16)\end{array}$ & $\begin{array}{l}\text { Vestbo } \\
(17)\end{array}$ \\
\hline $\begin{array}{l}\text { Journal and year } \\
\text { published }\end{array}$ & $\begin{array}{l}\text { BMC Pulm Med, } \\
2012\end{array}$ & $\begin{array}{l}\text { Respirology, } \\
2014\end{array}$ & $\begin{array}{l}\text { Respir Med, } \\
2014\end{array}$ & $\begin{array}{l}\text { Respir Med, } \\
2014\end{array}$ \\
\hline Country & Greece & Turkey & \multicolumn{2}{|c|}{$\begin{array}{l}\text { US, France, Germany, } \\
\text { Italy, Spain, UK }\end{array}$} \\
\hline Cohort & & & \multicolumn{2}{|c|}{ Adelphi Respiratory DSP } \\
\hline $\mathbf{N}$ & 90 & 119 & \multicolumn{2}{|c|}{1491} \\
\hline Gender (male), n (\%) & $82(91.1)$ & $116(97.5)$ & \multicolumn{2}{|c|}{$1019(68.3)$} \\
\hline Age, years & $67.4(8.7)$ & $59.5(9.3)$ & \multicolumn{2}{|c|}{$65.1(10.2)$} \\
\hline Current smoker, n (\%) & $70(77.8)$ & - & \multicolumn{2}{|c|}{$487(32.9)^{a}$} \\
\hline Packyears & $60.0(40.0-84.3)$ & $38.3(10.2)$ & \multicolumn{2}{|c|}{$30.0(20.0-45.0)^{\mathrm{b}}$} \\
\hline $\mathrm{BMI}, \mathrm{kg} / \mathrm{m}^{2}$ & $27.8(5.1)$ & $27.6(5.3)$ & \multicolumn{2}{|c|}{$26.5(23.4-29.4)^{c}$} \\
\hline $\mathrm{FEV}_{1}(\%$ pred. $)$ & $58.2(18.8)$ & $59.2(20.0)$ & \multicolumn{2}{|c|}{$62.6(17.1)$} \\
\hline $\mathrm{FEV}_{1} / \mathrm{FVC}(\%)$ & $55.7(10.7)$ & - & \multicolumn{2}{|c|}{-} \\
\hline LTOT, n (\%) & $1(1.1)$ & - & \multicolumn{2}{|c|}{$117(7.8)$} \\
\hline \multicolumn{5}{|l|}{ GOLD stage, n (\%) } \\
\hline$-\mathbf{I}$ & $15(16.7)$ & $17(14.3)$ & \multicolumn{2}{|c|}{$256(17.2)$} \\
\hline- II & $46(51.1)$ & $64(53.8)$ & \multicolumn{2}{|c|}{$936(62.8)$} \\
\hline - III & $21(23.3)$ & $30(25.2)$ & \multicolumn{2}{|c|}{$241(16.2)$} \\
\hline - IV & $8(8.9)$ & $8(6.7)$ & \multicolumn{2}{|c|}{$58(3.9)$} \\
\hline Exacerbations previous & $2(2.2)$ & $48(40.3)$ & \multicolumn{2}{|c|}{$465(31.2)$} \\
\hline \multicolumn{5}{|l|}{12 months $\geq 2, \mathrm{n}(\%)$} \\
\hline Hospitalizations previous & $5(5.6)$ & $28(23.5)$ & \multicolumn{2}{|c|}{$196(13.1)$} \\
\hline \multicolumn{5}{|l|}{12 months $\geq 1, \mathrm{n}(\%)$} \\
\hline $\begin{array}{l}\text { mMRC dyspnea grade } \\
\geq 2, \mathrm{n}(\%)\end{array}$ & $22(24.4)$ & $64(53.8)$ & \multicolumn{2}{|c|}{$758(50.8)$} \\
\hline CAT total score, points & $12.9(7.5)$ & $13.1(8.1)$ & \multicolumn{2}{|c|}{$21.0(8.8)$} \\
\hline CCQ total score, points & $1.6(1.0)$ & - & \multicolumn{2}{|c|}{-} \\
\hline SGRQ total score, points & $36.8(18.3)$ & - & \multicolumn{2}{|c|}{-} \\
\hline
\end{tabular}

a 12 missing; b 188 missing; c 44 missing; d 1 missing; e 22 missing; f 3 missing; g 1 missing; h 11 missing;

i 1 missing; i 16 missing; k 3 missing; 13 missing.

Values expressed as mean (SD), median (IQR) or number of patients (\%).

Abbreviations: $\mathrm{BMI}=$ body mass index; $\mathrm{CAT}=\mathrm{COPD}$ Assessment Test; $\mathrm{CCQ}=\mathrm{Clinical} \mathrm{COPD}$ Questionnaire; $\mathrm{FEV}_{1}=$ Forced Expiratory Volume in the first second; $\mathrm{FVC}=$ Forced Vital Capacity; GOLD = Global initiative for chronic Obstructive Lung Disease; LTOT= long-term oxygen therapy; mMRC $=$ modified Medical Research Council dyspnoea scale; SGRQ $=$ St. George's Respiratory Questionnaire. 


\begin{tabular}{|c|c|c|c|}
\hline Dataset resource & & & \\
\hline $\begin{array}{l}\text { Wilke } \\
\text { (3) }\end{array}$ & $\begin{array}{l}\text { Xie } \\
(73)\end{array}$ & $\begin{array}{l}\text { Yoshikawa } \\
\text { (74) }\end{array}$ & $\begin{array}{l}\text { Zogg } \\
(75)\end{array}$ \\
\hline $\begin{array}{l}\text { J COPD F, } \\
2014\end{array}$ & $\begin{array}{l}\text { Chin Med J, } \\
2014\end{array}$ & $\begin{array}{l}\text { Respirology, } \\
2014\end{array}$ & $\begin{array}{l}\text { BMC Res Notes, } \\
2014\end{array}$ \\
\hline The Netherlands & Shanghai & Japan & Switzerland \\
\hline- & - & & \\
\hline 698 & 844 & 58 & 68 \\
\hline $391(56.0)$ & $659(78.1)$ & $56(96.6)$ & $41(60.3)$ \\
\hline $64.8(8.9)$ & $68.0(9.1)$ & $72.1(9.2)$ & $67.2(10.4)$ \\
\hline $166(23.8)^{\mathrm{d}}$ & $623(73.8)$ & $20(34.5)$ & $32(47.1)$ \\
\hline $40.0(28.0-50.0)^{\mathrm{e}}$ & $22.5(15.0-31.0)^{\mathrm{h}}$ & $60.0(45.8-80.0)$ & $45.8(32.5)^{\mathrm{k}}$ \\
\hline $26.1(5.4)$ & $22.9(3.0)$ & $21.0(3.5)$ & $25.1(21.1-28.9)$ \\
\hline $54.7(22.3)$ & $48.0(17.2)$ & $50.8(19.7)$ & $64.3(21.9)$ \\
\hline $42.3(14.0)$ & $54.7(10.1)$ & $43.5(12.7)^{\mathrm{i}}$ & $50.1(12.4)$ \\
\hline $136(19.5)$ & $202(23.9)$ & $10(17.2)$ & $2(3.1)^{1}$ \\
\hline $115(16.5)$ & $31(3.7)$ & $5(8.6)$ & $13(19.1)$ \\
\hline $259(37.1)$ & $310(36.7)$ & $22(37.9)$ & $38(55.9)$ \\
\hline $220(31.5)$ & $366(43.4)$ & $25(43.1)$ & $12(17.6)$ \\
\hline $104(14.9)$ & $137(16.2)$ & $6(10.3)$ & $5(7.4)$ \\
\hline $330(47.3)$ & $386(45.7)$ & $7(12.1)$ & $8(11.8)$ \\
\hline $239(34.3)$ & $218(25.8)$ & $5(8.6)$ & - \\
\hline $490(70.3)$ & $534(63.3)$ & $36(62.1)$ & $28(41.2)$ \\
\hline $20.0(7.4)$ & $18.3(7.9)$ & $15.2(7.7)$ & $13.3(7.0)$ \\
\hline $2.3(1.1)^{\mathrm{f}}$ & - & - & - \\
\hline $54.0(22.0) \mathrm{g}$ & - & $42.0(15.9)^{\mathrm{i}}$ & - \\
\hline
\end{tabular}




\section{RESULTS}

Overall, 337 reports were identified, of which 63 were eligible (Figure 1). Forty-five author groups were able and willing to participate. Finally, 41 datasets were included in the patient level pooled analysis. At the time of inclusion, 3 articles were published with the dataset of the COPD History Assessment In SpaiN (CHAIN) cohort (14), 3 articles used the Adelphi Respiratory Disease Specific Program dataset (one of which is from another subcohort (15) than the other 2 articles $(16,17)), 1$ author group published 2 articles with the same dataset $(18,19)$, and 1 dataset did not have recently measured $\mathrm{FEV}_{1}$ (\% predicted) (5). In addition, the COPD and SYstemic consequences-COmorbidities NETwork (COSYCONET) steering committee approved to share their cohort baseline data (20). Table 1 provides all details per study.

Demographic and clinical characteristics of 18,577 patients with COPD are presented in Table 2. Most patients had a moderate or severe degree of airflow limitation. Spirometric grade 2 was the most prevalent (46\%). Using the GOLD 2017 cut-points, the majority of patients were classified in the high-symptom B/D groups: mMRC, 55.3\%; CAT, 83.6\%; CCQ, 78.8\%; and SGRQ 83.0\%.

The degree of airflow limitation correlated weakly-to-moderately with the mMRC dyspnea grade $(\mathrm{r}=-0.40, \mathrm{P}<.001)$, CAT total score $(\mathrm{r}=-0.26, \mathrm{P}<.001)$, CCQ total score $(\mathrm{r}=-0.37, \mathrm{P}<.001)$, and SGRQ total score $(\mathrm{r}=-0.36, \mathrm{P}<.001$; Figure 2$)$. Moreover, the symptom measures interrelated strongly, with the Pearson productmoment correlation coefficients ranging from 0.540 to 0.799 (all $\mathrm{P}<.001$; Figure 3).

\section{New Cut-Points}

Figure 4 shows the newly proposed cut-points. A CAT cut-point of 18 points, a CCQ cut-point of 1.9 points, and a SGRQ cut-point of 46.0 points reached the highest sensitivity and specificity vs the mMRC dyspnea grade of 2 or higher as point of reference.

\section{Frequency Distribution}

GOLD A/B/C/D frequencies based on current cut-points and the newly derived cut points are shown in Figure 5. Compared with the existing CAT cut-point $\geq 10$ points), the new cut-point ( $\geq 18$ points) re-classified $30.2 \%$ of the GOLD B/D patients into GOLD A/C. Compared with the existing CCQ cut-point ( $\geq 1$ point), the new cut-point $(\geq 1.9$ points) re-classified $23.9 \%$ of the GOLD B/D patients into GOLD A/C. Compared to the existing SGRQ cut-point ( $\geq 25$ points), the new cutpoint ( $\geq 46$ points) re-classified $34.3 \%$ of the GOLD B/D patients into GOLD A/C. 
Table 2. General characteristics of total population

\begin{tabular}{|c|c|c|c|}
\hline \multicolumn{2}{|l|}{ Variables } & \multicolumn{2}{|l|}{$\mathrm{n}=$} \\
\hline \multicolumn{2}{|l|}{$\overline{\text { Gender (male), n (\%) }}$} & 18,577 & $13,370(72 \cdot 0)$ \\
\hline \multicolumn{2}{|l|}{ Age, years } & 18,577 & $66.3(9.6)$ \\
\hline \multicolumn{2}{|l|}{ - $\quad 40-50$ years, $\mathrm{n}(\%)$} & & $1,122(6.0)$ \\
\hline \multicolumn{2}{|l|}{ - $\quad 51-60$ years, $\mathrm{n}(\%)$} & & $3,978(21.4)$ \\
\hline \multicolumn{2}{|l|}{ - $\quad 61-70$ years, $\mathrm{n}(\%)$} & & $6,985(37.6)$ \\
\hline \multicolumn{2}{|l|}{ - $\quad 71-80$ years, $\mathrm{n}(\%)$} & & $5,380(29.0)$ \\
\hline \multicolumn{2}{|l|}{$-\quad>80$ years, $\mathrm{n}(\%)$} & & $1,112(6.0)$ \\
\hline \multicolumn{2}{|l|}{ Current smoker, n (\%) } & 16,888 & $6,626(35.7)$ \\
\hline \multicolumn{2}{|l|}{ Pack years } & 14,234 & $38.0(23.0-52.5)$ \\
\hline \multicolumn{2}{|l|}{$\mathrm{BMI}, \mathrm{kg} / \mathrm{m}^{2}$} & 16,934 & $26.5(5.2)$ \\
\hline \multicolumn{2}{|l|}{$\mathrm{FEV}_{1}(\%$ pred.) } & 18,577 & $54.6(19.5)$ \\
\hline \multicolumn{2}{|l|}{$\mathrm{FEV}_{1} / \mathrm{FVC}(\%)$} & 13,692 & $51.8(12.1)$ \\
\hline \multicolumn{2}{|l|}{ LTOT, n (\%) } & 12,547 & $1,903(10.2)$ \\
\hline \multirow[t]{4}{*}{ GOLD spirometric grade, n (\%) } & -1 & 18,577 & $2,029(10.9)$ \\
\hline & -2 & & $8,611(46.4)$ \\
\hline & -3 & & $6,026(32.4)$ \\
\hline & -4 & & $1,911(10.3)$ \\
\hline \multicolumn{2}{|c|}{ Exacerbations previous 12 months $\geq 2, \mathrm{n}(\%)$} & 16,607 & $6,443(38.8)$ \\
\hline \multicolumn{2}{|c|}{ Hospitalizations previous 12 months $\geq 1, \mathrm{n}(\%)$} & 13,881 & $2,537(18.3)$ \\
\hline \multirow[t]{5}{*}{ mMRC grade, $n(\%)$} & & 18,577 & $2,183(11.8)$ \\
\hline & & & $6,122(33.0)$ \\
\hline & & & $5,474(29.5)$ \\
\hline & & & $3,598(19.4)$ \\
\hline & & & $1,200(6.5)$ \\
\hline \multicolumn{2}{|l|}{ mMRC dyspnea grade $\geq 2, \mathrm{n}(\%)$} & 18,577 & $10,272(55.3)$ \\
\hline \multicolumn{2}{|l|}{ CAT total score, points } & 18,577 & $18.4(8.4)$ \\
\hline \multicolumn{2}{|c|}{ Percentage subjects with value $\geq 10, \mathrm{n}(\%)$} & & $15,535(83.6)$ \\
\hline \multicolumn{2}{|l|}{ CCQ total score, points } & 2,047 & $2.1(1.3)$ \\
\hline \multicolumn{2}{|c|}{ Percentage subjects with value $\geq 1, \mathrm{n}(\%)$} & & $1,614(78.8)$ \\
\hline \multicolumn{2}{|l|}{ SGRQ total score, points } & 6,159 & $45.4(20.0)$ \\
\hline \multicolumn{2}{|c|}{ Percentage subjects with value $\geq 25, \mathrm{n}(\%)$} & & $5,114(83.0)$ \\
\hline
\end{tabular}

Values expressed as mean (SD), median (IQR) or number of patients (\%).

Abbreviations: $\mathrm{BMI}=$ body mass index; $\mathrm{CAT}=\mathrm{COPD}$ Assessment Test; $\mathrm{CCQ}=\mathrm{Clinical} \mathrm{COPD}$ Questionnaire; $\mathrm{FEV}_{1}=$ Forced Expiratory Volume in the first second; $\mathrm{FVC}=$ Forced Vital Capacity; GOLD = Global initiative for chronic Obstructive Lung Disease; LTOT= long-term oxygen therapy; mMRC $=$ modified Medical Research Council dyspnoea scale; SGRQ $=$ St. George's Respiratory Questionnaire 


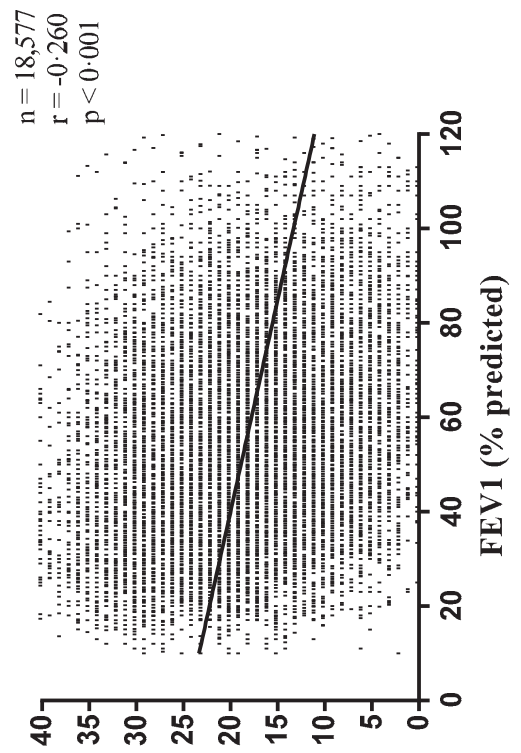

(słu!̣od) ว.I0כs [Pฺ0† LVD

$\dot{\varphi}$

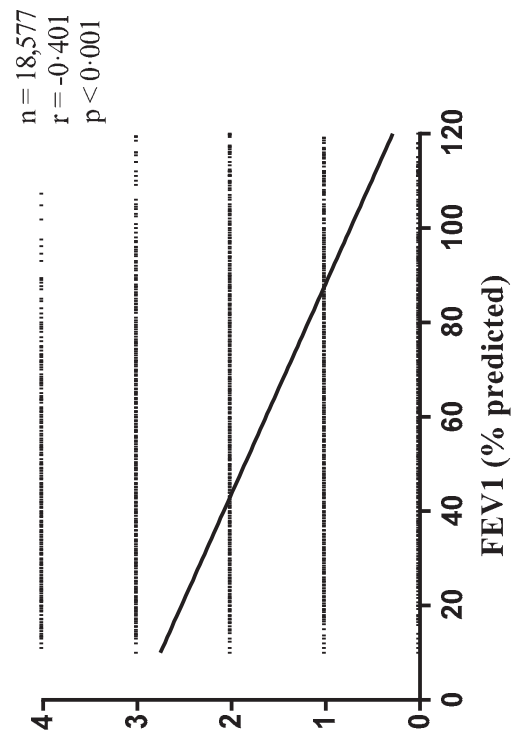

(słu!od) әрк.ı̊̊ raudsip วYWu
동ㅇㅇㅇ

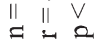

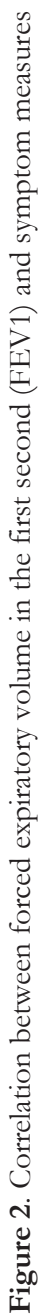

(słu!̣od) ว.I0วs [ย]0† Оวつ 


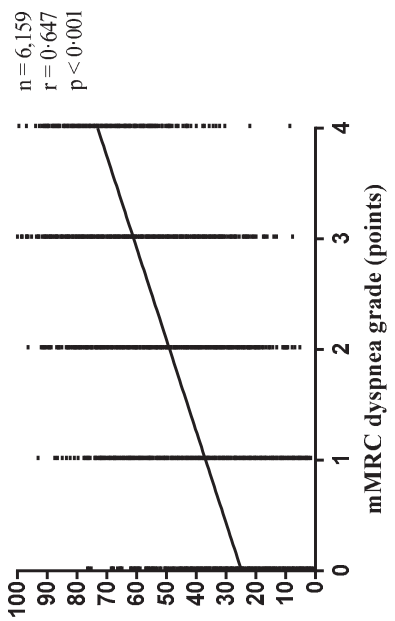

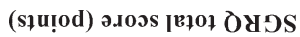

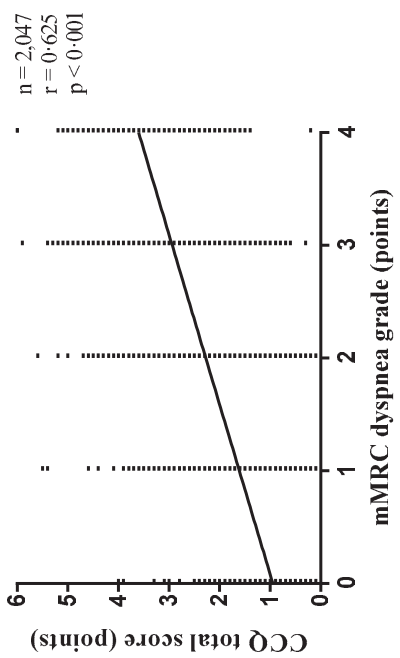

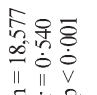

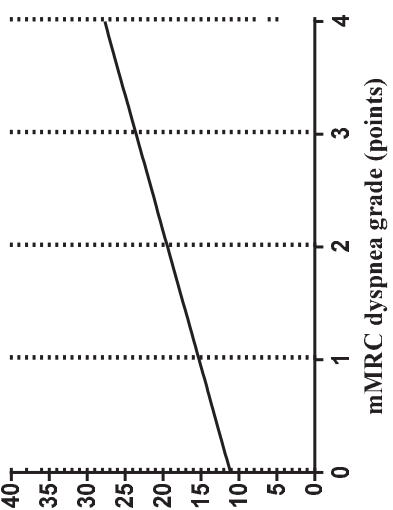

(słu!̣od) a.Ioos [r]01 LVO

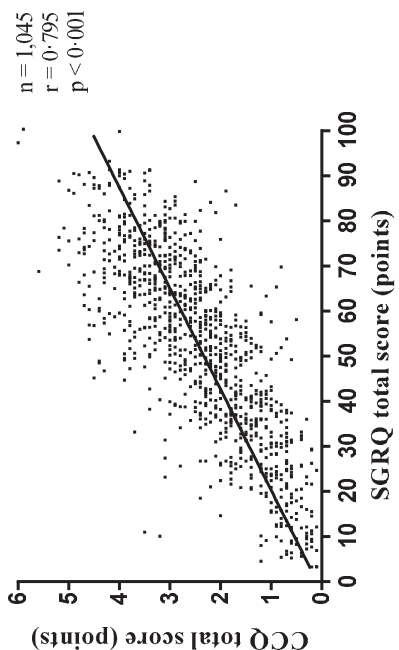

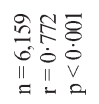

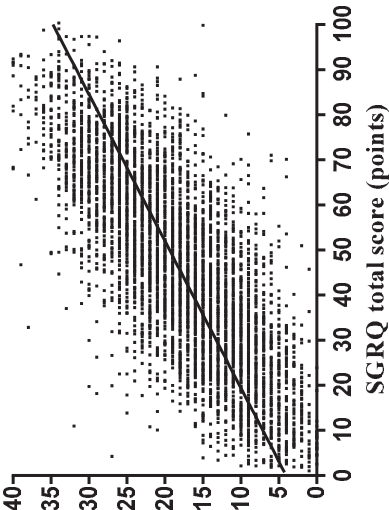

(s]u!od) 2.I00s [p]0] LVP

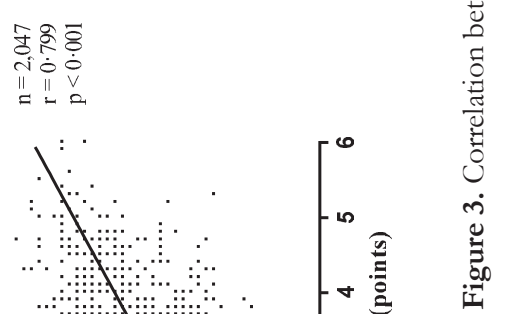


a)

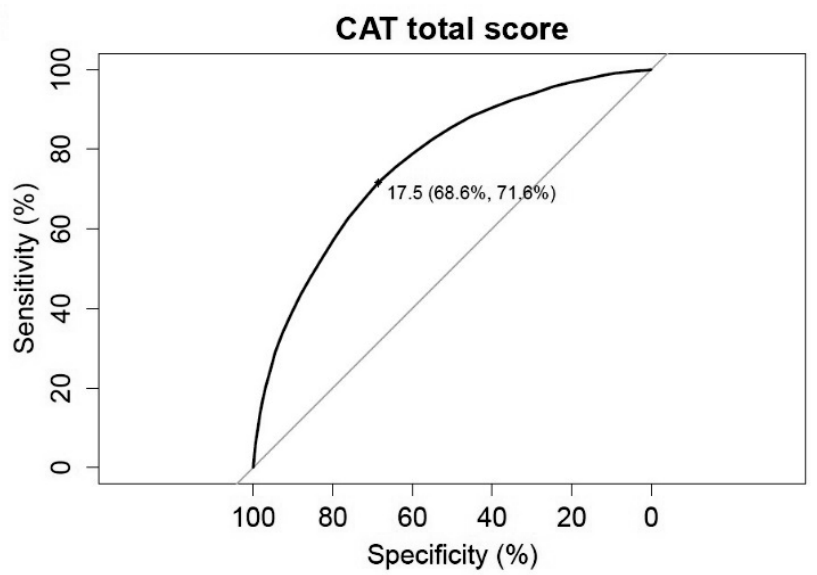

b)

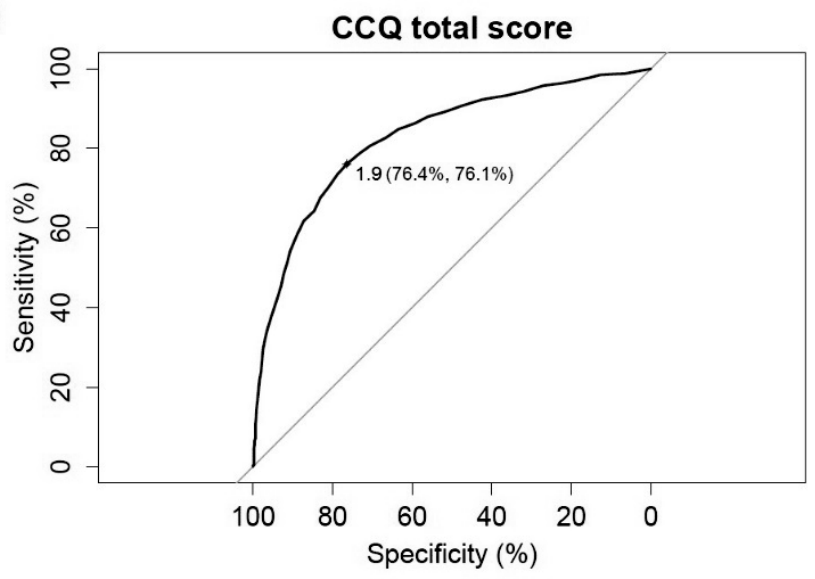

c)

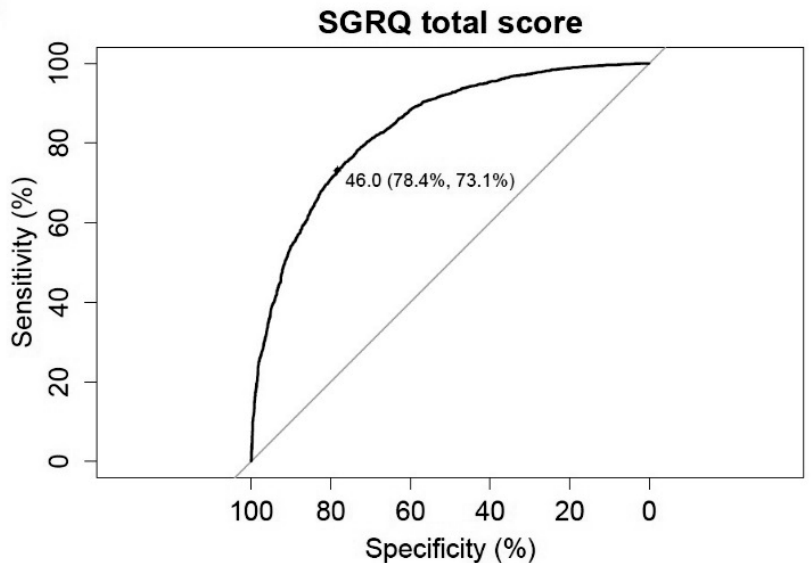

Figure 4. Receiver operating characteristic (ROC) curves showing best pairwise classification thresholds. $\mathrm{CAT}=\mathrm{COPD}$ Assessment Test; $\mathrm{CCQ}=$ Clinical COPD Questionnaire; $\mathrm{SGRQ}=\mathrm{St}$. George's Respiratory Questionnaire. 


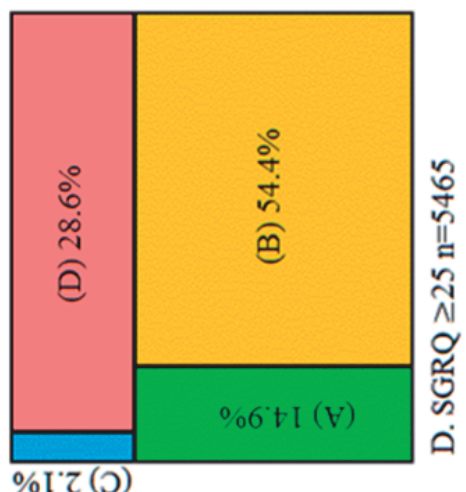

Redefining cut-points for high symptom burden
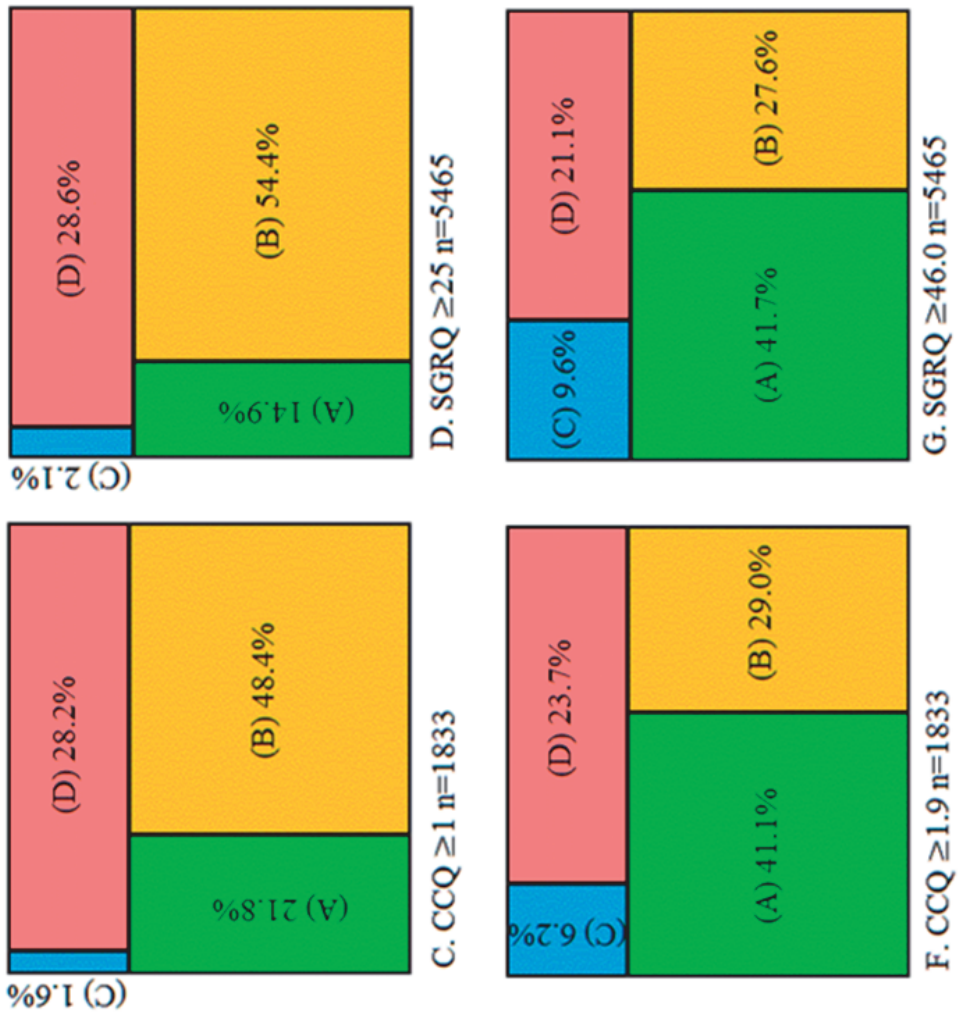

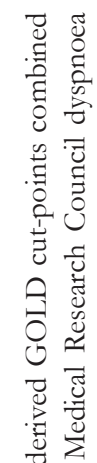

可

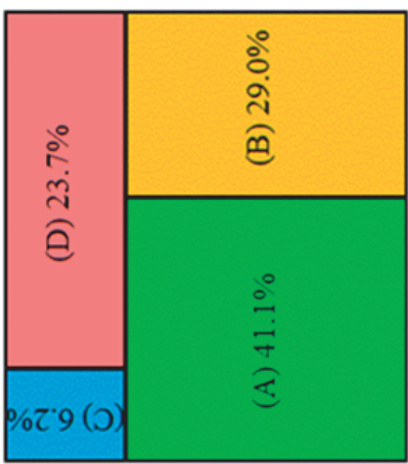

م્
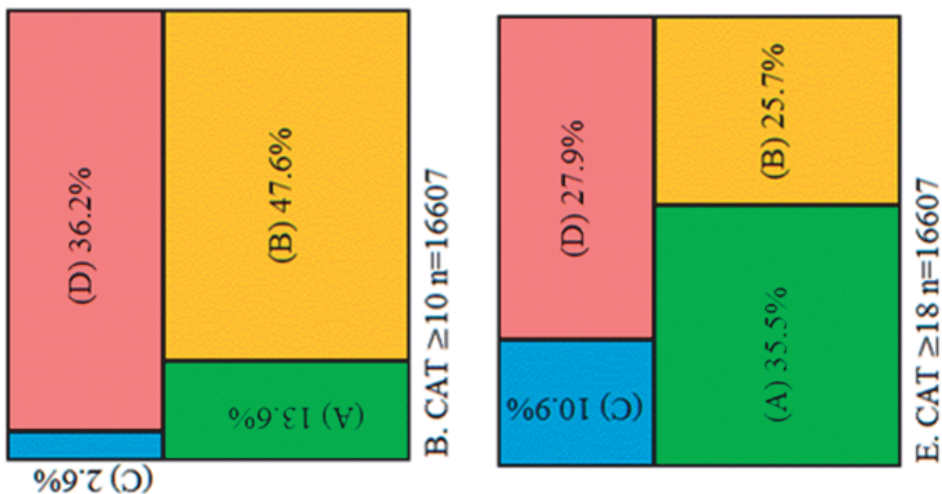

్ㅗㅇ

5.

幽

E

홍 월

ค

$\circlearrowleft$

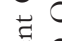

矛

I

동

ठ

ปี 11

क

忢通.

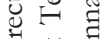

조

ปี

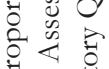

है

응

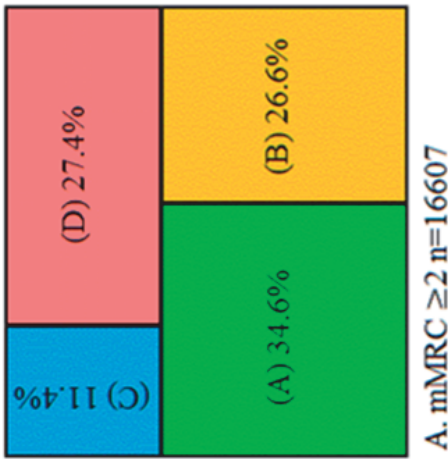

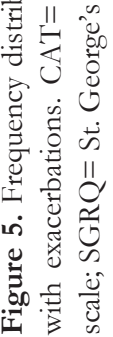




\section{DISCUSSION}

Healthcare professionals should be aware of the fact that the choice of symptom measure influences classification, and, in turn, also specific treatment recommendation in patients with COPD. Using $\mathrm{mMRC} \geq 2$ points as a reference, a CAT cut-point of 18 points, CCQ cut-point of 1.9 points, and SGRQ cut-point of 46.0 points reached the highest agreement. Implementation of these newly derived cut-points will influence the management of individual patients and the design and interpretation of clinical studies.

\section{Recommendations}

As the newly derived cut-points reached the highest sensitivity and specificity with the mMRC dyspnea grade of 2 or higher, guidelines committees may need to consider the use of a mMRC dyspnea grade 2 or higher, a CAT total score of 18 points or higher, a CCQ total score of 1.9 points or higher, or a total SGRQ score of 46.0 points or higher to classify patients with COPD as symptomatic (i.e., GOLD B or D; Figure 6). This recommendation is supported by the fact that a CAT total score $\geq 10$ points already occurs in $50 \%$ of current or former smokers without having any airway obstruction (76). The newly derived cut-points enable healthcare professionals to classify the largest proportion of patients into the same GOLD quadrant regardless of their choice of symptom measure.

\section{Clinical Consequences}

Future studies are needed to assess the effectiveness of bronchodilators in COPD patients with and without symptoms, using the newly derived cut-points. For example, GOLD A patients are advised to use short-acting bronchodilators, whereas GOLD B patients are advised to use long-acting bronchodilators (1). Therefore, the new cut-points may reduce the prescription of long-acting bronchodilators in patients who are currently GOLD B, and will become GOLD A by applying the new cut-points. Obviously, the question arises what to do with COPD patients with a mMRC grade below 2 and a CAT score between 10 (current cut-point) and 18 points (newly derived cut point)? This combination of scores suggests that these patients suffer from other symptoms than dyspnea, which can most probably not be treated satisfactorily with the current pulmonary drug therapy.

The newly proposed cut-points may also affect recruitment criteria for upcoming trial designs. Indeed, studies that previously applied the current cut-points, will have an overrepresentation of GOLD B or D patients. Sillen et al (77) showed that there is a lot of heterogeneity in GOLD group D, when applying the existing cut- 
points. In turn, adjusting cut-points of the symptom measures to the newly derived cut-points will increase baseline homogeneity of patient populations within observational COPD studies and intervention trials.

The current analysis confirms that the degree of airflow limitation only moderately correlates with the symptom measures. So, the degree of symptom burden cannot accurately be derived from spirometry. Therefore, healthcare professionals need to regularly assess symptoms in patients with COPD. Indeed, a change in symptom scores may even have a prognostic value in patients with COPD (78).

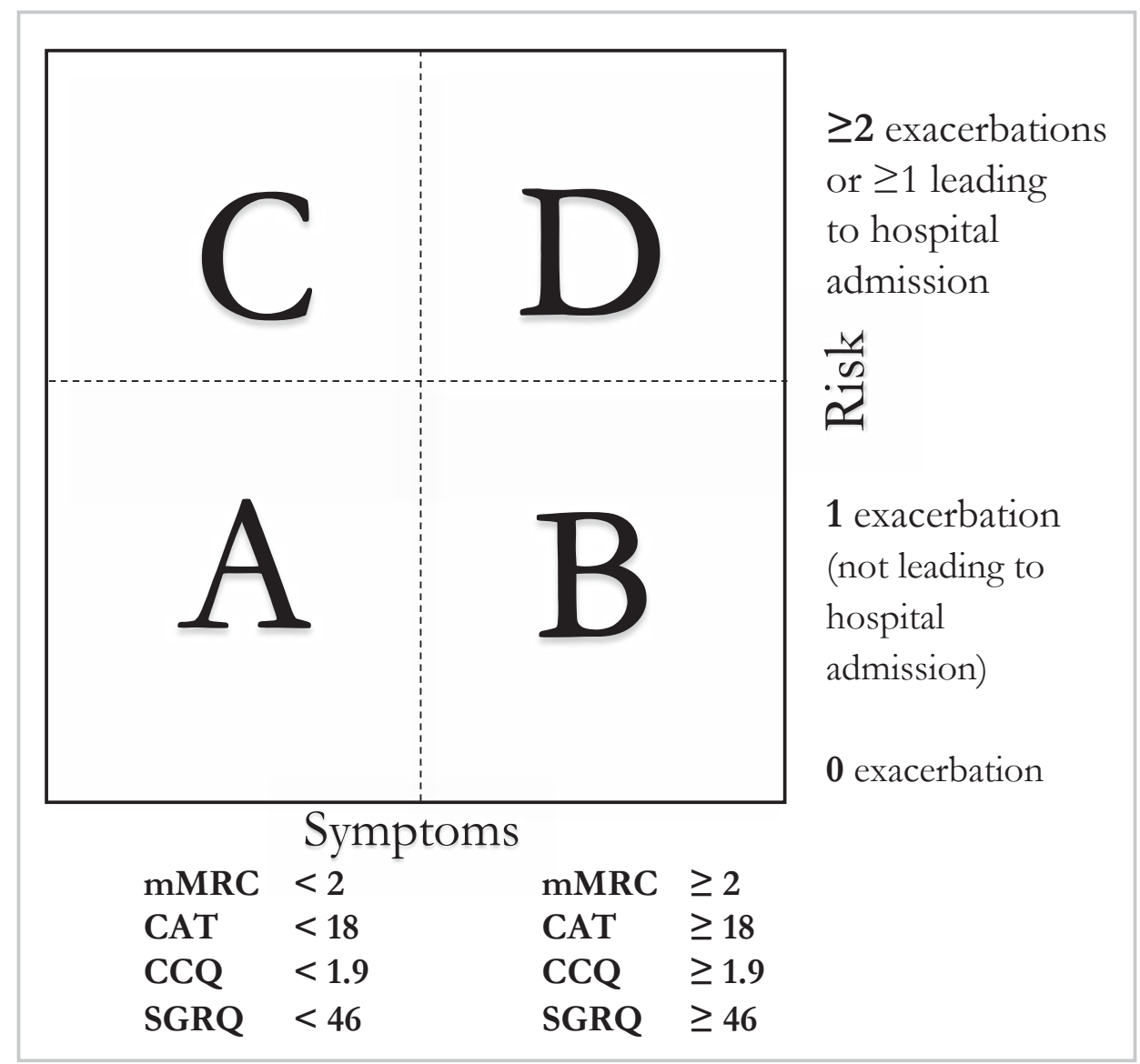

Figure 3. Suggested GOLD ABCD diagram, using the new cut-points to assess symptoms. CAT= COPD Assessment Test; $\mathrm{CCQ}=$ Clinical COPD Questionnaire; $\mathrm{GOLD}=$ Global initiative for chronic Obstructive Lung Disease; $\mathrm{mMRC}=$ modified Medical Research Council dyspnoea scale; $\mathrm{SGRQ}=$ St. George's Respiratory Questionnaire. 


\section{Chapter 8}

\section{Strengths and Limitations}

The pooled, multicenter, multinational, patient level dataset with a large number of patients and global coverage is a major strength. Indeed, this resulted in a heterogeneous sample of patients with COPD, also including a high number of patients with a low mMRC dyspnea grade (grade 0: 2183 patients; grade 1: 6122 patients), patients with a mild degree of airflow limitation (spirometric grade 1: 2029 patients), and 1,122 patients younger than 50 years of age. Moreover, patients were recruited from various care settings (i.e., primary care, general population, hospital outpatients). This makes the results more generalizable.

A limitation of the current study is that the largest proportion of patients was male $(72.0 \%)$. Although this seems to over-represent the male sex, it is probably a reliable representation of the current COPD population in the participating cohorts (79). Less data were available for the CCQ total score (2047 patients) and SGRQ total score (6159 patients). Furthermore, the definition of COPD, current, former or never smoker and the definition of exacerbations and hospitalizations could differ between studies. Finally, the mMRC dyspnea grade solely captures symptoms of dyspnea, which may, together with spirometry and history of exacerbations/hospitalizations, be a suitable guidance for treatment recommendations. Nevertheless, $\mathrm{mMRC}$ dyspnea scale may be too limited to truly understand the impact of COPD. Indeed, symptoms like fatigue, pain and insomnia, may also occur in patients with COPD (80). Therefore, CAT, CCQ, or SGRQ may be preferred to more broadly characterize the daily symptoms of patients with COPD. Obviously, when CAT, CCQ, and SGRQ are applied for the binary classification of high vs low symptoms, there will still be discrepancy between these symptom measures. So, the GOLD Scientific Committee may want to consider the choice of 1 symptom measure or applying the worst scoring questionnaire to classify patients into groups $\mathrm{A} / \mathrm{C}$ or $\mathrm{B} / \mathrm{D}$.

\section{CONCLUSIONS}

To objectively define a symptom burden score equivalent to a mMRC dyspnea grade of 2 or higher, a CAT total score of $\geq 18$ points, a CCQ total score of $\geq 1.9$ points, or a SGRQ total score of $\geq 46$ points should be used. Following this grading, about one-third of the patients in GOLD groups B/D are re-classified to GOLD groups A/C. This implies that guidelines committees may consider adapting our evidence-based cut-points of symptom measures. 


\section{REFERENCES}

1. Vogelmeier CF, Criner GJ, Martinez FJ, et al. Global strategy for the diagnosis, management, and prevention of chronic obstructive lung disease 2017 report: GOLD executive summary. AJRCCM; 2017.

2. Jones PW, Adamek L, Nadeau G, et al. Comparisons of health status scores with MRC grades in COPD: Implications for the GOLD 2011 classification. Eur Respir J; 2013;42:647-654.

3. Wilke S, Smid DE, Spruit MA, et al. The 2014 updated GOLD strategy: A comparison of the various scenarios. JCOPDF; 2014;2:212-220.

4. Casanova C, Marin JM, Martinez-Gonzalez C, et al. Differential effect of Mmrc dyspnea, CAT and CCQ for symptom evaluation within the new GOLD staging and mortality in COPD. Chest 2015;159:159-168.

5. Holt S, Sheahan D, Helm C, et al. Little agreement in GOLD category using CAT and mMRC in 450 primary care COPD patients in New Zealand. NPJ Prim Care Respir Med 2014;24:14025.

6. Agusti A, Hurd S, Jones P, et al. FAQs about the GOLD 2011 assessment proposal of COPD: A comparative analysis of four different cohorts. Eur Respir J 2013;42: 13911401.

7. Lee $\mathrm{CH}$, Lee J, Park YS, et al. Chronic obstructive pulmonary disease (COPD) assessment test scores corresponding to modified Medical Research Council grades among COPD patients. Korean J Intern Med 2015;30:629-637.

8. Tsiligianni IG, Alma HJ, de Jong C, et al. Investigating sensitivity, specificity, and area under the curve of the Clinical COPD Questionnaire, COPD Assessment Test, and Modified Medical Research Council scale according to GOLD using St George's Respiratory Questionnaire cutoff 25 (and 20) as reference. Int J Chron Obstruct Pulmon Dis 2016;11:1045-1052.

9. Kon SS, Canavan JL, Nolan CM, et al. The clinical chronic obstructive pulmonary disease questionnaire: Cut point for GOLD 2013 classification. Am J Respir Crit Care Med 2014;189:227-228.

10. Vogelmeier CF, Vestbo J, Hurd SS, et al. Changes in GOLD: Today and tomorrow. Lancet Respir Med 2015;3:424-426.

11. Jones PW, Harding G, Berry P, et al. Development and first validation of the COPD Assessment Test. Eur Respir J 2009;34:648-654.

12. Pickard AS, Yang Y, Lee TA. Comparison of health-related quality of life measures in chronic obstructive pulmonary disease. Health Qual Life Outcomes 2011;9:26.

13. Youden WJ. Index for rating diagnostic tests. Cancer 1950;3:32-35.

14. Lopez-Campos JL, Peces-Barba G, Soler-Cataluna JJ, et al. Chronic obstructive pulmonary disease history assessment in Spain: A multidimensional chronic obstructive pulmonary disease evaluation. Study methods and organization. Arch Bronconeumol 2012;48:453-459.

15. Price D, West D, Brusselle G, et al. Management of COPD in the UK primary-care setting: An analysis of real-life prescribing patterns. Int J Chron Obstruct Pulmon Dis 2014;9:889-904. 


\section{Chapter 8}

16. Jones PW, Nadeau G, Small M, et al. Characteristics of a COPD population categorised using the GOLD framework by health status and exacerbations. Resp Med 2014;108:129-135.

17. Vestbo J, Vogelmeier C, Small M, et al. Understanding the GOLD 2011 Strategy as applied to a real-world COPD population. Resp Med 2014;108:729-736.

18. da Silva GF, Morano MT, Sales MP, et al. Comparison of face-to-face interview and telephone interview administration of COPD assessment test: A randomized study. Qual Life Res 2014;23:1193-1197.

19. da Silva GP, Morano MT, Viana CM, et al. Portuguese-language version of the COPD Assessment Test: Validation for use in Brazil. J Bras Pneumol 2013;39: 402-408.

20. Karch A, Vogelmeier C, Welte T, et al. The German COPD cohort COSYCONET: Aims, methods and descriptive analysis of the study population at baseline. Resp Med 2016;114:27-37.

21. Han J, Dai L, Zhong N, Young D. Breathlessness or health status in chronic obstructive pulmonary disease: The impact of different definitions. COPD 2015; 12:115-125.

22. Grzelewska-Rzymowska I, Patora-Mikolajczyk J, Gorski P. Stratification of patients with COPD according to the 2011 GOLD report. Pneumonologia i Alergologia Polska 2014;82:415-421.

23. Zhang $\mathrm{R}$, Tan $\mathrm{X}, \mathrm{He} \mathrm{Q}$, et al. Comparison of symptom and risk assessment methods among patients with chronic obstructive pulmonary disease. Chin Med J 2014;127:25942598.

24. Paulin LM, Diette GB, Blanc PD, et al. Occupational exposures are associated with worse morbidity in patients with chronic obstructive pulmonary disease. Am J Respir Crit Care Med 2015;191:557-565.

25. Gimeno-Santos E, Raste Y, Demeyer H, et al. The PROactive instruments to measure physical activity in patients with chronic obstructive pulmonary disease. Eur Respir J 2015;46:988-1000.

26. Khurana S, Ravi A, Sutula J, et al. Clinical characteristics and airway inflammation profile of COPD persistent sputum producers. Respir Med 2014;108: 1761-1770.

27. Kurt OK, Tosun M, Kurt EB, Talay F. Pentraxin 3 as a novel biomarker of inflammation in chronic obstructive pulmonary disease. Inflammation 2015; 38:89-93.

28. Dal Negro RW, Bonadiman L, Turco P. Sensitivity of the COPD assessment test (CAT questionnaire) investigated in a population of 681 consecutive patients referring to a lung clinic: The first Italian specific study. Multidiscip Respir Med 2014;9:15.

29. Rieger-Reyes C, Garcia-Tirado FJ, Rubio-Galan FJ, Marin-Trigo JM. Classification of chronic obstructive pulmonary disease severity according to the new Global Initiative for Chronic Obstructive Lung Disease 2011 guidelines: COPD assessment test versus modified Medical Research Council scale. Arch Bronconeumol 2014;50:129-134.

30. Hwang YI, Jung KS, Lim SY, et al. A Validation Study for the Korean Version of Chronic Obstructive Pulmonary Disease Assessment Test (CAT). Tuberc Respir Dis 2013;74:256-263. 
31. Zhang Y, Tu YH, Fei GH. The COPD assessment test correlates well with the computed tomography measurements in COPD patients in China. Int J Chron Obstruct Pulmon Dis 2015;10:507-514.

32. Stoll P, Ulrich M, Bratke K, et al. Imbalance of dendritic cell co-stimulation in COPD. Respir Res 2015;16:19.

33. Nowak C, Sievi NA, Clarenbach CF, et al. Accuracy of the hospital anxiety and depression scale for identifying depression in chronic obstructive pulmonary disease patients. Pulmon Med 2014;2014: 973858.

34. Lopes AJ, Mafort TT. Correlations between small airway function, ventilation distribution, and functional exercise capacity in COPD patients. Lung 2014;192: 653-659.

35. Ohno T, Wada S, Hanada S, et al. Efficacy of indacaterol on quality of life and pulmonary function in patients with COPD and inhaler device preferences. Int J Chron Obstruct Pulmon Dis 2014;9:107-114.

36. Okutan O, Tas D, Demirer E, Kartaloglu Z. Evaluation of quality of life with the chronic obstructive pulmonary disease assessment test in chronic obstructive pulmonary disease and the effect of dyspnea on disease-specific quality of life in these patients. Yonsei Med J 2013;54:1214-1219.

37. Bai P, Sun Y, Jin J, et al. Disturbance of the OPG/RANK/RANKL pathway and systemic inflammation in COPD patients with emphysema and osteoporosis. Respir Res 2011;12:157.

38. Zhou QT, Mei JJ, He B, et al. Chronic obstructive pulmonary disease assessment test score correlated with dyspnea score in a large sample of Chinese patients. Chin Med J 2013;126:11-15.

39. Agusti A, Soler-Cataluna JJ, Molina J, et al. Does the COPD assessment test (CAT(TM)) questionnaire produce similar results when self- or interviewer administered? Qual Life Res 2015;24:2345-2354.

40. Billington J, Coster S, Murrells T, Norman I. Evaluation of a nurse-led educational telephone intervention to support self-management of patients with chronic obstructive pulmonary disease: A randomized feasibility study. COPD 2015;12:395-403.

41. Boutou AK, Tanner RJ, Lord VM, et al. An evaluation of factors associated with completion and benefit from pulmonary rehabilitation in COPD. BMJ Open Respir Res 2014;1:e000051.

42. de Torres JP, Marin JM, Martinez-Gonzalez C, et al. Clinical application of the COPD assessment test: Longitudinal data from the COPD History Assessment in Spain (CHAIN) cohort. Chest 2014;146:111-122.

43. Casanova C, Marin JM, Martinez-Gonzalez C, et al. New GOLD classification: Longitudinal data on group assignment. Respir Res 2014;15:3.

44. Chaplin E, Gibb M, Sewell L, Singh S. Response of the COPD Assessment Tool in stable and postexacerbation pulmonary rehabilitation populations. J Cardiopulmon Rehabil Prevent 2015;35:214-218.

45. Dodd JW, Hogg L, Nolan J, et al. The COPD assessment test (CAT): Response to pulmonary rehabilitation. A multicentre, prospective study. Thorax 2011;66: 425-429.

46. Horita N, Yomota M, Sasaki M, et al. Evaluation of the chronic obstructive pulmonary disease assessment test in Japanese outpatients. Clin Respir J 2013. 


\section{Chapter 8}

47. Jehn M, Donaldson G, Kiran B, et al. Tele-monitoring reduces exacerbation of COPD in the context of climate changeeA randomized controlled trial. Environ Health 2013;12:99.

48. Kelly JL, Bamsey O, Smith C, et al. Health status assessment in routine clinical practice: The chronic obstructive pulmonary disease assessment test score in outpatients. Respiration 2012;84:193-199.

49. Kim S, Oh J, Kim YI, et al. Differences in classification of COPD group using COPD assessment test (CAT) or modified Medical Research Council (mMRC) dyspnea scores: A cross-sectional analyses. BMC Pulmon Med 2013;13:35.

50. Kon SS, Dilaver D, Mittal M, et al. The Clinical COPD Questionnaire: Response to pulmonary rehabilitation and minimal clinically important difference. Thorax 2014;69:793-798.

51. Kwon N, Amin M, Hui DS, et al. Validity of the COPD assessment test translated into local languages for Asian patients. Chest 2013;143:703-710.

52. Lee SD, Huang MS, Kang J, et al. The COPD assessment test (CAT) assists prediction of COPD exacerbations in high-risk patients. Respir Med 2014;108:600-608.

53. Ladeira I, Gomes T, Castro A, et al. The overall impact of COPD (CAT) and BODE index on COPD male patients: Correlation? Revista Portuguesa de Pneumologia 2015;21:11-15.

54. Lopez-Campos JL, Fernandez-Villar A, Calero-Acuna C, et al. Evaluation of the COPD Assessment Test and GOLD patient types: A cross-sectional analysis. Int J Chron Obstruct Pulmon Dis 2015;10:975-984.

55. Manca S, Rodriguez E, Huerta A, et al. Usefulness of the CAT, LCOPD, EQ-5D and COPDSS scales in understanding the impact of lung disease in patients with alpha-1 antitrypsin deficiency. COPD 2014;11:480-488.

56. Maricic L, Vceva A, Visevic R, et al. Assessment of endothelial dysfunction by measuring von Willebrand factor and exhaled nitric oxide in patients with chronic obstructive pulmonary disease. Collegium antropologicum 2013;37: 1153-1160.

57. Mendoza L, Horta P, Espinoza J, et al. Pedometers to enhance physical activity in COPD: A randomised controlled trial. Eur Respir J; 2015:45347-45354.

58. Mihaltan F. "Inspirom"eOverview of the relationship between the pulmonologist and the COPD patient in Romania. Pneumologia 2015;64:24-28.

59. Miravitlles M, Barrecheguren M, Roman-Rodriguez M. Frequency and characteristics of different clinical phenotypes of chronic obstructive pulmonary disease. Int J Tuberc Lung Dis 2015;19:992-998.

60. Miravitlles M, Molina J, Quintano JA, et al. Factors associated with depression and severe depression in patients with COPD. Respir Med 2014;108: 1615-1625.

61. Minami S, Yamamoto S, Ogata Y, et al. Ambulatory pulse oximetry monitoring in Japanese COPD outpatients not receiving oxygen therapy. Multidisciplinary Respir Med 2014;9:24.

62. Nakken N, Janssen DJ, van den Bogaart EH, et al. An observational, longitudinal study on the home environment of people with chronic obstructive pulmonary disease: The research protocol of the Home Sweet Home study. BMJ Open 2014;4:e006098. 
63. Nishijima Y, Minami S, Yamamoto S, et al. Influence of indacaterol on daily physical activity in patients with untreated chronic obstructive pulmonary disease. Int J Chron Obstruct Pulmon Dis 2015;10:439-444.

64. Novotna B, Koblizek V, Zatloukal J, et al. Czech multicenter research database of severe COPD. Int J Chron Obstruct Pulmon Dis 2014;9:1265-1274.

65. Pothirat C, Kiatboonsri S, Chuchottaworn C. Validation of the new COPD assessment test translated into Thai in patients with chronic obstructive pulmonary disease. BMC Pulmon Med 2014;14:193.

66. Pothirat C, Chaiwong W, Phetsuk N, et al. Dialectal influence on chronic pulmonary disease assessment test: The reliability and validity study. Int J Chron Obstruct Pulmon Dis 2015;10:541-548.

67. Price DB, Baker CL, Zou KH, et al. Real-world characterization and differentiation of the Global Initiative for Chronic Obstructive Lung Disease strategy classification. Int J Chron Obstruct Pulmon Dis 2014;9:551-561.

68. Raghavan N, Lam YM, Webb KA, et al. Components of the COPD Assessment Test (CAT) associated with a diagnosis of COPD in a random population sample. COPD 2012;9:175-183.

69. Ringbaek T, Martinez G, Lange P. A comparison of the assessment of quality of life with CAT, CCQ, and SGRQ in COPD patients participating in pulmonary rehabilitation. COPD 2012;9:12-15.

70. Sigari N, Moghimi N, Shahraki FS, et al. Anti-cyclic citrullinated peptide (CCP) antibody in patients with wood-smoke-induced chronic obstructive pulmonary disease (COPD) without rheumatoid arthritis. Rheumatol Int 2015;35:85-91.

71. Tsiligianni IG, van der Molen T, Moraitaki D, et al. Assessing health status in COPD. A head-to-head comparison between the COPD assessment test (CAT) and the clinical COPD questionnaire (CCQ). BMC Pulmon Med 2012; 12:20.

72. Tulek B, Atalay NB, Yildirim G, et al. Cognitive function in chronic obstructive pulmonary disease: Relationship to global initiative for chronic obstructive lung disease 2011 categories. Respirology 2014;19:873-880.

73. Xie G, Zhang Y, Zhou X. New disease severity classification of patients with stable chronic obstructive pulmonary disease in Shanghai. Chin Med J 2014; 127:3046e3050.

74. Yoshikawa M, Fujita Y, Yamamoto Y, et al. Mini-Nutritional Assessment Short-Form predicts exacerbation frequency in patients with chronic obstructive pulmonary disease. Respirology 2014;19:1198-1203.

75. Zogg S, Durr S, Miedinger D, et al. Differences in classification of COPD patients into risk groups A-D: A cross-sectional study. BMC Res Notes 2014;7:562.

76. Woodruff PG, Barr RG, Bleecker E, et al. Clinical significance of symptoms in smokers with preserved pulmonary function. N Engl J Med 2016;374: 1811-1821.

77. Sillen MJ, Franssen FM, Delbressine JM, et al. Heterogeneity in clinical characteristics and comorbidities in dyspneic individuals with COPD GOLD D: Findings of the DICES trial. Resp Med 2013;107:1186-1194.

78. Wilke S, Jones PW, Mullerova $\mathrm{H}$, et al. One-year change in health status and subsequent outcomes in COPD. Thorax 2015;70:420-425. 
79. Buist AS, McBurnie MA, Vollmer WM, et al. International variation in the prevalence of COPD (the BOLD Study): A population-based prevalence study. Lancet 2007;370:741-750.

80. Janssen DJ, Spruit MA, Uszko-Lencer NH, et al. Symptoms, comorbidities, and health care in advanced chronic obstructive pulmonary disease or chronic heart failure. J Palliat Med 2011;14:735-743.

Reproduced with permission from JAMDA: DE Smid, FME Franssen, M Gonik, M Miravitlles, C Casanova, BG Cosio et al. Redefining Cut-Points for High Symptom Burden of the Global Initiative for Chronic Obstructive Lung Disease Classification in 18,577 Patients with Chronic Obstructive Pulmonary Disease. Journal of the American Medical Directors Association. 2017; 18(12): 1097.e111097.e24. (doi: 10.1016/j.jamda.2017.09.003). 


\section{Chapter 9}

General discussion 


\section{COPD MANAGEMENT IN THE INTERNATIONAL CONTEXT}

In 2011, the Global initiative for chronic Obstructive Pulmonary Disease (GOLD) introduced a new classification for COPD that moved beyond the degree of airflow limitation that defines this chronic lung disease. GOLD stated that effective COPD management should be based on individualized assessment of various aspects of the disease in order to reduce both current symptoms and future risk (1). Recently, the GOLD strategy was refined. Accordingly, assessment should first focus on spirometry to establish the presence of chronic airflow limitation (applying the fixed cut-point $\mathrm{FEV}_{1} / \mathrm{FVC}<0.70$ ) and its severity (based on $\mathrm{FEV}_{1}$ ) (1). Following, symptoms should be measured by recording mMRC, CAT or alternative questionnaires and the number of exacerbations and hospitalizations in the previous year should be recorded as a marker of future risk. Subsequently, by combining lung function, symptoms and risk assessment, patients with COPD are categorized in any of the four GOLD stages for airflow limitation (1, 2, 3 and 4) and quadrants (A, B, C or D). However, it is well-recognized that the choice of symptom measure and cut-points for abnormality impact the classification into GOLD quadrants $(2,3)$. This is, to a lesser extent, also seen in the choice of the risk assessment (4). Therefore, the current thesis aimed to study how healthcare professionals should assess symptom burden in COPD to optimize disease management strategies.

In addition to this comprehensive assessment and classification, GOLD suggests that more tests (e.g. high-resolution CT-imaging, exercise tests, pulse oximetry or arterial blood gas measurement) may need to be performed to assess the burden and complexity of disease and guide personalised treatments. Subsequent COPD treatment can be provided in various ways: pharmacologic treatment, nonpharmacologic treatment or other. Pharmacological treatment includes all treatment with respiratory medications, which should be patient-specific, guided by severity of lung function impairment, symptoms, risk of exacerbations, drug availability, and the patient's response (1). Non-pharmacologic treatment implies education, a smoking cessation program, self-management, physical activity stimulation, nutritional support, influenza vaccination, oxygen therapy, ventilator support and/or pulmonary rehabilitation. Pulmonary rehabilitation aims to optimize the physical and psychological functioning of patients with COPD by focussing on the severity of dyspnea, health status and functional performance, motivation, smoking status, education and nutritional support. As COPD is mainly studied in selected patient populations, this thesis aimed to investigate its characteristics in a broader population based sample, comparing physical status, mental status, and social status to non-COPD subjects. Subjects with other 
comorbidities (expressing comparable symptoms as COPD) and/or without a significant smoking history (>15 pack years) were not excluded, like in most studies (5). The results of this thesis (chapter 4) indicate that subjects with COPD have a reduced physical performance, a more impaired disease specific health status and are socially deprived compared to non-COPD subjects. These impairments need to be taken into consideration when setting up a COPD management program.

\section{CARE FOR COPD IN THE NETHERLANDS}

In the Netherlands, patients with COPD can be treated in primary, secondary or tertiary care. National directions are described in the 'COPD zorgstandaard' (6) and specified for primary care physicians in the 'NHG standaard COPD' (7). These standards recommend assessment of burden of disease in individual patients, consisting of a combination of spirometry, symptoms, exacerbations/ hospitalizations and body weight. Ideally outlined by the guidelines, patients with mild disease should be managed in primary care, while those with moderate or severe disease should be treated in secondary or tertiary care. According to the 'COPD zorgstandaard' referral to secondary care is advised when diagnostic problems are present (e.g. age $\leq 50$ years, $\mathrm{FEV}_{1}$ pred $<50 \% /<1,5$ liter or unintentional weight loss), when patients are not reaching treatment goals (e.g. rapidly progressive course or need for oxygen treatment) or when a patient wishes to have a more detailed analysis of their symptoms. In case of complex somatic and/or adaptation problems patients can be referred to an intense integral analysis by a specialized multidisciplinary team (rehabilitation). This concerns patients with a severe disease burden, according to the 'COPD zorgstandaard'. Though, as described before, it has to be taken into account that the choice of the symptom measure can influence the categorization of disease burden due to inconsistent cut-points. Remarkable is that the 'NHG standard COPD' guidelines mainly focus on primary and secondary health care. For example, they state that when the reason(s) for referral and/or diagnostics to secondary care have been addressed and/or when the chest physician is not able to contribute to reducing the disease burden patients should be referred back to their GP (7). Though, the current thesis shows that a proportion of secondary care patients with low burden of disease would allow for de-intensification of care. Based on the results (chapter 5), the absence of recent exacerbations and a low burden of disease could be included to the reasons for referral back to primary care. 
The 'COPD zorgstandaard' also recommends the use of the Assessment of Burden of COPD (ABC) tool, which aims to measure integrated health status with support of a computer program (8). It combines a patient-reported ABC scale with smoking status, exacerbations, dyspnea, body mass index, lung function and selfreported physical activity. The ABC scale measures the burden of COPD (based on the Clinical COPD Questionnaire (9)), consisting of the domains: mental state, functional state, symptoms, emotions and fatigue (10). Results are visualised, using coloured balloons to indicate patient-contentment per domain and treatment advice is provided. Though, Wilke and colleagues show that evidence and consistency are lacking in the development, validation and effectiveness of the $\mathrm{ABC}$ tool. For example, the rationale and aim of the $\mathrm{ABC}$ tool remain unclear, comorbidities are not accounted for and it is unknown how normative values are determined. Therefore, the ABC tool might only be an useful communication tool to involve patients in their disease management (11).

Dutch assessment guidelines are different from the international GOLD strategy. Dutch Standards recommend the application of the Global Lungs Initiative (GLI) reference values, suggesting that a post-bronchodilator $\mathrm{FEV}_{1} / \mathrm{FVC}$ ratio below the $5^{\text {th }}$ percentile (from reference values) is a better indicator than the fixed $\mathrm{FEV}_{1} / \mathrm{FVC}$ ratio below 0.7 (as recommended by GOLD) to determine the presence of a chronic airflow limitation. This may lead to differences between countries (12). Following, due to the complex clinical application of the GOLD diagram, low support of validity and discrepancies between symptom measures, Dutch standards do not recommend use of the ABCD groups, but focus on three levels of burden of disease (mild/moderate/severe). Also, assessment of symptoms is different. While GOLD emphasizes the use of mMRC and CAT as symptoms measures, the Dutch standards recommend the use of MRC and CCQ. The implications of these discrepancies for disease management and outcomes are unknown. Treatment recommended by the Dutch guidelines correspond to the international guidelines (7).

In the current thesis (chapter 5) characteristics and treatment in primary, secondary and tertiary care were examined. A substantial burden of disease is present in primary care. Secondary care patients are often highly symptomatic and many of them have frequent exacerbations. Tertiary care patients had the highest burden of disease in comparison with patients in primary and secondary care, mainly due to symptoms of dyspnea and a reduced mood and health status. This suggests that pulmonary rehabilitation is considered a treatment option for the most disabled patients. Moreover, a large proportion of secondary care patients remain highly symptomatic despite pharmaceutical and non-pharmaceutical treatment, while 
another proportion of secondary care patients with low burden of disease would allow for de-intensification of care. Also, despite a lower disease burden in primary care patients, non-pharmaceutical treatment and allied healthcare may need intensification.

\section{LESSONS FOR COPD ASSESSMENT, BASED ON OTHER CHRONIC DISEASES}

Besides guidelines for management of COPD, other guidelines for diagnostics and treatment of other chronic diseases are widely available. To get a complete understanding of the most optimal approach to assess and treat chronic diseases, a few concepts of these guidelines are described below. The American College of Cardiology/ American Heart Association (ACC/AHA) guidelines divides patient with heart failure in different stages (A to D), based on disease severity. Stage A and $B$ include patients at risk, while stage $C$ and $D$ represent patients with a diagnosis of heart failure. Directives how to perform a complete assessment of these patients is described in the guidelines. Remarkable, however, it states that no diagnostic test is exclusive to determine heart failure. It is largely a clinical diagnosis, based on a careful history and physical examination (13). The National Kidney Foundation Practice Guidelines for Chronic Kidney Disease also divides patients into different grades (A to $\mathrm{C}$ ) and stages (1 to 5), based on fixed cut-points to determine severity. A diagnosis of Chronic Kidney Disease is based on laboratory tests. The level of kidney function is associated with complications of chronic kidney disease. Additionally, a comprehensive description is given about risk factors for loss of kidney function (e.g. by examinations of the medical history) (14). The American College of Rheumatology (ACR) provides guidelines for assessment and treatment of Rheumatoid Arthritis, recommending a treat-to-target approach. This is a therapeutic concept considering well defined and specific physiologic targets as aims in controlling the pathophysiology of the disease. So, the diagnosis is based on meeting multiple established criteria. While symptoms are subjective experiences by the patients, criteria are mainly specified by fixed measurable numbers (e.g. defining duration of symptoms). Though, within this guideline, it is emphasized that treatment decisions should be made by the physicians and patient together, through a shared decision-making process (15).

Guidelines for other chronic diseases indicate that distributing patients into different stages or grades is of added value $(13,14)$. Mostly patients are divided based on fixed cut-points, e.g. lab results or amount of symptoms in a specific period of time. However, these guidelines also state that the view of the clinician 
comes first. Subsequently, a lot of attention is payed to possible comorbidities and/or the differential diagnosis. While a fixed cut-point for diagnosis of COPD is simple and independent of reference values, leading to consistency and diagnostic simplicity according to the GOLD strategy (1), an accurate diagnosis of COPD should have priority. The following recommendations are made for COPD assessment:

At first, a complete assessment should be performed of every COPD patient during their first consultation. Based on the current thesis (chapter 4 and 5), during assessment it is necessary to measure daily symptoms, functional status, mood status, health status, exacerbation and hospitalization history and possible comorbidities. Hereby, the opinion of the clinician and patient are central. Thus, the needs of the patient are determined derived from those outcomes, apart from echeloning, not based on a diagnosis. Moreover, previous studies stated that a shared treatment decision-making process, in which the patient actively participates, results in a better commitment and adherence to the selected regimen than to a regimen selected by the physician alone $(16,17)$. Consecutive, the patient should be distributed into one of the four GOLD stages and quadrants to get insight about the severity of the disease, including symptom- and risk assessment. However, fixed cut-points of assessment instruments should be validated in a large sample and matched to each other. Following, the patient should be referred to the most suitable type of healthcare, in which the specific treatment program will be determined though shared-decision making, based on outcomes of the assessment and needs of the patient.

\section{DICHOTOMOUS CLASSIFICATION}

The discussion about the application of fixed cut-points leads us to the consideration whether this is the most appropriate way to categorize patients with COPD. An advantage of fixed cut point is that these are easy to implement into clinical practice, as it does not include a complex calculation or requires reference values (1). Additionally, it has been used in numerous clinical trials. Most international treatment recommendations are derived from these studies $(1,18$, 19). Though, when applying these fixed cut-points for example with regard to spirometry, individuals over 50 years have a higher possibility of being overdiagnosed with COPD and individuals under 50 years of being underdiagnosed. Previous studies also emphasize the necessity of the application of GLI reference values to distinct pathophysiology from normal ageing $(20,21)$. This not only leads to incorrect prevalence rates, but also causes the danger of some patients (diagnosed with COPD based on fixed cut-points, not according 
to reference values) receiving treatment while no abnormalities are present. On the other hand, people who are not diagnosed with COPD according to the fixed cut-point, while reference values would indicate differently, no treatment will be provided, despite possible respiratory symptoms or an impaired health status.

Equivalent consequences are shown if we focus on the fixed cut-points for symptom measures to classify patients into GOLD groups A to D. The choice of symptom measure and corresponding cut-point impacts the classification of patients with COPD in GOLD A/C or B/D groups $(2,22,23)$. When applying the CAT $\geq 10$ cut-point, the CCQ $\geq 1$ cut-point and/or the SGRQ $\geq 25$ cut-point a higher proportion of patients is classified in GOLD B or D compared to the $m M R C \geq 2$ dyspnea grade. GOLD A patients are advised to use monotherapy with a bronchodilator, while GOLD B patients preferentially treated with one or more long-acting bronchodilators (1)] (24). So, general practitioners and chest physicians should be aware of the fact that the choice of symptom measure or applying different cut-points influences classification, and thus will influence the prescription of long-acting or short-acting bronchodilators and the choice of alternative medication in case recommended first medication does not work (24). Cut-points proposed by the current thesis will be described below.

\section{SUGGESTED CUT-POINTS}

Previous studies were not conclusive regarding the optimal instrument to measure symptoms and the applied cut-point to classify patients with COPD in high or low symptom groups. Some suggested the CAT $\geq 10$ cut-point as suggested by GOLD as point of reference $(25,26)$, while others suggest the $\mathrm{mMRC} \geq 2$ cut-point as point of reference $(22,27)$. A discrepancy between the mMRC and CAT scores in the same patients with COPD is not surprisingly, as the mMRC involves a question regarding the patient's degree of dyspnea and the CAT involves eight questions regarding various components of quality of life (26).

Originally, the CAT $\geq 10$ cut-point was meant to give an indication and was easy to remember in order to distinguish individuals with significant symptom burden from those with much less symptoms (28). Though, the mMRC has a strong and independent predictor of all-cause mortality $(22,25)$. Given that these threshold values impact patient classification (hence treatment recommendation), a validation in real patients was performed in the current thesis (chapter 8). Based on the easiness to implement and frequent use of the MMRC, the highest agreement of 
the $\mathrm{mMRC} \geq 2$ cut-point with other symptom measures was determined in a sample of 18,577 patients with COPD. A mMRC dyspnea grade of two or higher, a CAT total score of 18 points or higher, a CCQ total score of 1.9 points or higher, or a SGRQ total score of 46 points or higher should be used to define a high symptom burden, see Figure 1.

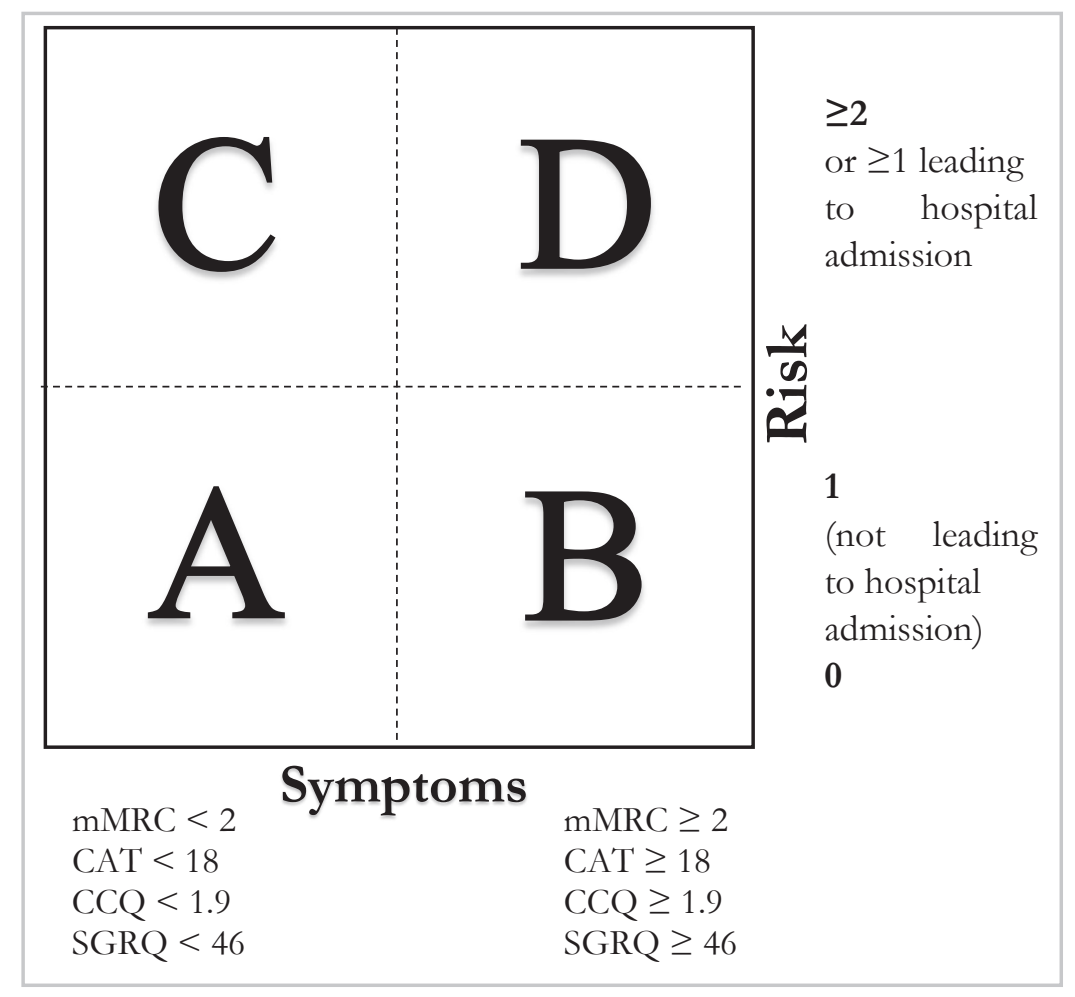

Figure 1. Suggested GOLD ABCD diagram, using the new cut-points

This recommendation is supported by the fact that a CAT total score of 10 points or higher already occurs in 50\% of current or former smokers without having any airflow limitation (17) and approximately $20 \%$ of the non-COPD subjects had an impaired health status according to the current cut-points suggested by GOLD (CAT $\geq 10$ points) (18). Moreover, the $95^{\text {th }}$ percentile of CAT total score in a nonCOPD population was determined at 18 points, as described in the current thesis (chapter 3). Recent research also indicated that the mMRC has approximately $92 \%$ agreement with current GOLD recommendations in primary, secondary and tertiary care, leading to good implementation of pharmacological care for COPD treatment in clinical practice (29). Guidelines Committees might consider adapting the recommended cut-points of the symptom measures. 


\section{PRACTICAL IMPLICATION AND CONSEQUENCES OF NEW CUT-POINTS}

The cut-points of the CAT $\geq 10$ points, CCQ $\geq 1$ point and SGRQ $\geq 25$ points give an underrepresentation of patients classified in groups $A$ and $C$, compared with mMRC cut-point of $\geq 2$ points. Indeed, the current study shows that the choice of symptom measure and cut-point impacts GOLD groups, see figure 2.

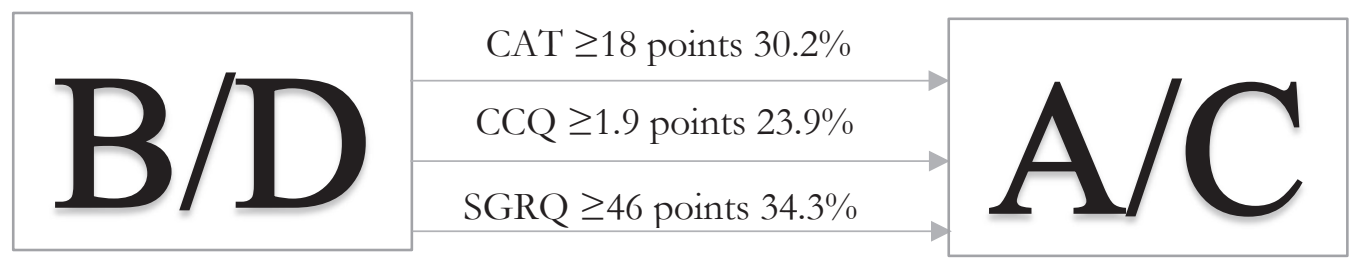

Figure 2. Changes in frequency distribution compared to the GOLD cut-points (CAT $\geq 10$ points, CCQ $\geq 1$ point, SGRQ $\geq 25$ points) found in the current thesis

Moreover, GOLD A/C patients classified by the mMRC have a worse health status in comparison with GOLD A/C patients classified by the CAT or CCQ. Other studies support these results (2). In addition, the current thesis shows that CAT GOLD B patients reported a worse health status compared to the other GOLD B group classified by the mMRC, CCQ or SGRQ (chapter 7). Moreover, higher symptoms of anxiety and depression were observed in mMRC GOLD A patients compared to the GOLD A patients based in the other symptom measures. Recent studies show that patients classified as GOLD C/D had a reduced physical activity level compared with patients classified as GOLD A/B, and physical activity was notably lower in patients with a mMRC score $\geq 2(30)$. Another study compared the current healthcare with the GOLD staging system (subdivided between the mMRC and CAT questionnaire), resulting in relatively equal distributions by ABCD grade when applying the GOLD mMRC system. Though, the GOLD CAT system put most patients into either B or D groups (31). In general, the impact of the choice of symptom measure is most pronounced in the low risk groups GOLD A/B.

The present thesis recommends application of the newly determined cut-points (mMRC, 2 points; CAT, 18 points; CCQ, 1.9 points; and SGRQ, 46 points). Compared to the current GOLD suggested cut-points, healthcare professionals are able to classify the majority of patients into the same GOLD quadrant and provide a more consistent application of medication and treatment. While Vestbo and colleagues show that COPD is a very heterogeneous disease (32), implementation of new cut-points will lead to more homogeneous patient populations in future 
studies. It will influence the management of individual patients and the design and interpretation of clinical studies. Existing inconsistencies in COPD patient classifications should be taken into consideration. Indeed, there will be an overrepresentation of GOLD B or D patients in studies that previously applied the GOLD 2014 cut-points for the CAT, CCQ and/or SGRQ.

When applying the new cut-points, a large proportion of COPD patients classified as highly symptomatic will be re-classified in low symptom groups, resulting in less treatment. Katajisto and colleagues imply that physical inactivity is independently associated with more use of short-acting symptom-relieving medications (33), which could indicate that maybe even less medication is needed in physical active COPD patients. Accordingly, the prescription of long-acting bronchodilators will be reduced in patients who are re-classified in low symptom groups. In contrast, recent research implied that a large proportion in CAT group B were undertreated, indicating that a large proportion of patients within the high-symptom groups, did not received long-acting bronchodilators. However, this study also shows that more than half of the patients received prescribed medications inconsistent with the first or second choice pharmacologic therapy listed in the GOLD strategy, e.g. the largest proportion of patients received a combination of medications that did not correspond to any of the GOLD recommendations (34). Other studies confirm the discrepancy between prescribed medication and medication recommended by the GOLD strategy (35-37). Moreover, Ninane and colleagues show that European experts recommend the use of long-acting bronchodilators, instead of short-acting bronchodilators, as first-choice treatment (38). So, it is questionable whether an increase in short-acting bronchodilators due to the reclassification into low symptom groups is desirable. Nevertheless, it this expected that the new cut-points will enable more uniform pharmacologic treatment, independently of the choice of symptom measure, leading to an improved value for healthcare systems.

\section{SUBSTANTIATION AND IMPORTANCE}

Former studies observed that patients and health professionals seldom interact, except during episodes of acute illness, also indicated as reactive "rescue care" (39). The current thesis (chapter 5) also found that current healthcare is often acute and reactive. Though, a proactive, planned and population-based approach (including smoking cessation, vaccinations, physical activity, and maintenance pharmacotherapy to reduce future exacerbations) has proven to more effectively reduce the physical, care-utilization, and financial burden of COPD $(24,40,41)$. 
This is supported by the Chronic Care Model (42). When comparing proactive care with usual care, proactive care more clearly improves health status (SGRQ: -10.3 units versus -0.6 units). In addition, many exacerbations remained uncovered in usual care (41). As proactive care results in less emergency or unscheduled visits, lower rates of hospitalizations and a shorter length of hospital utilization (43), it is expected that this approach will lower the costs of COPD care. However, we were not able to determine the cost-effectiveness of this approach. Nevertheless, we aim for an integrated healthcare system for patients with COPD, indicating that clinicians from primary, secondary and tertiary care should work together and there is consistency and transparency in outcomes of interventions. Consistency can be reached by matching the cut-points for various symptom measures in COPD. To reach the highest consistency in categorization of COPD patients, application of the worst scoring questionnaire om the $\mathrm{x}$-axis may be considered. Confidence and trust are critical to the effectiveness of health care, in which transparency (awareness of outcomes and interpretation by both the clinician as patient) and validation are needed $(44,45)$. The CAT is developed to improve the communication between the patient and clinician, and therefore improve transparency (46).

\section{EVALUATION OF CARE}

Besides the application of proactive care, also evaluation of care is needed. Evaluation of healthcare interventions and programs is an important component of decision making on the funding of new health technologies and wider dissemination of proven health interventions $(47,48)$. It is necessary to determine the treatment efficacy, defined as "a valid ascertainment of the effects of a given intervention as compared with an alternative intervention or with no treatment, in a controlled clinical context" (49). To determine if an intervention has sufficient responsiveness, beneficial effects of treatment should be demonstrated scientifically. Otherwise, e.g. an intervention might erroneously be judged effective, if it was coincidentally applied, while symptoms already may have resolved themselves without formal treatment. Criteria for appropriate evaluation of treatment efficacy are for example (49):

1. Based on broad and careful consideration of relevant empirical literature.

2. Take the level of methodological rigor and clinical sophistication, of the research supporting the intervention, into consideration.

3. Contemplate treatment conditions to which an intervention was compared.

4. Available evidence of patient-treatment matching should be considered. 
While the SGRQ, CAT, CCQ and HADS are responsive to pulmonary rehabilitation in patients with moderate to very severe COPD, not all changes in health status are clinically relevant. In 1989, the MCID was first introduced into the medical literature (50). Knowledge of MCIDs give a better interpretation of the magnitude of treatment effect and make a distinction between beneficial and harmful outcomes (51). MCIDs are also used to perform a sample size calculation and assist in interpreting statistical significant results $(52,53)$. In addition, the likelihood of hospital-free survival can be estimated by clinically relevant changes in health status (54). Recognition of the usefulness of the MCID is reflected in the increasing number of articles reporting MCIDs (50). However, there is a lot of discussion about which method to apply (anchor- or distribution-based approach) to estimate a MCID. Most studies prefer a distribution-based method, as this is sample specific (derived from sample size and distribution), in contrast to anchor-based methods which are derived from the patients' perspective $(55,56)$. The MCID in previous research is established at 4 points for the SGRQ (57), at 0.4 points for the CCQ (58$61)$, at 1.5 points for the hospital anxiety and depression scale (HADS) and between 1.6 points and 2.0 points for the CAT (62-64). Though, no previous literature has been published about the most suitable way to determine a MCID. As the MCID can vary due to type of intervention, baseline characteristics, statistical methods and/or population characteristics, validation of these MCIDs were needed. Therefore, mean MCIDs recommended by the current thesis (chapter 6) were calculated with as well anchor-based as distribution-based methods, resulting in a CAT ranging from -3.5 to -1.7 points, CCQ ranging from -0.5 to -0.2 points, HADS-A ranging from -2.0 to -1.1 points, and HADS-D ranging from -1.8 to -1.5 points). Following a range based on an equal weight for anchor-based and distribution-based MCIDs (1:1), and after increasing the weight for anchor-based MCIDs (i.e, 2:1; and 3:2) were calculated. Based on MCIDs estimated by previous research combined with our own estimated MCIDs, new MCIDs are suggested. A change of -0.4 points in CCQ and a change of -1.5 points in HADS were confirmed as a minimally clinically relevant difference. As the current thesis implies that CAT may be more sensitive for external influences than CCQ and HADS, it is not reliable to determine one single value as CAT MCID estimate. We propose that the estimated CAT MCID ranges between -3.0 to -2.0 points. As this is the first and only study taking both anchor-based and distribution-based methods into account, combined with previous research, it can be assumed that these MCIDs are reliable. 


\section{FUTURE RESEARCH}

While we were able to validate cut-points of the GOLD symptom measures in a large population, solely an estimated MCID range could be determined for the CAT. The current thesis indicates that the CAT may be more sensitive for external influences, and therefore it is not reliable to determine one single value as CAT MCID estimate. However, this goes beyond solely the CAT. Previous research also shows inconsistent results for MCIDs in other health measures (65-67). Therefore, future research should determine what is the most appropriate way to determine a MCID and which determinants should be taken into consideration to make a distinction between clinically relevant results and statistically significant results. While determining normative values, solely $\mathrm{FEV}_{1} / \mathrm{FVC}$ ratio was measured to determine COPD in patients and to exclude COPD in the control group. This means that the prevalence of emphysema is not accounted for in the control group, which could have influenced the calculation of normative values. To get a more reliable cut-point calculation, future research should also take diffusion capacity into account, e.g. with a diffusing capacity of the lung for carbon monoxide (DLCO) test. As the current thesis is the first to show the differences in COPD characteristics between the various health care settings, outcomes should be confirmed by performing comparable research in other populations. Now, only presumptions can be made concerning the consequences of healthcare costs, based on former research investigating comparable suggested proactive care. Future research needs to be performed to determine the cost effectiveness of the suggested healthcare management.

\section{CONCLUSION}

In conclusion, this thesis showed that patients with COPD suffer from an impaired health status and that a substantial burden of disease is present in all healthcare settings. While comprehensive health status assessment is challenging, it is important to look at the systemic effects and the impact of the disease to make sure suitable treatment can be provided. This thesis demonstrated that health status assessment and treatment for patient with COPD in its current form is not conducted to provide optimal individualized care. Focus on detailed characterization of individuals with COPD, in which suggested cut-points could give a more uniform classification into the GOLD quadrants, is recommended. Following, a more tailored proactive treatment should be provided, in which healthcare interventions and programs should be properly evaluated with reliable MCIDs. 


\section{REFERENCES}

1. Vogelmeier CF, Criner GJ, Martinez FJ, Anzueto A, Barnes PJ, Bourbeau J, et al. Global Strategy for the Diagnosis, Management, and Prevention of Chronic Obstructive Lung Disease 2017 Report: GOLD Executive Summary. American journal of respiratory and critical care medicine. 2017.

2. Jones PW, Adamek L, Nadeau G, Banik N. Comparisons of health status scores with MRC grades in COPD: implications for the GOLD 2011 classification. The European respiratory journal. 2013;42(3):647-54.

3. Casanova C, Marin JM, Martinez-Gonzalez C, de Lucas-Ramos P, Mir-Viladrich I, Cosio B, et al. Differential Effect of Modified Medical Research Council Dyspnea, COPD Assessment Test, and Clinical COPD Questionnaire for Symptoms Evaluation Within the New GOLD Staging and Mortality in COPD. Chest. 2015;148(1):159-68.

4. Wilke S, Smid DE, Spruit MA, Janssen DJ, Muris JWM, van der Molen T, et al. The 2014 Updated GOLD Strategy: A Comparison of the Various Scenarios. Journal of the COPD Foundation. 2014;2.

5. Herland K, Akselsen JP, Skjonsberg OH, Bjermer L. How representative are clinical study patients with asthma or COPD for a larger "real life" population of patients with obstructive lung disease? Respiratory medicine. 2005;99(1):11-9.

6. Nederland LA. Zorgstandaard COPD http://www.longalliantie.nl/files/5113/ 7994/2952/LAN_Zorgstandaard_COPD-2013-juni.pdf. 2013.

7. Geijer RM, Tuut MK, in't Veen JC, Broekhuizen BD, Chavannes NH, Smeele IJ. [The NHG guidelines 'Adult asthma' and 'COPD']. Nederlands tijdschrift voor geneeskunde. 2015;159:A9076.

8. Slok AH, in 't Veen JC, Chavannes NH, van der Molen T, Rutten-van Molken MP, Kerstjens HA, et al. Development of the Assessment of Burden of COPD tool: an integrated tool to measure the burden of COPD. NPJ primary care respiratory medicine. 2014;24:14021.

9. van der Molen T, Willemse BW, Schokker S, ten Hacken NH, Postma DS, Juniper EF. Development, validity and responsiveness of the Clinical COPD Questionnaire. Health and quality of life outcomes. 2003;1:13.

10. Slok AH, Kotz D, van Breukelen G, Chavannes NH, Rutten-van Molken MP, Kerstjens HA, et al. Effectiveness of the Assessment of Burden of COPD (ABC) tool on health-related quality of life in patients with COPD: a cluster randomised controlled trial in primary and hospital care. BMJ open. 2016;6(7):e011519.

11. Houben-Wilke S, Franssen FM, Kok I, Otten HJ, Wempe JP, Vercoulen JH. Assessment of Burden of COPD (ABC) tool: perception versus evidence. The European respiratory journal. 2017;49(3).

12. van Noordt M, van der Zee J, Groenewegen PP. Regional variation in hospital admission rates in The Netherlands, Belgium, northern France, Nordrhein-Westfalen. Gesundheitswesen. 1992;54(4):173-8.

13. Hunt SA, Abraham WT, Chin MH, Feldman AM, Francis GS, Ganiats TG, et al. 2009 Focused update incorporated into the ACC/AHA 2005 Guidelines for the Diagnosis and Management of Heart Failure in Adults A Report of the American College of 
Cardiology Foundation/American Heart Association Task Force on Practice Guidelines Developed in Collaboration With the International Society for Heart and Lung Transplantation. J Am Coll Cardiol. 2009;53(15):e1-e90.

14. Levey AS, Coresh J, Balk E, Kausz AT, Levin A, Steffes MW, et al. National Kidney Foundation practice guidelines for chronic kidney disease: evaluation, classification, and stratification. Ann Intern Med. 2003;139(2):137-47.

15. Arnett FC, Edworthy SM, Bloch DA, McShane DJ, Fries JF, Cooper NS, et al. The American Rheumatism Association 1987 revised criteria for the classification of rheumatoid arthritis. Arthritis Rheum. 1988;31(3):315-24.

16. Charles C, Gafni A, Whelan T. Decision-making in the physician-patient encounter: revisiting the shared treatment decision-making model. Soc Sci Med. 1999;49(5):651-61.

17. Wilson SR, Strub P, Buist AS, Knowles SB, Lavori PW, Lapidus J, et al. Shared treatment decision making improves adherence and outcomes in poorly controlled asthma. American journal of respiratory and critical care medicine. 2010;181(6):566-77.

18. Spruit MA, Augustin IM, Vanfleteren L, Janssen DJ, Gaffron S, Pennings HJ, et al. Differential response to pulmonary rehabilitation in COPD: multidimensional profiling. The European respiratory journal. 2015.

19. Han MK, Martinez CH, Au DH, Bourbeau J, Boyd CM, Branson R, et al. Meeting the challenge of COPD care delivery in the USA: a multiprovider perspective. The Lancet Respiratory medicine. 2016.

20. Vanfleteren LE. Asymptomatic COPD, until you take it to exertion. Thorax. 2016;71(9):781-2.

21. Soumagne T, Laveneziana P, Veil-Picard M, Guillien A, Claude F, Puyraveau M, et al. Asymptomatic subjects with airway obstruction have significant impairment at exercise. Thorax. 2016;71(9):804-11.

22. Casanova C, Marin JM, Martinez-Gonzalez C, de Lucas-Ramos P, Mir-Viladrich I, Cosio B, et al. Differential effect of mMRC dyspnea, CAT and CCQ for symptom evaluation within the new GOLD staging and mortality in COPD. Chest. 2015.

23. Miravitlles M, Huerta A, Fernandez-Villar JA, Alcazar B, Villa G, Forne C, et al. Generic utilities in chronic obstructive pulmonary disease patients stratified according to different staging systems. Health and quality of life outcomes. 2014;12:120.

24. Global Strategy For The Diagnosis, Management, and Prevention of Chronic, Obstructive Pulmonary Disease. Updated 2015. [PDF file]. www.goldcopd.com [updated januari 2015].

25. Lee CH, Lee J, Park YS, Lee SM, Yim JJ, Kim YW, et al. Chronic obstructive pulmonary disease (COPD) assessment test scores corresponding to modified Medical Research Council grades among COPD patients. The Korean journal of internal medicine. 2015;30(5):629-37.

26. Rhee CK, Kim JW, Hwang YI, Lee JH, Jung KS, Lee MG, et al. Discrepancies between modified Medical Research Council dyspnea score and COPD assessment test score in patients with COPD. International journal of chronic obstructive pulmonary disease. 2015;10:1623-31. 


\section{Chapter 9}

27. Henoch I, Strang S, Lofdahl CG, Ekberg-Jansson A. Health-related quality of life in a nationwide cohort of patients with COPD related to other characteristics. European clinical respiratory journal. 2016;3:31459.

28. Jones PW, Tabberer M, Chen WH. Creating scenarios of the impact of COPD and their relationship to COPD Assessment Test (CAT) scores. BMC pulmonary medicine. 2011;11:42.

29. Cabrera C, Casanova C, Martin Y, Mirabal V, Sanchez Mdel C, Alvarez F, et al. Agreement between a simple dyspnea-guided treatment algorithm for stable COPD and the GOLD guidelines: a pilot study. International journal of chronic obstructive pulmonary disease. 2016;11:1217-22.

30. Demeyer H, Gimeno-Santos E, Rabinovich RA, Hornikx M, Louvaris Z, de Boer WI, et al. Physical Activity Characteristics across GOLD Quadrants Depend on the Questionnaire Used. PloS one. 2016;11(3):e0151255.

31. Mapel DW, Dalal AA, Johnson PT, Becker LK, Hunter AG. Application of the new GOLD COPD staging system to a US primary care cohort, with comparison to physician and patient impressions of severity. International journal of chronic obstructive pulmonary disease. 2015;10:1477-86.

32. Agusti A, Calverley PM, Celli B, Coxson HO, Edwards LD, Lomas DA, et al. Characterisation of COPD heterogeneity in the ECLIPSE cohort. Respiratory research. 2010;11:122.

33. Katajisto M, Koskela J, Lindqvist A, Kilpelainen M, Laitinen T. Physical activity in COPD patients decreases short-acting bronchodilator use and the number of exacerbations. Respiratory medicine. 2015;109(10):1320-5.

34. Holt S, Sheahan D, Helm C, Tofield C, Corin A, Kocks JW. Little agreement in GOLD category using CAT and mMRC in 450 primary care COPD patients in New Zealand. NPJ primary care respiratory medicine. 2014;24:14025.

35. Vestbo J, Vogelmeier C, Small M, Higgins V. Understanding the GOLD 2011 Strategy as applied to a real-world COPD population. Respiratory medicine. 2014;108(5):72936.

36. Fitch K, Iwasaki K, Pyenson B, Plauschinat C, Zhang J. Variation in adherence with Global Initiative for Chronic Obstructive Lung Disease (GOLD) drug therapy guidelines: a retrospective actuarial claims data analysis. Current medical research and opinion. 2011;27(7):1425-9.

37. Seaman J, Leonard AC, Panos RJ. Health care utilization history, GOLD guidelines, and respiratory medication prescriptions in patients with COPD. International journal of chronic obstructive pulmonary disease. 2010;5:89-97.

38. Ninane V, Corhay JL, Germonpre P, Janssens W, Joos GF, Liistro G, et al. Inhaled treatment of COPD: a Delphi consensus statement. International journal of chronic obstructive pulmonary disease. 2017;12:793-801.

39. Fromer L. Implementing chronic care for COPD: planned visits, care coordination, and patient empowerment for improved outcomes. International journal of chronic obstructive pulmonary disease. 2011;6:605-14. 
40. Cramm JM, Nieboer AP. The chronic care model: congruency and predictors among patients with cardiovascular diseases and chronic obstructive pulmonary disease in the Netherlands. BMC health services research. 2012;12:242.

41. Koff PB, Jones RH, Cashman JM, Voelkel NF, Vandivier RW. Proactive integrated care improves quality of life in patients with COPD. The European respiratory journal. 2009;33(5):1031-8.

42. Coleman K, Austin BT, Brach C, Wagner EH. Evidence on the Chronic Care Model in the new millennium. Health Aff (Millwood). 2009;28(1):75-85.

43. Adams SG, Smith PK, Allan PF, Anzueto A, Pugh JA, Cornell JE. Systematic review of the chronic care model in chronic obstructive pulmonary disease prevention and management. Archives of internal medicine. 2007;167(6):551-61.

44. Eddy DM, Hollingworth W, Caro JJ, Tsevat J, McDonald KM, Wong JB, et al. Model transparency and validation: a report of the ISPOR-SMDM Modeling Good Research Practices Task Force--7. Value in health : the journal of the International Society for Pharmacoeconomics and Outcomes Research. 2012;15(6):843-50.

45. Sands DZ, Wald JS. Transforming health care delivery through consumer engagement, health data transparency, and patient-generated health information. Yearb Med Inform. 2014;9:170-6.

46. Jones PW, Harding G, Berry P, Wiklund I, Chen WH, Kline Leidy N. Development and first validation of the COPD Assessment Test. The European respiratory journal. 2009;34(3):648-54.

47. Clarke M. Non-random reflections on health services research. BMJ. 1998;316(7143):1543.

48. George PP, Heng BH, Lim TK, Abisheganaden J, Ng AW, Verma A, et al. Evaluation of a disease management program for COPD using propensity matched control group. Journal of thoracic disease. 2016;8(7):1661-71.

49. American Psychological A. Criteria for evaluating treatment guidelines. Am Psychol. 2002;57(12):1052-9.

50. Johnston BC, Thorlund K, Schunemann HJ, Xie F, Murad MH, Montori VM, et al. Improving the interpretation of quality of life evidence in meta-analyses: the application of minimal important difference units. Health and quality of life outcomes. 2010;8:116.

51. Johnston BC, Ebrahim S, Carrasco-Labra A, Furukawa TA, Patrick DL, Crawford MW, et al. Minimally important difference estimates and methods: a protocol. BMJ Open. 2015;5(10):e007953.

52. Revicki D, Hays RD, Cella D, Sloan J. Recommended methods for determining responsiveness and minimally important differences for patient-reported outcomes. Journal of clinical epidemiology. 2008;61(2):102-9.

53. Halme AS, Fritel X, Benedetti A, Eng K, Tannenbaum C. Implications of the minimal clinically important difference for health-related quality-of-life outcomes: a comparison of sample size requirements for an incontinence treatment trial. Value in health : the journal of the International Society for Pharmacoeconomics and Outcomes Research. 2015;18(2):292-8. 
54. Wilke S, Jones PW, Mullerova H, Vestbo J, Tal-Singer R, Franssen FM, et al. One-year change in health status and subsequent outcomes in COPD. Thorax. 2015;70(5):420-5.

55. Jones PW, Beeh KM, Chapman KR, Decramer M, Mahler DA, Wedzicha JA. Minimal clinically important differences in pharmacological trials. American journal of respiratory and critical care medicine. 2014;189(3):250-5.

56. Wright A, Hannon J, Hegedus EJ, Kavchak AE. Clinimetrics corner: a closer look at the minimal clinically important difference (MCID). The Journal of manual \& manipulative therapy. 2012;20(3):160-6.

57. Jones PW. St. George's Respiratory Questionnaire: MCID. Copd. 2005;2(1):75-9.

58. Kon SS, Dilaver D, Mittal M, Nolan CM, Clark AL, Canavan JL, et al. The Clinical COPD Questionnaire: response to pulmonary rehabilitation and minimal clinically important difference. Thorax. 2014;69(9):793-8.

59. Canavan JL, Dilaver D, Clark AL, Jones SE, Nolan CM, Kon SS, et al. Clinical COPD Questionnaire in patients with chronic respiratory disease. Respirology. 2014;19(7):100612.

60. Tsiligianni IG, van der Molen T, Moraitaki D, Lopez I, Kocks JW, Karagiannis K, et al. Assessing health status in COPD. A head-to-head comparison between the COPD assessment test (CAT) and the clinical COPD questionnaire (CCQ). BMC pulmonary medicine. 2012;12:20.

61. Kocks JW, Tuinenga MG, Uil SM, van den Berg JW, Stahl E, van der Molen T. Health status measurement in COPD: the minimal clinically important difference of the clinical COPD questionnaire. Respiratory research. 2006;7:62.

62. Dodd JW, Hogg L, Nolan J, Jefford H, Grant A, Lord VM, et al. The COPD assessment test (CAT): response to pulmonary rehabilitation. A multicentre, prospective study. Thorax. 2011;66(5):425-9.

63. Jones PW, Harding G, Wiklund I, Berry P, Tabberer M, Yu R, et al. Tests of the responsiveness of the COPD assessment test following acute exacerbation and pulmonary rehabilitation. Chest. 2012;142(1):134-40.

64. Kon SS, Canavan JL, Jones SE, Nolan CM, Clark AL, Dickson MJ, et al. Minimum clinically important difference for the COPD Assessment Test: a prospective analysis. The Lancet Respiratory medicine. 2014;2(3):195-203.

65. Singh SJ, Puhan MA, Andrianopoulos V, Hernandes NA, Mitchell KE, Hill CJ, et al. An official systematic review of the European Respiratory Society/American Thoracic Society: measurement properties of field walking tests in chronic respiratory disease. The European respiratory journal. 2014;44(6):1447-78.

66. Gayet-Ageron A, Jannot AS, Agoritsas T, Rudaz S, Combescure C, Perneger T. How do researchers determine the difference to be detected in superiority trials? Results of a survey from a panel of researchers. BMC Med Res Methodol. 2016;16:89.

67. Bennett DA. How to Distinguish between Statistically Significant Results and Clinically Relevant Results. Front Neurol Neurosci. 2016;39:37-49. 
Summary

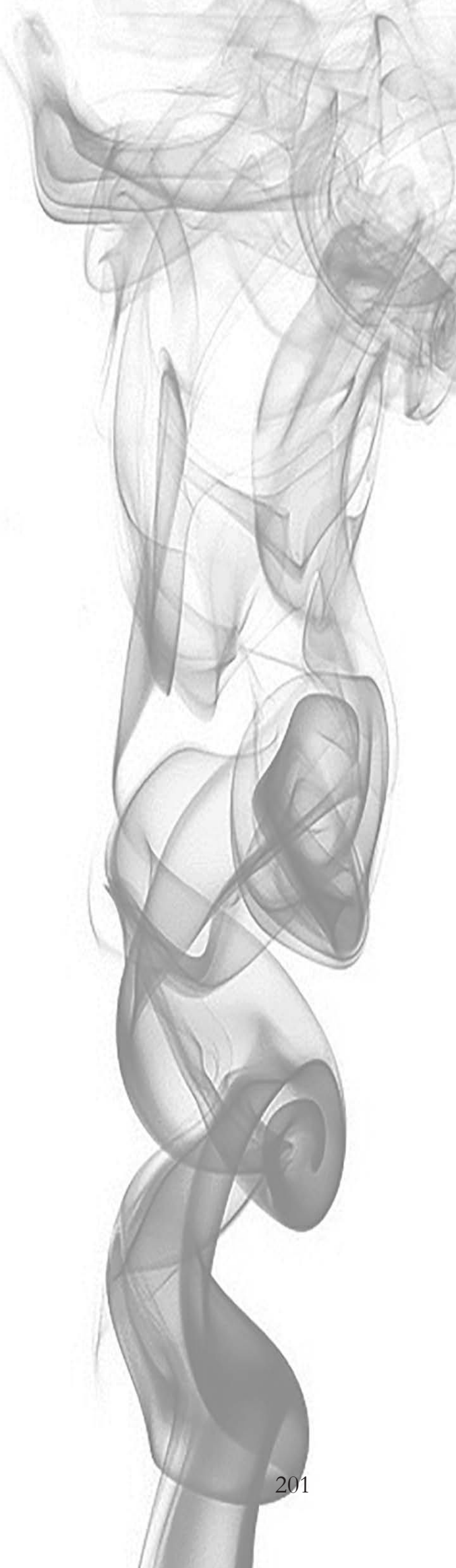


Chronic obstructive pulmonary disease (COPD) is defined by the Global initiative for chronic Obstructive Pulmonary Disease (GOLD) strategy as "a common preventable and treatable disease, characterized by persistent airflow limitation that is usually progressive and associated with an enhanced chronic inflammatory response in the airways and the lungs to noxious particles or gases". COPD has an increasing burden on society, and is a major cause of morbidity and mortality. To be able to provide proper treatment, it is necessary to correctly diagnose and categorize patients. However, it appears that the choice of the disease-specific symptom measure impacts GOLD groups, and cut-points of various questionnaires do not match in outcome. Therefore, the current thesis looked at disease burden in multiple populations and examined how to distinguish a low health status from a high health status.

To be able to suggest new cut-points for a uniform classification of high disease burden in patients with COPD, discrepancies and disadvantages of the current questionnaires suggested by GOLD (Saint George's Respiratory Questionnaire, SGRQ; Clinical COPD Questionnaire, CCQ; and COPD Assessment Test, CAT) were inventoried and described in Chapter 1. Moreover, the classification of a patient directly determines which treatment will be provided, resulting in the overall aim to be able to perform an adequate health status assessment in patients with COPD.

To study these aspects of health assessment the 'COPD Health status and Comorbidities' (Chance) study was designed. Chapter 2 shows that the Chance study is a monocentre study. It consists of an observational cross-sectional part and a longitudinal part, aiming for the assessment of demographic and clinical characteristics in primary care (100 patients), secondary care (100 patients) and tertiary care (500) patients with COPD, and in subjects without COPD (150 patients). The longitudinal part consisted of a comprehensive pulmonary rehabilitation programme performed at the highly-specialized pulmonary rehabilitation centre CIRO.

To determine a high disease burden, it is firstly important to know what should be interpreted as a normal disease burden. Therefore, non-COPD patient received the same questionnaires as COPD patients, whereby the $95^{\text {th }}$ percentile in this population was examined. Chapter 3 investigated whether an impaired health status would be better represented by the recommended GOLD CAT cut-point of 10 points, or the $95^{\text {th }}$ percentile of CAT score in a non-COPD population. Non-COPD had a mean CAT score of $6.7 \pm 5.2$ points and COPD subjects of $9.5 \pm 5.9$ points. The $95^{\text {th }}$ percentile was found at $>18$ points, and is suggested to be used as new CAT cut- 
point to indicate an impaired health status in patients with COPD. This chapter shows that one in five non-COPD subjects has an abnormal CAT score according to current international standards. When applying the $95^{\text {th }}$ percentile this number is significantly lower.

With the knowledge of health status characteristics in subjects with and without COPD, we also believed it was important to investigate coherent features. Chapter 4 described the physical status, mental status, and social status of patients with COPD and non-COPD subjects. As COPD is mainly studied in selected patient populations, for example a significant smoking history or various comorbidities are often excluded, coherent features were examined in a Dutch population-based sample. Subjects with mild-to-moderate COPD showed a reduced physical performance, a more impaired disease specific health status and are socially deprived compared to non-COPD subjects. So, healthcare professionals should be aware of the fact that subjects with mild COPD in the general population may experience specific impairments. Therefore, it is suggested to detect COPD in the general population by performing spirometry and measuring functional status and health status in subjects with an increased risk.

As care for patients with COPD can be provided in various healthcare settings, we examined differences in disease burden (daily symptoms, functional mobility, mood status and health status) and healthcare utilization between primary, secondary and tertiary care. Chapter $\mathbf{5}$ shows that the burden of disease gradually increases from COPD patients treated in primary and secondary care to those treated in tertiary care. Furthermore, we explored possibilities for healthcareoptimization. Additional interventions in secondary care patients who remain symptomatic despite pharmacologic and non-pharmacologic treatment are needed, while another proportion of low symptomatic secondary care patients would allow for de-intensification of care. This study emphasizes the need for detailed characterization of individuals with COPD and for a more tailored treatment, independent of the healthcare setting.

One of the aims in treatment for patients with COPD is to improve health status. However, not all changes are clinically relevant. Therefore, we looked at the minimum clinically important differences (MCIDs) for health status questionnaires between multiple studies applying various methods. In chapter 6 the responsiveness of health status questionnaires to pulmonary rehabilitation was assessed, confirming that SGRQ, CAT, CCQ, and HADS are responsive to pulmonary rehabilitation in patients with mild to very severe COPD. The MCID for CAT in previous studies ranged between -3.5 and -1.7 points (mean MCID: -2.9 points), for CCQ between 
-0.5 and -0.2 points (mean MCID: -0.4 points), for HADS-A between -2.0 and -1.1 points (mean MCID: -1.6 points), and for HADS-D between -1.8 and -1.5 points (mean MCID: -1.6 points). We propose that the estimated CAT MCID ranges between -3.0 and -2.0 points. Moreover, we propose an MCID range of -0.5 to -0.3 points for CCQ, -1.8 to -1.3 points for HADS-A, and -1.7 to -1.5 points for HADS-D.

At the time of executing the current thesis, the impact of the GOLD symptom measures and the different definitions of future risk was unknown. Therefore, chapter 7 describes the impact of the mMRC, CAT, CCQ, and SGRQ assessment tools and the 2 measures for exacerbation risk (exacerbation and hospitalization history) on the frequency distribution and clinical characteristics of the GOLD groups $\mathrm{A}$ to $\mathrm{D}$. It shows that the choice of symptom measure influences the frequency distribution of the new GOLD groups more than the measures for exacerbation risk. Moreover, health status and psychological symptoms vary between different outcome measures used to identify high and low symptom patients, in particular in GOLD groups A and B. Thus, the symptom measures impact the GOLD distribution as well as the clinical characteristics of the GOLD groups. Health care professionals should be aware that patients differ in terms of health status and symptoms of anxiety and depression based on the symptom measure used.

Instead of accepting differences and possible misclassification between different threshold values for symptom questionnaires, we validated the current cut-points for GOLD symptom measures in chapter 8. New cut-points were assessed by using the mMRC dyspnoea grade as a point of reference. The highest agreement between $\mathrm{mMRC} \geq 2$ points was found when applying a CAT cut-point of 18 points, CCQ cut-point of 1.9 points, and SGRQ cut-point of 46.0 points. Implementation of these newly derived cut-points make it possible to more objectively assess symptom burden of patient with COPD. As about one-third of the patients in GOLD groups B/D will be re-classified to GOLD groups A/C when applying the new cut-points, it will also influence the management of individual patients and the design and interpretation of clinical studies.

Altogether, chapter 9 provides a general discussion of the findings and limitations of the current thesis. In general, the thesis showed that patients with COPD suffer from an impaired health status and that a substantial burden of disease is present in all healthcare settings. Furthermore, it described that health status assessment and treatment for patient with COPD in its current form, is not conducted to provide optimal individualized care. This chapter also summarizes the necessities for 
adequate classification of patients with COPD to make sure suitable treatment can be provided, like assessing the systemic effects and the impact of the disease. Focus on detailed characterization of individuals with COPD, in which suggested cut-points could give a more uniform classification into the GOLD quadrants, is proposed. Also, recommendations for future research are suggested. For example, to properly evaluate healthcare interventions and programs, with reliable MCIDs. 

Samenvatting

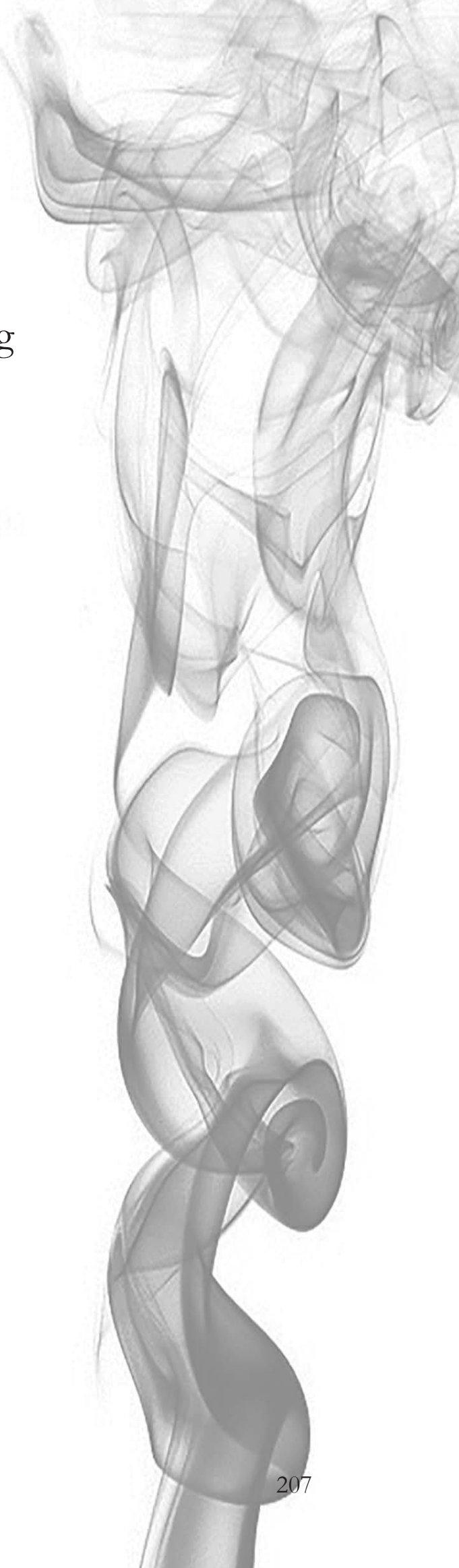


Chronische obstructieve longziekte (COPD) wordt gedefinieerd door de Global Initiative for Chronic Obstructive Pulmonary Disease (GOLD) strategie als "een veelvoorkomende en behandelbare ziekte, die wordt gekenmerkt door een blijvende luchtstroombeperking die meestal progressief is en geassocieerd wordt met een verhoogde chronische inflammatische respons in de luchtwegen en de longen tegen schadelijke deeltjes of gassen". COPD heeft een toenemende ziektelast in de samenleving en is een belangrijke oorzaak van morbiditeit en sterfte. Om de juiste behandeling te kunnen bieden is het noodzakelijk om patiënten correct te diagnosticeren en te categoriseren. Echter, het blijkt dat de keuze van de ziekte-specifieke vragenlijst GOLD-groepen beïnvloedt, en dat de afkappunten van verschillende vragenlijsten niet overeenkomen in uitkomst. Daarom heeft het huidige proefschrift gekeken naar ziektelast in meerdere populaties en onderzocht hoe een lage ziektelast kan worden onderscheiden van een hoge ziektelast.

Om nieuwe afkappunten voor een uniforme classificatie van een hoge ziektelast bij patiënten met COPD te kunnen adviseren, zijn de verschillen en nadelen van de huidige vragenlijsten die door GOLD zijn voorgesteld (Saint George's Respiratory Questionnaire, SGRQ, Clinical COPD Questionnaire, CCQ en COPD Assessment Test, CAT) geïnventariseerd en beschreven in hoofdstuk 1. Bovendien bepaalt de classificatie van een patiënt welke behandeling wordt verstrekt, wat resulteerde in het algemene doel om een adequate evaluatie van gezondheidsstatus in patiënten met COPD te kunnen uitvoeren.

Om de aspecten van de ziektelast te bestuderen is de 'COPD Health status and Comorbidities' (Chance) studie ontworpen. Hoofdstuk 2 laat zien dat de Chancestudie een monocenterstudie is. Het bestaat uit een cross-sectioneel deel en een longitudinaal deel, gericht op de evaluatie van demografische en klinische kenmerken in de eerstelijnszorg (100 patiënten), tweedelijnszorg (100 patiënten) en derdelijns zorg (500) patiënten met COPD en bij personen zonder COPD (150 patiënten). Het longitudinale deel bestond uit een uitgebreid revalidatieprogramma dat uitgevoerd werd bij het hooggespecialiseerde pulmonale revalidatiecentrum CIRO.

Om een hoge ziektelast te kunnen bepalen, was het in eerste instantie belangrijk om te weten wat kon worden geïnterpreteerd als een normale ziektelast. Om deze reden ontvingen de mensen zonder COPD dezelfde vragenlijsten als de COPD patiënten, waarbij het $95^{\text {ste }}$ percentiel in deze populatie werd bestudeerd. Hoofdstuk 3 heeft onderzocht of een lage ziektelast beter vertegenwoordigd zou zijn door het aanbevolen GOLD CAT-afkappunt van 10 punten, of het $95^{\text {ste }}$ percentiel van de CAT-score in een niet-COPD populatie. Mensen zonder COPD 
hadden een gemiddelde CAT score van 6,7 $\pm 5,2$ punten en patiënten met COPD van $9,5 \pm 5,9$ punten. Het $95^{\text {ste }}$ percentiel werd gevonden op $>18$ punten, en is aanbevolen om als nieuwe CAT-afkappunt te gebruiken om een verlaagde gezondheidsstatus aan te tonen bij patiënten met COPD. In dit hoofdstuk blijkt dat één op de vijf mensen zonder COPD een abnormale CAT-score heeft volgens de huidige internationale normen. $\mathrm{Bij}$ het toepassen van het $95^{\text {ste }}$ percentiel is dit aantal aanzienlijk lager.

Met de kennis van de ziektelastkenmerken bij mensen met en zonder COPD, vonden we het ook belangrijk om samenhangende kenmerken te onderzoeken. Hoofdstuk 4 beschreef de fysieke gesteldheid, mentale gesteldheid en sociale gesteldheid van patiënten met COPD en mensen zonder COPD. Aangezien COPD voornamelijk is bestudeerd in selectieve patiëntenpopulaties, waarbij bijvoorbeeld een significante rookgeschiedenis of verschillende comorbiditeiten vaak werden uitgesloten, zijn de samenhangende kenmerken onderzocht in een Nederlandse populatiegebaseerde steekproef. Patiënten met milde tot matige COPD toonden een verminderde fysieke prestatie, een lagere ziekte-specifieke gezondheidsstatus en zijn sociaal achtergesteld in vergelijking met mensen zonder COPD. Dus, zorgverleners moeten zich bewust zijn van het feit dat patiënten met milde COPD in de algemene populatie specifieke beperkingen kunnen ervaren. Daarom wordt voorgesteld om COPD in de algemene populatie te detecteren door spirometrie te verrichten en de functionele status en gezondheidsstatus te meten bij mensen met een verhoogd risico.

Aangezien de zorg voor patiënten met COPD kan worden uitgevoerd in diverse zorglijnen, hebben we de verschillen in ziektelast (dagelijkse symptomen, functionele mobiliteit, stemming en gezondheidsstatus) en in hoeverre mensen gebruik maken van de gezondheidszorg tussen eerstelijns-, tweedelijns- en derdelijnszorg onderzocht. Hoofdstuk 5 laat zien dat de ziektelast geleidelijk toeneemt van COPD patiënten die in de eerstelijns- en tweedelijnszorg behandeld worden naar patiënten die worden behandeld in de derdelijnszorg. Daarnaast hebben we mogelijkheden voor optimalisatie van de gezondheidszorg onderzocht. Aanvullende interventies zijn noodzakelijk bij patiënten die behandeld worden in de tweedelijnszorg die symptomatisch blijven, ondanks farmacologische en nietfarmacologische behandeling, terwijl een ander deel van de patiënten die behandeld wordt in de tweedelijnszorg met weinig symptomen het mogelijk maakt de zorg te verminderen. Deze studie benadrukt de noodzaak van een gedetailleerde karakterisering van personen met COPD en voor een meer geïndividualiseerde behandeling, onafhankelijk van de zorglijn. 
Een van de doelstellingen bij de behandeling van patiënten met COPD is het verbeteren van de gezondheidsstatus. Echter, niet alle veranderingen zijn klinisch relevant. Daarom hebben we gekeken naar de minimaal klinisch relevante verschillen (MCIDs) bij vragenlijsten over gezondheidsstatus tussen meerdere studies die verschillende methoden toepassen. In hoofdstuk 6 werd de responsiviteit van gezondheidsstatus vragenlijsten op pulmonale revalidatie onderzocht, waarbij bevestigd werd dat de SGRQ, CAT, CCQ en HADS reageren op pulmonale revalidatie bij patiënten met mild tot zeer ernstige COPD. De MCID voor CAT in eerdere studies varieerde tussen $-3,5$ en $-1,7$ punten (gemiddelde MCID: -2,9 punten), voor CCQ tussen $-0,5$ en $-0,2$ punten (gemiddelde MCID: -0,4 punten), voor HADS-A tussen $-2,0$ en $-1,1$ punten (gemiddelde MCID: - 1,6 punten) en voor HADS-D tussen $-1,8$ en $-1,5$ punten (gemiddelde MCID: $-1,6$ punten). De huidige studie toont aan dat de geschatte CAT MCID varieert tussen -3,0 en -2,0 punten. Verder zien we een MCID-bereik van $-0,5$ tot $-0,3$ punten voor CCQ, $-1,8$ tot $-1,3$ punten voor HADS-A en $-1,7$ tot $-1,5$ punten voor HADS-D.

Tijdens de uitvoering van het huidige proefschrift was het effect van de GOLD gezondheidsstatus vragenlijsten en de verschillende definities van toekomstig risico onbekend. Daarom beschreef hoofdstuk 7 het effect van de mMRC, CAT, CCQ en SGRQ en de twee maatstaven voor het risico op een exacerbatie (exacerbatie- en ziekenhuisopnamegeschiedenis) op de frequentieverdeling en klinische kenmerken van de GOLD-groepen A tot D. Het blijkt dat de keuze van de gezondheidsstatus vragenlijst de frequentieverdeling van de nieuwe GOLD-groepen meer beïnvloedt, dan de maatstaven voor het risico op een exacerbatie. Bovendien verschillen gezondheidsstatus en psychologische symptomen tussen verschillende vragenlijsten die gebruikt worden om patiënten met veel en weinig symptomen te identificeren, met name in GOLD-groepen A en B. Oftewel, gezondheidsstatus vragenlijsten beïnvloeden de GOLD-verdeling en de klinische kenmerken van de GOLD groepen. Zorgverleners moeten zich ervan bewust zijn dat de patiënten verschillen in gezondheidsstatus en symptomen van angst en depressie, afhankelijk van de gebruikte gezondheidsstatus vragenlijst.

In plaats van het accepteren van verschillen en mogelijke mis-classificatie tussen verschillende afkapwaarden voor gezondheidsstatus vragenlijsten, valideerden we de huidige afkappunten voor GOLD vragenlijsten in hoofdstuk 8. Nieuwe afkappunten werden berekend door gebruik te maken van de mMRC kortademigheids-graad als referentiepunt. De hoogste overeenkomst tussen een mMRC van $\geq 2$ punten is gevonden bij het toepassen van een CAT-cut-point van 18 punten, CCQ-punt van 1,9 punten en SGRQ-punt van 46,0 punten. Toepassen 
van deze nieuw afgeleide afkapwaarden maakt het mogelijk om de ziektelast van de patiënt met COPD objectief te beoordelen. Aangezien ongeveer een derde van de patiënten in GOLD-groepen B/D opnieuw worden ingedeeld bij GOLD-groepen $\mathrm{A} / \mathrm{C}$ bij de toepassing van de nieuwe afkappunten, zal het ook de behandeling van individuele patiënten beïnvloeden. Dit geldt ook voor het ontwerp en de interpretatie van klinische studies.

In hoofdstuk 9 wordt een algemene discussie gegeven van de bevindingen en beperkingen van het huidige proefschrift. Over het algemeen laat het proefschrift zien dat patiënten met COPD lijden aan een verlaagde gezondheidsstatus en dat er in alle zorglijnen een aanzienlijke ziektelast aanwezig is. Verder is beschreven dat de evaluatie van gezondheidsstatus en behandeling voor patiënten met COPD in zijn huidige vorm niet wordt uitgevoerd om optimale geïndividualiseerde zorg te bieden. In dit hoofdstuk worden ook de benodigdheden voor een adequate classificatie van patiënten met COPD opgesomd, om ervoor te zorgen dat er een passende behandeling kan worden gegeven, zoals het inventariseren van de systemische effecten en de ziektelast. Er wordt voorgesteld om te richten op een gedetailleerde karakterisering van personen met COPD, waarin de voorgestelde afkappunten een meer uniforme indeling kunnen geven in de GOLD-kwadranten. Ook worden aanbevelingen voor toekomstig onderzoek gedaan. Een voorbeeld hiervan is de noodzaak om interventies en programma's van de gezondheidszorg goed te evalueren, met betrouwbare MCIDs. 

Valorization addendum 
This thesis describes multiple studies with the aim to examine current health status assessment in patients with COPD and ultimately also to give advice on more adequate health status assessment. The results will be valorized in the current chapter, in which valorization means "the process of creating value from knowledge, by making knowledge suitable and/or available for social (and/or economic) use and by making knowledge suitable for translation into competitive products, services, processes and new commercial activities".

\section{RELEVANCE}

Care for patients with COPD can only be optimally provided when being aware of the systemic effects of COPD. This thesis showed that an impaired health status is present is all healthcare settings, while the current management of COPD is not very effective and suboptimal. Therefore, the recommendation to focus on detailed characterization of patients with COPD is critical to be able to provide targeted care. Previous research showed that interaction between patients and professionals, and proactive care improve the diagnostics of (an impaired) health status in patients with COPD. The CAT is developed to improve the communication between the patient and clinician. So, for both the clinician as the patient, the CAT is an easy tool to enhance awareness of symptoms. Though, treatment can vary when applying various questionnaires. Different threshold values for symptom questionnaires can result in misclassification and, in turn, different treatment recommendations. Therefore, this thesis examined the best fitting GOLD cutpoints suggested to provide consistency and transparency in health care for patients with COPD. Besides the application of proactive care and consistent cutpoints, evaluation of care is critical. It is necessary to determine the treatment efficacy and examine if an intervention has sufficient responsiveness, otherwise treatment might erroneously be judged effective.

\section{TARGET GROUPS}

Primarily the current results are important for health care providers, as professionals should be aware of disease burden, possible consequences and most suitable treatment options for patients with COPD. Also, patients with COPD should be aware of the importance to communicate with their clinician and have a say on which treatment they prefer to receive. Furthermore, guideline committees are a target group, as they should be informed about the current findings and could take these results into consideration for future recommendations. 


\section{Healthcare providers}

This thesis emphasizes the need for detailed characterization of individuals with COPD and for a more tailored treatment, independent of the healthcare setting. In order to develop and evaluate effective treatment for patients with COPD, individualized assessment is required. A better understanding of the presence and possible consequences of an impaired health status is important to recognize and respond to these symptoms. Therefore, healthcare professionals need to regularly assess symptoms in patients with COPD. Following, awareness of an impaired health status will make them able to inform, refer and advise a patient with COPD about possible treatment options. When clinicians from primary, secondary and tertiary care work together, they will be able to efficiently provide individualized care based on the patients' needs. The present thesis also gives important insights for healthcare providers. They should be aware of the fact that the choice of symptom measure influences classification, and, in turn, also specific treatment recommendation in patients with COPD.

\section{Patients with COPD}

The application of the new cut-points would re-classify about one-third of the patients with COPD. Because possible changes in COPD guidelines impact individual disease management, patients should be more involved in their own health status assessment. They need to be aware of the physical, mental and social impact of COPD. Previous research showed that patients are more likely to change their behaviour, when they have more knowledge about the disease and are more self-aware. Self-evaluation (tracking whether relevant changes have occurred in their disease symptoms) will increase the possibility to receive proper treatment and maintain independency, autonomy and adaptability. Patients should see the importance of communicating about their symptoms to the clinician.

\section{Guideline committees}

Previous research showed that the $\mathrm{mMRC}$ is a strong and independent predictor of all-cause mortality. Furthermore, former studies implied that a CAT cut point of $>18$ points more adequately predicts all-cause mortality. It also comprehensively categorizes patients with COPD according to the GOLD classification, which is in agreement with the findings of the current thesis. Guidelines committees may need to consider the use of a mMRC dyspnea grade two or higher, a CAT total score of 18 points or higher, a CCQ total score of 1.9 points or higher, or a total SGRQ score of 46.0 points or higher to classify patients with COPD as symptomatic. These cutpoints enable healthcare professionals to classify the largest proportion of patients into the same GOLD quadrant regardless of their choice of symptom measure. 


\section{ACTIVITIES AND/OR PRODUCTS}

Dissemination of the results is an important part of the valorization of a thesis. The results have led to multiple original articles in leading scientific national and international journals. The first findings of the current study were presented in 2014 during the Netherlands Respiratory Society (NRS) 6th Young Investigator Symposium (Amsterdam, Netherlands) with the abstract entitled "Functional status, mood status and health status in healthy individuals and patients with COPD treated in primary care, secondary care or tertiary care setting". During the European Respiratory Society (ERS) congress in 2015, the abstract entitled "Health status in patients with COPD and care provided in various healthcare settings" was demonstrated with a poster presentation (Amsterdam, Netherlands). Furthermore, results have been presented during courses and workshops organized by CIRO and other institutes.

Besides the above-mentioned dissemination of the current thesis, it is critical that future research is able to emerge from this perspective and show additional results in contrast or complementary to these findings. Guideline committees can only make influencing decisions when multiple studies show consequences of the current cut-points and verify new cut points. The same counts for healthcare providers to be able to apply the suggested recommendations for patients with COPD. The current thesis will be made available to a wider public.

\section{INNOVATION}

The following paragraph describes the added value of the results for the industry, whereby a distinction is made between the disease burden of COPD, GOLD strategy and evaluation of care.

\section{Disease burden of COPD}

This thesis demonstrated that subjects with mild-to-moderate COPD have an impaired health status. Patients with COPD have a reduced physical performance, a more impaired disease specific health status and are socially deprived compared to non-COPD subjects. This emphasizes the need for detailed characterization of individuals with COPD and for a more tailored treatment. The current thesis is also the first to reveal the need for additional interventions in secondary care patients who remain symptomatic despite pharmacologic and non-pharmacologic treatment, while another proportion of low symptomatic secondary care patients would allow for de-intensification of care. Moreover, complementing to the 
current COPD care, it is suggested to detect COPD in the general population by performing spirometry and measuring functional status and health status in subjects with an increased risk.

\section{GOLD strategy}

Nowadays, the GOLD strategy determines high symptoms by using various questionnaires: the $\mathrm{MMRC}$, (grade 2 or higher), the CCQ (1 point or higher), the CAT (10 points or higher), and the SGRQ (25 points or higher). At the start of this thesis, the impact of the suggested tools for symptoms of COPD and the different definitions of future risk on the frequency distribution and clinical characteristics of the GOLD groups remained unknown. The present dissertation shows that the choice of symptom measure impacts the classification of patients with COPD in GOLD A/C or B/D groups. It is the first to show normative values for CAT in a Dutch population (based on the $95^{\text {th }}$ percentile of the CAT in a non-COPD population), resulting in a new CAT cut-point of $>18$ points to indicate an impaired health status. Supplementary, the present thesis recommends application of newly determined cut-points (with the $\mathrm{MMRC}$ as point of reference): $\mathrm{mMRC} 2$ points; CAT 18 points; CCQ 1.9 points; and SGRQ 46 points. The current thesis also shows that the current GOLD cut-points give an underrepresentation of patients classified in groups $\mathrm{A} / \mathrm{C}$, compared with the newly derived points.

\section{Evaluation of care}

Previous studies already examined the responsiveness of the SGRQ, CAT, CCQ, and HADS to pulmonary rehabilitation in patients with COPD. Though, a variance in MCID estimates was observed, leading to a need for verification of the MCID estimates of the CAT, CCQ and HADS-A/D. It seemed reasonable to conclude that a change of -0.4 points in CCQ and a change of -1.5 points in HADS-A/D could be defined as clinically relevant. In contrast, MCIDs of the CAT were not comparable between studies, indicating that the CAT is possibly more sensitive for external influences than CCQ and HADS-A/D. Therefore, a new MCID range for CAT of -3.0 to -2.0 points is proposed. 

Dankwoord 
Dan is nu het moment aangekomen dat ik iedereen, die een bijdrage heeft geleverd aan mijn proefschrift, kan laten weten wat ze voor mij betekend hebben tijdens deze periode. Inmiddels ben ik er namelijk wel achter hoe belangrijk het is om hard werken te combineren met plezier en rust, waarin veel mensen hebben ondersteund.

Allereerst wil ik graag de personen bedanken die dit proefschrift mogelijk gemaakt hebben, namelijk de patiënten en controlepersonen die hebben deelgenomen. Zij waren beschikbaar voor onderzoek en hebben tijd vrij gemaakt om mij te ontvangen in hun huis. De eerste periode van mijn onderzoek ben ik voornamelijk met huisbezoeken bezig geweest. Dit heb ik altijd met veel plezier gedaan. Bedankt voor de gastvrijheid, beschikbaarheid en uiteraard ook voor alle lekkernij die zijn aangeboden.

Hooggeleerde promotor Prof. Wouters bedankt voor uw goede raad en de kritische feedback die u leverde op alle manuscripten. Ik heb veel van u geleerd en heb veel waardering voor uw kennis en ervaring. Ik ben u en Ingrid Augustin erg dankbaar dat ik de mogelijkheid heb gekregen om te promoveren binnen CIRO.

Dan ben ik aangekomen bij de personen die het meest betrokken zijn geweest bij dit proefschrift, te weten mijn tweede promotor en copromotor, Frits en Martijn. Bedankt voor jullie steun en toewijding. Ik heb veel waardering voor jullie professionaliteit, geduld (met name in de afrondende fase) en de hoeveelheid kennis die jullie hebben overgedragen. Het was niet altijd even leuk om lang te wachten op feedback en vervolgens te horen dat jullie toch weer andere ideeën hadden. Maar ik kan niet ontkennen dat dit wel altijd heeft geresulteerd in mooie innovatieve artikelen. Bedankt voor jullie samenwerking!

Ook wil ik Prof. Jean Muris, de huisartspraktijken (van Proosdij-Leistra te Stein, Gezondheidscentrum Heer te Maastricht, Gezondheidscentrum Dr. van Kleef te Maastricht, Huisartsenpraktijk Koppes/van Stijn te Elsloo, Medisch Centrum Elsloo, Medisch Centrum Ubachsberg, Gezondheidscentrum Geulle, Medisch Centrum West-Kerkrade en Gezondheidscentrum Hoensbroek Noord) en longartsen (dr. Arne van Belle, dr. Gernot Rhode, dr. Otte, dr. Lizza Hendriks, dr. Nicole Cobben, dr. Monique Hochstenbach, dr. Roy Sprooten, dr. Bettine Vosse, dr. Jesse Drijkoningen en dr. Anne-Marie Dingemans) die hebben meegeholpen aan de werving van de proefpersonen bedanken voor hun inzet. Ondanks jullie drukke schema's, heeft iedereen tijd vrij gemaakt om zich te laten informeren over dit onderzoek en gekeken naar mogelijkheden om patiënten te benaderen. Zonder jullie betrokkenheid had de inclusie hoogstwaarschijnlijk wel wat langer geduurd. 
[in English for all foreign coauthors:] I would like to thank all the coauthors for their critical appraisal of the manuscripts, good luck wishes and involvement during article submissions. Daarbij wil ik in het bijzonder Dorly Deeg, Martijn Huisman en Jan Poppelaars bedanken voor het vertrouwen om met de LASA-data aan de slag te gaan en de leuke samenwerking, waar twee mooie manuscripten uit voort zijn gekomen.

Leden van de beoordelingscommissie, bestaande uit Prof. Dr. J.M.G.A. Schols, Prof. Dr. F. Smeenk, Prof. Dr. G. Wesseling, Prof. Dr. H.A.M. Kerstjens en Prof. Dr. P-R. Burgel bedankt voor de beoordeling en goedkeuring van mijn dissertatie. [in English for Prof. Dr. P-R. Burgel:] Thank you for your critical assessment and approval of this dissertation.

Mijn dank gaat tevens uit naar de sponsoren van dit onderzoek, namelijk het Longfonds en GlaxoSmithKline (GSK). Bedankt voor de financiële ondersteuning die jullie gaven om het Chance-onderzoek te kunnen verwezenlijken en de interesse die werd getoond in de voortgang van het onderzoek.

Uiteraard wil ik ook graag mijn lieve collega's van CIRO bedanken: Sarah, Dionne, Nienke, Jeannet, Fiona, Cindy, Coby, Wai-Yan, Rafael, Anouk, Carmen, Yvonne, Esther en Vasilis. Het was altijd erg gezellig op kantoor en kon altijd bij jullie terecht voor hulp, klaag momenten, medeleven en afleiding (o.a. CIRO-roddels, onzin filmpjes, eetmomenten, vreemde sportoefeningen of normale wandelingen). Ps. Sorry Frits en Martijn, maar die afleiding hadden we vaak nodig om daarna weer extra hard door te kunnen werken :)! Nadat ik wist dat ik na mijn proefschrift niet meer bij CIRO zou blijven vond ik het voornamelijk jammer jullie niet meer zo vaak te kunnen zien, maar hoop dat we onze uitetentjes, babybezoekjes en misschien zelfs ons sinterklaas-dobbelspel (als de buren niet thuis zijn, haha) kunnen blijven voortzetten.

Alle CIRO-medewerkers bedankt voor jullie betrokkenheid bij wetenschappelijk onderzoek. Daarbij wil ik graag Miriam extra bedanken voor al hulp met statistische testen. Vaak snapte ik er helemaal niks van en deed jij je best om me alle ins en outs te vertellen. Soms werd het daardoor nog ingewikkelder, maar wel altijd met het resultaat dat ik wist waar ik op moest letten en op welke knoppen ik moest klikken.

Naast alle collega's van CIRO heb ik mijn nieuwe collega's van Vincere vaak genoeg lastiggevallen met de voortgang van mijn proefschrift. Bedankt voor jullie luisterend oor en vooral de motiverende gesprekken om niet te veel uitstelgedrag te vertonen. Daarnaast geeft het werken bij Vincere me veel energie en plezier, wat de combinatie van werk en proefschrift afronden een stuk fijner maakte. 
Mam en pap, ik vond het altijd erg fijn om bij jullie te vertellen wat de voortgang van mijn proefschrift was. Jullie weten me altijd te motiveren om door te zetten (ook als ik er zelf even klaar mee ben) en de positieve kant te belichten. Bedankt voor de mooie basis die jullie mij hebben gegeven. Jullie hebben me altijd laten weten dat jullie in mij geloven, waar ik veel steun aan heb ervaren. De familieetentjes zorgde naast gezelligheid er ook voor dat ik niet zelf hoefde koken en meer tijd had voor leuke dingen. René en Elena, jullie hadden hier ook een grote bijdrage in. Tevens bedankt voor de gezellige avondjes, uitstapjes en mooie bruiloft die ik heb mogen bijwonen. Daarnaast wil ik Ger bedanken voor alle keren dat hij vanuit Weert naar onze verjaardagen, feestjes en familiemomenten kwam. Ik vind het altijd erg gezellig, ondanks je rare vragen en vele opmerkingen haha :). Shaira en Chanti, bedankt voor alle steun en interesse die jullie in mijn toonden. Ik ben blij dat ik me altijd zo welkom voel in jullie familie.

Verder wil ik graag Daan en Benito speciaal bedanken. Daan, naast dat je een geweldige zus bent, mijn beste vriendin en een super moeder voor Dahnétje, vind ik het heerlijk om met jou les te geven. Je hebt naast veel praktische zaken (mee mogen eten, tijd vrijmaken en overnemen van taakjes) ook mentaal steun gegeven. Jouw hulp, positieve woorden en alle gezellige momenten hebben er zeker voor gezorgd dat ik een leuke afwisseling had tussen serieus en gefocust werken vs. gezelligheid en ontspanning. Uiteraard heeft Benito hier ook veel aan bijgedragen door de (meestal, haha) leuke trainingen en speciale optredens die ik mee heb mogen doen.

Ik heb tevens erg genoten van de energie die Dahné en Tysonn altijd hebben gegeven. De vrolijkheid, onschuld en liefde die deze kleine boefjes uitstralen zorgt ervoor dat ik bewust blijf van hetgeen wat echt telt: familie, geluk en gezondheid. Dit heeft er meerdere malen voor gezorgd dat mijn stressniveau niet te hoog opliep en ik mijn gedachtes even op wat anders kon zetten.

Lissy en Babet, mijn paranimfen, bedankt voor jullie onvoorwaardelijke vriendschap. Jullie staan altijd voor mij klaar. Ik kan met alles bij jullie terecht en zijn altijd betrokken geweest bij de voortgang van mijn proefschrift. We konden altijd sparren over de dingen waar ik tegenaan liep, maar gelukkig praatten we ook over veel andere dingen. Als ik weer een drukke werkweek had gehad was ik altijd blij als ik langs kon komen om te ontspannen, lachen en genieten van lekkere hapjes. Jullie zijn voor mij heel waardevol en hoop nog heel lang vriendinnen met jullie te zijn, bedankt! 
Daarnaast wil ik graag mijn vrienden Iris en Kayl, Audry, Mandy, Maren, Thalia en Bruno, Kim, Marieke, Gwen, Jascha en Raesita, Tom, Dean en Sean bedanken voor alle lekkere eetdates, spelletjesavonden, feestjes en bankhang-momenten. Ik kon altijd bij jullie terecht (soms klagen, haha) over de voortgang van mijn proefschrift en de daarmee samenhangende ups (artikel gepubliceerd, nieuwe ondervindingen en het mogen deelnemen aan een congres) en downs (artikel afgewezen, wachten op feedback en het vele werk). Jullie gezelligheid was hele fijne afleiding. Ik heb geen vier jaar onderzoek nodig om te bewijzen dat de hypothese "life is better with friends" waar is, bedankt.

Dansen en lesgeven samen met mijn dansgenoten en leerlingen hebben er ook vaak voor gezorgd dat ik mijn gedachten kon verzetten. Ik heb er na 15 jaar nog heel veel plezier in. Dat heeft grotendeels te maken met het plezier dat ik bij mijn leerlingen zie, de onzin die mijn teamgenoten altijd uithalen en het teamverband, dat ik voel als we hard werken voor ons volgende doel.

En dan kom ik uiteindelijk aan bij de belangrijkste persoon, Rakesh. Jij bent degene die mij in alle opzichten heeft gesteund en altijd nuchter bleef op momenten dat ik even niet meer wist hoe ik het allemaal moest combineren. De maand dat ik promoveer, is dezelfde maand dat we 10 jaar bij elkaar zijn en hoop dat nog een paar keer te kunnen verdubbelen. Ik bewonder hoe lief je voor me bent en wat je allemaal doet om mij gelukkig te maken: samen reizen, lekker koken, helpen met klusjes, uren met elkaar praten, samen een filmpje kijken, interesse tonen in mijn hobby etc. Gelukkig komt er nu een rustigere periode aan en kunnen we nog meer tijd aan elkaar besteden. Ik hou ontzettend veel van jou 

Curriculum vitae 
Dionne Smid werd geboren op 24 januari 1990 in Heerlen. In 2008 behaalde ze haar vwo-diploma aan het Romboutscollege, te Brunssum. Datzelfde jaar startte ze met haar studie Gezondheidswetenschappen (Specialisatie: Geestelijke Gezondheidskunde en Therapie) aan de Universiteit te Maastricht. Ze heeft haar afstudeerscriptie voor de bacheloropleiding geschreven over 'vermijdingsgedrag bij chronische en acute pijn', waarmee ze in 2011 haar studie heeft afgerond. In 2012 heeft ze haar Master Mental Health diploma gehaald, te Universiteit Maastricht, aangevuld met de aantekening testdiagnostiek. In haar masterstudie heeft ze haar afstudeerscriptie geschreven over 'de obsessief compulsieve persoonlijkheidsstoornis'. Begin 2011 is ze tevens gestart met een stage als psychodiagnostisch medewerker bij Licom NV, te Heerlen. Dit heeft zich verder vormgegeven in een baan. Daarna is ze gestart aan haar promotieonderzoek, gericht op het meten van gezondheidsstatus bij mensen met COPD, bij CIRO Expertisecentrum voor Chronisch Orgaanfalen in Horn. Dit onderzoek werd uitgevoerd onder supervisie van Prof. Dr. Emiel F.M. Wouters, Prof. Dr. Martijn A. Spruit en Dr. Frits M.E. Franssen. De bevindingen van het promotieonderzoek werden op verschillende internationale congressen gepresenteerd. Naast veel interesse voor onderzoek, heeft ze graag patiëntencontact en werkt ze volgaarne samen met de patiënt naar een optimale gezondheidsstatus. In 2016 is ze, naast de afronding van haar promotieonderzoek, gestart als psycholoog bij Vincere GGZ, te Sittard. 
List of publications 
Wilke S*, Smid DE*, Spruit MA, Janssen DJ, Muris JWM, van der Molen T, et al. The 2014 Updated GOLD Strategy: A Comparison of the Various Scenarios. Journal of the COPD Foundation. 2014. (*joint first author)

Mesquita R, Wilke S, Smid DE, Janssen DJA., Franssen FME, Probst VS, Wouters EFM, Muris JWM, Pitta F, Spruit MA. Timed Up \& Go test in COPD: changes over time, validity and responsiveness to pulmonary rehabilitation. European respiratory journal. 2014.

Smid DE, Wilke S, Jones PW, Muris JW, Wouters EF, Franssen FM, et al. Impact of cardiovascular comorbidities on COPD Assessment Test (CAT) and its responsiveness to pulmonary rehabilitation in patients with moderate to very severe COPD: protocol of the Chance study. BMJ Open. 2015.

Mesquita R, Wilke S, Smid DE, Janssen DJ, Franssen FM, Probst VS, et al. Measurement properties of the Timed Up \& Go test in patients with COPD. Chronic Respiratory Disease. 2016.

Smid DE, Spruit MA, Houben-Wilke S, Muris JWM, Rohde GGU, Wouters EFM, Franssen FME. Burden of COPD in patients treated in different care settings in the Netherlands. Respiratory Medicine. 2016.

Janssen DJ, Wilke S, Smid DE, Franssen FM, Augustin IM, Wouters EF, et al. Relationship between pulmonary rehabilitation and care dependency in COPD. Thorax. 2016.

Braeken DCW, Wilke S, Smid DE, Rohde GGU, Drijkoningen JJC, Wouters EFM, Spruit MA, Franssen FME. Sputum microbiology predicts health status in COPD. International Journal of Chronic Obstructive Pulmonary Disease. 2016.

Braeken DCW, Spruit MA, Houben-Wilke S, Smid DE, Rohde GGU, Wouters EFM, Franssen FME. The impact of exacerbations on adherence and outcomes of pulmonary rehabilitation in patients with COPD. Respirology. 2017

Smid DE, Franssen FME, Houben-Wilke S, Vanfleteren LEGW, Janssen DJA, Wouters EFM, Spruit MA. Responsiveness and MCID estimates for CAT, CCQ and HADS in patients with COPD undergoing pulmonary rehabilitation: a prospective analysis. Journal of the American Medical Directors Association. 2017. 
Smid DE, Spruit MA, Deeg DJ, Huisman M, Poppelaars J, Wouters EFM, Franssen FME. How to determine an impaired health status in COPD? Results from a population-based study. Netherlands Journal of Medicine Netherlands Journal of Medicine. 2017.

Smid DE, Franssen FME, Gonik M, Miravitles M, Casanova C, Cosio BG, de Lucas-Ramos P, Marin JM, Martinez C,Mir I, Soriano J, de Torres P, Adamek L, Agusti A, Atalay NB, Billington J, Boutou AK, Chaplin E, Coster S, Dodd JW, Dürr S, Fernandez-Villar A, Groenen MTJ, Guimarães M, Hejduk K, Higgins V, Hopkinson NS, Horita N, Houben-Wilke S, Janssen DJA, Jehn M, Joerres R, Jones PW, Karch A, Kelly JL, Kim YI, Kimura H, Koblizek V, Kocks JWH, Kon SSC, Kwon N, Ladeira I, Lee SD, Leuppi LJD, Lopez-Campos JL, Man WD-C, Maricic L, Mendoza L, Miedinger D, Mihaltan F, Minami S, van der Molen T, Murrells TJ, Nakken N, Nishijima Y, Norman IJ, Novotna B, O’Donnell DE, Ogata Y, Pereira D.E, Piercy J, Price D, Pothirat C, Raghavan N, Ringbaek T, Sajkov D, Singh S, Sigari N, Small M, da Silva GF, Tanner RJ, Tsiligianni IG, Tulek B, Tzanakis N, Vanfleteren LEGW, Watz H, Webb KA, Wouters EFM, Xie GG, Yoshikawa M, Brighenti-Zogg S, and Spruit MA. Redefining the cut-points for high symptom burden of the GOLD COPD classification: a patient level pooled analysis in 18577 patients. Journal of the American Medical Directors Association. 2017.

Smid DE, Spruit MA, Deeg DJ, Huisman M, Poppelaars J, Wouters EFM, Franssen FME. The physical, mental and social impact of COPD in a population based sample. Submitted to NPJ Primary Care Respiratory Medicine.

McNamara RJ, Houben-Wilke S, Franssen FME, Smid DE, Vanfleteren LEGW, Groenen MTJ, Uszko-Lencer NHMK, Wouters EFM, Alison JA, Spruit MA. Determinants of functional, peak and endurance exercise capacity in people with COPD. Submitted to Respiratory Medicine. 
